\title{
Development of a Sustainability Evaluation and Control Framework for Chemical Processes
}

\section{Shuyun Li}

West Virginia University, syli@mix.wvu.edu

Follow this and additional works at: https://researchrepository.wvu.edu/etd

Part of the Process Control and Systems Commons

\section{Recommended Citation}

$\mathrm{Li}$, Shuyun, "Development of a Sustainability Evaluation and Control Framework for Chemical Processes" (2019). Graduate Theses, Dissertations, and Problem Reports. 7382.

https://researchrepository.wvu.edu/etd/7382

This Dissertation is protected by copyright and/or related rights. It has been brought to you by the The Research Repository @ WVU with permission from the rights-holder(s). You are free to use this Dissertation in any way that is permitted by the copyright and related rights legislation that applies to your use. For other uses you must obtain permission from the rights-holder(s) directly, unless additional rights are indicated by a Creative Commons license in the record and/ or on the work itself. This Dissertation has been accepted for inclusion in WVU Graduate Theses, Dissertations, and Problem Reports collection by an authorized administrator of The Research Repository @ WVU.

For more information, please contact researchrepository@mail.wvu.edu. 


\title{
Development of a Sustainability Evaluation and Control Framework for Chemical Processes
}

\author{
Shuyun Li \\ Dissertation submitted to the \\ Benjamin M. Statler College of Engineering and Mineral Resources \\ At West Virginia University \\ In partial fulfillment of the requirements for the degree of \\ Doctor of Philosophy in \\ Chemical Engineering \\ Fernando V. Lima, Ph.D., Chair \\ Debangsu Bhattacharyya, Ph.D. \\ David S. Mebane, Ph.D. \\ Stephen E. Zitney, Ph.D. \\ Gerardo J. Ruiz-Mercado, Ph.D. \\ Department of Chemical and Biomedical Engineering \\ Morgantown, West Virginia \\ 2019
}

Keywords: sustainability, sustainability assessment, GREENSCOPE, life cycle inventory, advanced process control, multi-objective optimization 


\title{
Abstract \\ Development of a sustainability evaluation and control framework for chemical processes
}

\author{
Shuyun Li
}

Industry, government, and society have begun to shift from economic stand-alone focus to the inclusion of sustainability in the decision-making process. This shift can be attributed to the growing environmental and social awareness that makes consumers and stakeholders not only care about product quality and cost, but also products and processes that minimize the environmental impact and conserve natural resources. As a result, some progress has been made in recognizing and understanding the challenges of sustainable development, which helps evaluating the sustainability performance of a specific process/product. In particular, sustainability assessment tools and methodologies have been developed to help the future engineer and scientist with designing and optimizing the chemical processes in terms of sustainability. However, an efficient framework for the integration of advanced process control with sustainability assessment technologies is still missing.

In this dissertation, a novel process systems framework for integrating sustainability assessment, optimization, and advanced control is developed to simultaneously optimize and control chemical process systems at the optimal operating points considering efficiency, environmental, economic and energy aspects. This proposed framework bridges gaps in the literature by addressing the following challenges: 1) assessment of sustainability performance at steady-state and dynamic operations; 2) integration of sustainability indicators into a process control framework. Specifically, the proposed framework contains three main components: an integrated sustainability assessment tool, a multi-objective optimization formulation, and an 
advanced control strategy. The integrated sustainability assessment tool is developed using a userfriendly automation interface that enables the communication between process simulation, pollution control units (PCUs), life cycle inventory (LCI) generation, and the U.S. EPA's GREENSCOPE (Gauging Reaction Effectiveness for the ENvironmental Sustainability of Chemistries with a Multi-Objective Process Evaluator) tool. With the sustainability indicators for chemical processes, a multi-objective optimization problem is formulated to identify the Pareto set of most sustainable operating conditions using a genetic algorithm for the decision-making step. To better balance the trade-off between economic and environmental aspects, a sustainable control strategy is implemented to drive the process to the chosen Pareto optimal solution while meeting pre-defined sustainability constraints. For the control implementation, a novel visualization method is developed to visualize the dynamic multidimensional sustainability indicators during transient.

To illustrate the effectiveness of the developed framework, two chemical processes are addressed: i) a continuous fermentation process for bio-ethanol production, for which the implemented sustainable process control scheme can improve the performance in terms of sustainability by $9.65 \% \sim 16.86 \%$ for different operating conditions; and ii) a biomass/coal cogasification process for syngas production with the end goal of methanol manufacturing, for which the optimal sustainable operating condition is identified using a multi-objective optimization and then control is implemented to drive the system to the chosen setpoint, while maintaining the process within sustainable zones during transient. The performed case studies indicate that the proposed framework can be a powerful tool for assessing and controlling chemical processes for sustainability. 
Dedicated to my parents, husband, and son 


\section{Acknowledgments}

I have been encouraged by many people along the journey of my Ph.D. studies over the past five years.

I would like to first express my sincerest gratitude and appreciation to my advisor, Dr. Fernando V. Lima. You have always been there for me whenever I needed your support. Thank you for putting your trust in me and allowing me to explore a variety of interesting projects. Thank you for pushing me to always think as a Ph.D. does, to do better when I am not good enough, and to aim higher when I have reached a milestone. Your wisdom has inspired me in many ways as I searched for a better idea in my research. Your positive energy has given me strength whenever I feel frustrated. Your advising and mentoring will always guide me in my future career.

I would also like to thank my committee members, Dr. Gerardo J. RuizMercado, Dr. Debangsu Bhattacharyya, Dr. David S. Mebane and Dr. Stephen E. Zitney. I have had many valuable discussions with you in my research. Through these discussions, I was able to understand better the meaning of my projects, and explore alternative methods that are better suitable for the problem I was trying to solve. During my research, I have had many meetings with Dr. Ruiz-Mercado from EPA and I am greatly thankful to the valuable suggestions on the sustainability work.

I have been fortunate to get the chance to work with a group of wonderful people at West Virginia University: Juan, Gaurav, Xin, Rebecca, Vitor, Brent, Ron, 
Selorme, San, Yifan, Jacob, I-Wen, Qian, Lei, Yuan, Xiao, Qiao, Yan. It has been a great pleasure to know all of you in my life, and I know we will always keep in touch.

I would like to extend my thankfulness to my awesome spiritual friends and mentors: Cindy, Lili, Marry \& Chuck, May, Jenny \& Chuck, Jing, Grace, and Larry. I could not imagine what my life would be without your support and help during my difficult times. Thank you all for the enlightening words to keep me moving forward on my PhD study.

Finally and most importantly, thanks to my family members. Throughout my life, you have supported me with your unconditional love and caring. You always have faith in me and encourage me to be a better person. To my "tiger mom" and "easy-going" dad, thank you for always be there for me. To my husband and son, thank you for being part of my life and reshaping my life in better ways. To my sister and brother, thank you for the help, support, and happy times. 


\section{Table of Contents}

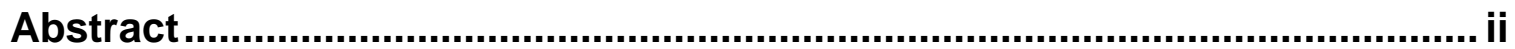

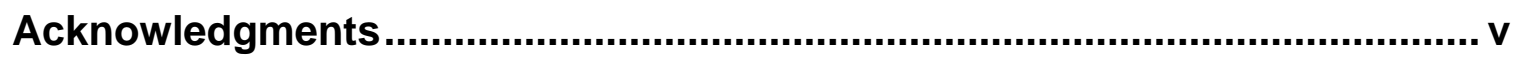

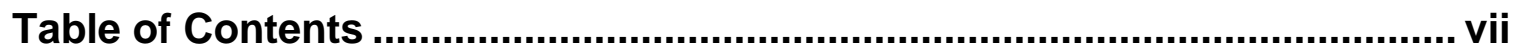

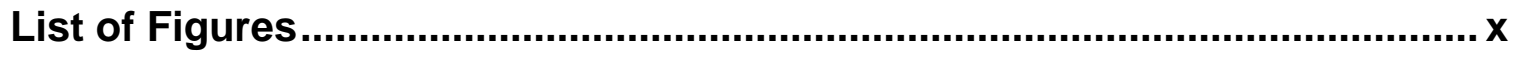

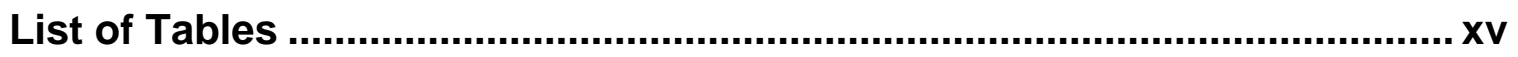

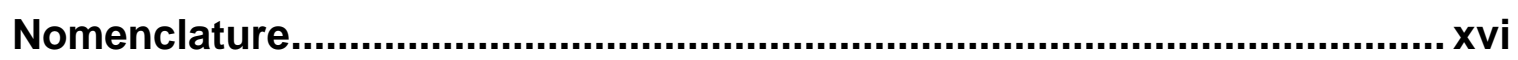

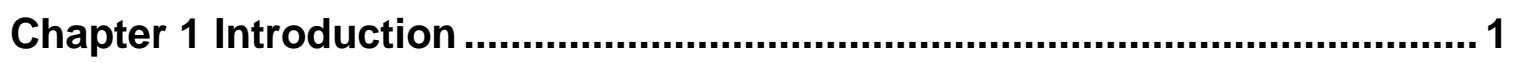

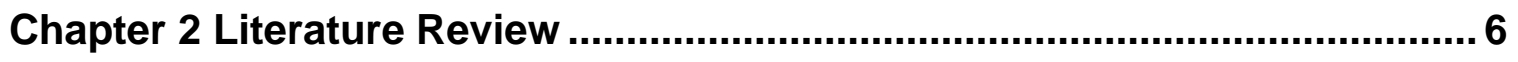

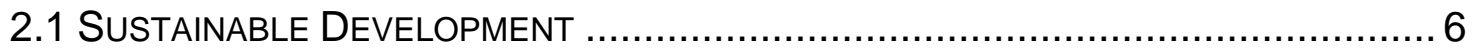

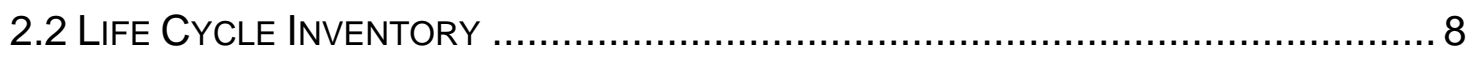

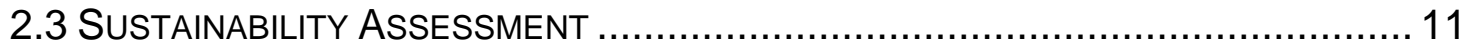

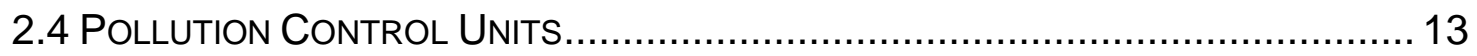

2.5 MULTI-OBJECTIVE OPTIMIZATION FOR SUSTAINABILITY................................. 16

2.6 PROCESS DYNAMICS AND CONTROL FOR SUSTAINABILITY............................ 18

Chapter 3 Integrated Tool Development for Rapid Life Cycle Inventory ..... 20

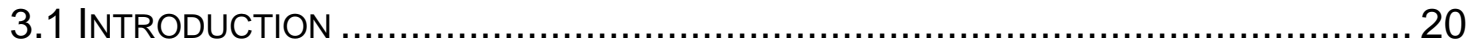

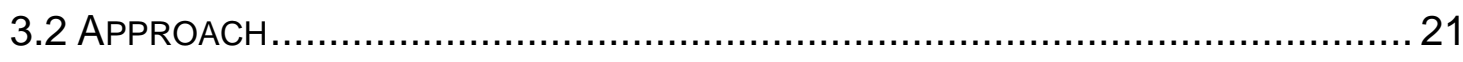

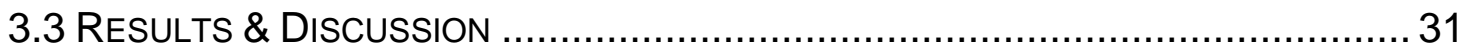

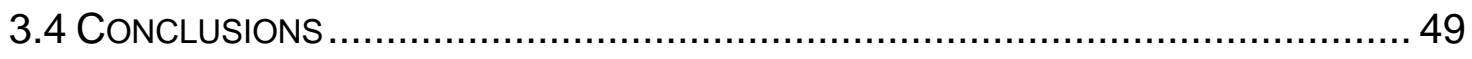

Chapter 4 Integrated Tool Development for Sustainability Assessment..... 51 


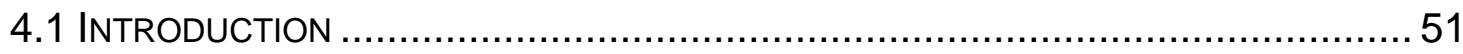

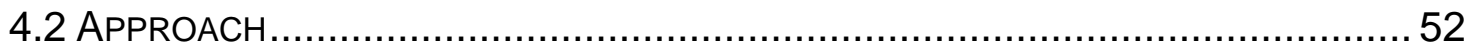

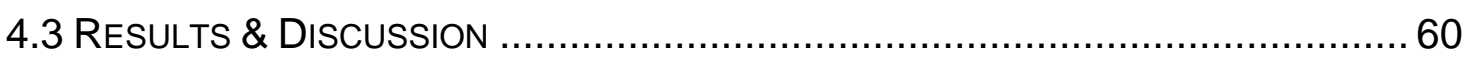

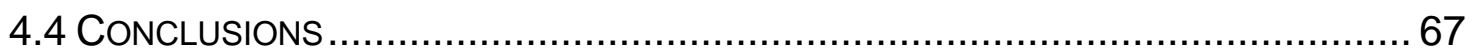

Chapter 5 Process Control for Sustainability: Motivating Example..............68

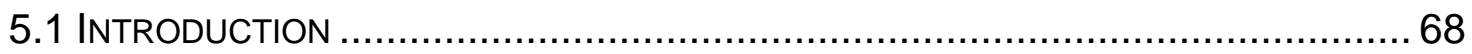

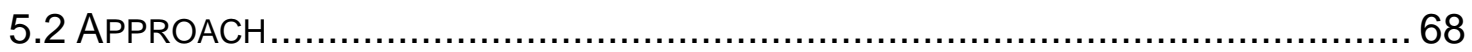

5.3 Case Study: Fermentation Process Model....................................... 72

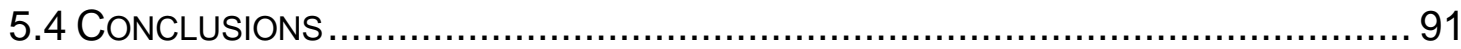

Chapter 6 A Novel Control Strategy for Sustainability of Chemical

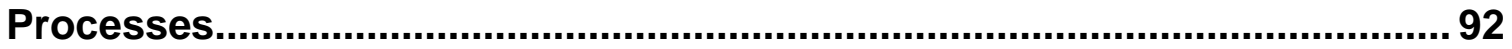

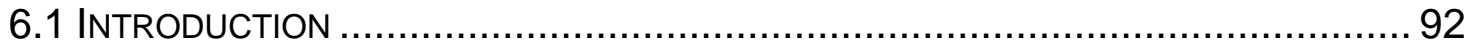

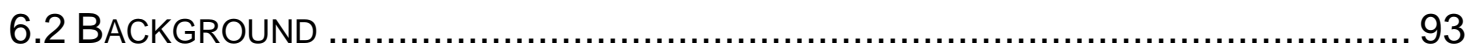

6.3 Process Control for Sustainable Process Operations ...................... 94

6.4 VISUALIZATION OF DYNAMIC SUStaINABILITY PERFormanCE ..........................96

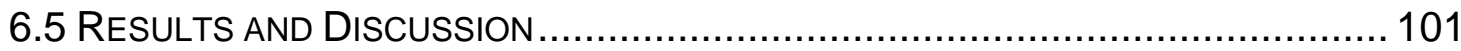

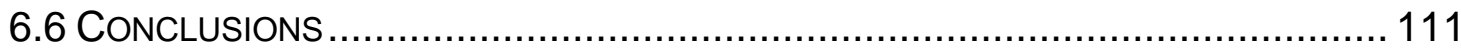

Chapter 7 Multi-objective Optimization and Sustainable Process Control:

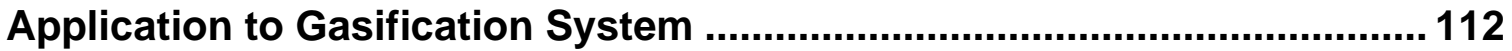

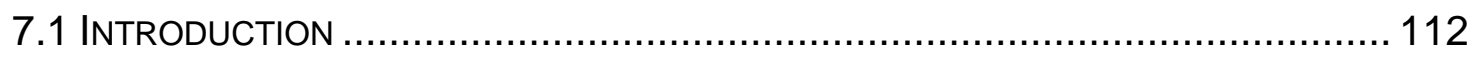

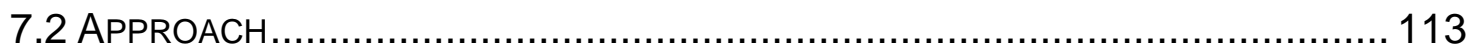

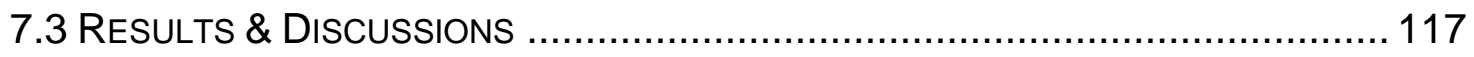


7.4 CONCLUSIONS.......

Chapter 8 Conclusions and Recommendations 125

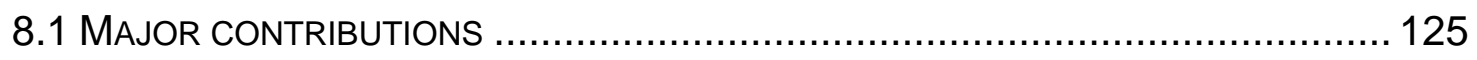

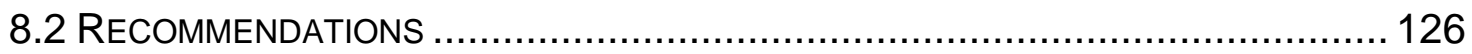

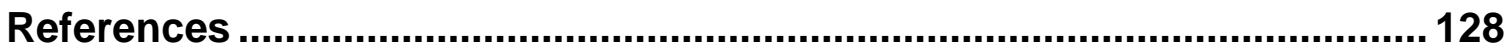

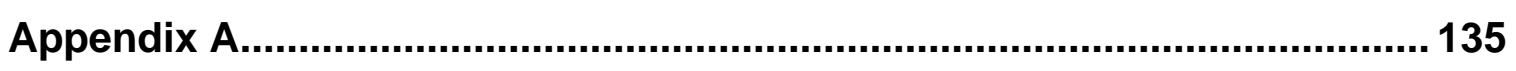




\section{List of Figures}

Figure 1.1 Schematic of process assessment tool and control framework for sustainability developed in this dissertation

Figure 3.1 Process systems framework for pollution control and LCl generation.......... 22

Figure 3.2 Counter-current packed spray scrubber schematic.................................. 24

Figure 3.3 A simplified diagram of a gas-fired boiler system .................................... 25

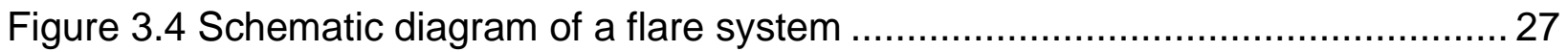

Figure 3.5 Block flow diagram of a thermal oxidizer system...................................... 28

Figure 3.6 Aspen Hysys flowsheet for methanol synthesis ....................................... 34

Figure 3.7 Aspen Hysys flowsheet for the sour gas treatment process......................... 35

Figure 3.8 CHEMCAD flowsheet for the simulated acetic acid manufacturing process 37

Figure 3.9 Incorporation of PCUs into acetic acid process simulation results for rapid

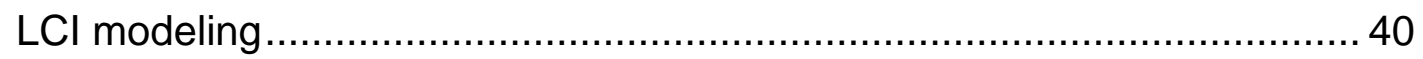

Figure 4.1 Process systems framework for pollution control and sustainability

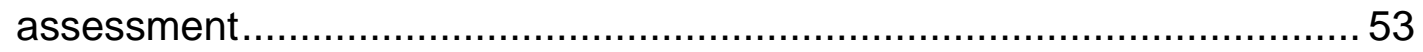

Figure 4.2 Automation interface between simulators and developed PCUs ................. 54

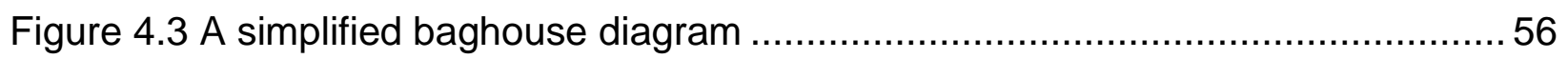

Figure 4.4 A simplified air-stripper schematic diagram ........................................... 56

Figure 4.5 A simplified GAC schematic diagram (adapted from EPA report) ................57

Figure 4.6 Inputs and outputs of GREENSCOPE framework for sustainability

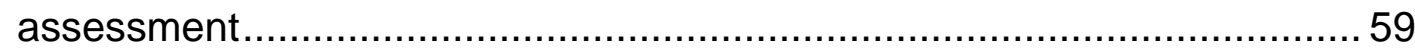

Figure 4.7 Integrating process simulation with PCUs for sustainability assessment ......61

Figure 4.8 Environmental indicators with/without pollution control units ...................... 63 
Figure 4.9 Efficiency indicators with/without pollution control units 64

Figure 4.10 Economic indicators with/without pollution control units ........................... 65

Figure 4.11 Energy indicators with/without pollution control units ..............................6 66

Figure 5.1 Schematic representation of ant's rule of pursuit .................................... 70

Figure 5.2 General structure of the algorithm for the advanced control approach.........72

Figure 5.3 Schematic diagram of the fermentation reactor........................................ 73

Figure 5.4 Open-loop simulations: concentration profiles of key component (a), biomass

(b), substrate (c) and product in fermentor (d) and membrane side (e) and temperature profile (f) for different $\mathrm{Dm}$, in values ................................ 80

Figure 5.5 Closed-loop simulation (Case 1): concentration (key component, biomass, substrate, product in fermentor and membrane sides) and input profiles .. 82

Figure 5.6 Closed-loop simulation (Case 1): temperature (fermentor and jacket) and input profiles. 83

Figure 5.7 Radar plot with GREENSCOPE indicators for the closed-loop and open-loop simulations (Case 1) 83

Figure 5.8 Closed-loop simulation (Case 2): concentration (key component, biomass, substrate, product in fermentor and membrane sides) and input profiles .. 85

Figure 5.9 Closed-loop simulation (Case 2): temperature (fermentor and jacket) and input profiles 85

Figure 5.10 Radar plot with GREENSCOPE indicators for the closed-loop and openloop simulations (Case 2) 86

Figure 5.11 Closed-loop simulation (Case 3): concentration (key component, biomass, substrate, product in fermentor and membrane sides) and input profiles .. 87 
Figure5.12 Closed-loop simulation (Case 3): temperature (fermentor and jacket) and input profiles.

Figure 5.13 Radar plot with GREENSCOPE indicators for closed-loop simulations with different $D_{\text {in }}$ (Case 3). 88

Figure 5.14 Closed-loop simulation (Case 4): concentration (key component, biomass, substrate, product in fermentor and membrane sides) and input profiles .. 89

Figure 5.15 Closed-loop simulation (Case 4): temperature (fermentor and jacket) and input profiles. 90

Figure 5.16 Radar plot with GREENSCOPE indicators for the closed-loop and openloop simulations (Case 4) ............................................................. 90

Figure 6.1 Schematic diagram of the fermentation reactor....................................... 93

Figure 6.2 Proposed framework for novel sustainable process control ........................95

Figure 6.3 Visualization method for monitoring high-dimensional sustainability performance: (a) 2D radar plot; (b) 3D radar plot 99

Figure 6.4 Process open-loop simulation dynamics: (a) concentration profiles of different components and (b) reactor temperature profile 101

Figure 6.5 Dynamic sustainability performance of open-loop simulation (red represents less sustainable while green more sustainable according to calculated SI values): (a) 3D sustainability indicator dynamic radar plot; (b) 2D projection of sustainability indicator radar plot 101

Figure 6.6 Case 1 - closed-loop simulation without sustainability constraint: output ( $\mathrm{y}_{1}$ and $\left.\mathrm{y}_{2}\right)$ and input $\left(\mathrm{u}_{1}\right.$ and $\left.\mathrm{u}_{2}\right)$ profiles 105 
Figure 6.7 Case 1 - dynamic sustainability performance without sustainability constraint:

(a) 3D sustainability indicator dynamic radar plot; (b) 2D projection of sustainability indicator radar plot. 105

Figure 6.8 Case 1 - closed-loop simulation with sustainability constraint: output ( $\mathrm{y}_{1}$ and $\left.\mathrm{y}_{2}\right)$ and input $\left(\mathrm{u}_{1}\right.$ and $\left.\mathrm{u}_{2}\right)$ profiles 106

Figure 6.9 Case 1 - dynamic sustainability performance with sustainability constraint: (a) 3D sustainability indicator dynamic radar plot; (b) 2D projection of sustainability indicator radar plot. 106

Figure 6.10 Case 1 - comparison between control without WI constraint (red line) and control with WI constraint (blue line) at three representative sample points

Figure 6.11 Case 2 - closed-loop simulation without sustainability constraint: output ( $\mathrm{y}_{1}$ and $\left.\mathrm{y}_{2}\right)$ and input $\left(\mathrm{u}_{1}\right.$ and $\left.\mathrm{u}_{2}\right)$ profiles 109

Figure 6.12 Case 2 - dynamic sustainability performance without sustainability constraint: (a) 3D sustainability indicator dynamic radar plot; (b) 2D projection of sustainability indicator radar plot 109

Figure 6.13 Case 2 - Closed-loop simulation with sustainability constraint: output ( $\mathrm{y}_{1}$ and $\left.\mathrm{y}_{2}\right)$ and input ( $\mathrm{u}_{1}$ and $\left.\mathrm{u}_{2}\right)$ profiles 110

Figure 6.14 Case 2 - Dynamic sustainability performance with sustainability constraint: (a) 3D sustainability indicator dynamic radar plot; (b) 2D projection of sustainability indicator radar plot 
Figure 6.15 Case 2 - Comparison between control without WI constraint (red line) and control with WI constraint (blue line) at three representative sample points

Figure 7.1 Schematic of the sustainable control strategy based on multi-objective optimization 113

Figure 7.2 NSGA-III algorithm flowsheet 115

Figure 7.3 Weighting method for the decision maker 116

Figure 7.4 Aspen Hysys model of entrained flow gasifier 119

Figure 7.5 Communications between different software interface 120

Figure 7.6 Pareto frontier of biomass/coal co-gasification process 122

Figure 7.7 Selected operating condition for MPC controller ..... 122

Figure 7.8 MPC results: input and output profiles 123

Figure 7.9 Sustainability performance of closed-loop simulation 124 


\section{List of Tables}

Table 3.1 Summary on brief descriptions, strengths and limitations of developed PCUs in Chapter 3 29

Table 3.2 A summary of user input parameters required for applying each PCU module for LCI modeling.... 31

Table 3.3 LCl input results before and after waste streams have been processed by PCUs 39

Table 3.4 LCl output results before and after waste streams have been processed by PCUs 39

Table 3.5 Life cycle inventory inputs for methanol production from coal 44

Table 3.6 LCl outputs before and after waste streams have been processed by PCUs per kilogram of methanol produced from coal

Table 3.7 Raw material and utility life cycle inventory for methanol production from biomass

Table 3.8 LCI before and after waste streams have been processed by PCUs for biomass case 46

Table 3.9 Uncontrolled emissions from coal and biomass-based methanol process .. 47

Table $3.10 \mathrm{LCl}$ input for entire process from coal to AA .......................................... 48

Table $3.11 \mathrm{LCl}$ output for entire process from coal to AA........................................ 49

Table 5.1 Parameter values for the fermentation process model.............................. 76

Table 7.1 Parameters of chemical kinetics for gasification process ........................ 119 


\section{Nomenclature}

\begin{tabular}{|c|c|}
\hline Variables & Definition (Units) \\
\hline$A_{1} / A_{2}$ & Exponential factors in Arrhenius equation \\
\hline$A_{M}$ & Area of membrane $\left(\mathrm{m}^{2}\right)$ \\
\hline$A I$ & Analysis indicator \\
\hline$A_{T}$ & Heat transfer area $\left(\mathrm{m}^{2}\right)$ \\
\hline$C_{i}$ & Concentration of component $\mathrm{i}\left(\mathrm{kg} / \mathrm{m}^{3}\right)$ \\
\hline$C_{p, r}$ & Heat capacity of the reactants $(\mathrm{kJ} / \mathrm{kg} / \mathrm{K})$ \\
\hline$C_{p, w}$ & Heat capacity of cooling water $(\mathrm{kJ} / \mathrm{kg} / \mathrm{K})$ \\
\hline$D_{\text {in }}$ & Inlet fermentor dilution rate $\left(\mathrm{h}^{-1}\right)$ \\
\hline$D_{j}$ & Cooling water flow rate $\left(\mathrm{h}^{-1}\right)$ \\
\hline$D_{\text {out }}$ & Outlet fermentor dilution rate $\left(\mathrm{h}^{-1}\right)$ \\
\hline$D_{m, \text { in }}$ & Inlet membrane dilution rate $\left(\mathrm{h}^{-1}\right)$ \\
\hline$D_{m, \text { out }}$ & Outlet membrane dilution rate $\left(\mathrm{h}^{-1}\right)$ \\
\hline$E_{a 1} / E_{a 2}$ & Activation energy $(\mathrm{kJ} / \mathrm{mol})$ \\
\hline$f_{i}$ & Objective function i \\
\hline$F_{i j}$ & Normalized objective function matrix \\
\hline$K_{S}$ & Monod constant $\left(\mathrm{kg} / \mathrm{m}^{3}\right)$ \\
\hline$K_{T}$ & Heat transfer coefficient $\left(\mathrm{kJ} / \mathrm{h} / \mathrm{m}^{2} / \mathrm{K}\right)$ \\
\hline$k_{l}$ & Empirical constant $\left(\mathrm{h}^{-1}\right)$ \\
\hline$k_{2}$ & Empirical constant $\left(\mathrm{m}^{3} / \mathrm{kg} \cdot \mathrm{h}\right)$ \\
\hline$k_{3}$ & Empirical constant $\left(\mathrm{m}^{6} / \mathrm{kg}^{2} \cdot \mathrm{h}\right)$ \\
\hline$m_{s}$ & Maintenance factor based on substrate $(\mathrm{kg} / \mathrm{kg} \cdot \mathrm{h})$ \\
\hline$m_{p}$ & Maintenance factor based on product $(\mathrm{kg} / \mathrm{kg} \cdot \mathrm{h})$ \\
\hline$M$ & Mixer \\
\hline$M W$ & Molecular weight (g/mole) \\
\hline$\alpha$ & Membrane permeability (m/h) \\
\hline $\mathrm{P}$ & Correction factor \\
\hline$r_{i}$ & Reaction rate of component i $\left(\mathrm{kg} / \mathrm{m}^{3}\right)$ \\
\hline$R$ & Gas constant \\
\hline$T I$ & Temperature indicator \\
\hline$T_{j}$ & Temperature of cooling water in the jacket $(\mathrm{K})$ \\
\hline$T_{w, i n}$ & Inlet temperature of cooling water $(\mathrm{K})$ \\
\hline$T_{r}$ & Temperature of the reactor $(\mathrm{K})$ \\
\hline$u(t)$ & Input variables \\
\hline$V_{F}$ & Fermentor volume $\left(\mathrm{m}^{3}\right)$ \\
\hline
\end{tabular}




\begin{tabular}{|c|c|}
\hline Variables & Definition (Units) \\
\hline$V_{M}$ & Membrane volume $\left(\mathrm{m}^{3}\right)$ \\
\hline$V_{j}$ & Cooling jacket volume $\left(\mathrm{m}^{3}\right)$ \\
\hline$w_{i}$ & Weighting factor i \\
\hline$x(t)$ & State variables \\
\hline$Y_{s x}$ & Yield factor based on substrate $(\mathrm{kg} / \mathrm{kg})$ \\
\hline$Y_{p x}$ & Yield factor based on product $(\mathrm{kg} / \mathrm{kg})$ \\
\hline \multicolumn{2}{|c|}{ Greek Symbols } \\
\hline$\alpha_{i}$ & The number of moles of species in biomass pyrolysis \\
\hline$\rho_{r}$ & Reactants density $\left(\mathrm{kg} / \mathrm{m}^{3}\right)$ \\
\hline$\rho_{w}$ & Cooling water density $\left(\mathrm{kg} / \mathrm{m}^{3}\right)$ \\
\hline$\mu$ & Specific growth rate $\left(\mathrm{h}^{-1}\right)$ \\
\hline$\mu_{\max }$ & Maximum specific growth rate $\left(\mathrm{h}^{-1}\right)$ \\
\hline$\Delta H$ & Heat of fermentation reaction $(\mathrm{kJ} / \mathrm{kg})$ \\
\hline$\omega_{i}$ & Mass fraction of species i in biomass pyrolysis \\
\hline$v_{i}$ & Weighted normalized objective matrix \\
\hline \multicolumn{2}{|l|}{ Subscripts } \\
\hline $\mathrm{CO}$ & Carbon monoxide \\
\hline $\mathrm{CO}_{2}$ & Carbon dioxide \\
\hline $\mathrm{CH}_{4}$ & Methane \\
\hline $\mathrm{H}_{2}$ & Hydrogen \\
\hline $\mathrm{H}_{2} \mathrm{O}$ & Water \\
\hline e & Key component inside the fermentor \\
\hline $\mathrm{e}_{0}$ & Inlet key component to the fermentor \\
\hline $\mathrm{P}$ & Product (ethanol) inside the fermentor \\
\hline $\mathrm{P}_{0}$ & Inlet product to the fermentor \\
\hline PM & Product (ethanol) inside the membrane \\
\hline$S$ & Substrate inside the fermentor \\
\hline $\mathrm{S}_{0}$ & Inlet substrate to the fermentor \\
\hline $\mathrm{X}$ & Biomass inside the fermentor \\
\hline $\mathrm{X}_{0}$ & Inlet biomass to the fermentor \\
\hline
\end{tabular}




\section{Chapter 1 Introduction}

Chemical industries utilize a wide range of feedstocks to manufacture petrochemical, biofuel, food, microelectronics, textile, and pharmaceutical products. At the same time, these industries exert some of the most profound impact on the environment especially due to their ubiquitous nature and the lack of environmental consciousness and efficient sustainable process systems engineering methods. Recently, this situation is changing as society, government, and industry have realized that sustainable practices can be implemented with reduced economic penalty and harm to the environment and human health. Many researchers and private/public initiatives have been working on implementing sustainable development practices. Such practices have components related to sustainable design frameworks and sustainability assessment tools. However, an efficient framework for the integration of advanced process control with sustainability assessment tools is still missing. This dissertation describes the first attempt to directly integrate sustainability assessment tools with advanced control strategies to simultaneously optimize and control chemical processes during operation.

The objective in this research is to provide a systematic framework to optimize and control chemical process systems at the optimal operating points considering efficiency, environmental, economic and energy aspects. The proposed methods in this framework focus on optimization, advanced control and life cycle inventory (LCl) analysis with the application to chemical processes. The specific aims for the proposed approach are:

Aim \#1: Develop a sustainable control strategy for chemical processes based on a multi-objective optimization method. This sustainable control strategy includes three main steps: process and sustainability evaluation model construction, multi-objective optimization formulation, and implementation of advanced control strategy. 
$>$ Aim \#2: Incorporate LCI analysis into the developed process systems framework. In this specific aim, the developed sustainable control strategy is implemented in reduced models to provide more accurate information on LCI data.

$>$ Aim \#3: Apply the developed methods to chemical processes. This aim includes two specific tasks: implementation of the developed sustainable control strategy to the selected units of the gasification process and the fermentation process.

The main results in this dissertation correspond to: (i) development of a comprehensive sustainability tool for $\mathrm{LCl}$ generation and evaluation that integrates process simulation, pollution control units, $\mathrm{LCl}$ and sustainability indicators in this tool; (ii) integration of the developed tool with multi-objective optimization for better balancing the conflicting sustainability indicators (e.g., economic and environmental aspects); and (iii) development of a sustainable control framework to consider the sustainability performance during transients. Figure 1.1 presents a schematic of the process assessment tool and control framework for sustainability developed in this dissertation.

The contributions of this dissertation have resulted in the following products:

Peer reviewed papers:

$>$ Li, S., Ruiz-Mercado, G.J., and Lima, F.V., A Novel Process Systems Engineering (PSE) Scheme for Sustainability. (Chapter 7) (In preparation)

$>$ Li, S., Ruiz-Mercado, G.J., and Lima, F.V., A Novel Visualization and Control Strategy for Dynamic Sustainability of Chemical Processes. (Chapter 6) (Submitted for publication)

$>$ Li, S., Ruiz-Mercado, G.J., and Lima, F.V., Simulation-based Computational Framework for Sustainability Assessment and Pollution Control of Chemical Manufacturing Processes. (Chapter 4) (In preparation)

$>$ Li, S., Feliachi, Y., Agbleze, S., Ruiz-Mercado, G.J., Smith, R.L., Meyer, D.E., Gonzalez, M.A. and Lima, F.V., 2018. A Process Systems Framework for Rapid Generation of Life Cycle Inventories for Pollution Control and Sustainability Evaluation. Clean Technologies and Environmental Policy, 20, pp.1543-1561. (Chapter 3)

$>$ Li, S., Mirlekar, G., Ruiz-Mercado, G., J., and Lima, F., V., 2016. Development of Chemical Process Design and Control for Sustainability. Processes, 4(3). (Chapter 5) 
Mirlekar, G., Li, S., and Lima, F., V., 2017. Design and Implementation of a Biologically Inspired Optimal Control Strategy (BIO-CS) for Chemical Process Control. Industrial \& Engineering Chemistry Research, 56(22).

$>$ Mirlekar, G., Gebreslassie, B.H., Li, S., Diwekar, U.M. and Lima, F.V., 2018. An Integrated Biomimetic Control Strategy with Multi-agent Optimization for Nonlinear Chemical Processes. IFAC-PapersOnLine, 51(18):55-60.

> Lima, F., V., Li, S., Mirlekar, G., Sridhar, L., N., and Ruiz-Mercado, G., J., 2016. Modeling and Advanced Control for Sustainable Process Systems. G. Ruiz-Mercado and H. Cabezas (eds.), Elsevier. (Invited Book Chapter)

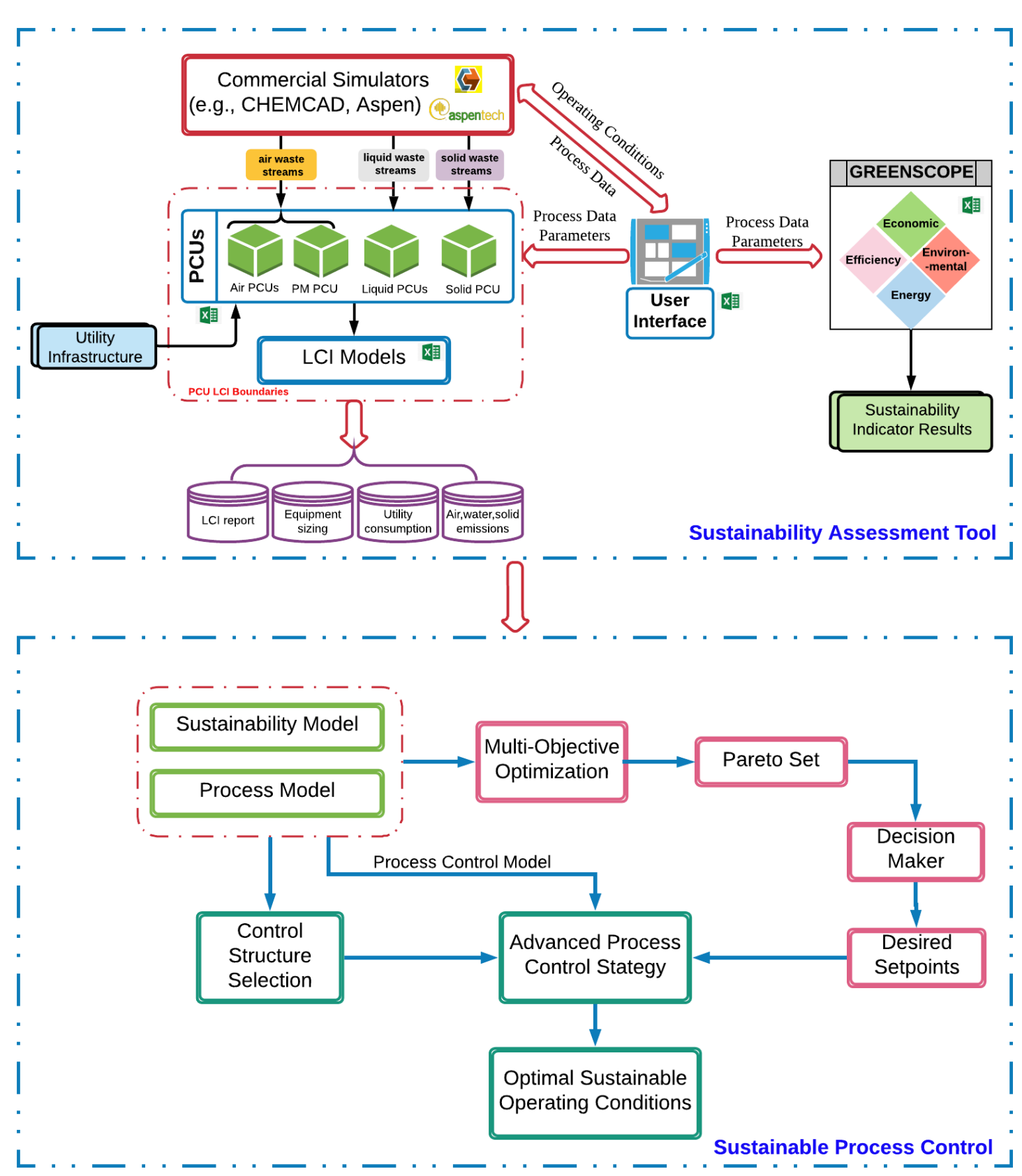

Figure 1.1 Schematic of process assessment tool and control framework for sustainability developed in this dissertation 


\section{Oral presentations:}

> Li, S., Ruiz-Mercado, G., J. and Lima, F., V., "A Multi-Layer Process Control Framework for Sustainability: Application to Biomass/Coal Co-Gasification System." In AIChE Annual Meeting, Orlando, FL, 2019.

$>$ Li, S., Mirlekar G., and Lima, F., V., "Model Predictive Control with Real-Time Sustainability Monitoring: Application to an Advanced Energy System." In AIChE Annual Meeting, Orlando, FL, 2019.

$>$ Li, S., Ruiz-Mercado, G., J. and Lima, F., V., "A Multi-layer Computational Framework for Sustainable and Resilient Chemical Process Design." In AIChE Enterprise and Infrastructure Resilience Conference, Cincinnati, OH, 2019.

$>$ Li, S., Ruiz-Mercado, G., J. and Lima, F., V., "A Novel Model Predictive Control Scheme for Sustainability: Application to Biomass/Coal Co-Gasification System." In AIChE Annual Meeting, Pittsburgh, PA, 2018.

$>$ Li, S., Agbleze S., Ruiz-Mercado, G., J. and Lima, F., V., "Simulation-Based Computational Framework for Sustainability Assessment and Life Cycle Inventory Generation." In AIChE Annual Meeting, Pittsburgh, PA, 2018.

$>$ Li, S., Ruiz-Mercado, G., J. and Lima, F., V., “A Simulation-based Computational Framework for Pollution Control Units (PCU) and Estimation of Life Cycle Inventories (LCI) from Chemical Manufacturing Processes.” In ICOSSE, Cincinnati, OH, 2018.

> Mirlekar, G., Gebreslassie, B., H., Li, S., Diwekar, U., M., and Lima, F., V., “An Integrated Biomimetic Control Strategy with Multi-agent Optimization for Nonlinear Chemical Processes." In IFAC ADCHEM, Shenyang, China, 2018.

$>$ Li, S., Ruiz-Mercado, G., J. and Lima, F., V., "Process Control for Sustainability and LCI Monitoring: Application to Biomass/Coal Co-gasification System. ” In AIChE Annual Meeting, Minneapolis, MN, 2017.

$>$ Li, S., Ruiz-Mercado, G., J. and Lima, F., V., "A Sustainable Framework for Chemical Manufacturing and for the Integration of Advanced Control with Sustainability Assessment". In AIChE Annual Meeting, San Francisco, CA, 2016.

$>$ Lima, F., V., Li, S., Mirlekar, G., Sridhar, L., N., and Ruiz-Mercado, G., J., "Modeling and Advanced Control for Sustainable Process Systems”. In AIChE Annual Meeting, Salt Lake City, UT, 2015.

The outline for the remaining chapters of this dissertation includes a literature review, which is presented first. Then, the developed tool for rapid life cycle inventory (LCl) is introduced, followed by the integrated framework for sustainability assessment. Both tools are demonstrated via a coal/biomass co-gasification process. Next, the process control for sustainability is motivated, using an example associated with a fermentation process. Then, a novel control strategy for 
sustainability is proposed, including a novel visualization method for dynamic multivariable sustainability indicators and the addition of a sustainability constraint. This new framework is illustrated considering previous case studies. Finally, this novel control framework is integrated with a multi-objective optimization algorithm for a coal/biomass co-gasification process, followed by the conclusions and recommendations for future work. 


\section{Chapter 2 Literature Review}

This chapter presents an overview of the reviewed literature to perform this research, including the main topics of sustainable development, life cycle inventory (LCI), sustainability assessment, pollution control units, multi-objective optimization for sustainability, and process dynamics and control for sustainability.

\subsection{Sustainable Development}

Chemical processes exert some of the most profound impact on the environment especially due to their ubiquitous nature and the importance of chemical products to our modern society (e.g., antibiotics, varieties of foods, energy, fuels, etc.). In recent years, environmental consciousness has been growing and has become critical in the decision-making step of industrial processes. This awareness has led to the formulation of the concept of sustainability and sustainable development in the past century ${ }^{1,2}$.

In particular, sustainable development has been defined in terms of economic, environmental and social factors, such as the development of economic prosperity and the establishment of a more equitable society without depriving the future generations' standard of living ${ }^{3}$. The definition of sustainable development provides a guideline for working towards a new and better society. From the perspective of engineers, sustainability is typically considered to have environmental, economic and social dimensions that should be balanced and jointly optimized. The following engineering definition has been proposed for sustainability 4,5: "for a man-made system, sustainable development is a continual improvement in one or more of the three domains of sustainability, i.e., economic, environmental and societal without causing degradation in any of the rest, either now or in the future, when compared, with quantifiable metrics, to a similar system that it is intended to replace." In terms 
of engineering decision-making, the following definition ${ }^{6}$ is also important: "a sustainable process is one that constrains resource consumption and waste generation to an acceptable level, making a positive contribution to the satisfaction of human needs, and providing enduring economic value to the business enterprise."

Despite these available definitions, there is still an ongoing debate on the characterization of sustainable development and the assessment of a process design and operation in terms of sustainability. For example, in process systems engineering, what should be the methodologies and approaches employed to obtain a sustainable process operation through design, optimization and control? In the past, there were several contributions and methods developed that focus on the minimization of the environmental impact of chemical industries. Specifically, three basic principles for green engineering, end of pipe technologies, pollution prevention, and water minimization, were introduced ${ }^{7}$. Recently, due to the available sustainability assessment tools and methods, many process systems engineering (PSE) methods have been developed with regards to integrating sustainability into supply chain, process design and multi-objective optimization at different scales. For example, literature on sustainable supply chain management showed the progress of taking into consideration environmental and social impacts by integrating sustainability into the developed framework ${ }^{8,9}$. Along the same lines, sustainable process design and multi-objective optimization (MOO) methods have been demonstrated on a variety of applications from molecular chemistry ${ }^{10}$ to ecosystems ${ }^{11}$. The detailed literature review on life cycle inventory (LCl), sustainability assessment tools, pollution control units, and PSE methods for sustainability is performed below. 


\subsection{Life Cycle Inventory}

Life Cycle Assessment (LCA) is a standard tool for sustainable decision-making among product and process alternatives ${ }^{12}$. Specifically, LCA takes into account mass and energy flows as well as environmental releases in the life cycle of a product, from the extraction of raw materials, production, and use to disposal/recycling ${ }^{13}$. LCA is increasingly applied to identify and quantify the farreaching impacts of a process/product within its life cycle. For example, an integrated framework of LCA and pollution control/prevention can provide holistic results beyond a single process and thus help to identify those alternatives that enhance sustainability in addition to environmental protection ${ }^{14}$. Additionally, the information LCA provides can guide decision-makers (e.g., individual facility, environmental policy makers) to improve decisions in terms of sustainability. Although many contributions have been made in LCA recently, the efficient and accurate modeling of chemical processes for rapid $\mathrm{LCl}$ generation is still challenging. $\mathrm{LCl}$, as a fundamental step of LCA, is used to quantify the energy use and raw material inputs as well as environmental releases accurately throughout a product's life cycle.

Currently, there are about 85,500 chemicals reported in the EPA's TSCA Chemical Substance Inventory ${ }^{15}$, with 9,626 of those being active in commerce ${ }^{16}$. However, in contrast, substances included in the most common LCA databases represent only a portion of these chemicals. In addition, there is a lack of consistency, transparency, and available procedures for finding reliable LCI data. Particularly, obtaining consistent LCl data is one of the most time-consuming steps of an LCA. Poor data availability and inconsistency of data may lead to unrealistic results and conclusions. Some of the existing challenges in $\mathrm{LCl}$ generation are due to the lack of systematic process systems (e.g., design and simulation) tools to develop 
chemical process models for rapidly obtaining and analyzing $\mathrm{LCl}$ results at early development stages.

Typically, there are two methods to generate LCl data for a product, process or activity. The top-down approach relies on facility-level data ${ }^{17}$, while the bottom-up approach depends on process design approaches for sets of unit operations ${ }^{18}$. Some benefits of the top-down approach are that the data reported by companies can be more realistic. However, some adverse issues regarding the top-down method include large data gaps related to variations in reporting requirements, potential lack of transparency regarding the underlying process technology production rates represented in databases, allocation of facility-level emissions, material and energy inputs to a single chemical process within multi-process facilities, and limited coverage of reported substances ${ }^{18}$. In contrast, the bottom-up approach possesses some benefits and limitations as well. Some benefits include estimates of material and energy inputs for a direct LCl connectivity with the life cycle stages beyond the process of interest and process specificity. In addition, there is no need to apply allocation to the collected $\mathrm{LCl}$ and the inventory can be tracked down to process equipment unit allocation. However, process modeling assumptions and extensive process systems engineering (PSE) knowledge in process design and simulation are required to develop a full chemical production process and apply a bottom-up approach for $\mathrm{LCl}$ modeling.

As described by Subramanian and Golden ${ }^{19}$, there are several bottom-up methodologies to deal with $\mathrm{LCl}$ estimation data gaps/modeling: molecular structurebased neural network modeling ${ }^{20}$, input-output schema for calculation of mass and energy flows using heuristics and on-site data ${ }^{21}$, estimating gate-to-gate life cycle using chemical process design techniques ${ }^{22}, \mathrm{LCl}$ estimation using the inherent 
burden approach ${ }^{23}$, obtaining inventory data using stoichiometric equations from technical literature, and proxy $\mathrm{LCl}$ data $^{24}$. Along the same lines, Yao and Masanet ${ }^{25}$ developed generic unit operation models to estimate the life cycle energy and greenhouse gas (GHG) emissions for chemical processes at early or R\&D stages. Another study conducted by U.S. EPA combined the Environmentally-Extended Input-Output (EEIO) analysis with LCA methods based on more recent economic and environmental data of U.S. goods and services ${ }^{26}$. In addition, other bottom-up approaches employ computer-aided process simulation for estimating LCl data ${ }^{27-31}$. The bottom-up methods in literature can be roughly grouped in two types: process flow approaches and matrix-based methods ${ }^{32}$. LCl results from process flow methods are calculated based on process balance models and thus are more accurate when compared to matrix-based methods that employ a set of simultaneous simple equations for each unit. Also, matrix-based $\mathrm{LCl}^{33}$ can be easily applied for advanced LCl analysis with the limited application to single-output processes.

Although many software and databases have been available for LCA, obtaining reliable Life Cycle Inventory (LCI) data is still challenging. The challenges include: 1) plant data are protected by industrial parties as confidential information; 2) it requires effort and expertise to build LCl model via modeling and calculations; 3 ) there is a variety of unit operations and process configurations.

Current methods for generating $\mathrm{LCl}$ are process simulation, process engineering calculations, molecular structure models and using proxy data. Each approach possesses advantage and disadvantages and LCA practitioners should choose the suitable method based on availability of data and the technique skills. For chemical processes, process simulators (e.g., CHEMCAD ${ }^{34}$, Aspen $^{35}$ ) are widely used to 
generate gate-to-gate (from raw material to product) $\mathrm{LCl}$ data and calculate sustainability indicators. Such methods take into consideration different operating conditions and process configurations even at the early design stage, although they require process systems engineering (PSE) knowledge. The resulting sustainability results from those methods can provide guidance for the decision maker on selecting the optimal operating conditions and process design.

\subsection{Sustainability Assessment}

Chemical manufacturing process is recognized as one of the main contributors to natural resources consumption, environmental pollution and ecosystem degradation, although its contribution to societal needs and development is critical. It is urgent and imperative to address this paradox by developing sustainable products and processes for satisfying the needs of present and future generations. Fortunately, growing recognition of the environmental issues has prompted government, industry and individuals to apply sustainability analysis in decisionmaking steps and daily life. For example, plastics are now being banned in many areas of United States and other countries due to solid waste accumulation in land and oceans. However, there are many other unsustainable chemical products and processes still providing goods and service for the needs of present generations while compromising the ability of future generations to meet their needs. In addition, replacing unsustainable products with sustainable ones in our society is being held back by the difficulty of evaluating sustainability performance of a specific process/product and the lack of appropriate tools for sustainability ${ }^{36}$. The advancement and maturity of the available tools to a great extent will determine the future engineer and scientist's skill for designing and improving the chemical processes in terms of sustainability. 
In this respect, the available sustainability assessment tools and metrics have been developed for quantifying the sustainability performance at different scales ${ }^{37-}$ 41. Among these tools, they can be grouped into two main categories: metricorientated methods and the aforementioned LCA. For metric-orientated methods, their focus is to transfer the abstract concept of sustainability into well-defined indicators in economic, environmental and social aspect within a predefined boundary. On the contrary, LCA is intended to quantify the environmental impact of a selected product or process within its life cycle "from cradle to grave". Both of such system information analysis methods are useful and complementary for sustainability assessment.

With the deeper understanding of "sustainability" in the engineering perspective, many metrics/indicators have been developed to quantify "three pillars" of sustainability performance (economic, environmental or social aspects) ${ }^{42}$. The resulting Indicators can be classified into three types: 1) one-dimensional indicators which describe the performance in one pillar; 2) two-dimensional indicators which interpret interactive performance in two of the three pillars; 3) three-dimensional indicators which characterize the performance in three pillars. For example, several key sustainability indices developed by American Institute of Chemical Engineers ${ }^{43}$ and UK Institution of Chemical Engineering ${ }^{44}$ include environmental impact, safety, product stewardship, innovation and societal measures. Such developed indicators are typically aggregated based on subjective weights. A recent too ${ }^{38,45-48}$ developed by the US Environmental Protection Agency, GREENSCOPE (Gauging Reaction Effectiveness for the ENvironmental Sustainability of Chemistries with a multiObjective Process Evaluator) was proposed as a systematic methodology for the evaluation of process performance and sustainability. A set of environmental, 
material, energy, and economic indicators was employed to describe process aspects in terms of a quantitative sustainability measurement scale. Thus, GREENSCOPE quantitatively characterizes how sustainable the process utilizes energy, material goods and services to generate a valuable product, while maximizing its social and economic benefits, and minimizing or eliminating negative environmental impacts. Besides, GREENSCOPE can provide clear quantified limits for comparing process performances and designs between themselves and determining if some sustainability improvements or better operating conditions have been achieved. In addition, the worst and best case can be adapted according to design needs, decision-makers, and product specifications. The desired GREENSCOPE indicators could also be employed to optimize the process performance if incorporated into multi-objective optimization problems. A recent contribution detailed the implementation and use of this sustainability evaluation and design tool for the manufacturing of biodiese $\left.\right|^{45,47,48}$. The capability of this tool is demonstrated to identify the major process aspects or conditions favorable for the attainment of sustainable improvements.

\subsection{Pollution Control Units}

Over the past several decades, the United States and many other countries have enacted legislation and regulations to limit releases to the environment as well as to alleviate the adverse effects of pollution by human activities. The U.S. Environmental Protection Agency (U.S. EPA) has made important progress to advance environmental protection strategies from end-of pipe treatment to pollution prevention $^{49}$. The Clean Air Act (CAA) of 1970 and the Clean Water Act (CWA) of 1977 are regulatory foundations used to mitigate the environmental and human health concerns associated with air and water quality. In addition, the Toxic 
Substances Control Act (TSCA) of 1976 provides EPA the authority to demand reporting, record-keeping and testing requirements, and restrictions relating to chemical substances and/or mixtures manufactured or processed, including imports, in the United States and in the chemical industry. For example, as part of the CAA, EPA is charged with setting the National Ambient Air Quality Standards (NAAQS). These standards limit the ambient concentrations of six criteria air pollutants: groundlevel ozone (including volatile organic compounds, VOCs), carbon monoxide (CO), sulfur dioxide $\left(\mathrm{SO}_{2}\right)$, particulate matter $(\mathrm{PM})$, nitrogen oxides $\left(\mathrm{NO}_{x}\right)$, and lead $(\mathrm{Pb})$. Therefore, as stationary sources of air, solid, and water pollutants, chemical processes are subject to federal, state, and local air quality regulations. Such regulations require chemical plants to undertake several emission-permitting procedures during construction and operation. However, feasibility-level designs typically do not consider the impacts associated with emission control technologies in process sustainability analysis for real-world decision making.

PCUs, as the end-pipe technology for chemical process, have been developed and implemented on waste streams of industrial processes to destroy or remove the pollutant species with extra energy before releasing to environment. For example, different treatments can be selected for typical pollutants (particle matter, VOCs, Acid gas, CO and lead) in the air streams based on the characteristics of the pollutant. The typical air pollution control devices include fabric filters, electrostatic precipitators, incinerator, flare and wet scrubber, etc. For the water treatment plant, it is designed to remove odors, color and turbidity as well as other contaminants, typically including primary treatment (remove solids), secondary treatment (biological processes) and tertiary treatment (deodorize and decolorized the wastewater). One major concern of implementation of such pollution control devices 
is that they are expensive and energy demanding, decreasing efficiency and economic performance of industrial processes. Thus, the mindset of implementing pollution control units in industry is to fulfil the environmental legislations and avoid penalties for grossly pollution behaviors. The integration of pollution control, $\mathrm{LCl}$ and sustainability assessment can give us new insight and detailed information on how to evaluate comprehensively available solutions for a given waste stream and balance environmental and economic impacts in the decision-making step.

However, the available methods and tools don't take into consideration the process emissions or merely provide roughly estimation on emissions during $\mathrm{LCl}$ and sustainability assessment calculations. For example, controlled emission values were calculated as a certain fraction of the involved chemical component in the process $^{21,24}$, total process emissions are calculated as the sum of estimated fugitive losses, global mass balance fractions, and flue gas emissions from controlled combustion units ${ }^{22}$, as well as generic emission estimation models are based on direct emissions for energy requirements and plant efficiency ${ }^{23}$. In considering some examples of pollution control equipment modeling for inclusion in $\mathrm{LCl}$, Bojarski et al. ${ }^{27,23}$, described the modeling of process units for the treatment of waste streams (air and liquid) based on black box models and distribution function values. Another example includes equipment modeling and simulation focused on air emissions (flue gas) treatment for carbon capture ${ }^{29,50}$. In addition, Bhatt et al. ${ }^{51}$ evaluated the technoeconomic impacts of emission controls to comply with air quality regulations of a biorefinery and its location and production scale. Therefore, these limitations on controlled emissions data, pollutant-of-interest targeting (i.e., carbon capture), and cost analysis approaches demonstrate the need to develop methods and frameworks for handling controlled emission modeling when simulating LCls given 
the importance of emission streams and regulations in environmental impact evaluations. Moreover, performing a more detailed material and energy balance when implementing pollution control systems will allow designers to consider additional material input flows, accessory equipment, and the energy consumption required for emission controls. In addition, the footprint (construction material (e.g., carbon steel) and land use) associated with these system changes will affect the overall profile of emission controls. At this level of detail through LCI modeling, the importance of considering emission controls for rapid LCI modeling of a chemical manufacturing process was demonstrated in our group ${ }^{52}$.

\subsection{Multi-objective Optimization for Sustainability}

In recent years, with the progress in understanding sustainability, the incorporation of sustainability into chemical process optimization has become a research highlight in process systems engineering ${ }^{53}$. In the last two decades, several emerging fields have been proposed in the area of sustainable design and optimization, such as process integration ${ }^{54}$, process intensification ${ }^{55}$, multi-objective optimization $^{56-59}$ and real-time operation along with sustainable corporate-scale management ${ }^{60}$. One common way to incorporate sustainability indicators (environmental and social aspects) into process design and optimization is to treat such indicators as constraints in the problem objective of maximizing profitability or minimizing the cost of the operations. For example, when minimum environmental risks/impacts related to non-routine and routine releases were considered, the optimal trade-off between cost and environmental impacts was obtained by employing the $\varepsilon$-constraint method, assuming the environmental impact targets were within ranges imposed by a selected amount defined by $\varepsilon^{61}$. 
In addition, a hierarchical design procedure was proposed to synthesize economically efficient separation processes, taking into consideration environmental factors as constraints ${ }^{62}$. Recently, a modular approach for sustainable chemical process design was developed through the integration of quantitative economics and environmental indicators with qualitative indicators in social aspects ${ }^{63}$. Compared to the aforementioned methods, multi-objective optimization schemes have a higher potential to obtain the optimal trade-offs between conflicting economic and environmental objectives. For example, a global optimization method for sustainable design was developed, in which a large-scale algae processing network was simultaneously optimized in terms of minimizing the unit cost and global warming potential associated indicators ${ }^{59}$.

Also, life cycle assessment (LCA) principles have been taken into account in the formulation of superstructure multi-objective optimization problems for the design of sustainable chemical process flowsheets. Along the same line, a framework that combines a multi-objective optimization approach, LCA and principal component analysis was introduced and applied to the synthesis of biological processes with economic and environmental concerns. However, LCA methodologies need a large amount of data within a wide boundary, which are usually difficult to obtain, especially in the beginning of a process design. In addition, it is not clear how certain are Life Cycle Inventory (LCl) data obtained from commercial packages for a particular process under study and LCA does not provide boundary values for process related aspects at any stage and scale of a chemical process design. Finally, a review of multi-objective optimization associated with economic and environmental objectives from the process synthesis and supply chain management point of view was presented ${ }^{64}$. Overall, the reported systems literature studies address 
optimization methodologies for sustainability focused on three components: decision-making sequence, sustainable design framework and design assessment tools.

\subsection{Process Dynamics and Control for Sustainability}

Studies concerning the sustainability of real-time process operations are still at the early stages, despite the fact that control techniques and theory have evolved significantly in the last two decades ${ }^{37}$. For instance, advanced non-linear model predictive control (NMPC) techniques can control non-linear, large-scale chemical processes effectively and safely even at the presence of disturbances and uncertainties. In particular, advanced features of control techniques have been under development in academia, such as economic MPC ${ }^{65}$, stochastic MPC ${ }^{66}$, and safeness-index based MPC ${ }^{67}$. However, to this day, the primary focus of the process control area is to improve the economic or safety related performance of the process, regardless of environmental and social costs. There are only a few reported studies on process operations employing sustainability-oriented control strategies. A recent review ${ }^{68}$ described the challenges of incorporating sustainability goals into process control and stated that sustainability will be a major driver for controller development in the future due to the pressure of taking the sustainable principles into account during process operations. In reference ${ }^{69}$, a method was proposed to integrate deterministic dynamic optimization with optimal control for addressing the sustainability of a batch reactor. Another application of deterministic optimal control strategies was reported to improve energy efficiency in manufacturing processes ${ }^{70}$. In these last two studies, only utilities-related environmental impacts were considered. As described in the literature ${ }^{68}$, the scarcity of studies on sustainable process control can be attributed to the lack of strategies that can effectively 
integrate process sustainability aspects into the advanced controller framework, considering the conflicting nature of sustainability indicators (e.g., economic vs. environmental aspects). 


\section{Chapter 3 Integrated Tool Development for Rapid Life Cycle Inventory}

\subsection{Introduction}

To bridge the gap between PSE, LCl methods, and pollution control needs identified in the literature, the contribution discussed in this chapter corresponds to the development of a process systems framework that involves the incorporation of PCU modules into process simulation and LCI data generation associated with the PCUs and the entire process. The parameterized PCU modules are developed employing a user-friendly Excel interface with the goal of making the models easier to use by decision-makers with little process data or limited knowledge on specific waste treatment technologies, including non-engineer LCA practitioners. In essence, the proposed PCU reduced models are intended to augment existing capacity of commercial process simulators. Some distinguished features included in the PCU modules are: 1) parameterized input variables with default/suggested values;2) easy customization for application to different cases; and 3) ability for integration with different commercial process simulation software.

The biomass/coal to acetic acid manufacturing process is employed to illustrate the application of the proposed framework. This case study is selected for analysis as a representative technology that is described in various forms of literature. Currently, there are numerous works published that describe the acetic acid production process ${ }^{71-74}$, which include its $\mathrm{LCl}$ modeling using the top-down ${ }^{17}$ and bottom-up approaches ${ }^{18}$. Therefore, this study will analyze the $\mathrm{LCl}$ modeling implications of implementing technologies to reduce pollutant emissions from chemical manufacturing. A key output of this work is a set of parameterized pollution control modules that can be used by LCA practitioners to include pollution control in 
their LCl models by specifying a set of key operational parameters. The current baseline design will consider multiple control devices to reduce emissions.

\subsection{Approach}

\subsubsection{Framework}

An overview of the proposed process systems framework is provided in Figure 3.1. In this framework, a chemical process manufacturing simulation is built while considering the different approaches to manufacture the desired product from different feedstocks. Unit operation infrastructure (e.g., steel consumption, land use, etc.) and utility (e.g., heating, cooling, and electricity) requirements change for different feedstocks and product(s) quality. Even though the current framework includes more detailed bottom-up inventory modeling based on process simulation, the PCU modules could just as easily be applied if a practitioner already has information on a waste stream to be treated and can specify the necessary parameters, i.e., skip process simulation and proceed directly to PCU module application. The outputs of the LCI modeling are the desired product, side products, and waste streams. These waste streams are then sent to the developed parameterized (simplified) modules for various PCUs that could append the production LCl with pollution abatement based on user inputs. In this way, the boundaries of the PCU LCl are specific to the control device and not the entire manufacturing process (red box in Figure 3.1). These narrow boundaries enable the control device models to become modular in nature and support plug-and-play application for LCA projects in general. The composition of the waste streams dictates the type of unit operation infrastructure, utility and ultimately the PCU used to remediate such waste streams. 
In this contribution, LCl will be generated for the inputs to the process: feedstock, utility and infrastructure as well as outputs: emissions and by/co-product(s). Emissions associated with process energy use (e.g., utility) are outside the boundary of this study as shown in Figure 3.1. Note that PCUs for water discharges and solid waste release inventories are not developed in this chapter, but are also included for a complete representation (these units are described in the next chapter).

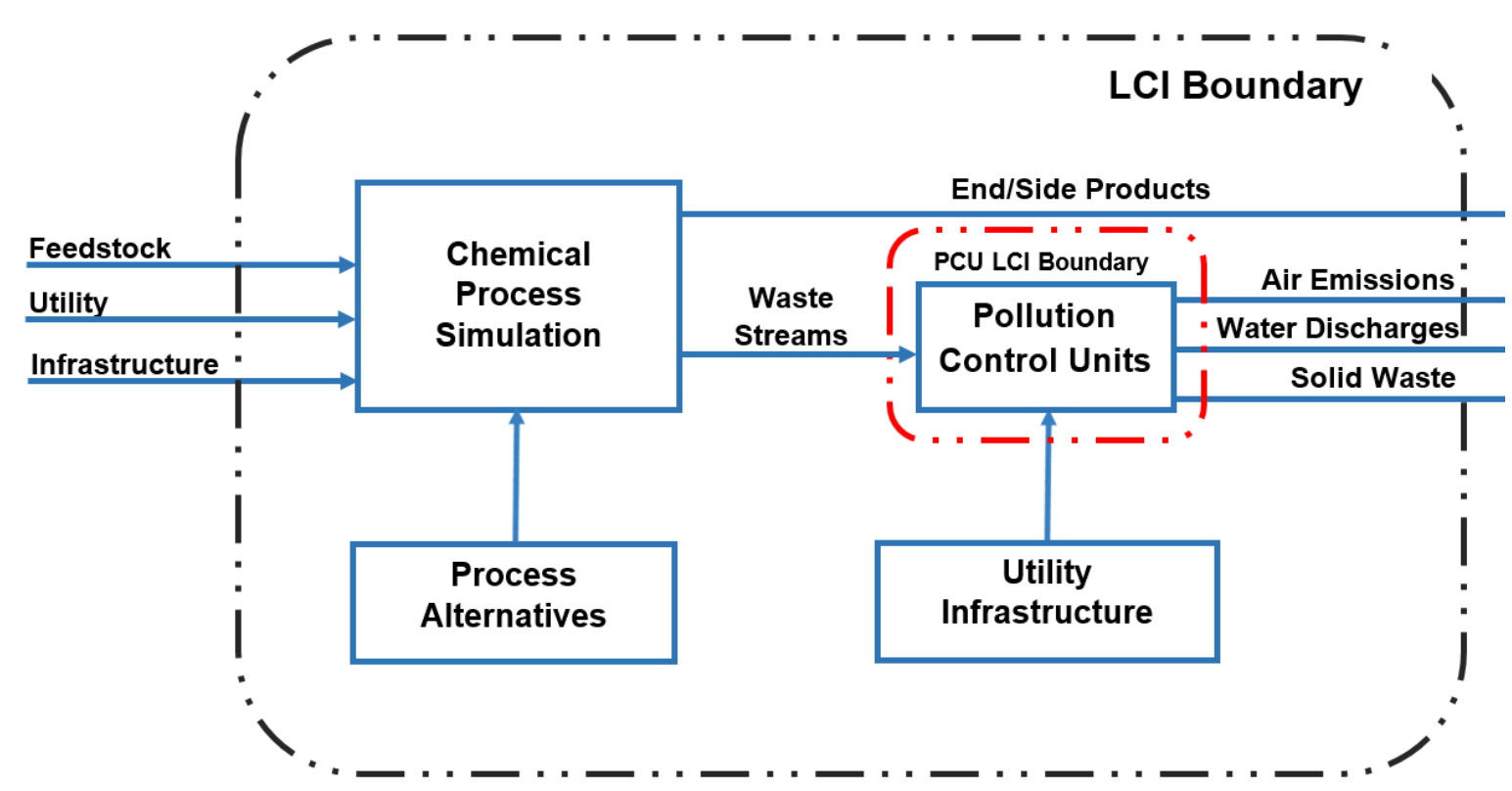

Figure 3.1 Process systems framework for pollution control and LCl generation

\subsubsection{Pollution Control Units}

The design and implementation of PCUs require the evaluation of many aspects such as the waste stream to be treated, physicochemical properties of the pollution streams, selection of control equipment, and evaluation of the exhaust to meet expected outcomes and performance. The quality and quantity of the pollutants directly influence the size of the PCUs. Therefore, any upstream process modification that either can eliminate or minimize the amount of pollutant to be treated will reduce the needs and cost for pollution control. For example, replacing 
the feedstock and changing process operating conditions can be considered if an important reduction in pollution generation can be achieved.

For air pollution control, four representative pieces of equipment are developed for obtaining their input/output mass and energy performance and their infrastructure needs (material of construction and land use). However, there are many types of equipment depending on the pollutant characteristics, which can be classified into two main categories: control equipment for removal of pollution particulate and those for the removal of noxious gases ${ }^{75}$. In addition, the EPA ${ }^{76}$ for techno-economic evaluation purposes classifies pollution controls (recapture, destruction, precombustion, combustion, post-combustion) according to some of the pollutants that must be in compliance with an air quality standard: $\mathrm{CO}$, volatile organic compounds (VOCs), $\mathrm{PM}$, oxides of nitrogen ( $\mathrm{NOx}$ ), and some acid gases (primarily $\mathrm{SO}_{2}$ and $\mathrm{HCl}$ ).

In this contribution, the focus is placed on demonstrating the needs and benefits of adding the effects of pollution control for rapid LCI modeling of a chemical manufacturing process by designing, modeling, and simulating four PCUs for noxious gas removal. The four air PCUs are designed using Microsoft Visual Basic for Applications (VBA) in Microsoft Exce ${ }^{\circledR}$. These PCUs simulate the purification of gas-phase waste streams from a chemical process and provide rapid $\mathrm{LCl}$ estimates for the corresponding process ${ }^{52}$. The PCUs considered in this study are described below.

Scrubbers

Scrubbers ${ }^{77}$, or gas absorbers, as pollution control devices, are used widely in industry for the purification of waste gas streams containing inorganic contaminants, such as $\mathrm{HCl}, \mathrm{H}_{2} \mathrm{~S}$, and $\mathrm{NH}_{3}$ and organics such as $\mathrm{CO}_{2}$ (see scrubber schematic in Figure 3.2). Some applicable pollutants removed include PM less than or equal to 
$10 \mu \mathrm{m}$ in aerodynamic diameter $\left(\mathrm{PM}_{10}\right)$, $\mathrm{PM}$ less than or to equal $2.5 \mu \mathrm{m}$ in aerodynamic diameter $\left(\mathrm{PM}_{2.5}\right)$, precursors of secondary $\mathrm{PM}$ from hazardous air pollutants (PMна), inorganic gases (e.g., $\mathrm{SO}_{2}$, ammonia, chlorides), and VOCs. Scrubbers can employ a variety of techniques including packing materials, perforated trays, and sprayers to force close contact between the polluted gas and the gas scrubbing liquid flowing through the scrubber. The liquid solvents used to achieve this removal are water, mineral oils, or non-volatile hydrocarbons. Removal efficiencies typically range from $90.0 \%$ to $99.9 \%$ and can be attained with higher solvent surface areas, for example, the use of spray nozzles in spray scrubbers. The physical properties of the pollutant and solvent dictate the physical absorption process taking place. The parameters for a wet scrubber (i.e., size, flowrate of solvent) are then determined by the physical properties, removal efficiency, and equilibrium data ${ }^{76,78}$. Refer to publication ${ }^{52}$ for the full detail of design equations and parameters of this unit.

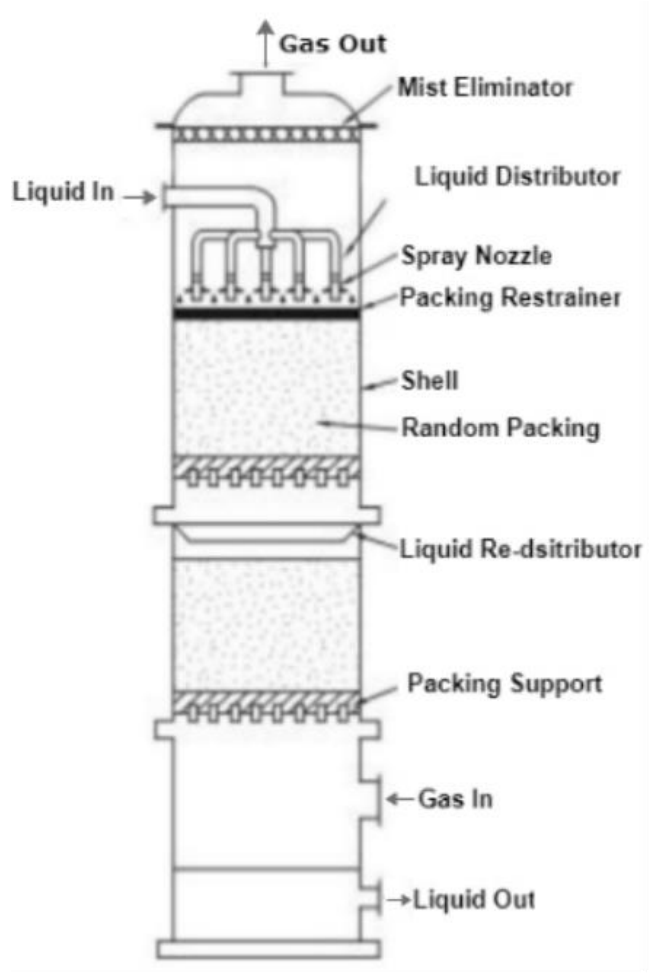

Figure 3.2 Counter-current packed spray scrubber schematic 


\section{Boilers}

Contaminated streams that have no chemical recovery value and are combustible (some VOCs) can be treated with boilers. Fire tube and water tube boilers both use waste gas as an auxiliary fuel to produce steam that can be utilized for power or heating needs in a process (see boiler schematic in Figure 3.3). For pollution control purposes, the waste gas is typically combined with natural gas or other fuels, but high combustion temperature and additional pollution controls may be needed to achieve a complete combustion ${ }^{79}$. In a fire tube boiler, the hot gases from the combustion of the waste gas-fuel mixture move through the tubes while the water is heated in the shell of the boiler. Here the hot gases are passed multiple times through the tubes. Design of fire tube boilers are limited by regulations on diameter and operating pressures. In a water tube boiler, water entering the boiler moves through tubes exposed to the heat generated from the waste gas-fuel combustion. The heated water is circulated, while the steam is withdrawn. Refer to publication $^{52}$ for the full detail of design equations and parameters of the boiler when employed as a noxious gas removal unit.

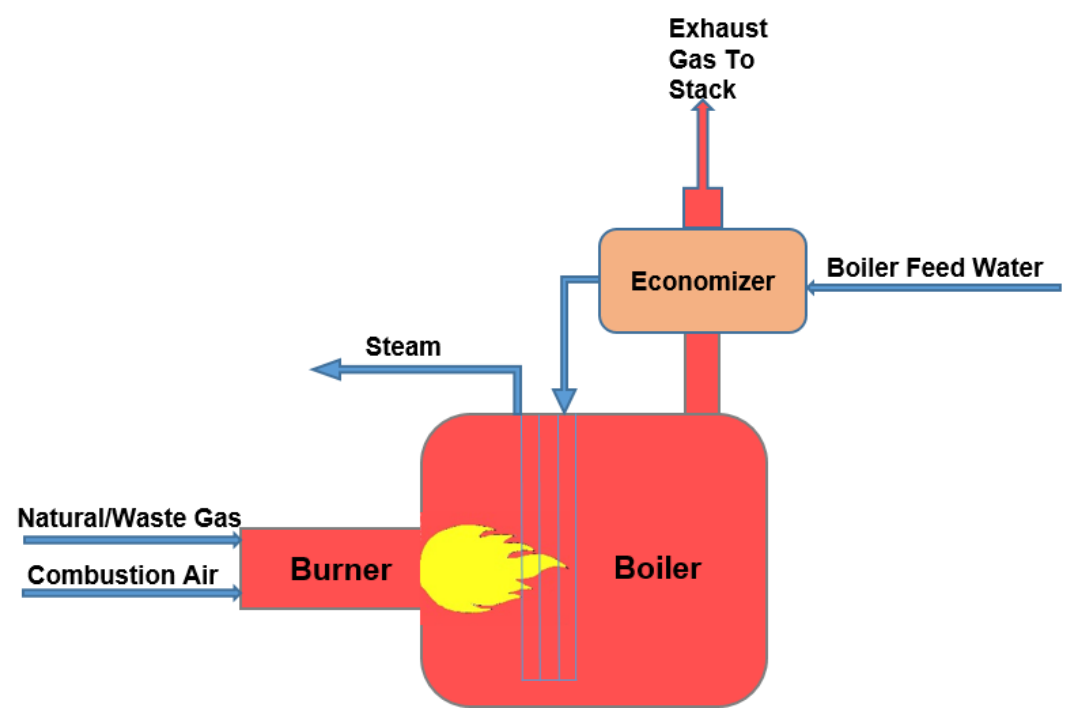

Figure 3.3 A simplified diagram of a gas-fired boiler system 


\section{Flare Units}

Flare units ${ }^{76}$ are used to completely combust compounds introduced into the unit, typically VOCs (except halogenated compounds), via an open flame (see flare schematic in Figure 3.4). The combustion is considered complete if the products are carbon dioxide and water, while incomplete combustion results in the formation of carbon monoxide or other partially oxidized organic compounds. A flare can achieve VOC destruction greater than $98 \%$. There are three different types of flares in terms of the method for increasing mixing at the flare tip: steam-assisted, air-assisted, and non-assisted. Steam-assisted flares inject steam in the combustion zone to generate turbulence and induce air into the flame. The steam requirements for smokeless burning depends on the composition and flowrate of the mixture ${ }^{52}$. Air-assisted flares increase the mixing required for smokeless operation using compressed air provided by a compressor placed at the bottom of the unit. The amount of compressed air entering the unit is about 1.2 times the steam flowrate since steam is more efficient in preventing smoke formation. This configuration is usually used when steam is not available, or the flare unit is small (when it is not economically feasible for an airassisted flare with large vent gas flowrate $)^{80}$. A non-assisted flare essentially burns the vent gas without the aid of steam/air. Its use is limited to handle waste gas streams with a low carbon/hydrogen ratio (such as methane) that can burn without producing smoke ${ }^{81}$. Refer to publication ${ }^{52}$ for the full detail of design equations and parameters of flare units for VOC destruction. 


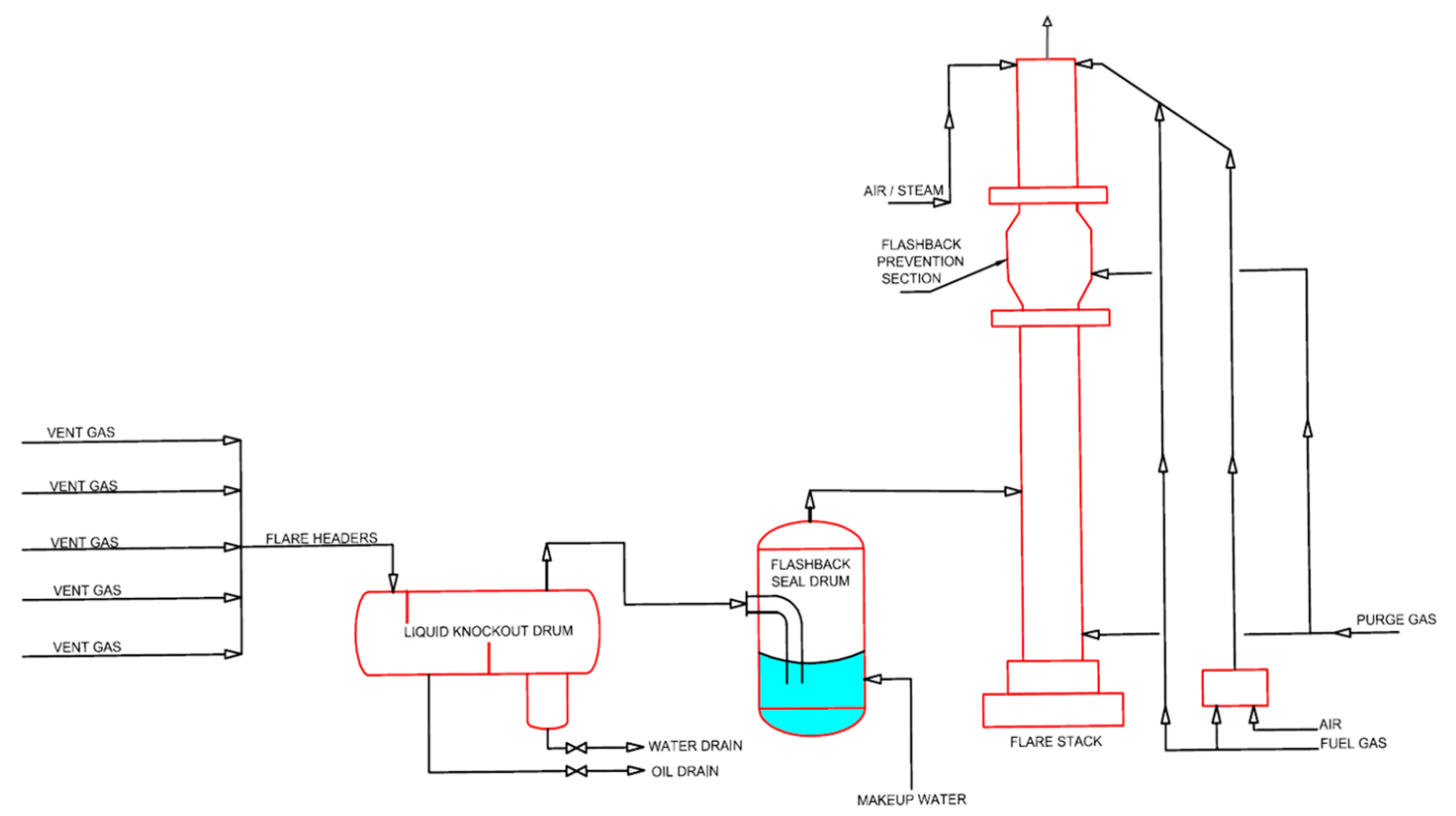

Figure 3.4 Schematic diagram of a flare system

\section{Thermal Oxidizers}

Thermal oxidizers ${ }^{76}$, or incinerators, are one of the best-known methods for industrial waste gas disposal (see thermal oxidizer schematic in Figure 3.5). Thermal oxidizers are used to control the release of VOCs and CO through thermal or catalytic incineration, and are generally used when the waste gases are diluted mixtures of combustible gases and air (air content should be greater than 98\%). The advantage of using a thermal oxidizer is that almost any VOCs can be oxidized to $\mathrm{CO}_{2}$ and water safely and cleanly in the presence of high temperature and enough oxygen. This unit incinerates compounds and typically requires natural gas as an auxiliary fuel to aid in the combustion process. The amount of natural gas required can be decreased by recovering heat from the effluent stream of the combusted products. Heat exchange between the flue gas and inlet stream prior to entering the combustion chamber can 
achieve this with typical energy recovery as high as $70 \%$. Refer to publication ${ }^{52}$ for the full detail of design equations and parameters of the thermal oxidizer PCU.

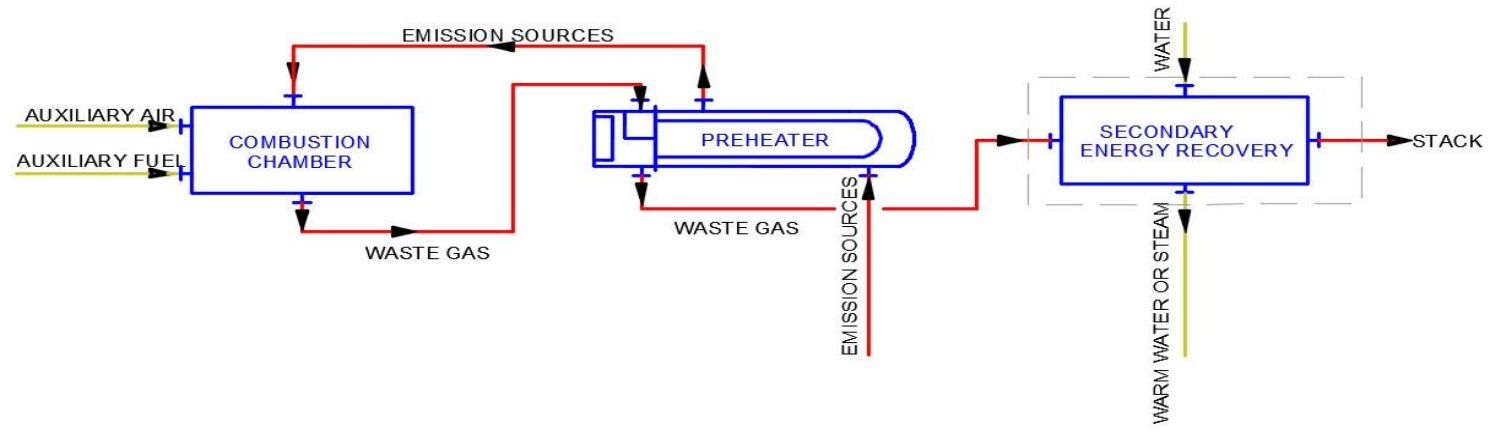

Figure 3.5 Block flow diagram of a thermal oxidizer system

As mentioned above, the objective of the proposed PCU simulators is to introduce a method for estimating the LCl, including mass, energy, material, and footprint of air pollution control technologies to reduce or eliminate the emissions of potentially hazardous air pollutants from industrial waste streams. Table 3.1 provides a summary with brief descriptions, strengths and limitations associated with the different PCUs, which may serve as guidelines for users on how to select the PCUs for particular applications of interest. In general, the scrubber and thermal oxidizer are typically chosen for diluted waste streams, while the boiler and flare systems are more flexible w.r.t. concentrations of the waste streams to be treated. 
Table 3.1 Summary on brief descriptions, strengths and limitations of developed PCUs in Chapter 3

\begin{tabular}{|c|c|c|c|}
\hline PCUs & Brief Descriptions & Strengths & Limitations \\
\hline Scrubber & $\begin{array}{l}\text { - Absorption is widely used as } \\
\text { a pollution control technique } \\
\text { for inorganic emissions }\end{array}$ & $\begin{array}{l}\text { - Good for inorganic acid gases } \\
\text { - Raw material and/or product } \\
\text { can be recovered }\end{array}$ & $\begin{array}{l}\text { - Need suitable solvents } \\
\text { that should be easily } \\
\text { regenerated or disposed in } \\
\text { an environmentally } \\
\text { acceptable manner }\end{array}$ \\
\hline Boiler & $\begin{array}{l}\text { Existing boilers can be used } \\
\text { to control emission streams } \\
\text { containing organic compounds }\end{array}$ & $\begin{array}{l}\text { - High destruction efficiency } \\
(98 \%) \\
\text { - Small capital cost with no fuel } \\
\text { cost } \\
\text { - High recovery of the } \\
\text { combustion heat }\end{array}$ & $\begin{array}{l}\text { - Limited in dealing with } \\
\text { emission streams with } \\
\text { corrosive compounds and } \\
\text { variations in terms of } \\
\text { flowrate and contents } \\
\text { - Only applied for low } \\
\text { flowrate waste gases (less } \\
\text { than } 20 \% \text { of the natural } \\
\text { gas volumetric flowrate) } \\
\text { with high heating values } \\
\text { (higher than } 5,589 \mathrm{~kJ} / \mathrm{m}^{3} \\
\text { (at } 1 \text { atm, } 20{ }^{\circ} \mathrm{C} \text { )) }\end{array}$ \\
\hline Flare & $\begin{array}{l}\text { - Flare is commonly used for } \\
\text { disposal of waste gases for } \\
\text { chemical plants } \\
\text { - Flares can be used for } \\
\text { controlling almost any VOC } \\
\text { emission stream }\end{array}$ & $\begin{array}{l}\text { - High destruction efficiency } \\
\text { - Can handle fluctuations in } \\
\text { emitted VOC and inert contents } \\
\text { and flow rates }\end{array}$ & $\begin{array}{l}\text { - No organics can be } \\
\text { recovered } \\
\text { - Large flowrate of waste } \\
\text { streams only } \\
\text { - No combustion heat can } \\
\text { be recovered }\end{array}$ \\
\hline $\begin{array}{l}\text { Thermal } \\
\text { Oxidizer }\end{array}$ & $\begin{array}{l}\text { - Thermal oxidizer (TO) is used } \\
\text { to control a wide variety of } \\
\text { continuous emission streams } \\
\text { containing dilute VOCs }\end{array}$ & $\begin{array}{l}\text { - High destruction efficiency } \\
\text { - Wide applicability } \\
\text { - Possible to recover heat energy }\end{array}$ & $\begin{array}{l}\text { - No organics can be } \\
\text { recovered } \\
\text { - Capital intensive } \\
\text { - It is not suitable for } \\
\text { streams with highly } \\
\text { variable flows }\end{array}$ \\
\hline
\end{tabular}


Table 3.2 describes a summary of user input parameters required for each PCU module. In the modules, users just need to adjust operational parameters and perform process design for integration if necessary, as the modules provide guidelines and default values that facilitate the functionality of the framework in generating LCl data for non-engineer users. In particular, the developed PCUs can serve as a plug-and-play role for LCA projects only requiring the information on the waste stream to be treated. Note that many of these data entries have suggested default values, which can be found (in parenthesis) in Table 3.2. For more detailed information on these parameters, please refer to publication ${ }^{52}$. Waste gas flowrate and composition are key parameters for obtaining the $\mathrm{LCl}$ results. In addition, the user would need to enter more data if the pollutants of interest are not listed in the internal database. After describing the set of PCUs developed for LCI modeling, and to demonstrate the objectives of this work, the above PCU modules are applied to an acetic acid from biomass/coal simulation case study. The acetic acid case study was chosen due to previous work on applications of the top-down ${ }^{17}$ and bottom-up ${ }^{18}$ approaches for estimating LCl. 
Table 3.2 A summary of user input parameters required for applying each PCU module for LCI modeling

\begin{tabular}{|c|c|c|c|c|}
\hline & \multicolumn{4}{|c|}{ Pollution Control Unit } \\
\hline & Scrubber & Boiler & Flare & Thermal Oxidizer \\
\hline \multirow{13}{*}{ 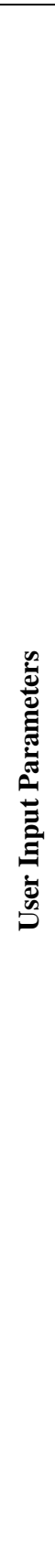 } & \multicolumn{4}{|c|}{ Waste gas flowrate } \\
\hline & \multicolumn{4}{|c|}{ Waste gas composition } \\
\hline & Inlet temperature $\left(30^{\circ} \mathrm{C}\right)$ & Inlet temperature $\left(40^{\circ} \mathrm{C}\right)$ & Inlet temperature $\left(40^{\circ} \mathrm{C}\right)$ & Inlet temperature $\left(40{ }^{\circ} \mathrm{C}\right)$ \\
\hline & Pressure $(\sim 101.325 \mathrm{kPa})$ & Pressure $(\geq 101.325 \mathrm{kPa})$ & Pressure $(>101.325 \mathrm{kPa})$ & Pressure $(\sim 101.325 \mathrm{kPa})$ \\
\hline & $\begin{array}{l}\text { Fresh solvent composition } \\
(100 \% \text { solvent })\end{array}$ & Excess of air $(5 \%)$ & Liquid mass fraction $(0.05)$ & $\begin{array}{ll}\text { Designed } & \text { control } \\
\text { efficiency }(99 \%) & \\
\end{array}$ \\
\hline & $\begin{array}{l}\text { Designed removal efficiency } \\
(99 \%)\end{array}$ & & Liquid density $\left(795 \mathrm{~kg} / \mathrm{m}^{3}\right)$ & $\begin{array}{l}\text { Designed energy recovery } \\
(70 \%)\end{array}$ \\
\hline & \multirow{2}{*}{$\begin{array}{l}\text { Waste gas viscosity and } \\
\text { pollutant diffusivity in air (if } \\
\text { not listed in the internal } \\
\text { database) }\end{array}$} & \multirow{2}{*}{$\begin{array}{l}\text { Boiler size in terms of } \\
\text { heat content of fuel gas: } \\
\text { small size }(<29.3 \mathrm{MW}) \\
\text { and large size }(>29.3 \\
\text { MW). Heat content of } \\
\text { waste gas should be } \\
\text { smaller than } 50 \% \text { of } \\
\text { boiler's heat needs and > } \\
11,630 \mathrm{~kJ} / \mathrm{kg} \text {. }\end{array}$} & Flare type (steam-assisted) & $\begin{array}{ll}\text { Operation } & \text { temperature } \\
\left(871.1^{\circ} \mathrm{C}\right) & \end{array}$ \\
\hline & & & $\begin{array}{l}\text { Designed combustion efficiency } \\
(98 \%)\end{array}$ & \multirow[t]{6}{*}{ Fan efficiency $(70 \%)$} \\
\hline & \multirow{3}{*}{$\begin{array}{l}\text { Pollutant diffusivity in air and } \\
\text { solvent properties (if not } \\
\text { listed in the internal database) }\end{array}$} & \multirow{5}{*}{$\begin{array}{l}\text { Burner type: the amount of } \\
\mathrm{CO} \text {, NOx, VOCs } \\
\text { emissions are related to } \\
\text { burner type. For smaller } \\
\text { size boilers, uncontrolled } \\
\text { burners might be able to } \\
\text { meet the environmental } \\
\text { standards. Controller- } \\
\text { Low-NOx burner is } \\
\text { recommended for larger } \\
\text { size boilers. }\end{array}$} & Designed Mach number (0.2) & \\
\hline & & & $\begin{array}{l}\text { Maximum allowable thermal } \\
\text { radiation }\left(1.58 \mathrm{~kW} / \mathrm{m}^{2}\right)\end{array}$ & \\
\hline & & & Radiation fraction $(0.3)$ & \\
\hline & $\begin{array}{l}\text { Packing size and properties: } \\
\text { (Raschig rings ceramic, } 2 \text { '”) }\end{array}$ & & $\begin{array}{l}\text { Wind velocity (yearly average } \\
\text { wind velocity of local area) }\end{array}$ & \\
\hline & $\begin{array}{l}\text { Equilibrium data: equilibrium } \\
\text { line data and saturation } \\
\text { solubility data are required for } \\
\text { the primary pollutant; } \\
\text { solubility data for other } \\
\text { components are needed if it is } \\
\text { a multi-component system }\end{array}$ & & $\begin{array}{l}\text { Recommended horizontal distance } \\
\text { to the stack center ( } 50 \mathrm{~m} \text { ). For this } \\
\text { recommendation, a typical stack } \\
\text { height value can be calculated ( } 30 \\
\mathrm{~m} \text { ). }\end{array}$ & \\
\hline
\end{tabular}

\subsection{Results \& Discussion}

\subsubsection{Chemical Process Simulation}

Due to the increasing projected global energy demand and the need to move away from fossil fuels, biomass has received considerable attention as a feedstock 
and energy source. Biomass is a renewable feedstock alternative with the potential for ameliorating the environmental effects of using fossil fuels (e.g., coal). However, the utilization of biomass is facing some challenges, such as limited and intermittent availability/supply, as well as its low energy density. Two scenarios associated with acetic acid manufacturing from coal/biomass are analyzed. In this work, Aspen Hysys $^{35}$ and CHEMCAD ${ }^{34}$ are used to model the acetic acid production process from coal/biomass. As described in Figures 3.6 - 3.8, the entire biomass/coal to acetic acid process consists of three subprocesses: (i) the biomass/coal to syngas section which includes gasification, water-gas-shift reaction, and sour gas treatment; (ii) the methanol synthesis; and (iii) the methanol-to-acetic acid subprocess. Note the gasification-to-methanol simulation that includes gasification, water-gas-shift reaction, sour gas treatment, and methanol synthesis step is modelled in Aspen Hysys due to the software capabilities for working with different fluid packages, as well as different sour gas treatment options. Using a previously developed simulation as a reference, the methanol-to-acetic acid process with a production rate of 300,000 $t$ of end product per year is simulated in CHEMCAD.

\section{Methanol Synthesis Process Simulation}

Figure 3.6 presents the Aspen Hysys flowsheet setup used for methanol synthesis process from coal/biomass. The flowsheet is built and conditions are obtained based on previously published literature ${ }^{82,83}$. In this flowsheet, coal and biomass are approximately simplified using pseudo components based on the atomic ratio of hydrogen to carbon. Biomass in this work is assumed to be comprised of wood chips, with the typical composition of $55 \mathrm{wt} \%$ carbon, $32 \mathrm{wt} \%$ oxygen, and $10 \mathrm{wt} \%$ hydrogen, $2 \mathrm{wt} \%$ sulfur and $1 \mathrm{wt} \%$ of other species ${ }^{84}$. Coal is represented by a pseudo component hydrocarbon ${ }^{85}\left(\mathrm{C}_{18} \mathrm{H}_{20}\right)$ based on the weight of $\mathrm{C}$ and $\mathrm{H}$ in the 
coal. With the assumed biomass and coal raw materials as well as oxygen and water, an entrained flow gasifier is used to convert the hydrocarbon feed into raw synthesis gas. In addition, as shown in Figure 3.6, the gasifier island step includes three parts: partial oxidizer (POX) (CSTR100-102), radiant synthesis gas cooler (RSC) (E100) and water quench (MIX-101).

High temperature conditions in the POX can improve the conversion rate to syngas (typical conversion rates for biomass/coal to syngas are $50 \mathrm{wt} \% / 65 \mathrm{wt} \%$, respectively) and the RSC helps to recover part of the heat via steam generation while cooling the process syngas to around $800^{\circ} \mathrm{C}$. Then the quench water drops the water temperature in the syngas to around $200^{\circ} \mathrm{C}$. The downstream units from the gasifier are mostly standard gas phase processes, including the sour water gas shift (SWGS) reactor and acid gas removal (AGR) process, followed by the methanol synthesis (MS) step. Before entering the SWGS part, particles and traces of acid gas in raw syngas are removed through a wet scrubber (Scrubber). In the SWGS part, the ratio of hydrogen/carbon in the syngas required for methanol synthesis can be adjusted to 2 even if only biomass is used as feedstock. Then, as shown in Figure 3.7, monoethanolamine (MEA) is used to remove acid gases $\left(\mathrm{H}_{2} \mathrm{~S}\right.$ and $\left.\mathrm{CO}_{2}\right)$ and the sweet syngas from the top of the absorber ( $\mathrm{T}-103)$ goes to the methanol reactor, while the rich MEA solvent is regenerated by the stripper (T-101). To reach high conversion rate to methanol ( 90\%) as well as ensure high methanol purity (99.5 wt\%) required by the AA production process, most of the gas stream (in Stream 25) from the top of the separator (V-103) is recycled back to the methanol reactor (GBR100). The methanol synthesis reaction is exothermic and the optimal reaction temperature for this process is around $200^{\circ} \mathrm{C}$. 


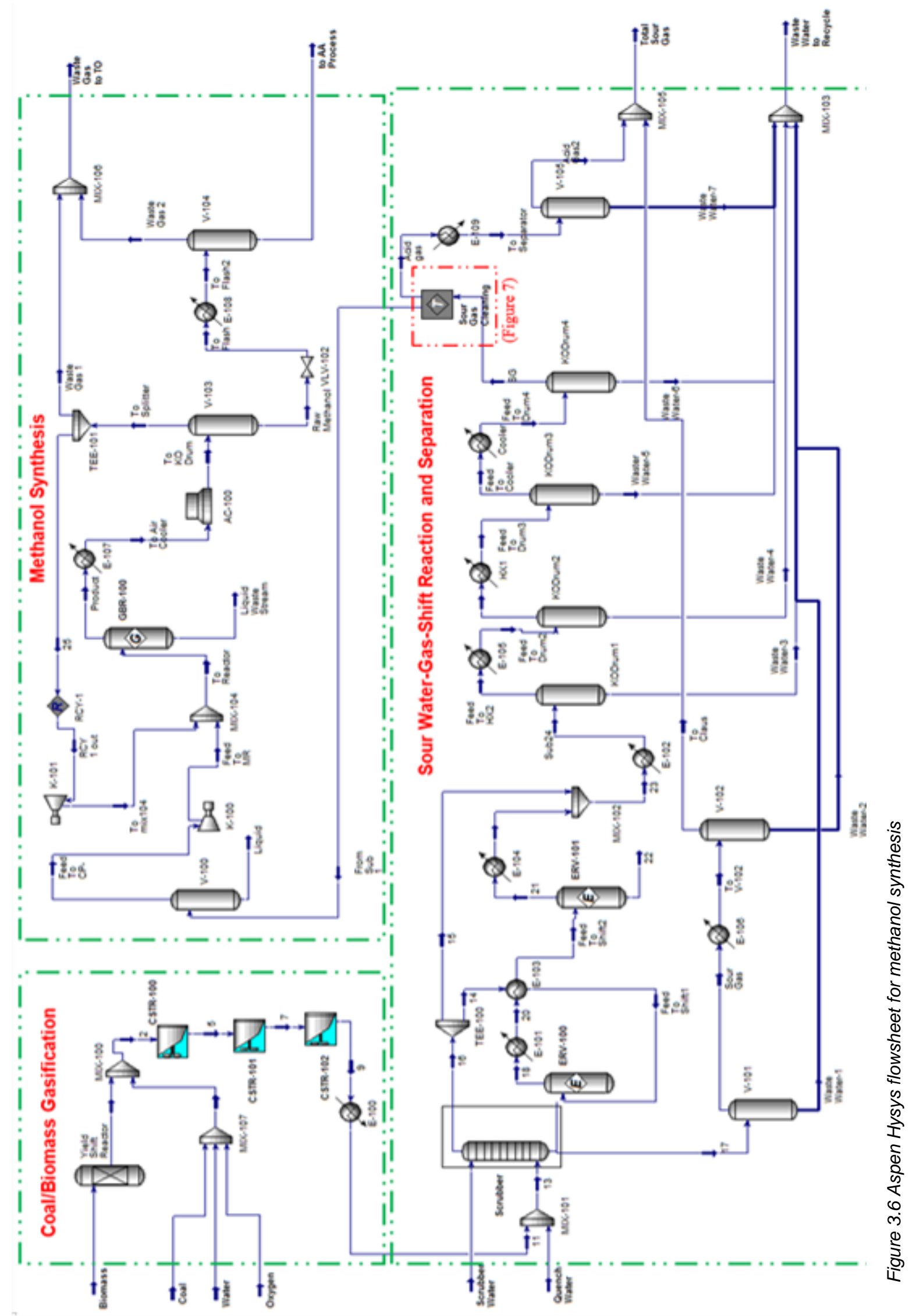




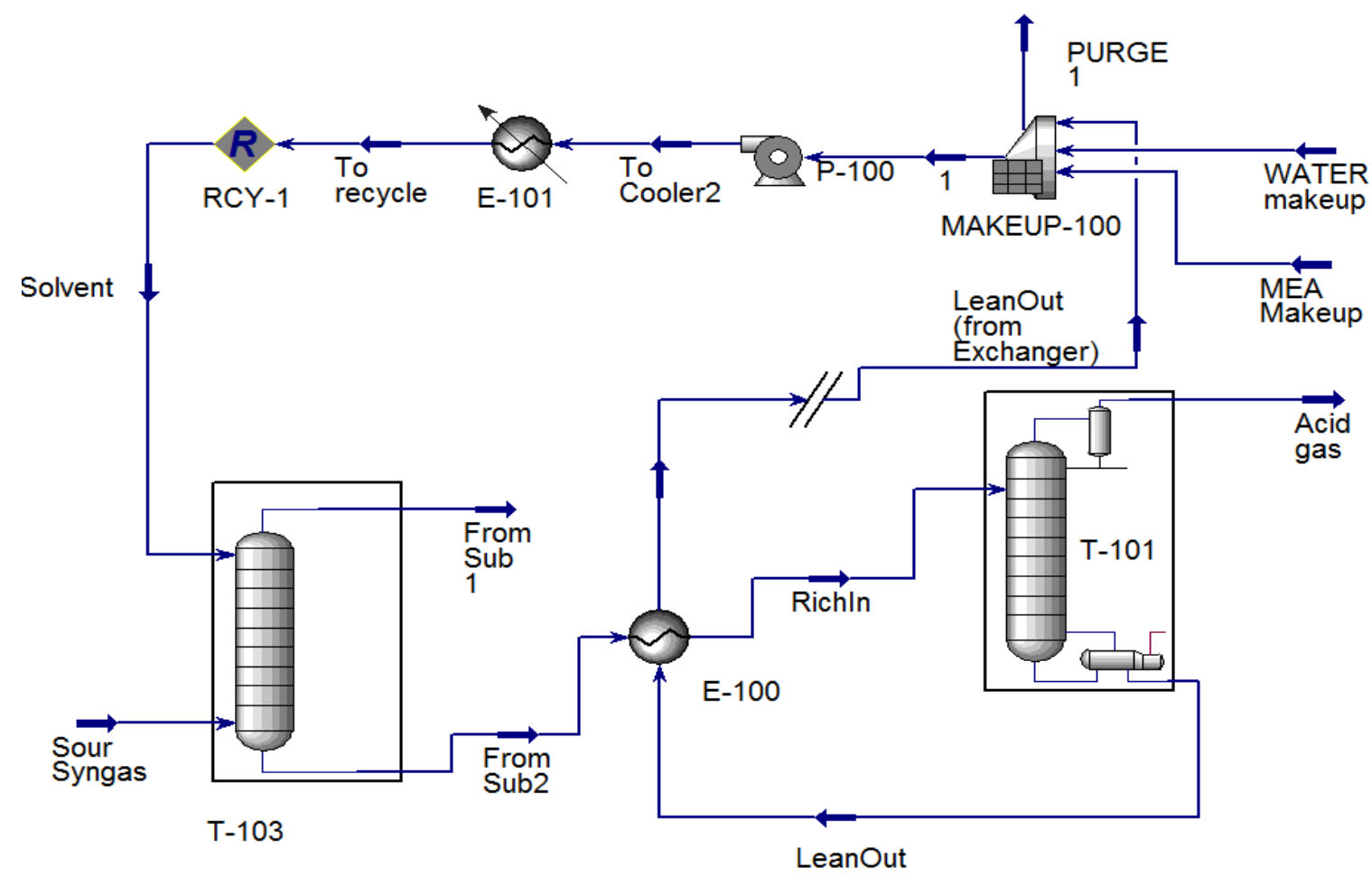

Figure 3.7 Aspen Hysys flowsheet for the sour gas treatment process

\section{Acetic Acid Process Simulation}

The simulation of the acetic acid process, as illustrated by the CHEMCAD process flow diagram in Figure 3.8, includes the calculated temperatures, pressures, and compositions for each stream and unit operation throughout the process flow diagram.

A description of the streams and unit operations begins with the fresh methanol and methyl iodide (MI) streams (Streams 1 and 9) being mixed and preheated by passing through a heat exchanger integrated unit (Unit 6) which transfers the excess heat from the reactor outlet stream (Stream 14). This stream is mixed with a fresh stream of $\mathrm{CO}$ (Stream 26) and a recycling stream (Stream 25) from downstream operations (flash vessel and absorption column). The resulting 
stream then enters the isothermal methanol carbonylation reactor (Unit 10) at temperature of $189^{\circ} \mathrm{C}$, where the reaction mechanism shown below occurs. In order to achieve a methanol conversion of $98.5 \%$ in the simulation, $91.5 \%$ of the carbon monoxide is reacted. The outlet reactor stream pressure is reduced using an adiabatic flash valve (Unit 11). The stream is cooled and the resulting vaporliquid mixture is flashed in Unit 19 to remove non-condensable compounds. The flashed stream (Stream 18), which is rich in acetic acid is then sent to the distillation column (Unit 16) for further purification of the final acetic acid product. The rigorous multi-stage vapor-liquid equilibrium multicomponent column is designed to produce a bottom product stream (Stream 19) with a content of 98 mol\% acetic acid. The product stream is depressurized and cooled enough to produce acetic acid (Stream 21) at $45{ }^{\circ} \mathrm{C}$ and $101.325 \mathrm{kPa}$, i.e., ready for storage. In addition, the gas stream from the distillation column (Stream 22) is conditioned in a heat exchanger and sent to the absorption column (Unit 24) where a portion of the valuable condensable compounds are absorbed by using part of the fresh methanol as solvent (Stream 5). The liquid stream from absorber Unit 24 (Stream 24) recovers part of the methyl iodide, methyl acetate, and hydrogen iodide, which are recycled back into the reactor unit. The gas leaving the absorption column (Stream 6) is vented as Gas Releases of uncontrolled air emissions. This stream, along with the Gas Releases from Stream 27, may contain hydrogen iodide, methyl iodide, methanol, methyl acetate and methane, some of which may cause skin and lung irritation, digestive disorders in addition to being an asphyxiant (in the case of methanol) ${ }^{82}$. The pollution control units developed in this work previously described are used next to simulate the remediation process of these waste 
streams, as well as to provide more realistic $\mathrm{LCl}$ results for use in a sustainability evaluation.

$$
\begin{array}{ll}
\mathrm{CH}_{3} \mathrm{OH}+\mathrm{CO} \stackrel{\text { Catalyst }(\mathrm{HI})}{\longrightarrow} \mathrm{CH}_{3} \mathrm{COOH} & \text { (main reaction) } \\
\mathrm{CH}_{3} \mathrm{OH}+\mathrm{CH}_{3} \mathrm{COOH} \rightarrow \mathrm{CH}_{3} \mathrm{COOCH}_{3}+\mathrm{H}_{2} \mathrm{O} & \text { (side reaction) } \\
\mathrm{CH}_{3} \mathrm{OH}+\mathrm{CH}_{3} \mathrm{COOH} \rightarrow \mathrm{CH}_{3} \mathrm{CH}_{2} \mathrm{COOH}+\mathrm{H}_{2} \mathrm{O} & \text { (side reaction) }
\end{array}
$$

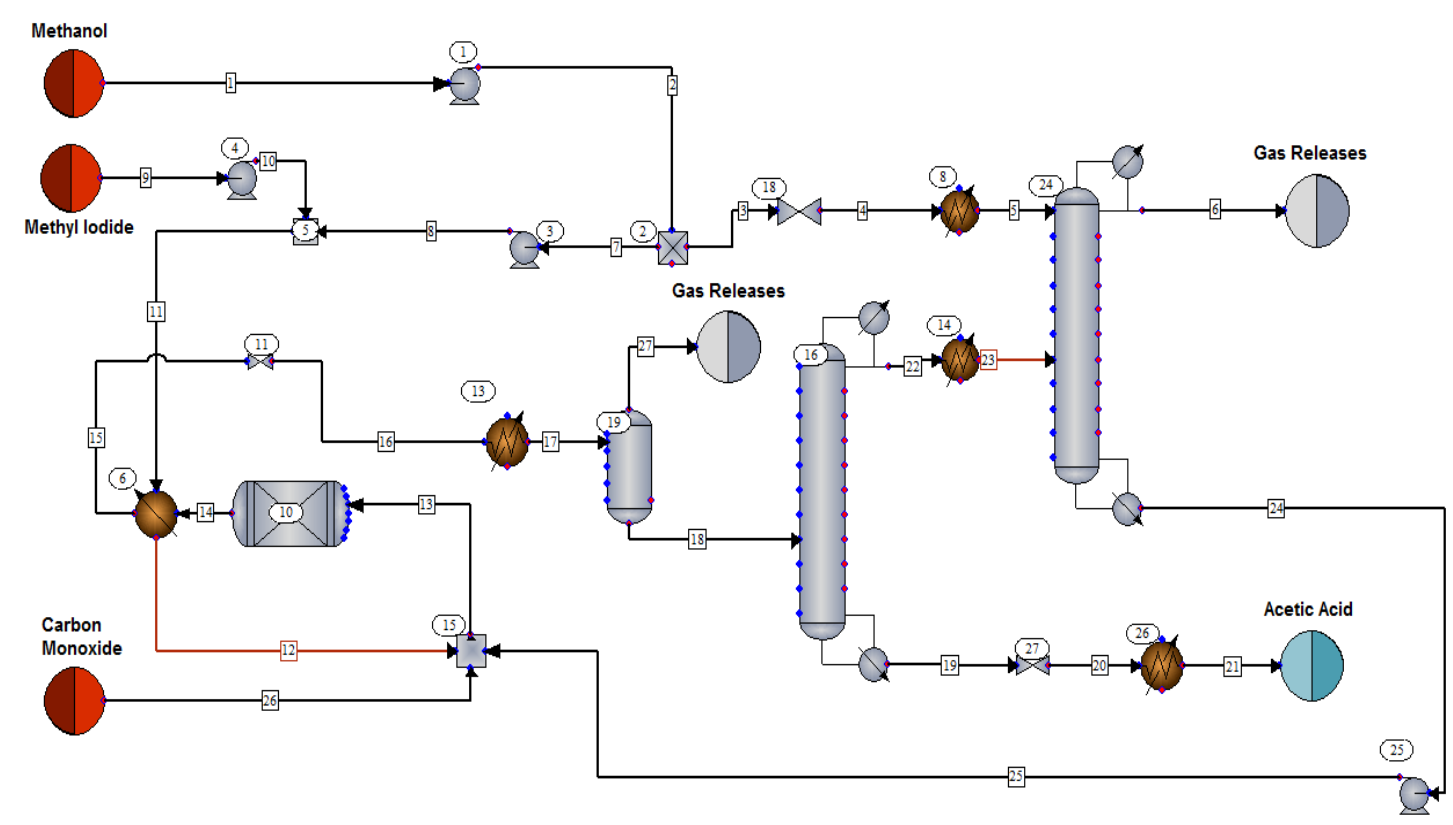

Figure 3.8 CHEMCAD flowsheet for the simulated acetic acid manufacturing process

\subsubsection{LCI Results}

Incorporation of PCUs into Acetic Acid Process Simulation Results

As mentioned above, many researchers and engineers are trying to reduce or control pollution and emissions from chemical processes, in addition to making their product competitive in terms of cost. The proposed approach of integrating process simulation with PCU modules for $\mathrm{LCl}$ generation can be employed across a wide range of applications, for both new product design as well as retrofit/upgrade scenarios. The acetic acid manufacturing process is employed here to illustrate how the developed PCU simulators can enable the rapid estimation of controlled emissions, utility and construction material consumption as well as land footprint 
information for $\mathrm{LCl}$ generation. The calculations of construction material and footprint are typically based on the plant life time (20 years in this case study), as shown in equations (3.1-3.2).

$$
\begin{gathered}
\text { LCI Material Index }=\frac{\text { total material weight }}{\text { product yearly flowrate } \times \text { plant life time }(\text { years })}[\mathrm{kg} / \mathrm{kg} \text { product per year }] \\
\text { LCI Footprint Index }=\frac{\text { total area }}{\text { product yearly flowrate }}\left[\mathrm{m}^{2} / \mathrm{kg} \text { product per year }\right]
\end{gathered}
$$

Tables 3.3 and 3.4 show the $\mathrm{LCl}$ input/output results from the application of three PCUs (scrubber, boiler and flare) to the methanol-to-acetic acid (AA) sub-process. In Table 3.4, the stream compositions are shown without PCUs (under "Simulation") as well after application of each PCU (with their respective name), in which the LCl outputs include the exit concentration of chemicals from the emission streams (streams 6 and 27 in Figure 3.9) after implementing each PCU as shown in Figure 3.9. The "Emission with PCUs" column depicts the releases after applying the three in-series PCUs (see Figure 3.9) while the LCl inputs show the electricity, utility consumption, facility material and land use associated with the construction and operation of the selected PCUs. Note that the percentage change for inputs (in Table 3.3) is calculated by dividing the PCU subtotal by the simulation inputs (under "Simulation" in Table 3.3) and then multiplying the result by $100 \%$. Also, the percentage change for outputs (in Table 3.4) is calculated by the emissions with PCUs minus the simulation emissions (under "Simulation" in Table 3.4), and then dividing the resulting quantity by the simulation emissions (multiplied by $100 \%$ ). In addition, as described in Table 3.2, the collection of some waste stream data and the selection of equipment parameters were required for the implementation of the PCU modules for obtaining the corresponding $\mathrm{LCl}$ results. 
Table 3.3 LCl input results before and after waste streams have been processed by PCUs

\begin{tabular}{|c|c|c|c|c|c|c|c|}
\hline \multirow{2}{*}{ LCI Inputs } & \multirow{2}{*}{ Units } & \multirow{2}{*}{ Simulation } & \multicolumn{4}{|c|}{ Simulation with emission control units } & \multirow{2}{*}{$\begin{array}{c}\text { Percentage } \\
\text { change }\end{array}$} \\
\hline & & & Scrubber & Boiler & Flare & PCU Subtotal & \\
\hline Air & $\mathrm{kg} / \mathrm{kg} \mathrm{AA}$ & 0 & 0 & $1.63 \mathrm{E}-1$ & $1.36 \mathrm{E}-2$ & $1.76 \mathrm{E}-1$ & $\infty$ \\
\hline Natural Gas & $\mathrm{scm} / \mathrm{kg} \mathrm{AA}$ & 0 & 0 & $9.16 \mathrm{E}-3$ & $1.43 \mathrm{E}-2$ & $2.34 \mathrm{E}-2$ & $\infty$ \\
\hline $\begin{array}{l}\text { Purge Gas } \\
\text { (Nitrogen) }\end{array}$ & $\mathrm{scm} / \mathrm{kg}$ AA & 0 & 0 & 0 & $1.24 \mathrm{E}-3$ & $1.24 \mathrm{E}-3$ & $\infty$ \\
\hline Steam & $\mathrm{kg} / \mathrm{kg} \mathrm{AA}$ & $7.79 \mathrm{E}-1$ & 0 & $-2.84 \mathrm{E}-1$ & 0 & $-2.84 \mathrm{E}-1$ & $-37 \%$ \\
\hline $\begin{array}{l}\text { Solvent } \\
\text { ( Water) }\end{array}$ & $\mathrm{kg} / \mathrm{kg} \mathrm{AA}$ & 0 & $2.47 \mathrm{E}+0$ & 0 & 0 & $2.47 \mathrm{E}+0$ & $\infty$ \\
\hline Electricity & $\mathrm{kW} / \mathrm{kg} \mathrm{AA}$ & $5.60 \mathrm{E}-3$ & $5.90 \mathrm{E}-5$ & $8.11 \mathrm{E}-5$ & 0 & $1.40 \mathrm{E}-4$ & $3 \%$ \\
\hline $\begin{array}{c}\text { Construction } \\
\text { Material }\end{array}$ & $\begin{array}{l}\mathrm{kg} /(\mathrm{kg} \mathrm{AA} \\
\text { per year) }\end{array}$ & $2.03 \mathrm{E}-6$ & $8.43 \mathrm{E}-8$ & $4.88 \mathrm{E}-7$ & $1.43 \mathrm{E}-5$ & $1.49 \mathrm{E}-5$ & $733 \%$ \\
\hline Footprint & $\begin{array}{l}\mathrm{m}^{2} /(\mathrm{kg} \mathrm{AA} \\
\text { per year) }\end{array}$ & $1.02 \mathrm{E}-4$ & $4.47 \mathrm{E}-8$ & $7.73 \mathrm{E}-7$ & $1.60 \mathrm{E}-6$ & $2.42 \mathrm{E}-6$ & $2 \%$ \\
\hline
\end{tabular}

A negative sign (-) represents decrease (in percentage) or generation (for steam in the boiler), while " $\infty$ " represents division by zero in calculation of percentages (for cases without corresponding inlet stream).

Table 3.4 LCl output results before and after waste streams have been processed by PCUs

\begin{tabular}{|c|c|c|c|c|c|c|c|}
\hline \multirow{2}{*}{ LCI Output } & \multirow{2}{*}{ Units } & \multirow{2}{*}{ Simulation } & \multicolumn{3}{|c|}{ Simulation with emission control units } & \multirow{2}{*}{$\begin{array}{l}\text { Emissions } \\
\text { with PCUs }\end{array}$} & \multirow{2}{*}{$\begin{array}{c}\text { Percentage } \\
\text { change }\end{array}$} \\
\hline & & & Scrubber & Boiler & Flare & & \\
\hline $\begin{array}{c}\text { Carbon } \\
\text { Monoxide }\end{array}$ & $\mathrm{kg} / \mathrm{kg} \mathrm{AA}$ & $4.39 \mathrm{E}-2$ & $4.36 \mathrm{E}-2$ & 7.15E-4 & 8.73E-4 & $8.73 \mathrm{E}-4$ & $-98 \%$ \\
\hline $\begin{array}{l}\text { Carbon } \\
\text { Dioxide }\end{array}$ & $\mathrm{kg} / \mathrm{kg} \mathrm{AA}$ & $5.45 \mathrm{E}-4$ & $5.42 \mathrm{E}-4$ & $9.68 \mathrm{E}-2$ & $1.36 \mathrm{E}-1$ & $1.36 \mathrm{E}-1$ & $24868 \%$ \\
\hline Methane & $\mathrm{kg} / \mathrm{kg} \mathrm{AA}$ & $1.97 \mathrm{E}-4$ & $1.97 \mathrm{E}-4$ & $2.18 \mathrm{E}-6$ & $1.09 \mathrm{E}-9$ & $1.09 \mathrm{E}-9$ & $-100 \%$ \\
\hline Water & $\mathrm{kg} / \mathrm{kg} \mathrm{AA}$ & $1.55 \mathrm{E}-4$ & 0 & $6.81 \mathrm{E}-3$ & $3.21 \mathrm{E}-2$ & $3.89 \mathrm{E}-2$ & $25015 \%$ \\
\hline Methanol & $\mathrm{kg} / \mathrm{kg} \mathrm{AA}$ & $3.10 \mathrm{E}-5$ & 0 & 0 & 0 & 0 & $-100 \%$ \\
\hline Acetic Acid & $\mathrm{kg} / \mathrm{kg} \mathrm{AA}$ & $5.89 \mathrm{E}-4$ & 0 & 0 & 0 & 0 & $-100 \%$ \\
\hline Methyl Acetate & $\mathrm{kg} / \mathrm{kg} \mathrm{AA}$ & $2.14 \mathrm{E}-3$ & $2.13 \mathrm{E}-3$ & 0 & 0 & 0 & $-100 \%$ \\
\hline $\begin{array}{c}\text { Hydrogen } \\
\text { Iodide }\end{array}$ & $\mathrm{kg} / \mathrm{kg} \mathrm{AA}$ & $1.84 \mathrm{E}-3$ & 0 & 0 & 0 & 0 & $-100 \%$ \\
\hline Propionic Acid & $\mathrm{kg} / \mathrm{kg}$ AA & $1.57 \mathrm{E}-7$ & 0 & 0 & 0 & 0 & $-100 \%$ \\
\hline NOX & $\mathrm{kg} / \mathrm{kg} \mathrm{AA}$ & 0 & 0 & $2.07 \mathrm{E}-5$ & $1.96 \mathrm{E}-5$ & $1.96 \mathrm{E}-5$ & $\infty$ \\
\hline $\mathrm{PM}(<1 \mu \mathrm{m})$ & $\mathrm{kg} / \mathrm{kg}$ AA & 0 & 0 & $1.63 \mathrm{E}-6$ & $1.63 \mathrm{E}-6$ & $1.63 \mathrm{E}-6$ & $\infty$ \\
\hline Nitrogen & $\mathrm{kg} / \mathrm{kg} \mathrm{AA}$ & 0 & 0 & $1.24 \mathrm{E}-1$ & $1.34 \mathrm{E}-1$ & $1.34 \mathrm{E}-1$ & $\infty$ \\
\hline Oxygen & $\mathrm{kg} / \mathrm{kg}$ AA & 0 & 0 & $1.89 \mathrm{E}-3$ & $4.50 \mathrm{E}-4$ & $4.50 \mathrm{E}-4$ & $\infty$ \\
\hline
\end{tabular}

A negative sign (-) represents decrease (in percentage) or generation (for steam in the boiler), while " $\infty$ " represents division by zero in calculation of percentages (for cases without corresponding inlet stream). 


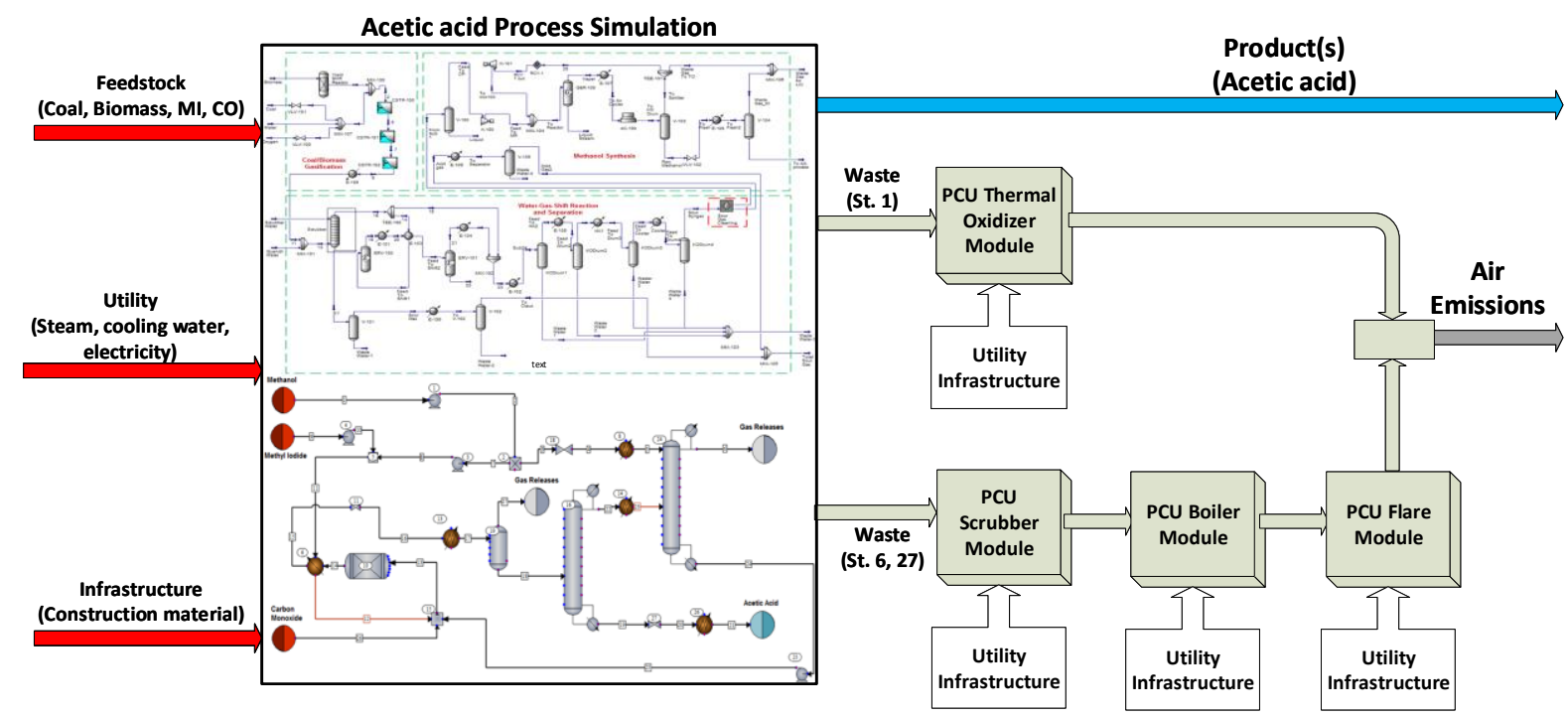

Figure 3.9 Incorporation of PCUs into acetic acid process simulation results for rapid LCI modeling

After performing an engineering evaluation of the complete system, the decision regarding the appropriate pollution control technologies to use needs to be made based on the analysis of the source, component and flowrate of the emission(s). A systematic analysis may be required if a sequence of pollution control technologies should be employed to treat the waste streams. Therefore, it was found for the acetic acid sub-process, waste streams 27 and 6 (see Figure 3.8) should be combined for treatment by the developed PCU modules as shown in Figure 3.9. In addition, as described in Table 3.4, the waste streams from the acetic acid process (denoted as "Simulation") consists of inorganic acids, VOCs (e.g., methyl acetate, acetic acid, methanol and methane) as well as CO. To effectively treat this stream, the first step is to remove hydrogen iodide $(\mathrm{HI})$ by employing a scrubber, which is the most widely used pollution control device for soluble inorganic contaminants from gas streams. In the developed scrubber module, solvent, packing material, size and operating conditions can be set based on the pollutant of interest and its inlet concentration. For $\mathrm{HI}$, the scrubber is simulated as a packed column containing 2" Raschig Rings, and a shell material of 304 Stainless Steel. From Table 3.4, it can be observed that $\mathrm{HI}$ has been effectively removed by the scrubber with an efficiency of $100 \%$. The 
scrubber unit was designed based on the required $\mathrm{HI}$ removal efficiency $(99 \%)$. However, 5.3 times the solvent flowrate demanded by the required $\mathrm{HI}$ removal efficiency was required to soak the whole packing material of the scrubber tower ${ }^{86}$, resulting in a higher removal efficiency of $100 \%$. Water, methanol, acetic acid, and propionic acid are more soluble in water than $\mathrm{HI}$, thus after scrubber, all of them are zero. In addition, the utility consumption, construction material and footprint results are calculated by the scrubber simulator, as shown in Table 3.3 (see publication ${ }^{52}$ for calculation procedures).

The output from the scrubber mainly consists of $\mathrm{CO}$ and methyl acetate and thus can be fed to the boiler to recover the combustion heat value. Since the heat input in this stream is low, a small sized boiler (10 MW) is used with an uncontrolled burner type (see publication ${ }^{52}$ for calculation procedures). It is important to note that waste gas is mixing with natural gas as the fuel for the boiler and the heat input of waste gas should not be larger than that of natural gas. In the design case for boiler simulator, the percentage of waste gas heat input can be adjusted by changing the size of the boiler. In this work, boiler is considered as a pollution control unit that processes all the emissions from the scrubber. However, it might be the case in reality that only part of the waste emissions can be treated by the existing boiler at a specific facility and the rest of the waste stream has to go through other PCUs. For the purpose of demonstrating all the designed PCUs, the outlet stream from the boiler is released to the environment through the flare unit, which causes a large construction material need for the flare unit.

The pollution control devices are thus able to produce a resulting stream after treatment that is more environmentally-friendly. Table 3.4 shows the detailed LCl output results for scrubber, boiler, and flare. Please note that boilers are initially rated 
for a specific fuel (e.g., natural gas), and operational performance can degrade, heat transfer equipment can be damaged, and emissions can increase with changes in fuels burned ${ }^{87}$. In addition, there are some restrictions on burning hazardous waste that is not categorized as a fuel in industrial boilers ${ }^{79}$. Those restrictions describe a minimum heating value requirement for the waste, prohibiting their blending to augment the heating value of the waste, and exclusion of burning dioxin-listed wastes. In summary, this table clearly shows the scrubber has the capability to remove those species which have a large solubility in the solvent, such as $\mathrm{HI}$, methanol, and acetic acid, while bringing down the boiler net steam consumption by $36.5 \%$. The large amount of $\mathrm{CO}_{2}$ released to the environment is due to the boiler and flare converting all combustible species to $\mathrm{CO}_{2}$. The resulting $\mathrm{CO}_{2}$ could be sent to carbon capture and storage units for further processing. A comparison between the proposed bottom-up method with commercial $\mathrm{LCl}$ databases is available in publication $^{52}$.

Incorporation of PCU models into Methanol Synthesis Simulation Results

The synthesis of methanol, as the main feedstock for acetic acid production, is analyzed through the comparison of gate-to-gate $\mathrm{LCl}$ data modeling under two cases: 1) methanol produced from coal; 2) methanol produced from biomass. In addition, the methanol synthesis for both scenarios are studied in order to fulfill the production demand of acetic acid. Both processes have waste streams that are sent to the external PCU modules for treatment. The proposed method provides rapid yet accurate LCl data estimates of controlled emissions that could be used by nonengineer LCA practitioners when the LCI information is not readily available from industry, literature, or commercial software. 
Coal-Based Simulation: For this case of coal as the feedstock to generate methanol, a summary of the LCl inputs, with and without the PCUs, including the raw materials and utilities, is presented in Table 3.5. Oxygen, as one of the required resources for the methanol production process, is assumed to be obtained from air separation units that are considered outside of the process $\mathrm{LCl}$ boundary. In addition, the boundary does not include pretreatment of raw material (e.g., coal/biomass grinding/drying). The steam reported in Table 3.5 is the steam produced by recovering the heat within the process after the deduction of the steam needed for the process heating duty, as provided by the process simulator. The electricity requirements in this table are estimated based on the assumption that efficiencies for pumps and compressors are $75 \%$ and $70 \%$, respectively.

Concerning emissions from the process, as described in Figure 3.6, there are two waste streams that need to be treated prior to release: 1) the waste stream from mixer-106 (waste stream 1), which is composed primary of $\mathrm{CO}$ and methanol; and 2) the waste stream from mixer-105 (waste stream 2), comprised mostly of $\mathrm{CO}_{2}$ and $\mathrm{H}_{2} \mathrm{~S}^{82}$. Waste stream 2 is assumed to be sent to absorption units to separate $\mathrm{CO}_{2}$ from $\mathrm{H}_{2} \mathrm{~S}$, followed by Carbon Capture and Storage (CCS) and Claus unit technologies to handle the two acid gases, respectively. The developed thermal oxidizer module (see publication ${ }^{52}$ for calculation procedures) unit is employed to treat the VOCs present in waste stream 1 as shown in Figure 3.9, with the generated $\mathrm{LCl}$ output results described in Table 3.6. Please note that $\mathrm{N}_{2}$ and $\mathrm{O}_{2}$ in the emission stream (in Table 3.6) are calculated based on the excess air required by the thermal oxidizer. By adjusting the operating temperature and residence time of the thermal oxidizer, the destruction efficiency of the VOCs obtained reached as high as $99.5 \%$. Although estimated utility use is reported, the inputs (and emissions) related to fuel 
used to generate the steam and electricity are assumed to occur in upstream processes.

Table 3.5 Life cycle inventory inputs for methanol production from coal

\begin{tabular}{|c|c|c|c|c|}
\hline \multirow{2}{*}{ LCl Inputs } & Units & \multirow{2}{*}{ Simulation } & Simulation with & \multirow{2}{*}{ Percent change } \\
\cline { 4 - 4 } & & & Thermal Oxidizer & \\
\hline Oxygen & $\mathrm{kg} / \mathrm{kg} \mathrm{MeOH}$ & $2.62 \mathrm{E}+0$ & $2.62 \mathrm{E}+0$ & 0 \\
\hline Water & $\mathrm{kg} / \mathrm{kg} \mathrm{MeOH}$ & $1.11 \mathrm{E}+0$ & $1.11 \mathrm{E}+0$ & 0 \\
\hline Coal & $\mathrm{kg} / \mathrm{kg} \mathrm{MeOH}$ & $1.61 \mathrm{E}+0$ & $1.61 \mathrm{E}+0$ & 0 \\
\hline MEA & $\mathrm{kg} / \mathrm{kg} \mathrm{MeOH}$ & $1.33 \mathrm{E}-5$ & $1.33 \mathrm{E}-5$ & 0 \\
\hline Steam & $\mathrm{kg} / \mathrm{kg} \mathrm{MeOH}$ & $4.57 \mathrm{E}+1$ & $4.57 \mathrm{E}+1$ & 0 \\
\cline { 2 - 4 } (Flowrate/Duty) & $\mathrm{MJ} / \mathrm{kg} \mathrm{MeOH}$ & $9.78 \mathrm{E}+1$ & $9.78 \mathrm{E}+1$ & 0 \\
\hline Cooling Water & $\mathrm{kg} / \mathrm{kg} \mathrm{MeOH}$ & $7.19 \mathrm{E}+2$ & $7.19 \mathrm{E}+2$ & 0 \\
\cline { 2 - 4 } (Flowrate/Duty) & $\mathrm{MJ} / \mathrm{kg} \mathrm{MeOH}$ & $1.32 \mathrm{E}+2$ & $1.32 \mathrm{E}+2$ & 0 \\
\hline Electricity & $\mathrm{MJ} / \mathrm{kg} \mathrm{MeOH}$ & $3.20 \mathrm{E}-1$ & $3.51 \mathrm{E}-1$ & $9.7 \%$ \\
\hline Air & $\mathrm{kg} / \mathrm{kg} \mathrm{MeOH}$ & 0 & $8.21 \mathrm{E}+0$ & $\infty$ \\
\hline Natural Gas & $\mathrm{scm} / \mathrm{kg} \mathrm{MeOH}$ & 0 & $8.49 \mathrm{E}-2$ & $\infty$ \\
\hline Construction Material & $\mathrm{kg} /(\mathrm{kg} \mathrm{MeOH} / \mathrm{yr})$ & $5.76 \mathrm{E}-4$ & $5.79 \mathrm{E}-4$ & $0.5 \%$ \\
\hline \multirow{2}{*}{ Footprint } & $\mathrm{m} /(\mathrm{kg}$ & - & $1.85 \mathrm{E}-7$ & $\infty$ \\
\hline & $\mathrm{MeOH} / \mathrm{yr})$ & & & \\
\hline
\end{tabular}

“ $\infty$ " represents division by zero in calculation of percentages (for cases without corresponding inlet stream), while "-" means the inventory data is not calculated for the methanol synthesis process footprint

Table 3.6 LCl outputs before and after waste streams have been processed by PCUs per kilogram of methanol produced from coal

\begin{tabular}{|l|c|c|c|c|}
\hline LCl Outputs & Units & Simulation & $\begin{array}{c}\text { Simulation with } \\
\text { Thermal Oxidizer }\end{array}$ & $\begin{array}{c}\text { Percentage } \\
\text { change }\end{array}$ \\
\hline Methane & $\mathrm{kg} / \mathrm{kg} \mathrm{MeOH}$ & $1.41 \mathrm{E}-3$ & 0 & $-100 \%$ \\
\hline Carbon Dioxide & $\mathrm{kg} / \mathrm{kg} \mathrm{MeOH}$ & $7.03 \mathrm{E}-3$ & $9.43 \mathrm{E}-1$ & $13313 \%$ \\
\hline Carbon Monoxide & $\mathrm{kg} / \mathrm{kg} \mathrm{MeOH}$ & $5.88 \mathrm{E}-1$ & $9.18 \mathrm{E}-3$ & $-98 \%$ \\
\hline Hydrogen & $\mathrm{kg} / \mathrm{kg} \mathrm{MeOH}$ & $8.65 \mathrm{E}-2$ & 0 & $-100 \%$ \\
\hline Methanol & $\mathrm{kg} / \mathrm{kg} \mathrm{MeOH}$ & $2.04 \mathrm{E}-2$ & $1.02 \mathrm{E}-4$ & $-99.5 \%$ \\
\hline Nitrogen & $\mathrm{kg} / \mathrm{kg} \mathrm{MeOH}$ & 0 & $6.30 \mathrm{E}+0$ & $\infty$ \\
\hline Oxygen & $\mathrm{kg} / \mathrm{kg} \mathrm{MeOH}$ & 0 & $1.91 \mathrm{E}+0$ & $\infty$ \\
\hline
\end{tabular}

“ $\infty$ " represents division by zero in calculation of percentages

Biomass-Based Simulation: The flowsheet for the biomass case study was kept as similar as possible to the coal case study to allow for direct comparison. The operating conditions, such as the oxygen and water flowrates as well as the bypass 
fraction to the water-gas shift reactor, were adjusted according to the biomass conversion rate and syngas composition, in order to produce a methanol with similar purity and production rate needed for the subsequent acetic acid synthesis subprocess. For generating LCl results, the considered LCl boundary and assumptions on the efficiencies of pumps and compressors still hold. When compared to the coal case study, the LCl results, reported in Table 3.7, for the oxygen and water inlets are less than those for the coal case study, due mainly to the fact that biomass is richer in oxygen content and consists of $15 \%$ water. However, the $\mathrm{LCl}$ results for biomass for steam and cooling water usage are greater than those in the coal case study. This can be attributed to the biomass' lower energy density and a larger quantity of biomass being needed to generate the same amount of syngas.

In addition, the syngas quality from the biomass, in terms of $\mathrm{H}_{2} / \mathrm{CO}$, is much lower than that generated from coal. Thus, greater quantities of utilities, such as steam and cooling water, for the biomass are consumed when compared to coal. Electricity estimates for the two cases studies were found to be equivalent. When referring to waste streams, both waste streams exist for the two cases studies: 1) waste stream from mixer-106 (waste stream 1), which is mainly composed of CO and methanol; 2) waste stream from mixer-105 (waste stream 2), including mostly $\mathrm{CO}_{2}$ and $\mathrm{H}_{2} \mathrm{~S}$. The result of treating waste stream 1 employing the thermal oxidizer PCU is shown in Table 3.8, which is similar to the results from the coal case study. However, the acid gases in waste stream 2 that would be sent to downstream units as described above is much lower than that for the coal case study, as shown in Table 3.9. This table depicts the comparison of the results of the uncontrolled emissions from both the coal and biomass-based case studies. 
Table 3.7 Raw material and utility life cycle inventory for methanol production from biomass

\begin{tabular}{|c|c|c|c|c|}
\hline \multirow{2}{*}{ LCI Inputs } & Units & Simulation & Simulation with & Percent change \\
\hline & & & Thermal Oxidizer & \\
\hline Oxygen & $\mathrm{kg} / \mathrm{kg} \mathrm{MeOH}$ & 8.01E-1 & $8.01 \mathrm{E}-1$ & 0 \\
\hline Water & kg/kg MeOH & $1.00 \mathrm{E}-1$ & $1.00 \mathrm{E}-1$ & 0 \\
\hline Biomass & $\mathrm{kg} / \mathrm{kg} \mathrm{MeOH}$ & $2.74 \mathrm{E}+0$ & $2.74 \mathrm{E}+0$ & 0 \\
\hline \multirow{2}{*}{$\begin{array}{c}\text { Steam } \\
\text { (Flowrate/Duty) }\end{array}$} & $\mathrm{kg} / \mathrm{kg} \mathrm{MeOH}$ & $4.57 \mathrm{E}+1$ & 4.57E+1 & 0 \\
\hline & $\mathrm{MJ} / \mathrm{kg} \mathrm{MeOH}$ & $9.78 \mathrm{E}+1$ & $9.78 \mathrm{E}+1$ & 0 \\
\hline \multirow{2}{*}{$\begin{array}{l}\text { Cooling Water } \\
\text { (Flowrate/Duty) }\end{array}$} & $\mathrm{kg} / \mathrm{kg} \mathrm{MeOH}$ & $7.19 E+2$ & $7.19 E+2$ & 0 \\
\hline & $\mathrm{MJ} / \mathrm{kg} \mathrm{MeOH}$ & $1.32 \mathrm{E}+2$ & $1.32 \mathrm{E}+2$ & 0 \\
\hline Electricity & $\mathrm{MJ} / \mathrm{kg} \mathrm{MeOH}$ & $3.20 \mathrm{E}-1$ & $3.54 \mathrm{E}-1$ & $10.8 \%$ \\
\hline Air & $\mathrm{kg} / \mathrm{kg} \mathrm{MeOH}$ & 0 & $8.21 E+0$ & $\infty$ \\
\hline Natural Gas & $\mathrm{scm} / \mathrm{kg} \mathrm{MeOH}$ & 0 & $5.38 \mathrm{E}-2$ & $\infty$ \\
\hline Construction Material & $\begin{array}{c}\mathrm{kg} /(\mathrm{kg} \\
\mathrm{MeOH} / \mathrm{yr})\end{array}$ & $5.76 \mathrm{E}-4$ & $5.81 \mathrm{E}-4$ & $0.9 \%$ \\
\hline Footprint & $\begin{array}{c}\mathrm{m}^{2} /(\mathrm{kg} \\
\mathrm{MeOH} / \mathrm{yr})\end{array}$ & - & $8.55 \mathrm{E}-7$ & $\infty$ \\
\hline
\end{tabular}

“ $\infty$ " represents division by zero in calculation of percentages (for cases without corresponding inlet stream) while "-" means the inventory data is not calculated for methanol simulation case

Table 3.8 LCI before and after waste streams have been processed by PCUs for biomass case

\begin{tabular}{|l|c|c|c|c|}
\hline \multirow{2}{*}{ LCl Outputs } & Units & Simulation & $\begin{array}{c}\text { Simulation with } \\
\text { Thermal Oxidizer }\end{array}$ & Percentage change \\
\hline Methane & $\mathrm{kg} / \mathrm{kg} \mathrm{MeOH}$ & $1.03 \mathrm{E}-2$ & 0 & $-100 \%$ \\
\hline Carbon Dioxide & $\mathrm{kg} / \mathrm{kg} \mathrm{MeOH}$ & $1.28 \mathrm{E}-3$ & $8.76 \mathrm{E}-1$ & $68337 \%$ \\
\hline Carbon Monoxide & $\mathrm{kg} / \mathrm{kg} \mathrm{MeOH}$ & $5.44 \mathrm{E}-1$ & $8.53 \mathrm{E}-3$ & $-98.4 \%$ \\
\hline Hydrogen & $\mathrm{kg} / \mathrm{kg} \mathrm{MeOH}$ & $7.97 \mathrm{E}-2$ & 0 & $-100 \%$ \\
\hline Methanol & $\mathrm{kg} / \mathrm{kg} \mathrm{MeOH}$ & $2.04 \mathrm{E}-2$ & $3.84 \mathrm{E}-5$ & $-99.8 \%$ \\
\hline Nitrogen & $\mathrm{kg} / \mathrm{kg} \mathrm{MeOH}$ & 0 & $6.30 \mathrm{E}+0$ & $\infty$ \\
\hline Oxygen & $\mathrm{kg} / \mathrm{kg} \mathrm{MeOH}$ & 0 & $1.91 \mathrm{E}+0$ & $\infty$ \\
\hline
\end{tabular}

“œ” represents division by zero in calculation of percentages (for cases without corresponding inlet stream) 
Table 3.9 Uncontrolled emissions from coal and biomass-based methanol process

\begin{tabular}{|c|c|c|c|}
\hline LCl Output & Units & Coal Case & Biomass Case \\
\hline Methane & $\mathrm{kg} / \mathrm{kg} \mathrm{MeOH}$ & $6.39 \mathrm{E}-6$ & $6.51 \mathrm{E}-5$ \\
\hline Carbon Dioxide & $\mathrm{kg} / \mathrm{kg} \mathrm{MeOH}$ & $3.09 \mathrm{E}+0$ & $2.13 \mathrm{E}+0$ \\
\hline Hydrogen Sulfide & $\mathrm{kg} / \mathrm{kg} \mathrm{MeOH}$ & $5.86 \mathrm{E}-2$ & $5.60 \mathrm{E}-4$ \\
\hline Carbon Monoxide & $\mathrm{kg} / \mathrm{kg} \mathrm{MeOH}$ & $5.31 \mathrm{E}-3$ & $9.96 \mathrm{E}-3$ \\
\hline Water & $\mathrm{kg} / \mathrm{kg} \mathrm{MeOH}$ & $3.97 \mathrm{E}-2$ & $2.69 \mathrm{E}-2$ \\
\hline Nitrogen & $\mathrm{kg} / \mathrm{kg} \mathrm{MeOH}$ & $7.03 \mathrm{E}-5$ & $3.26 \mathrm{E}-5$ \\
\hline Hydrogen & $\mathrm{kg} / \mathrm{kg} \mathrm{MeOH}$ & $8.37 \mathrm{E}-4$ & $1.20 \mathrm{E}-3$ \\
\hline
\end{tabular}

Analysis of Coal to AA Production Process

As described in the process simulation section, the entire process can be separated in two parts (methanol synthesis and acetic acid production) and the previous $\mathrm{LCl}$ results were obtained and analyzed separately. The $\mathrm{LCl}$ input and output results in this section are based on the same functional unit (kg AA) using coal as feedstock, as shown in Tables 3.10 and 3.11. Note the results for the two parts are for the scenario including pollution control unit simulations. Specifically, a thermal oxidizer was used in the coal to methanol part for treating the gas phase waste from the methanol synthesis reactor, while a scrubber, boiler and flare were used for treatment in the methanol to acetic acid process. As shown in Table 3.10, greater quantities of utilities (cooling water, electricity, and steam) were used in the methanol synthesis part when compared to the utility values needed for the methanol to acetic acid process. This can be attributed to the complexity of the methanol synthesis process, which includes gasification, sour water gas shift reaction, acid gas cleaning part and methanol reactor process steps.

For the $\mathrm{LCl}$ output results, the first part of the process releases $\mathrm{CO}, \mathrm{CO}_{2}, \mathrm{H}_{2} \mathrm{~S}$, and small amounts of $\mathrm{CH}_{4}, \mathrm{CH}_{3} \mathrm{OH}$, as well as $\mathrm{H}_{2}$. While the acetic acid process portion generates $\mathrm{CO}_{2}$ with small quantities of $\mathrm{NO}_{x}, \mathrm{CO}$ and $\mathrm{PM}$. It is important to note the source for each species as this can guide further investigation on how to 
handle and treat such emissions. For example, the sources of $\mathrm{CO}_{2}$ emissions, from the two parts of the process, are different even though both release a high quantity of $\mathrm{CO}_{2}$. More specifically, $\mathrm{CO}_{2}$ from the methanol process, which is primarily generated by the water gas shift reaction, can be separated from other species present in the stream and then go to carbon capture and storage (CCS). Additional processing steps are required to collect the $\mathrm{CO}_{2}$ generated from the acetic acid process, as the majority of $\mathrm{CO}_{2}$ originates from the combustion in the boiler and flare.

Table 3.10 LCl input for entire process from coal to $A A$

\begin{tabular}{|c|c|c|c|c|}
\hline \multirow{2}{*}{ LCl Input } & Units & $\begin{array}{c}\text { Coal to } \\
\text { Methanol } \\
\text { Simulation }\end{array}$ & $\begin{array}{c}\text { Methanol-to- } \\
\text { Acetic Acid } \\
\text { Simulation }\end{array}$ & Total \\
\hline Oxygen & $\mathrm{kg} / \mathrm{kg} \mathrm{AA}$ & $1.42 \mathrm{E}+0$ & 0 & $1.42 \mathrm{E}+0$ \\
\hline Water & $\mathrm{kg} / \mathrm{kg} \mathrm{AA}$ & $5.98 \mathrm{E}-1$ & 0 & $5.98 \mathrm{E}-1$ \\
\hline Coal & $\mathrm{kg} / \mathrm{kg} \mathrm{AA}$ & $8.70 \mathrm{E}-1$ & 0 & $8.70 \mathrm{E}-1$ \\
\hline Carbon Monoxide & $\mathrm{kg} / \mathrm{kg} \mathrm{AA}$ & 0 & $5.09 \mathrm{E}-1$ & $5.09 \mathrm{E}-1$ \\
\hline Methanol & $\mathrm{kg} / \mathrm{kg} \mathrm{AA}$ & 0 & $5.39 \mathrm{E}-1$ & $5.39 \mathrm{E}-1$ \\
\hline Methyl lodide & $\mathrm{kg} / \mathrm{kg} \mathrm{AA}$ & 0 & $2.03 \mathrm{E}-3$ & $2.03 \mathrm{E}-3$ \\
\hline $\begin{array}{c}\text { Steam } \\
\text { (Flowrate/Duty) }\end{array}$ & $\mathrm{kg} / \mathrm{kg} \mathrm{AA}$ & $2.47 \mathrm{E}+1$ & $4.95 \mathrm{E}-1$ & $2.52 \mathrm{E}+1$ \\
\hline $\begin{array}{c}\text { Cooling Water } \\
\text { (Flowrate/Duty) }\end{array}$ & $\mathrm{MJ} / \mathrm{kg} \mathrm{AA}$ & $5.28 \mathrm{E}+1$ & $1.75 \mathrm{E}+0$ & $5.46 \mathrm{E}+1$ \\
\cline { 2 - 5 } & $\mathrm{MJ} / \mathrm{kg} \mathrm{AA}$ & $3.88 \mathrm{E}+2$ & $4.37 \mathrm{E}-1$ & $3.89 \mathrm{E}+2$ \\
\hline Electricity & $\mathrm{MJ} / \mathrm{kg} \mathrm{AA}$ & $1.90 \mathrm{E}-1$ & $6.65 \mathrm{E}-2$ & $2.56 \mathrm{E}-1$ \\
\hline Air & $\mathrm{kg} / \mathrm{kg} \mathrm{AA}$ & $4.44 \mathrm{E}+0$ & $1.76 \mathrm{E}-1$ & $4.61 \mathrm{E}+0$ \\
\hline Natural Gas & $\mathrm{kg} / \mathrm{kg} \mathrm{AA}$ & $4.59 \mathrm{E}-2$ & $2.34 \mathrm{E}-2$ & $6.93 \mathrm{E}-2$ \\
\hline $\begin{array}{c}\text { Purge Gas } \\
\text { (Nitrogen) }\end{array}$ & $\mathrm{kg} / \mathrm{kg} \mathrm{AA}$ & 0 & $1.24 \mathrm{E}-3$ & $1.24 \mathrm{E}-3$ \\
\hline Solvent (water) & $\mathrm{kg} / \mathrm{kg} \mathrm{AA}$ & 0 & $2.47 \mathrm{E}+0$ & $2.47 \mathrm{E}+0$ \\
\hline $\begin{array}{c}\text { Construction } \\
\text { Material }\end{array}$ & $\mathrm{kg} /(\mathrm{kg} \mathrm{AA} / \mathrm{yr})$ & $3.13 \mathrm{E}-4$ & $1.49 \mathrm{E}-5$ & $3.28 \mathrm{E}-4$ \\
\hline
\end{tabular}


Table 3.11 LCl output for entire process from coal to $A A$

\begin{tabular}{|c|c|c|c|c|}
\hline \multirow{2}{*}{ LCl Output } & Units & $\begin{array}{c}\text { Coal to } \\
\text { Methanol } \\
\text { Simulation }\end{array}$ & $\begin{array}{c}\text { Methanol-to- } \\
\text { Acetic Acid } \\
\text { Simulation }\end{array}$ & Total \\
\hline Carbon Monoxide & $\mathrm{kg} / \mathrm{kg} \mathrm{AA}$ & $7.83 \mathrm{E}-3$ & $8.73 \mathrm{E}-4$ & $8.71 \mathrm{E}-3$ \\
\hline Carbon Dioxide & $\mathrm{kg} / \mathrm{kg} \mathrm{AA}$ & $2.18 \mathrm{E}+0$ & $1.36 \mathrm{E}-1$ & $2.32 \mathrm{E}+0$ \\
\hline Methane & $\mathrm{kg} / \mathrm{kg} \mathrm{AA}$ & $3.45 \mathrm{E}-6$ & 0 & $3.45 \mathrm{E}-6$ \\
\hline Water & $\mathrm{kg} / \mathrm{kg} \mathrm{AA}$ & $2.15 \mathrm{E}-2$ & 0 & $2.15 \mathrm{E}-2$ \\
\hline Methanol & $\mathrm{kg} / \mathrm{kg} \mathrm{AA}$ & $5.51 \mathrm{E}-5$ & 0 & $5.51 \mathrm{E}-5$ \\
\hline Acetic Acid & $\mathrm{kg} / \mathrm{kg} \mathrm{AA}$ & 0 & 0 & 0 \\
\hline Methyl Acetate & $\mathrm{kg} / \mathrm{kg} \mathrm{AA}$ & 0 & 0 & 0 \\
\hline Hydrogen lodide & $\mathrm{kg} / \mathrm{kg} \mathrm{AA}$ & 0 & 0 & 0 \\
\hline Propionic Acid & $\mathrm{kg} / \mathrm{kg} \mathrm{AA}$ & 0 & 0 & 0 \\
\hline NOx & $\mathrm{kg} / \mathrm{kg} \mathrm{AA}$ & 0 & $1.96 \mathrm{E}-5$ & $1.96 \mathrm{E}-5$ \\
\hline PM $(<1 \mu \mathrm{m})$ & $\mathrm{kg} / \mathrm{kg} \mathrm{AA}$ & 0 & $1.63 \mathrm{E}-6$ & $1.63 \mathrm{E}-6$ \\
\hline Hydrogen Sulfide & $\mathrm{kg} / \mathrm{kg} \mathrm{AA}$ & $3.17 \mathrm{E}-2$ & 0 & $3.17 \mathrm{E}-2$ \\
\hline Hydrogen & $\mathrm{kg} / \mathrm{kg} \mathrm{AA}$ & $4.52 \mathrm{E}-4$ & 0 & $4.52 \mathrm{E}-4$ \\
\hline
\end{tabular}

\subsection{Conclusions}

The objective in this chapter was to develop a generic and integrated framework for rapid LCl generation of PCU modules by adopting systematic methods for process modeling, simulation, and design. Specifically, process simulation that included mass and energy balances was employed for providing $\mathrm{LCl}$ data which otherwise may be incomplete without considering the impacts of implementing pollution control systems for process waste streams. The developed PCUs were comprised of modules for treating gas releases that provide $\mathrm{LCl}$ information regarding land footprint and utility and material use. The effectiveness of the proposed framework was demonstrated on the acetic acid manufacturing process from a coal/biomass feedstock. The outputs from the acetic acid simulation were used as input streams to the respective PCU modules. Those suitable PCUs were successfully implemented to remove process pollutants and recover the combustion heat. A comparison between $\mathrm{LCl}$ results with and without application of the 
developed PCU modules demonstrated considerable variations in material compositions, energy demand, and infrastructure that cannot be omitted when generating a suitable $\mathrm{LCl}$. For the current case study, the $\mathrm{LCl}$ results, when comparing methanol production from biomass vs. coal, showed the biomass case requires more utility demand (steam and cooling water), while generating less $\mathrm{CO}_{2}$ and $\mathrm{H}_{2} \mathrm{~S}$. In Chapter 7, co-gasification of coal and biomass is investigated as a potentially economically attractive and technically viable alternative to the conversion of biomass to energy and chemicals while improving the sustainability performance of the coal gasification process. Furthermore, an advanced process control strategy ${ }^{89,90}$ is investigated as a potentially sustainable process control approach for biomass/coal co-gasification process. From this investigation, it is anticipated a determination on the optimum combination of coal and biomass to balance the raw material input to reduce emissions without sacrificing desired production rate and profitability that can be achieved. This contribution demonstrates the needs and benefits of adding the effects of pollution control units for rapid LCI modeling of a chemical manufacturing process by designing, modeling, and simulating PCUs for noxious gas removal. These parameterized PCU modules can simplify pollution control modeling when compared to fully simulating the units by providing rapid $\mathrm{LCI}$ estimates that could be used by non-engineer LCA practitioners when LCI information is not readily available from industry or literature. 


\section{Chapter 4 Integrated Tool Development for Sustainability Assessment}

\subsection{Introduction}

Previous chapter demonstrated the effectiveness and necessity of incorporating PCUs into process simulation for gate-to-gate LCI data generation. Based on previous work, this chapter is focusing on the extension of the capability of the developed PCUs for an integrated sustainability assessment tool. The new features of the proposed tool are: 1) an automation interface between simulators, parameterized PCUs and sustainability assessment tool; 2) PCU models for air, solid and liquid waste treatment; 3) capability to generate GREENSCOPE sustainability indicator results. Specifically, the user-friendly automation interface is built via Microsoft Excel-VBA to enable the communication between process simulators (e.g., CHEMCAD, Aspen) and Excel tools for sustainability assessment, PCUs and LCI generation. The employed Excel tools enable the augmentation of a simulator's capability in terms of waste treatment technologies and sustainability assessment. For the solid and liquid PCUs introduced in this chapter, similar distinguished features are kept as in the other PCUs, such as parametrized input variables with default/suggested values and easy customization for different applications. GREENSCOPE, as one of most comprehensive sustainability assessment tools, can be accessed via the proposed framework to provide additional useful information on where and by how much the implemented PCUs can improve the process performance. The objective of the proposed framework is to provide a generic software interface that facilitates the communication between sustainability assessment tools at different scales (such as GREENSCOPE and LCA) and process simulation packages with the augmented ability of adding suitable PCU techniques. 
The developed framework is applied to a case study of an Acetic Acid manufacturing process. The proposed framework is generic and can also be implemented for other applications. The outline of the rest of this chapter is as follows: the overall integrated framework is presented in the next subsection, followed by the details on the newly developed pollution control units and the sustainability assessment tool. Then, the proposed framework is implemented for the addressed case study.

\subsection{Approach}

Figure 4.1 shows the overview of the proposed framework for integrating process modeling/simulation with pollution control units (PCUs), LCl generation, and sustainability assessment. Specifically, a user-friendly automation interface is built via Microsoft Excel-VBA to enable the communication between process simulators and Excel tools, such as GREENSCOPE, PCUs and LCl generation. In this framework, a chemical process manufacturing simulation is built to monitor utility (e.g., heating, cooling, and electricity) requirements and estimate unit operation infrastructure (e.g., steel consumption, land use, etc.). To augment the capability of commercial simulators in terms of PCU techniques, a library of parameterized PCU models has been developed to deal with air, liquid and solid wastes from a typical chemical plant. The air PCUs were detailed in Chapter 3 and the particle matter (PM), liquid, and solid PCUs are discussed below. 


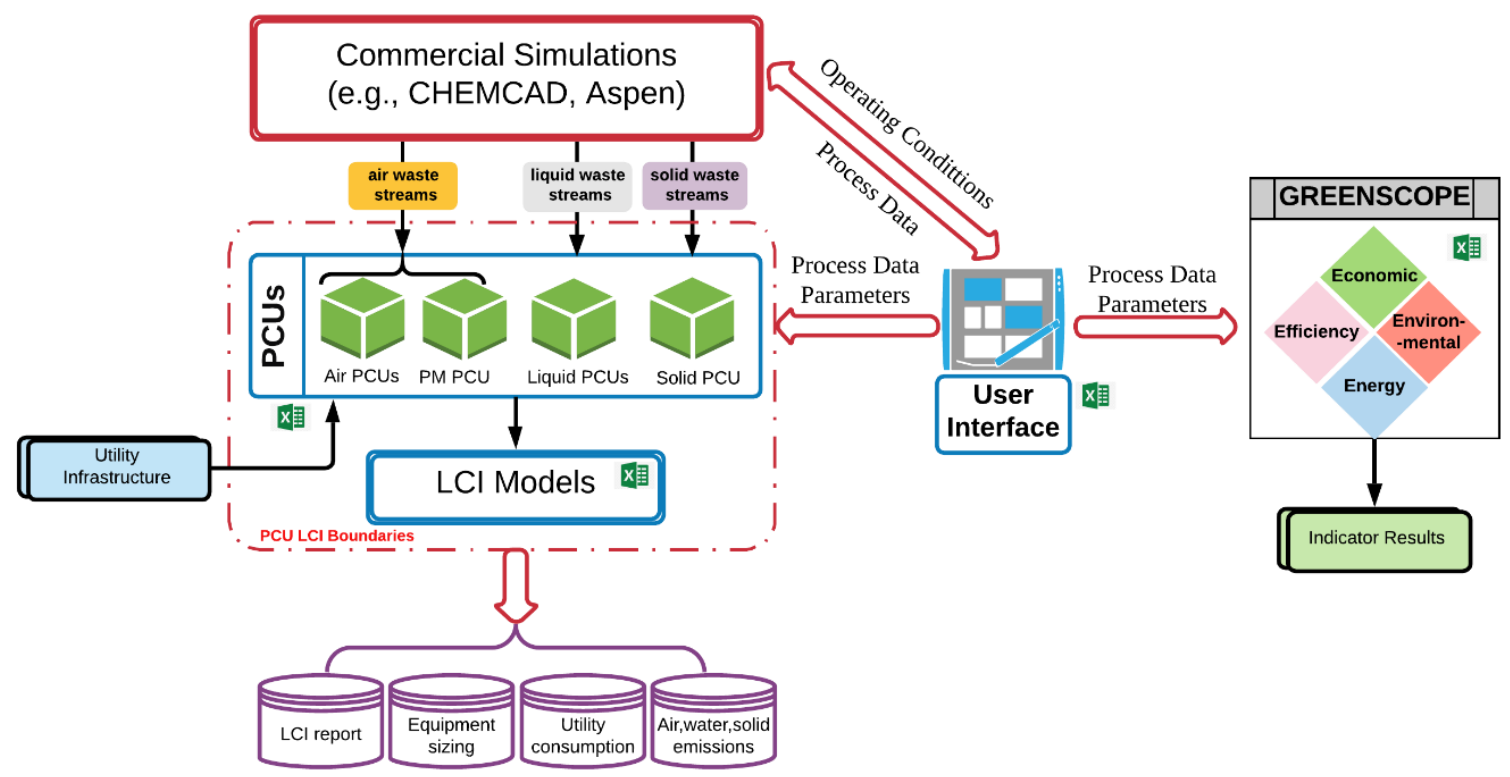

Figure 4.1 Process systems framework for pollution control and sustainability assessment

One characteristic of proposed framework is that the developed user interface can transfer the process data (e.g., stream information) into the PCUs library automatically. Specifically, the user interface can extract all the stream information from the simulator when the simulation converged. Then the user can choose certain waste streams to be treated by the appropriate PCU model to estimate the utility, equipment and end emission to environment associated with this treatment. Figure 4.2 shows an example of the interface in the developed software environment. In this interface, the user can open, run a simulation file, and then match the interested waste streams (stream 13 in the example) with a PCU model (Stripper PCU for water treatment in the example) from the developed PCU library. Upon finishing these steps, the user can click the button of "Upload Waste Stream to PCU" and all the stream info (showing in Figure 4.2(b)) is automatically entered for the selected PCU calculation. The user only needs to check/enter some required PCU parameter values (in the lower part of Figure 4.2(b)) to generate the LCl data. This interface is thus a convenient and easy approach for the generation of the waste stream treatment results by only clicking a few buttons. Moreover, the user can change 
operating conditions of the simulation in Excel through the VBA interface and repeat the above procedures to generate waste treatment data for a different case.

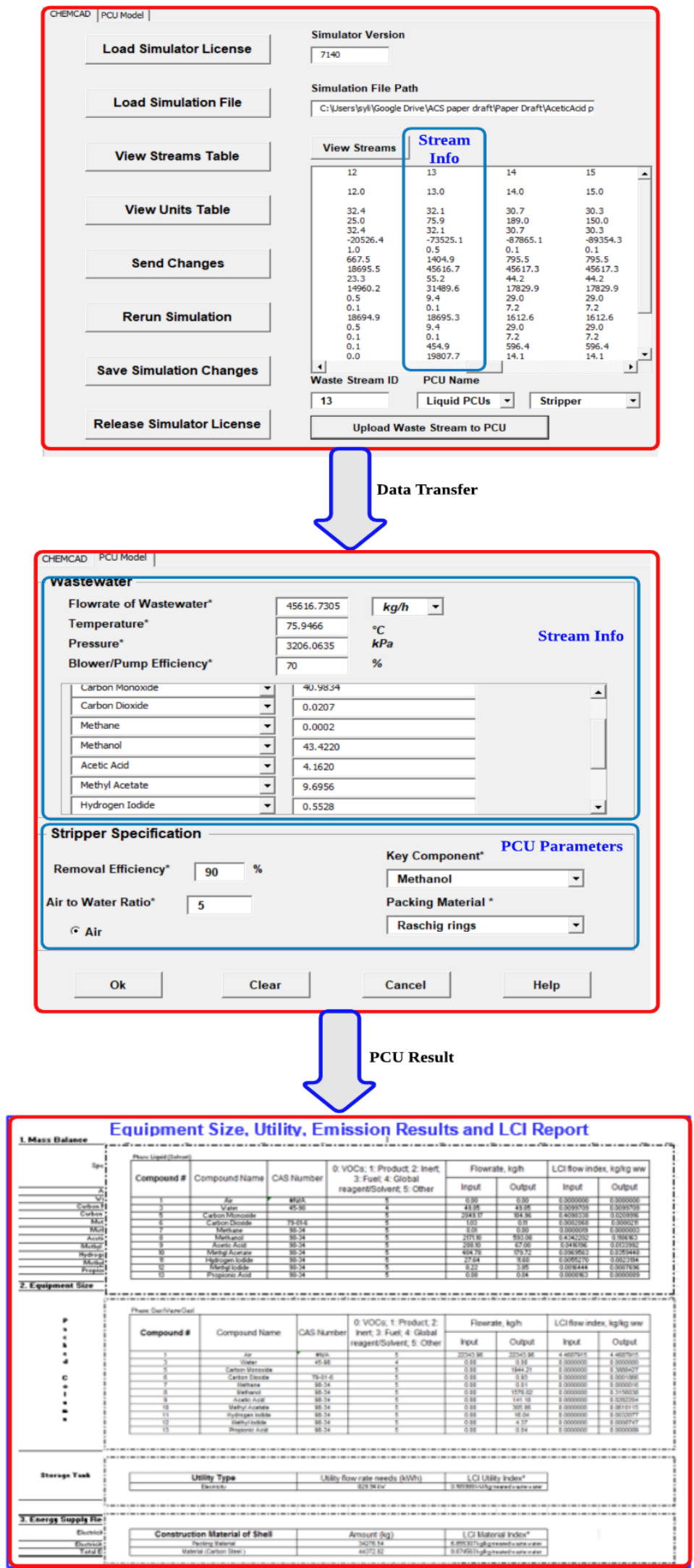

Figure 4.2 Automation interface between simulators and developed PCUs 
Once the data from process simulations and PCU models is obtained, GREENSCOPE indicators can be calculated to describe the performance in efficiency, economic, environmental and energy aspects. Please note that the current interface can only transfer part of the required data (e.g., stream information, unit operation, etc.) to GREENSCOPE and an improved automation interface between the process simulator, PCU and GREENSCOPE is under development in our group.

\subsubsection{New Pollution Control Units}

Particle Matter PCU: Baghouse

Baghouses $^{91-93}$ (or fabric filters), as particle matter (PM) devices, typically include one or more compartments containing rows of long, cylindrical bags (or tubes) made of woven or felted fabric. Dirty air (dust-laden gas) is directed into the baghouse compartment and can be either on the inside or the outside of the bags depending on the cleaning method. Particles start to accumulate on the surface of the bags until sufficient pressure drop is reached. Generally, the baghouses are operated cyclically, alternating between relatively long period of filtering and short period of cleaning. During cleaning, dust that has accumulated on the bags is removed from the fabric surface and deposited in a hopper for subsequent disposal. The proper design procedures for baghouses and a baghouse model will be illustrated in a forthcoming publication. 


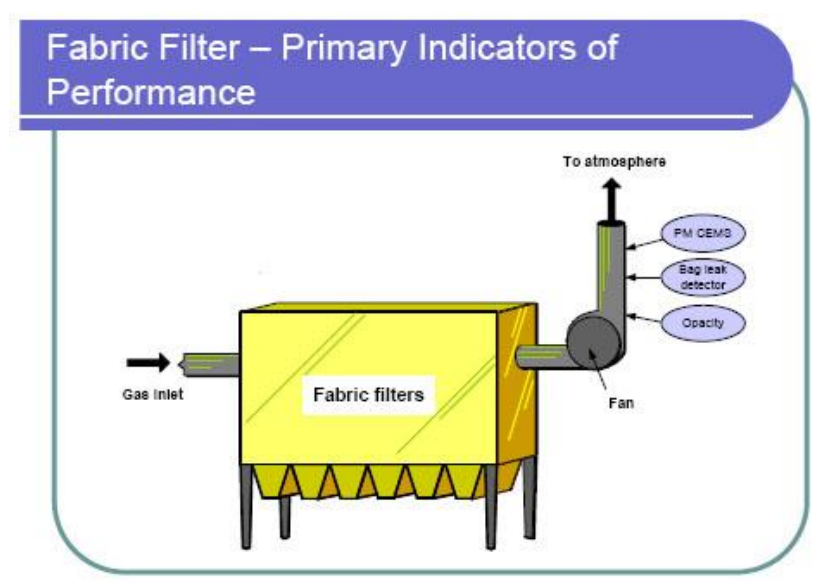

Figure 4.3 A simplified baghouse diagram (adapted from EPA report)

Wastewater Treatment PCU: Stripper

Stripping processes are used to remove VOCs or some volatile species $\left(\mathrm{H}_{2} \mathrm{~S}\right.$ and $\mathrm{NH}_{3}$ ) from waste water. As shown in Figure 4.4, the feed waste water after conditioning typically enters at the top of the tower while the stripping gas (air is used in this simulator) is introduced at the bottom. The proper design procedures for the stripper and the stripper module will be available in a forthcoming publication.

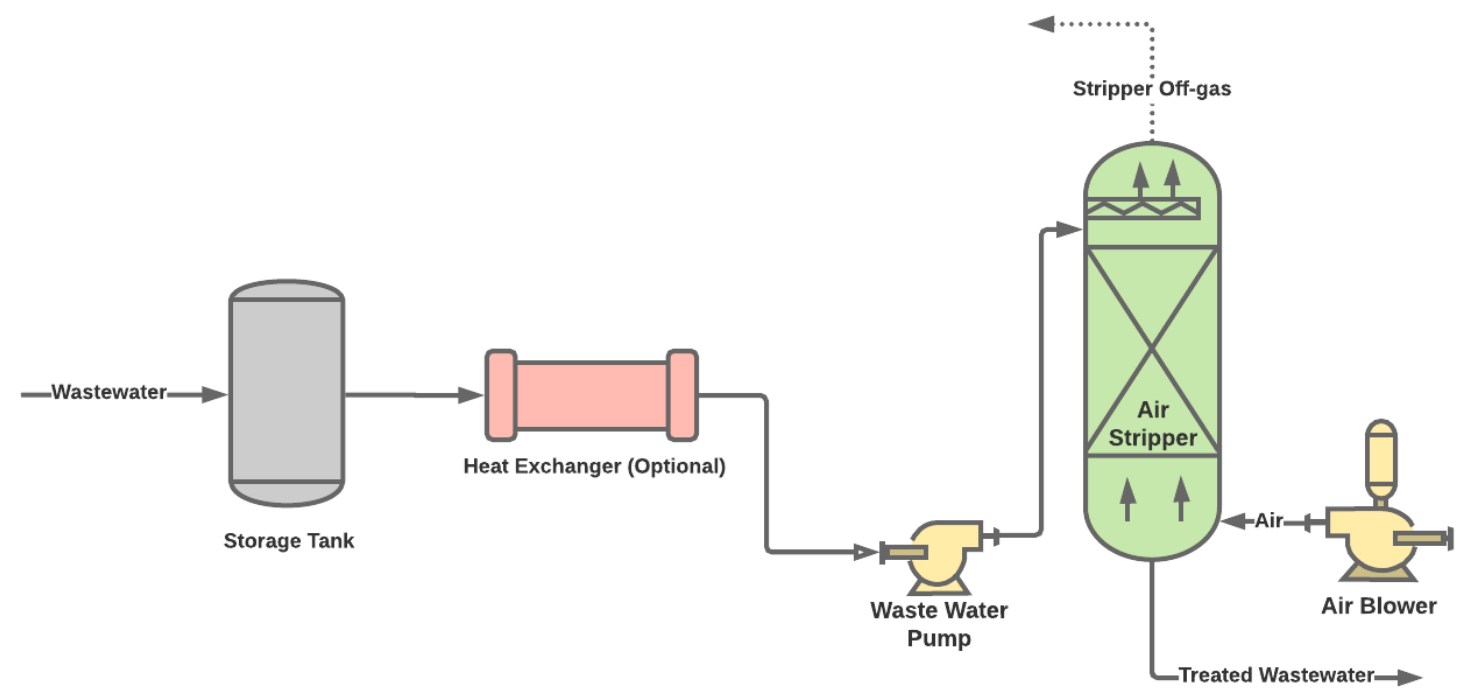

Figure 4.4 A simplified air-stripper schematic diagram 
Wastewater Treatment PCU: GAC

Granular activated carbon (GAC) units use a porous adsorptive media with extremely high internal surface area. GACs are manufactured from a variety of raw materials with porous structures, including bituminous coal, lignite coal, peat, wood, coconut shells, among others. Physical and/or chemical manufacturing processes are applied to these raw materials to create and/or enlarge their pores, resulting in a porous structure with a large surface area per unit mass. A schematic diagram of the GAC system is shown in Figure $4.5^{94}$. In the GAC system, pollutants are adsorbed by the GAC contactors until the carbon is no longer able to adsorb new molecules. At this point, the carbon is considered as "spent" and need to be replaced by new or reactivated carbon. GAC beds also require periodic backwash to prevent head loss or biomass accumulation. The proper design procedures and calculations for the GAC system are based on an EPA report by the Office of Water, which will be available in a forthcoming publication.

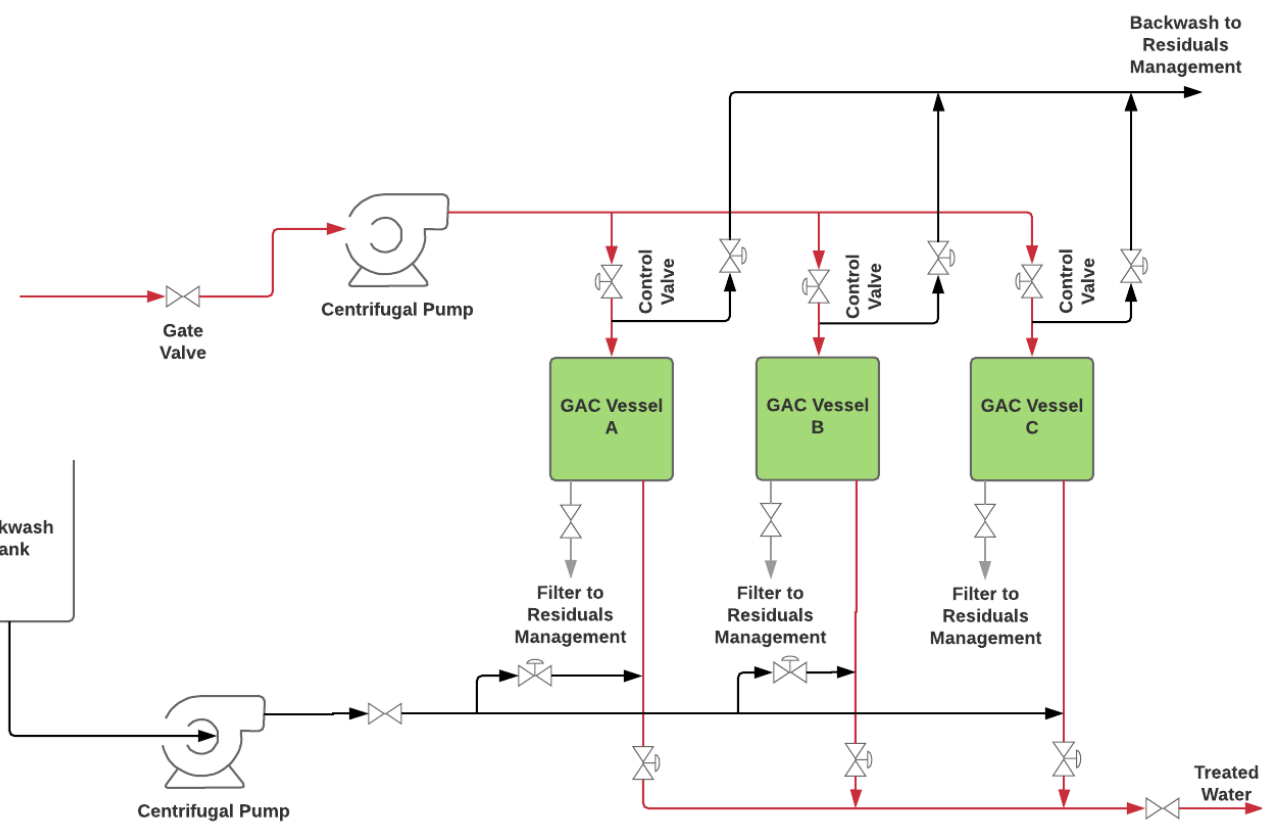

Figure 4.5 A simplified GAC schematic diagram (adapted from EPA report) 
Solid Waste Treatment PCU: Biomass/MSW Gasifier

Biomass/Municipal Solid Waste (MSW) gasification is a technology that uses a controlled process involving heat, steam, and air/oxygen to convert biomass to $\mathrm{H}_{2}$ and $\mathrm{CO}$ and other products, without combustion. In particular, gasification is the conversion of feedstocks into useful and convenient gaseous fuel or chemicals that can be burned to release energy or used for production of value-added chemicals. This document is to illustrate the proper design procedures for the gasifier system. Gasification of biomass is typically carried out in a relatively high temperature range of 800 to $1000^{\circ} \mathrm{C}$, comparing to 300 to $650^{\circ} \mathrm{C}$ for pyrolysis. The design procedure and the example calculation for the gasifier simulator will be available in a forthcoming publication.

\subsubsection{Sustainability Assessment Tool: GREENSCOPE}

GREENSCOPE, as a sustainability evaluation and design tool by US EPA, facilitates a holistic sustainability performance analysis for chemical processes to help process engineers and decision-makers with comparing multiple processes or locating the area for improving or deciding the optimal trade-offs in terms of sustainability. To quantitatively describe process sustainability performance, GREENSCOPE employs a set of sustainability indicators (SI) in four areas: efficiency (26 SIs), economics (33 SIs), environment (66 SIs) and energy (14 SIs). Specifically, efficiency indicators describe the process performance in terms of mass transfer operations by connecting material input and output with the desired product. Economic indicators are based on the profitability criteria for commercial chemical process considering raw material costs, utility costs, capital and labor costs, etc. Out of $\sim 66$ environmental indicators, environmental, health, and safety (EHS) potential 
risks are measured according to the involved input materials, operating conditions and potential impact of releases. For the energy indicators, two different thermodynamic methods (energy and exergy) are used to characterize the thermodynamic efficiencies of the process. More detailed information on the indicators' definitions, calculation and application is available in the literature $e^{45,47,48}$. As shown in Figure 4.6, GREENSCOPE is an effective tool to translate process, feedstocks, utilities, equipment, and product information into a sustainability measurement scale.

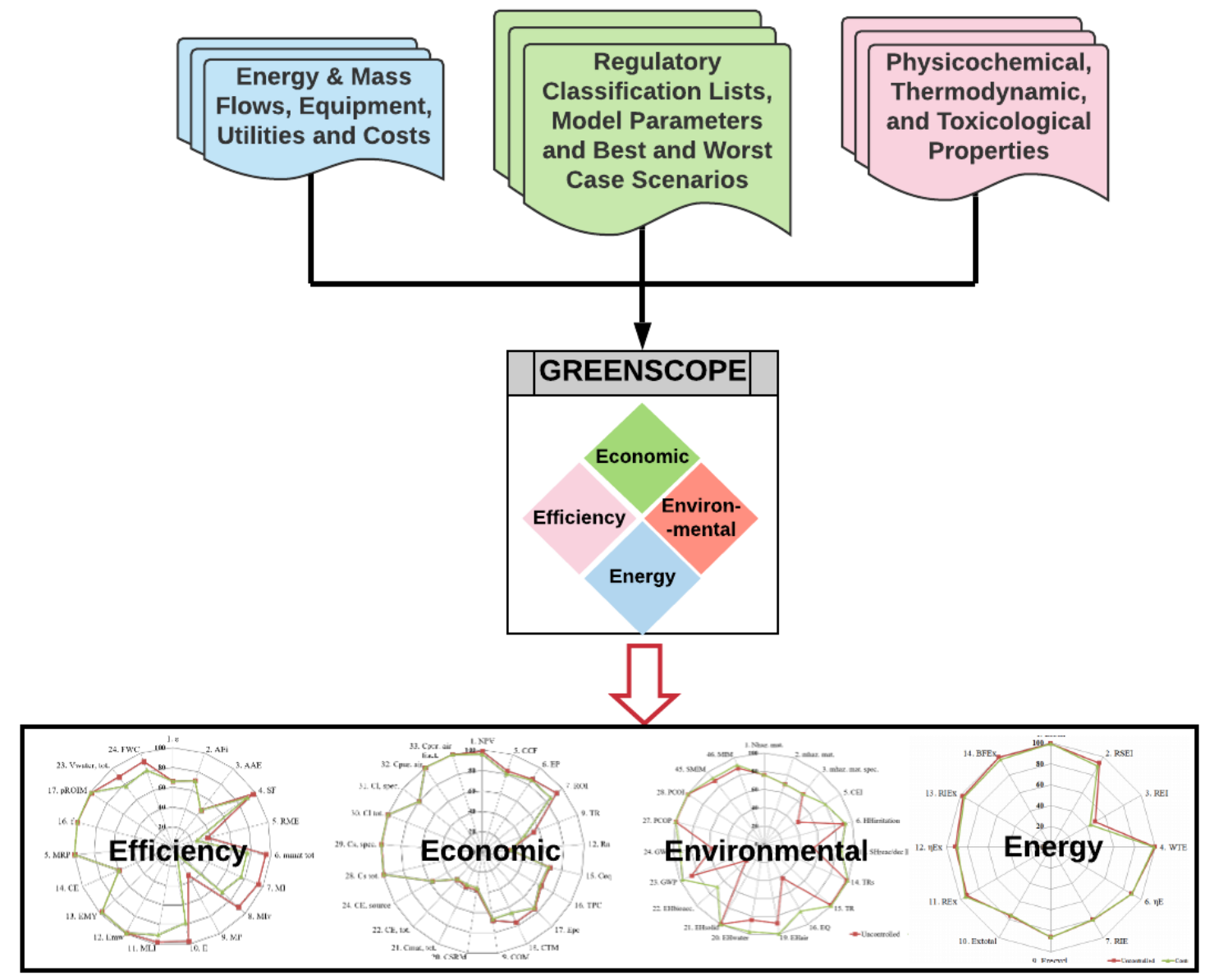

Figure 4.6 Inputs and outputs of GREENSCOPE framework for sustainability assessment

One important and unique feature of GREENSCOPE is the employed dimensionless sustainability indicator score, which can be calculated by the following equation: 


$$
\text { Sustianability Indicator Score }(\%)=\frac{(\text { Actual }- \text { Worst })}{(\text { Best }- \text { Worst })} \times 100 \%
$$

Where best case represents $100 \%$ sustainable while worst case $0 \%$ sustainable for each indicator. Selection of two reference values for normalizing the indicators offers some advantages for applying GREENSCOPE to different scenarios. The dimensionless indicators can be lumped into a two- or three- dimensional sustainability indicator for process optimization or control studies based on a systematic weighting method ${ }^{95}$. Also, indicator scores help the user to identify an area for improvement as they represent the degree of the sustainability performance (higher score means more sustainable). Guidelines on how to select the best and worst case values for the indicators can be found in the literature ${ }^{47}$.

As shown in Figure 4.6, the required input data for GREENSCOPE includes mass \& energy flows, equipment, utility information and their associated cost, regulatory classification and toxicological properties, in addition to the best- and worst-case reference values. One effective way of collecting such required process data is by modeling the process via process simulators, which provide with obtaining mass and energy balances information, equipment sizing and cost.

\subsection{Results \& Discussion}

The study below demonstrates a gate-to-gate sustainability performance assessment by implementing the GREENSCOPE and PCU framework on a biomass/coal-to-acetic acid (AA) manufacturing process. The system boundary for the sustainability evaluation is from feedstocks to products / emissions, which

corresponds to the "gate-to-gate boundary for GREENSCOPE" in Figure 4.7. The AA process simulation is performed using commercial simulators (Aspen Hysys and CHEMCAD), for which the detailed simulation information was provided in Chapter 3. 


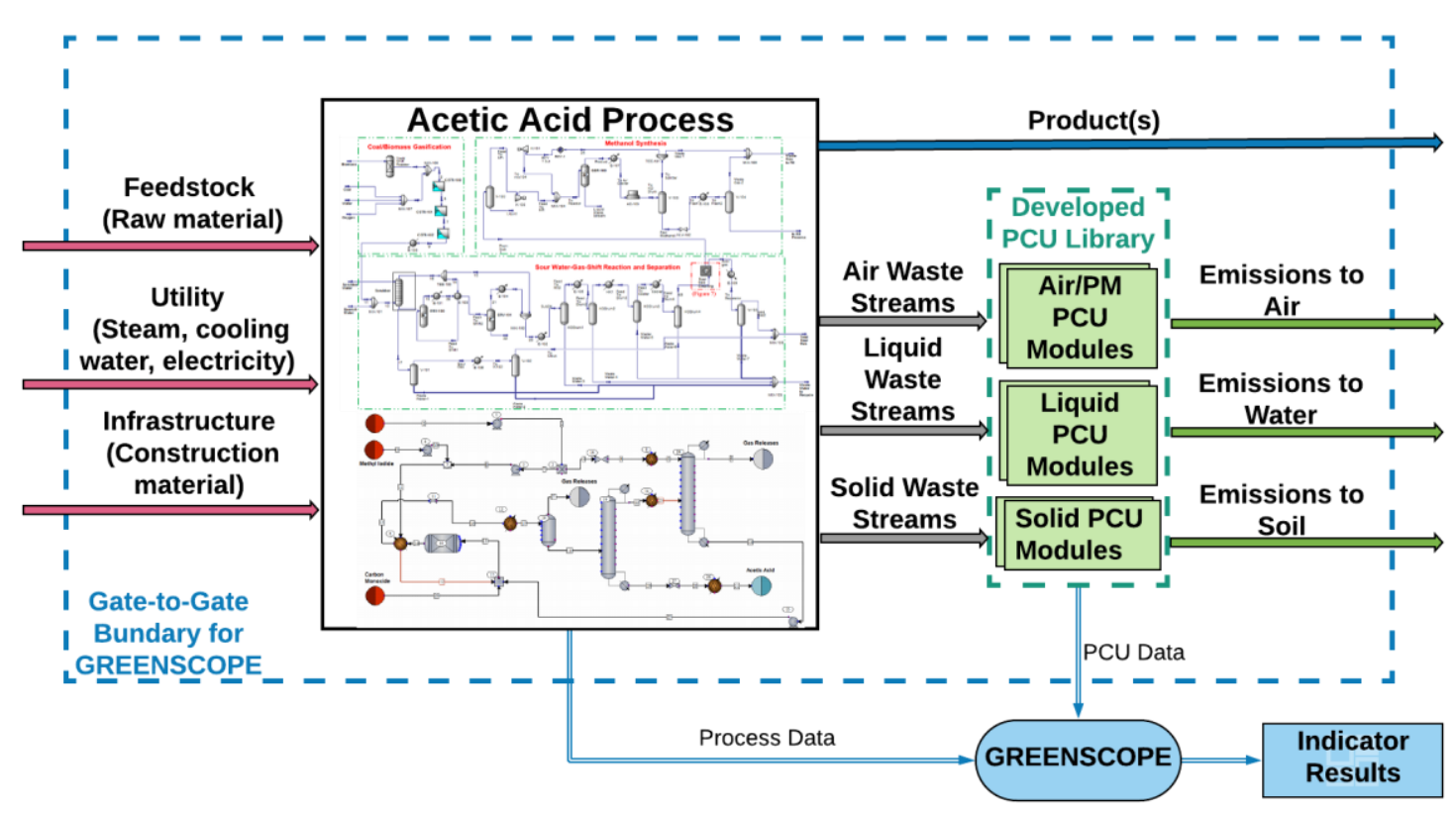

Figure 4.7 Integrating process simulation with PCUs for sustainability assessment

\subsubsection{Chemical Process Inputs \& Emissions}

Sustainability assessment needs a clearly defined boundary in which the system will be evaluated. In this work, the entire biomass/coal to chemical manufacturing process constitutes a gate-to-gate boundary for sustainability evaluation (as shown in Figure 4.7). The performed sustainability assessment using GREENSCOPE is then focused on a gate-to-gate analysis (e.g., from the raw materials to end product) where the engineers have the firsthand opportunity to examine the sustainability performance for different process operating conditions or design alternatives.

The required inputs for GREENSCOPE include material and energy flows (encompassing releases, ancillary inputs, and process energy), economic parameters and results (including production costs and revenues), and physicochemical, thermodynamics, and toxicological properties, as depicted in Figure 4.6. GREENSCOPE user guide ${ }^{96}$ provides a complete description of the required data and parameters. The process data for the AA production from biomass/coal is based upon the rigorous steady-state Aspen Hysys simulation 
results. The input streams include the feedstock, catalysts, chemicals (solvent), makeup water, etc. The output streams consist of the product, air, wastewater, and solid emissions. The intermediate mass flows between the unit operations within the process are not required as the performed sustainability assessment is for the process level and not the unit operation level.

In addition to mass input-output flows, substance property data that include physicochemical (i.e., density, heat capacity, enthalpy of combustion, etc.), thermodynamic, and toxicological properties (e.g., acute toxicity, chronic toxicity, carcinogenicity, reproductive toxicity, etc.) are also required for the calculation of the environmental-based indicators. Physicochemical and toxicological properties or parameter values can generally be found using various sources depending on conditions or assumptions. The substance potency factor (e.g., PFCO2, PFH2S) contributions that are employed to evaluate atmospheric and aquatic effect indicators (e.g., atmospheric acidification potential, ozone-depletion potential, photochemical oxidation potential) are based on GREENSCOPE default values which in turn were collected from the literature. The substance data requirements and potential data sources are also detailed in the GREENSCOPE user guide ${ }^{96}$.

The key inputs for calculating economic-based indicators are derived from the Aspen Economic Analyzer, including equipment sizing and cost as well as operating costs. Specifically, the Aspen Hysys process model solution provides mass and energy balances for each unit operation, from which the capital and operating costs can be estimated based on economic assumptions.

For the AA process, appropriate PCUs have been implemented to treat the waste air, liquid and solid streams before releasing to the environment. For the air waste streams, please refer to the treatment details in Chapter 3. For the liquid waste 
streams, the GAC unit is used to remove the heavy metals before releasing to the municipal water treatment plant. Landfill was selected to deposit the ash from gasifier. Refer to Tables A1-A3 for the detailed information on the waste stream treatment results.

\subsubsection{GREENSCOPE Results for Different Categories}

\section{Environmental}

Figure 4.8 shows the environmental indicators with/without PCUs. As expected, the implemented PCUs can effectively improve most of the environmental indicator performances (see results for controlled emissions). In particular, CEI (Chemical Exposure Index), EQ (Environmental Quotient), and GWI (Global Warming Intensity) increased by $35.65 \%, 41.56 \%, 34.93 \%$, respectively (when compared controlled to uncontrolled results). Such improvements are mainly due to the removal of the harmful chemicals in air and liquid waste streams.

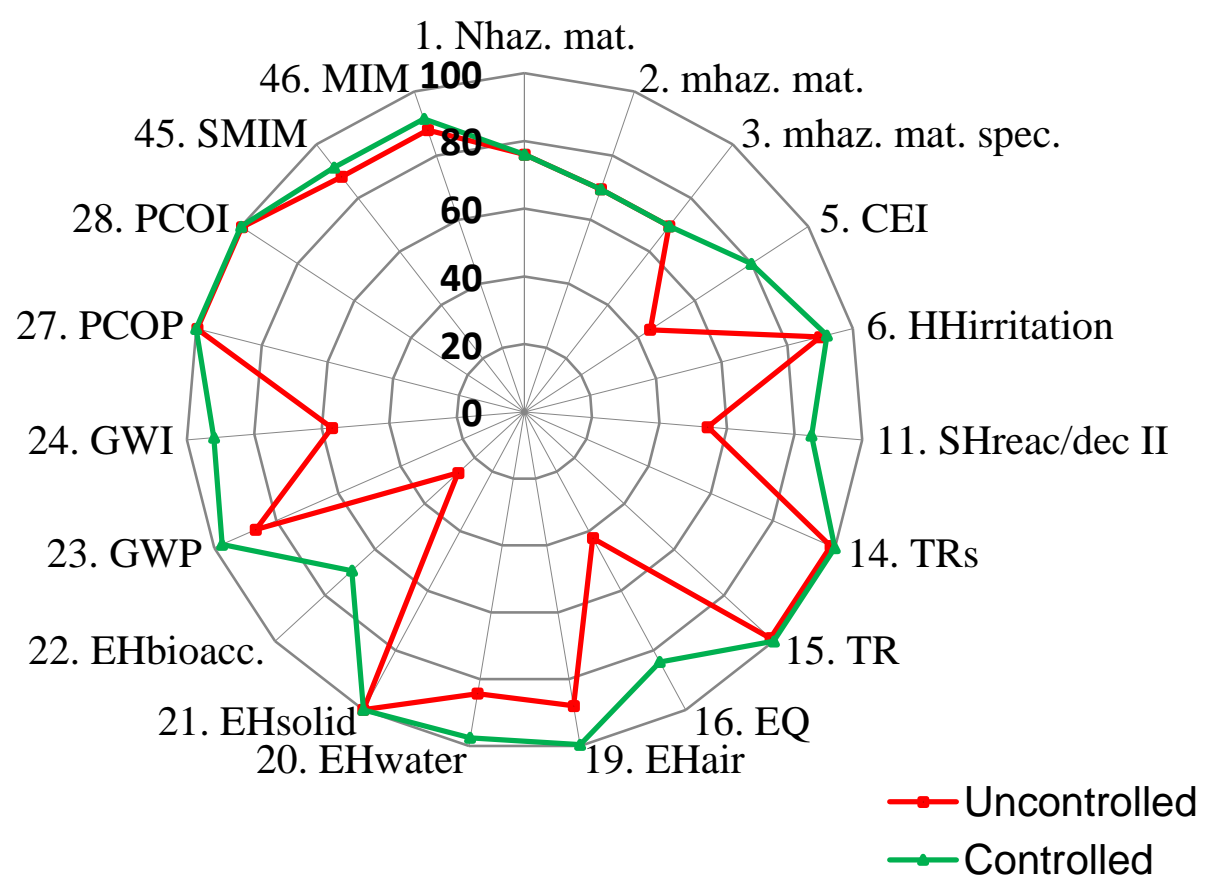

Figure 4.8 Environmental indicators with/without pollution control units 


\section{Efficiency}

As shown in Figure 4.9, the radar plots show that some efficiency indicator scores decrease when pollution treatment units are added to the process, especially total material consumption (mmat.,tot.), and Mass Intensity (MI), which dropped by $18.94 \%, 19.98 \%$, respectively. This can be explained by the fact that extra materials have to be used for designing the flare, scrubber and waste water treatment units.

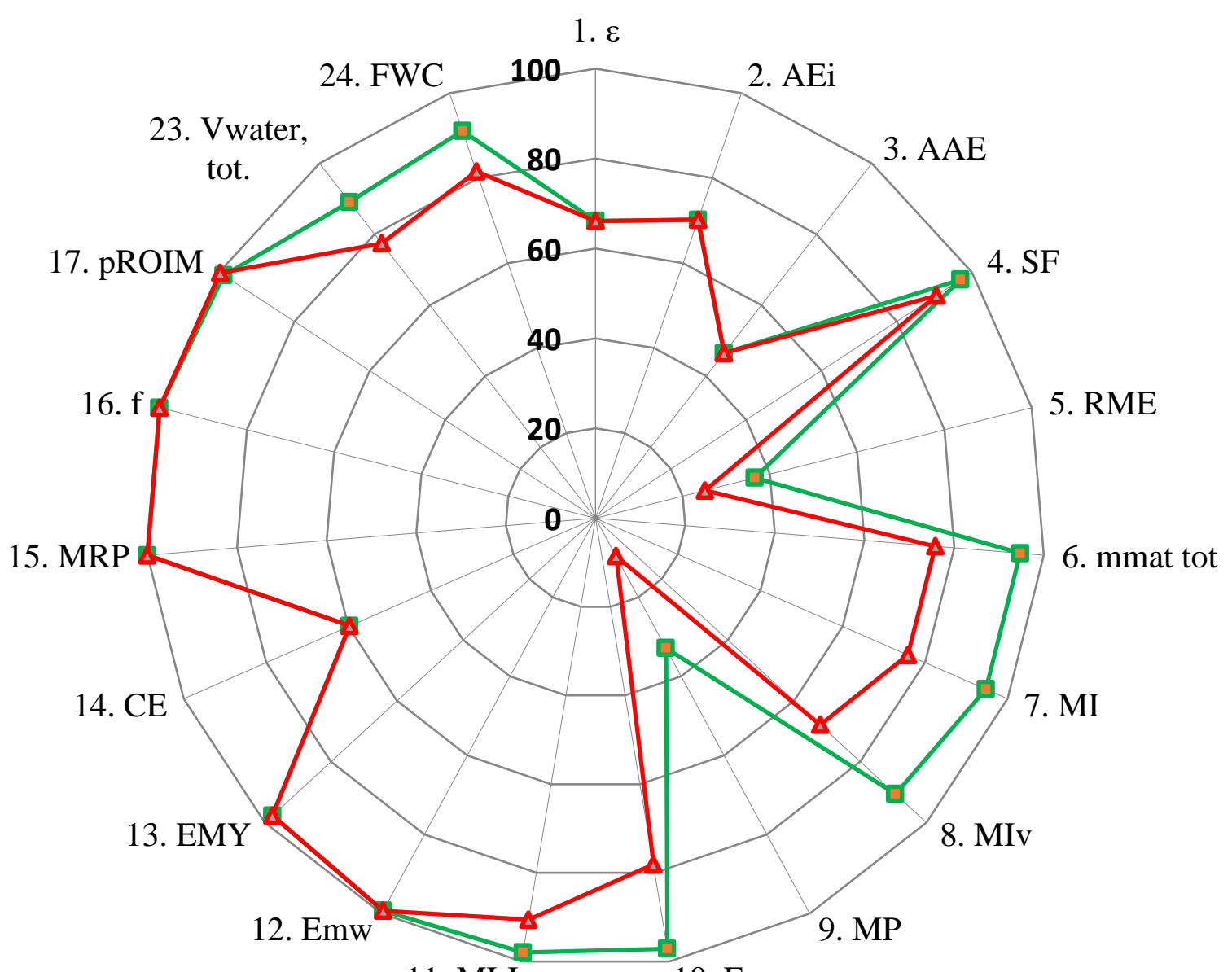

11. MLI

10. $\mathrm{E}$

$\rightarrow-$ Uncontrolled

$\rightarrow$ Controlled

Figure 4.9 Efficiency indicators with/without pollution control units 


\section{Economic}

Figure 4.10 shows that the NPV (Net Present Value), EP (Economic Potential), CTM (Capital Cost) and CSRM (Specific Raw Material Cost) indicators dropped by $2.70 \%, 1.20 \%, 10.13 \%, 2.34 \%$, respectively, due to the capital investment and raw material used for designing and implementing the PCUs.

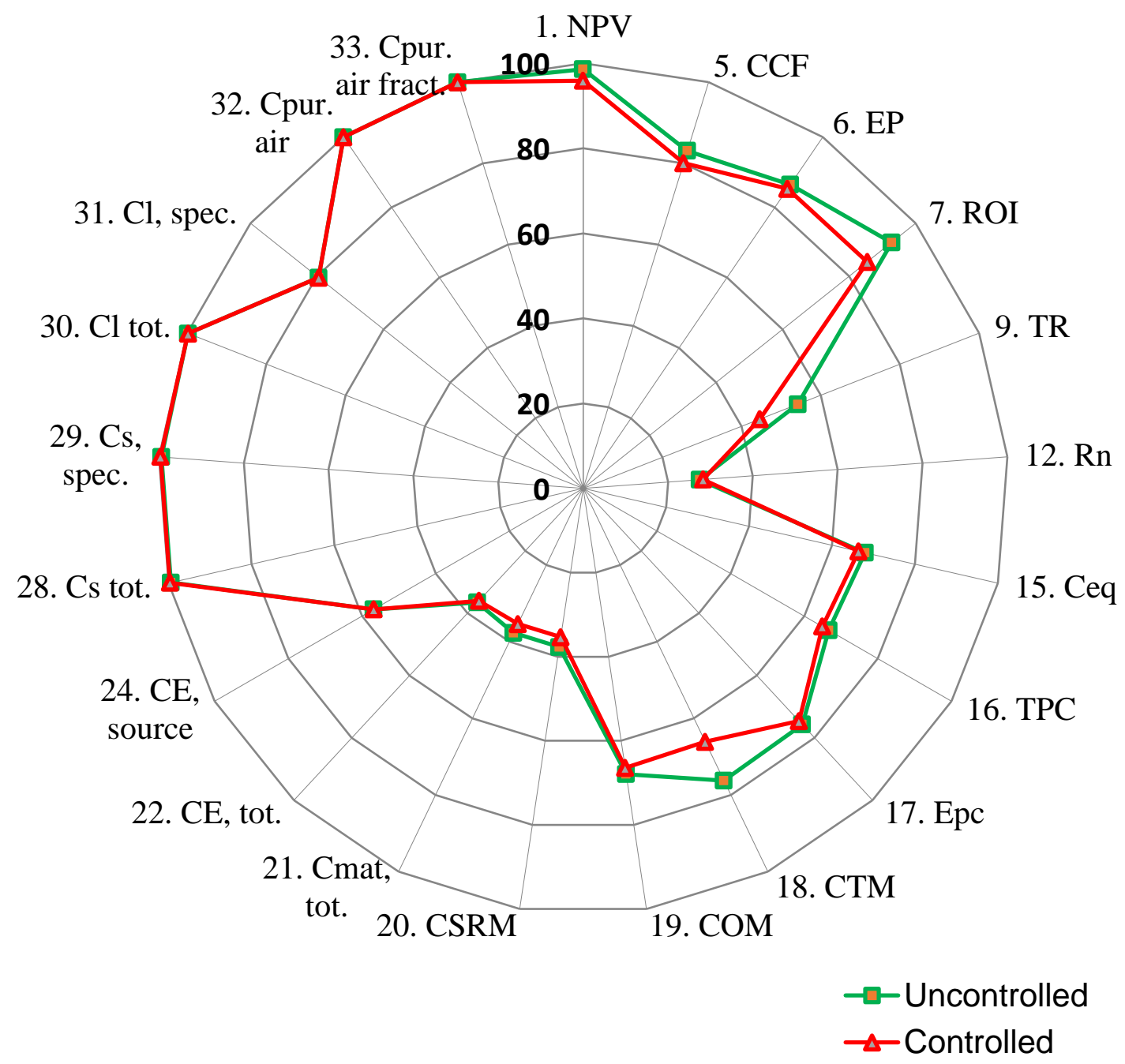

Figure 4.10 Economic indicators with/without pollution control units 


\section{Energy}

As shown in Figure 4.11, the RSEI (Specific Energy Intensity) and WTE (Waste Treatment Energy) indicators dropped by $3.32 \%, 1.69 \%$, respectively, while other energy indicators remained the same after implementing the PCUs. The small drop in energy indicator values can be attributed to the fact that part of the waste gas from the methanol synthesis has been used as fuel in the boiler as well as landfill for solid waste and the GAC unit were not energy-intensive steps.

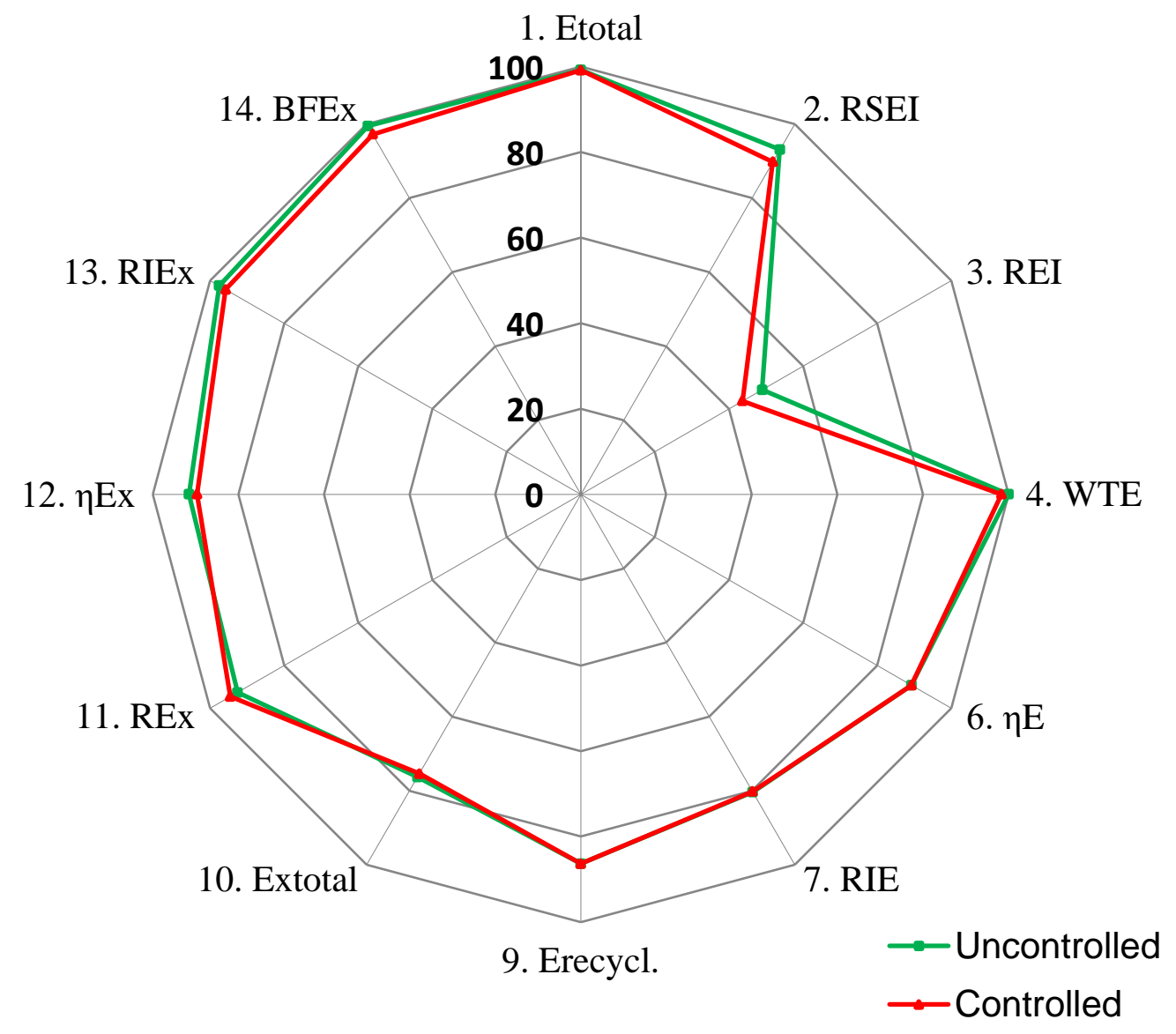

Figure 4.11 Energy indicators with/without pollution control units 


\subsection{Conclusions}

The proposed framework in this chapter can bridge existing gaps between sustainability assessment, LCI generation, pollution control and process modeling (using commercial simulators). Moreover, the developed PCU modules can improve process data collection and have potential for automation with commercial software to reduce the effort for collecting and processing data. The effectiveness of the proposed framework was illustrated through the acetic acid manufacturing process example for which sustainability trade-offs were quantified using GREENSCOPE. Such framework is general and can be applied to any chemical processes. 


\section{Chapter 5 Process Control for Sustainability: Motivating Example}

\subsection{Introduction}

As a step forward to address the gap in research on process control for sustainability, a novel framework is proposed in this chapter for process systems that integrates an advanced process control strategy with sustainability assessment tools. The developed framework is employed to identify and assess the optimal process operation in terms of sustainability performance. Specifically, a set of steady-state alternatives for the chemical process is generated through the implementation of an advanced biomimetic control strategy, and the obtained process operating points are evaluated employing selected indicators from the GREENSCOPE assessment tool ${ }^{96}$ in efficiency, environmental, energy and economic aspects. Such a comprehensive assessment of sustainability performance provides information on quantifying the benefits that the implementation of the biomimetic controller brings towards achieving a more sustainable process operation. The developed framework is applied to a fermentation process for bioethanol production. The outline of the rest of this chapter is as follows: the sustainability assessment tools and indicators are presented in the next subsection, followed by the advanced controller development and algorithm. These tools provide a general framework for optimizing and controlling chemical processes in terms of sustainability. Then, the proposed approach is implemented for the case study of a fermentation process.

\subsection{Approach}

\subsubsection{Selected GREENSCOPE Indicators}

As stated by the green chemistry and engineering principles ${ }^{2,97}$, chemical processes and products that reduce or eliminate the use and generation of 
hazardous substances should be developed by preventing waste, performing real time analysis and control for pollution and accident prevention, maximizing mass, energy, space and time efficiency, etc ${ }^{46}$. In addition, when a more sustainable performance is achieved, this must be ensured under any type of beyond the gate (front-edge changes) and/or process stage perturbations.

As mentioned above, society, government, and industry have created initiatives regarding the implementation in practice of sustainable development. However, it is often unclear the effects (positive or negative) of these new practices have on the environment. In order to offer a more comprehensive and quantitative description of environmental, social, and economic effects, the U.S. E.P.A. GREENSCOPE tool introduced above aims for supporting decision makers when developing, designing, and evaluating sustainable processes and products. The tool can show which indicators have improved and where additional opportunities for improvement exist. The indicator scores describe product and process performance on a sustainability measurement scale, determining whether chemical products and processes are more or less sustainable. GREENSCOPE is implemented here along with process control for the first time.

\subsubsection{Novel Advanced Control Approach}

Many biological systems have been a source of inspiration for advanced control methods because of the success of these systems in solving difficult problems encountered in nature. In this subsection, an advanced biomimetic control approach to address the challenges involved in chemical processes is briefly described. This approach is the combination of a biologically-inspired multi-agent-based algorithm with optimal control concepts for the calculation of optimal trajectories of individual agents. The multi-agent-based algorithm is essentially inspired by the ants' rule of 
pursuit idea ${ }^{98}$ which is shown schematically in Figure 5.1. As per this ants' rule, the first ant is supposed to find food by walking around at random. This pioneer ant would then trace a wiggly path back to the nest and start "group recruitment." The subsequent ants (or agents) would follow one after the other straighten the trail a little starting from the original path until the agents' paths converge to a line connecting the nest and the food source, despite the individual ant's lack of sense of geometry. Thus, by cooperating in large numbers, ants (or agents) accomplish tasks that would be difficult to achieve individually. This is an excellent example of how biological systems can efficiently solve problems encountered in nature by cooperative behavior.

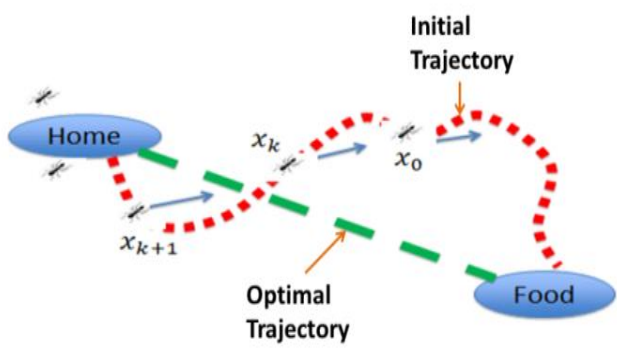

Figure 5.1 Schematic representation of ant's rule of pursuit

This idea serves as inspiration for the development of a novel optimal control approach for chemical systems to reach the optimal operating point in terms of sustainability. To translate this idea into an optimal control algorithm, first a chemical system with a dynamic model represented by ordinary differential equations and differential-algebraic equations is defined. This dynamic model corresponds to the relationship between the state and control/input variables. The agent's "home" is the initial conditions for each variable while the "food" stands for the desired operating point of the system. The solution of the optimal control problem for each agent gives the trajectories of these variables to connect home to food through an optimal control action. Next, it is assumed that there is an available initially feasible trajectory pair 
for the state and control variables, which is obtained through prior knowledge of the system. This trajectory corresponds to agent $0(\mathrm{a} 0)$ or leader's trajectory for the initialization of the algorithm. In addition, two important parameters that define the leader-follower local interactions need to be specified, the pursuit time, $\Delta$, and the sampling time, $\delta$.

The initial conditions for each state variable of the follower are the follower's trajectory points based on the discretization by the sampling time, $\delta$. The final destination for the follower agent is obtained from the leader's trajectory discretization based on the sampling time, $\delta$, as well as the pursuit time, $\Delta$, outlined in the algorithm in Figure 5.2. The initial conditions and the final destinations are provided to the optimal control solver, in this case dynopt, for the computation of the optimal trajectories. Specifically, dynopt is a set of MATLAB functions that use the orthogonal collocation on finite elements method for the determination of optimal control trajectories. The inputs of this toolbox are the dynamic process model, the objective function to be minimized, and the set of equality and inequality constraints. The outputs from this toolbox are the optimal control laws and state trajectories. For the first step calculation, the optimal control trajectories of each follower are computed numerically using $d y n o p t$ by aiming at the leader's position at $\Delta$ time units as the current target. The obtained control law is then applied for $\delta$ time units, before repeating the procedure outlined in Figure 5.2. The developed algorithm employs dynopt to solve all the intermediate problems associated with the local interaction of the agents to generate the state and the optimal control trajectories ${ }^{99}$. 


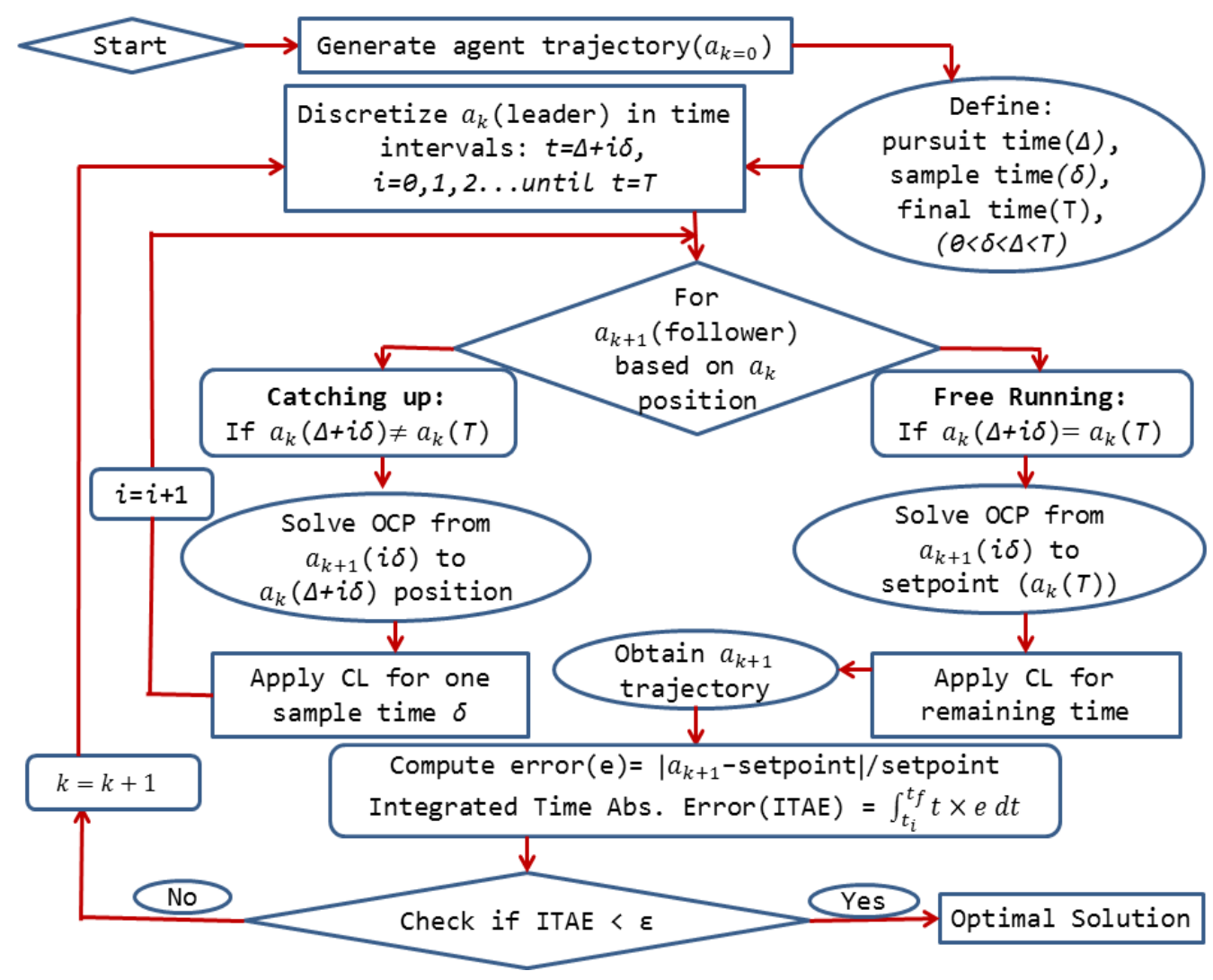

Figure 5.2 General structure of the algorithm for the advanced control approach

\subsection{Case Study: Fermentation Process Model}

Ethanol derived from renewable sources such as corn, sugar cane, and beets is a potential sustainable fuel to control and decrease air pollution from internal combustion engines and reduce the dependence on fossil fuels. Herein, a process model is considered for a homogeneous, perfectly-mixed continuous culture fermentor for ethanol production equipped with an ethanol-selective removal membrane and a cooling jacket for temperature control. A schematic diagram of the fermentation reactor is shown in Figure 5.3. The reactor is modeled as a continuous stirred tank (CSTR) with constant substrate feed flow. The outlet flow from the reactor contains the product, the unreacted substrate, as well as biomass. Biomass plays the role of catalyst for substrate conversion and is the product of fermentation, while substrate is a solution of glucose for feeding the micro-organism (in this case, Zymomonas mobilis). Moreover, ethanol is the desired product of the process and 
an inhibitor for the enzymatic reactions. To prevent end-product inhibition and improve the productivity and efficiency of the fermentation process, an in-situ ethanol-removal membrane is used so the ethanol is removed as it is being produced.

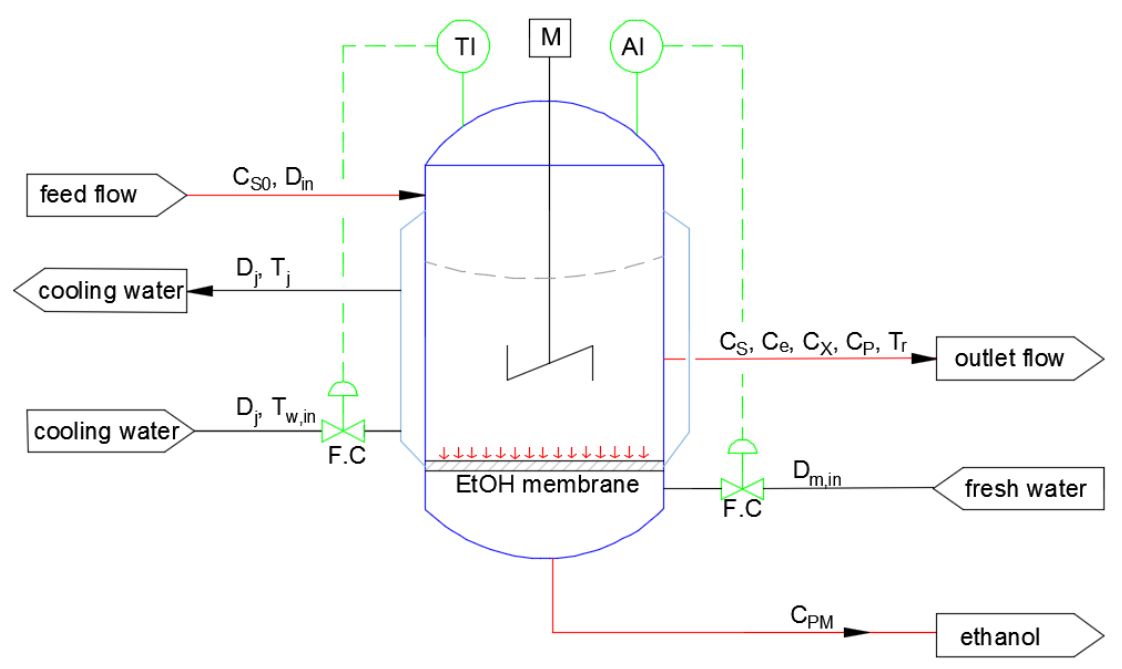

Figure 5.3 Schematic diagram of the fermentation reactor

The ethanol fermentation process involves living microorganisms and has two main reactions: 1) microbial growth reaction, in which certain amount of substrate is consumed for the growth of biomass under favorable environmental conditions (temperature, $\mathrm{pH}$, etc.) and 2) metabolite reaction, in which substrate (referred to as reactant) is converted into product through the catalytic action of enzymes ${ }^{100-103}$. For process design and control purposes, several models for fermentation processes are available in the literature based on kinetic expressions of different complexity ${ }^{104,105}$. For example, cellular components, enzymes, and proteins can be used to express the process kinetics. However, typical models consider only the kinetic expressions of fermentation for constant temperature conditions. The proposed mathematical model here takes into consideration the temperature effect on kinetics parameters, mass and heat transfer, in addition to the kinetic equations modified from the indirect inhibition structural model developed in the literature ${ }^{100-103}$. 
In this structural model, it is assumed the inhibition effect of ethanol is on the formation of a key component (that includes RNA and proteins in biomass), instead of directly on fermentation. To accurately describe the formation rate of the key component at low ethanol concentrations and under substrate-limited conditions, the formation rate expression for the key component is a function of substrate concentration, given by:

$$
r_{e}=f\left(C_{P}\right) f\left(C_{S}\right) C_{e}
$$

A Monod-type equation is taken for $f\left(C_{S}\right)$ :

$$
f\left(C_{S}\right)=\frac{C_{S}}{K_{S}+C_{S}}
$$

The function $f\left(C_{P}\right)$ is empirically described by a second-order polynomial of the following form:

$$
f\left(C_{P}\right)=k_{1}-k_{2} C_{P}+k_{3} C_{P}^{2}
$$

The expressions for biomass growth rate and substrate consumption rate can be taken from the classic maintenance model ${ }^{106}$, where the biomass growth rate is defined as:

$$
r_{X}=\mu C_{X}
$$

in which $\mu$, as the specific growth rate, can be expressed as follows:

$$
\mu=\mu_{\max } \cdot \frac{C_{S}}{\left(K_{S}+C_{S}\right)}
$$

In addition, the substrate consumption rate can be written as:

$$
-r_{S}=\left(\frac{1}{Y_{s x}}\right) r_{X}+m_{S} C_{X}
$$

in which the first term accounts for the growth of biomass while the second term for the maintenance of biomass.

The expression for the maximum specific growth rate, $\mu_{\max }$, involves the ratio of the key component to biomass, and the temperature effect:

$$
\mu_{\text {max }}=P \cdot \frac{C_{e}}{C_{X}} \cdot f(T)
$$

in which $P$ is a correction factor and $f(T)$ can be obtained by fitting a set of experimental data from the literature ${ }^{107}$ to the following equation: 


$$
f(T)=A_{1} \cdot e^{-\frac{E_{a 1}}{R T}}-A_{2} \cdot e^{-\frac{E_{a 2}}{R T}}
$$

The dynamic mass balances for the key component, biomass, and substrate are expressed by:

$$
\begin{aligned}
\frac{d C_{e}}{d t}= & \left(k_{1}-k_{2} C_{P}+k_{3} C_{p}^{2}\right) \frac{C_{S} C_{e}}{\left(K_{S}+C_{S}\right)}+D_{\text {in }} C_{e, 0}-D_{\text {out }} C_{e} \\
& \frac{d C_{X}}{d t}=P \cdot f(T) \cdot \frac{C_{S} C_{e}}{K_{S}+C_{S}}+D_{\text {in }} C_{X, 0}-D_{\text {out }} C_{X} \\
\frac{d C_{S}}{d t}= & \left(\frac{-P}{Y_{s x}}\right) \cdot f(T) \cdot \frac{C_{S} C_{e}}{\left(K_{S}+C_{S}\right)}-m_{S} C_{X}+D_{\text {in }} C_{S, 0}-D_{\text {out }} C_{S}
\end{aligned}
$$

As the product flows out of the system through the fermentor and the membrane, mass balances are derived for the product in both compartments and are given by:

$$
\begin{gathered}
\frac{d C_{P}}{d t}=\left(\frac{P}{Y_{p x}}\right) \cdot f(T) \cdot \frac{C_{S} C_{e}}{\left(K_{S}+C_{S}\right)}+m_{p} C_{X}+D_{\text {in }} C_{P, 0}-D_{\text {out }} C_{P}-\left(\frac{\alpha}{V_{F}}\right)\left(C_{P}\right. \\
\left.-C_{P M}\right) \\
\frac{d C_{P M}}{d t}=\left(\frac{\alpha}{V_{M}}\right)\left(C_{P}-C_{P M}\right)+D_{m, \text { in }} C_{P M, 0}-D_{m, \text { out }} C_{P M}
\end{gathered}
$$

in which

$$
\alpha=A_{M} \cdot P_{M}
$$

Using the overall mass balances for the fermentor and membrane, the outlet dilution rate for both compartments are respectively defined as:

$$
\begin{aligned}
D_{\text {out }} & =D_{\text {in }}-\frac{\alpha \cdot\left(C_{P}-C_{P M}\right)}{V_{F} \cdot \rho_{r}} \\
D_{m, \text { out }} & =D_{m, \text { in }}+\frac{\alpha \cdot\left(C_{P}-C_{P M}\right)}{V_{M} \cdot \rho_{r}}
\end{aligned}
$$

Moreover, the energy balances for the reactor and the cooling jacket are the following:

$$
\begin{gathered}
\frac{d T_{r}}{d t}=D_{i n}\left(T_{i n}-T_{r}\right)+\frac{r_{S} \cdot \Delta H}{\rho_{r} \cdot C_{p, r}}-\frac{K_{T} A_{T} \cdot\left(T_{r}-T_{j}\right)}{V_{F} \rho_{r} \cdot C_{p, r}} \\
\frac{d T_{j}}{d t}=D_{j}\left(T_{w, i n}-T_{j}\right)+\frac{K_{T} A_{T} \cdot\left(T_{r}-T_{j}\right)}{V_{j} \rho_{w} \cdot C_{p, w}}
\end{gathered}
$$

Thus, the derived mathematical model for the fermentation process is represented by a set of seven ordinary differential equations for key component, biomass, substrate, product, and temperature and two algebraic equations of outlet 
dilution rates. Table 5.1 provides the parameter values of the model and the initial operating conditions used in this Zymomonas mobilis fermentation problem (see all variables' definitions and units in the Nomenclature section).

Table 5.1 Parameter values for the fermentation process model

\begin{tabular}{ll}
\hline$A_{1}=0.6225$ & $K_{S}=0.5 \mathrm{~kg} / \mathrm{m}^{3}$ \\
$A_{2}=0.000646$ & $K_{T}=360 \mathrm{~kJ} /\left(\mathrm{m}^{2} \cdot \mathrm{K} \cdot \mathrm{h}\right)$ \\
$A_{T}=0.06 \mathrm{~m}^{2}$ & $m_{s}=2.16 \mathrm{~kg} /(\mathrm{kg} \cdot \mathrm{h})$ \\
$A_{M}=0.24 \mathrm{~m}^{2}$ & $m_{P}=1.1 \mathrm{~kg} /(\mathrm{kg} \cdot \mathrm{h})$ \\
$C_{e, 0}=0 \mathrm{~kg} / \mathrm{m}^{3}$ & $P=4.54$ \\
$C_{x, 0}=0 \mathrm{~kg} / \mathrm{m}^{3}$ & $P_{M}=0.1283 \mathrm{~m} / \mathrm{h}$ \\
$C_{S, 0}=150.3 \mathrm{~kg} / \mathrm{m}^{3}$ & $V_{F}=0.003 \mathrm{~m}^{3}$ \\
$C_{P, 0}=0 \mathrm{~kg} / \mathrm{m}^{3}$ & $V_{M}=0.0003 \mathrm{~m}^{3}$ \\
$C_{P M, 0}=0 \mathrm{~kg} / \mathrm{m}^{3}$ & $V_{j}=0.00006 \mathrm{~m}^{3}$ \\
$C_{p, r}=4.18 \mathrm{~kJ} /(\mathrm{kg} \cdot \mathrm{K})$ & $Y_{s x}=0.0244498 \mathrm{~kg} / \mathrm{kg}$ \\
$C_{p, w}=4.18 \mathrm{~kJ} /(\mathrm{kg} \cdot \mathrm{K})$ & $Y_{P x}=0.0526315 \mathrm{~kg} / \mathrm{kg}$ \\
$E_{a 1}=55 \mathrm{~kJ} / \mathrm{mol}$ & $T_{i n}=30{ }^{\circ} \mathrm{C}$ \\
$E_{a 2}=220 \mathrm{~kJ} / \mathrm{mol}$ & $T_{w, i n}=25{ }^{\circ} \mathrm{C}$ \\
$k_{1}=16.0 \mathrm{~h}^{-1}$ & $\Delta H=220 \mathrm{~kJ} / \mathrm{mol}^{3}$ \\
$k_{2}=0.497 \mathrm{~m}^{3} /(\mathrm{kg} \cdot \mathrm{h})$ & $\rho_{r}=1080 \mathrm{~kg} / \mathrm{m}^{3}$ \\
$k_{3}=0.00383 \mathrm{~m} /\left(\mathrm{kg}^{2} \cdot \mathrm{h}\right)$ & $\rho_{w}=1000 \mathrm{~kg} / \mathrm{m}^{3}$ \\
\hline
\end{tabular}

\subsubsection{Open-Loop Simulation}

For the Zymomonas mobilis fermentation process addressed here, sustained oscillations of biomass, substrate, and product profiles have been widely reported $^{108,109}$. An effective controller is therefore required to eliminate oscillations and take the process to an optimal operating steady state. However, the design and implementation of a high-performance control algorithm for this fermentation process in terms of productivity and sustainability is a challenging task, mainly due to its highly nonlinear dynamics. To address these challenges, this subsection introduces a new sustainable process control framework that combines the biomimetic control strategy detailed above with the GREENSCOPE sustainability assessment tool. In the performed case studies, the purpose of the implemented biomimetic controller is to keep key state variables at their set points through the optimization of the control 
actions. Thus, in this case, the objective function is formulated to minimize the differences between product concentration and temperature (as key state variables) and their set points. The sustainability performance of the process after the controller implementation can then be evaluated through selected GREENSCOPE indicators shown in the Appendix (see Table A4 for indicator details). Specifically, the obtained GREENSCOPE indicator scores provide information on whether the implementation of the biomimetic controller for the fermentation process enables a more sustainable process operation when compared to a base case.

Before the implementation of the sustainable process control framework, it is worth analyzing the dynamics of the fermentation process. In agreement with the literature, the results of open-loop simulations in Figure 5.4 show that oscillations are more prone to occur at high ethanol concentrations due to the end-product inhibition effect. Ethanol has great impact on the cell membrane composition and inhibits enzymatic reactions. Temperature, as another important operating variable, not only affects the activity of biomass, but indicates the energy consumed by the process affecting its economic performance. Thus, an attractive control strategy consists of regulating the concentration of product and the reactor temperature at optimal operating points in terms of process sustainability and productivity. The present study is an extension of previous work ${ }^{110}$ regarding the fermentation process that had a strategy of controlling product concentration through manipulating $D_{i n}$. In this chapter, the membrane dilution rate, $D_{m, i n}$, as well as cooling water flow rate, $D_{j}$, are chosen as the manipulated variables for the regulation of ethanol concentration, $C_{P}$, and fermentor temperature, $T_{r}$, respectively. It is shown below that using $D_{m, i n}$ as manipulated variable is an efficient way to stabilize the system and improve the productivity of the reactor. 
To analyze the effect of $D_{m, i n}$ on the fermentation process, a set of open-loop simulations was completed in which $D_{m, i n}$ varied from 0 to $0.45 \mathrm{hr}^{-1}$ and $D_{j}$ was set to zero. For these simulations, the system was integrated using ode $15 \mathrm{~s}$ solver in MATLAB for the given differential and algebraic equations that were solved simultaneously. Figure 5.4 shows the concentration profiles of the key component, biomass, substrate, product in the fermentor and membrane sides, as well as temperature profiles in the fermentor for the open-loop simulations with different membrane dilution rates. As expected, a higher $D_{m, i n}$ can efficiently reduce or even eliminate the oscillatory behavior of the concentrations and can enhance the substrate conversion rate. This can be explained by the reduction of the end-product inhibition when more ethanol is removed through the ethanol-selective membrane at the cost of using more fresh water. It is important to note that this fermentation process has multiple equilibrium states as a consequence of autocatalytic reactions. To obtain an optimal steady-state operating condition in terms of sustainability and examine the effectiveness of the proposed biomimetic controller, an open-loop case is chosen as the benchmark and then higher and lower setpoints are used for closedloop simulations. Through comparison of the GREENSCOPE indicators for the benchmark and closed-loop simulations, a systematic decision can be made in terms of moving the process operation in the right direction towards a more sustainable steady state. 


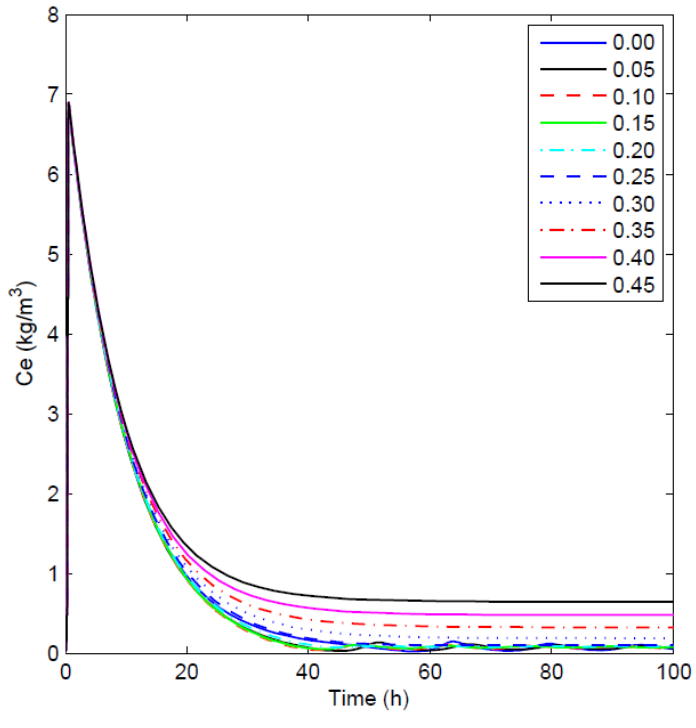

(a)

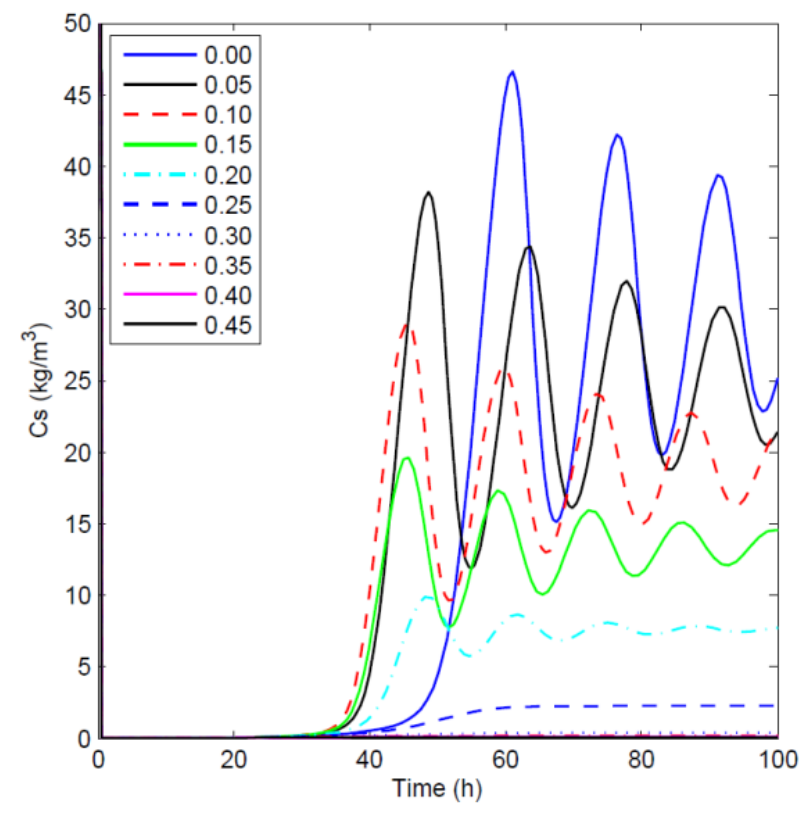

(c)

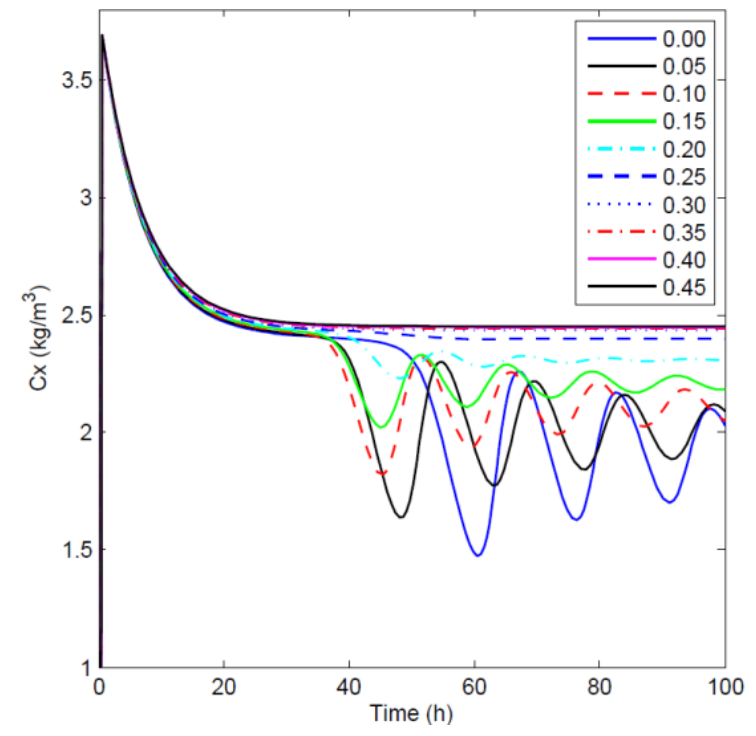

(b)

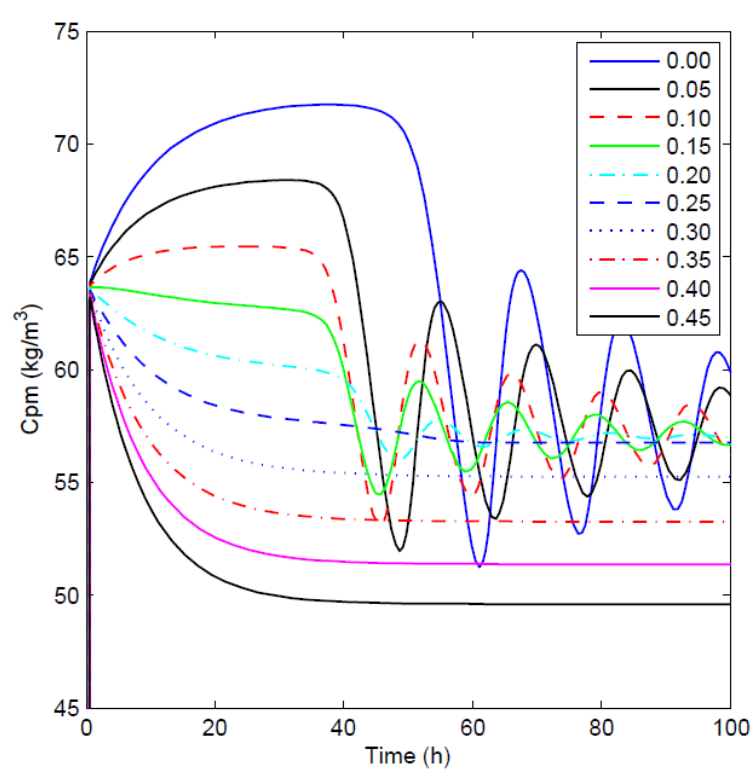

(d) 


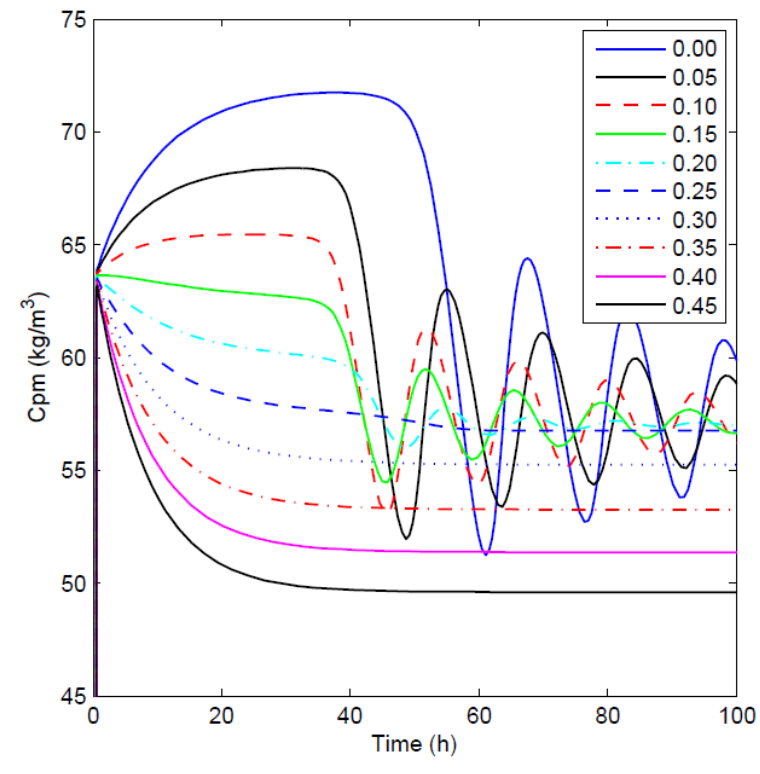

(e)

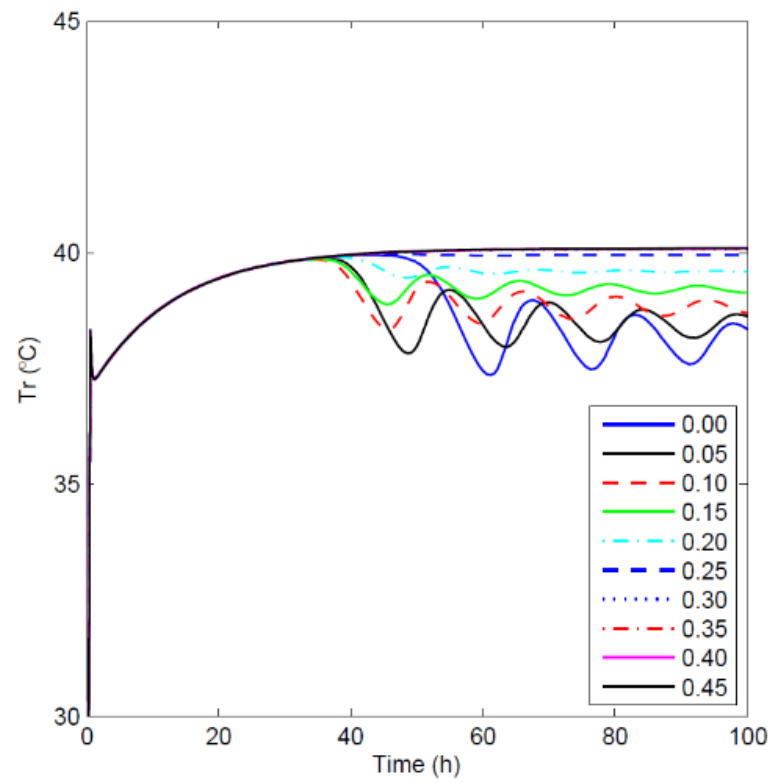

(f)

Figure 5.4 Open-loop simulations: concentration profiles of key component (a), biomass (b), substrate (c) and product in fermentor (d) and membrane side (e) and temperature profile (f) for different $\mathrm{D}_{\mathrm{m} \text {,in }}$ values

\subsubsection{Closed-loop Simulations}

Four case studies are presented here to evaluate the implementation of the biomimetic control framework for sustainability. The first two cases are designed to demonstrate the effectiveness of the implementation of the proposed controller by its ability to take the system to higher and lower setpoints when compared to the benchmark within the shortest response time possible. These cases use an initial $D_{\text {in }}$ value of $0.1 \mathrm{~h}^{-1}$. The new achieved steady states are evaluated and compared in terms of sustainability using selected GREENSCOPE indicators. Based on the results of the first two cases, Cases 3 and 4 are then performed to locate the optimal steady-state operation for a higher $D_{\text {in }}$ of $0.2 \mathrm{~h}^{-1}$, which corresponds to a higher volumetric productivity for the fermentor. For all simulations, the parameter values in Table 5.1 are kept constant. 
Case 1: In case 1, the open-loop simulation with $D_{m \text {,in }}$ of $0.20 \mathrm{~h}^{-1}$ is chosen as benchmark since it represents the highest achievable product concentration with reduced oscillations as it approaches the steady state. In particular, for this case, the dynamic behavior in Figure 5.4 shows oscillations of mid-range amplitudes within 80 hours before the system finally achieves its steady state at around 100 hours. It is important to note there is still some substrate left in the reactor at steady state as depicted in the substrate profile of Figure 5.4. This can be explained by the fact the environmental conditions in this case, such as temperature and ethanol concentration, are not favorable for a high substrate conversion rate. Thus, there should be some room for improvement of process performance by the implementation of an effective control strategy in terms of efficiency and productivity, if the system is optimized to convert all substrate into product. To attain this goal of increasing the process efficiency, a higher setpoint for the controlled variable, $C_{P}$, of $65 \mathrm{~kg} / \mathrm{m}^{3}$, when compared to the steady-state product concentration of the benchmark case, $57.16 \mathrm{~kg} / \mathrm{m}^{3}$, is used. In addition, an optimal temperature value, $30^{\circ} \mathrm{C}$, for $T_{r}$ is employed in the closed-loop simulation. Both open-loop and closedloop simulations start at the same initial points and the inlet dilution rate, $D_{\text {in }}$, is kept at $0.1 \mathrm{hr}^{-1}$. Figure 5.5 and Figure 5.6 depict the closed-loop simulation results for the concentrations of key component, biomass, substrate, product and temperature as well as the input profiles. Note that, with the implementation of the proposed biomimetic control strategy, the original oscillations are eliminated and merely a trace of substrate unreacted, $0.043 \mathrm{~kg} / \mathrm{m}^{3}$, is left in the reactor. However, in terms of sustainable performance, the radar plot of Figure 5.7 shows the controller implementation only slightly improves three GREENSCOPE indicators in three categories (Efficiency, Economic, and Environmental), Reaction Yield (RY), Water 
Intensity $(W I)$, and Economic Potential $(E P)$, towards a more sustainable process operation. Another key aspect is the steady-state biomass concentration value of $2.50 \mathrm{~kg} / \mathrm{m}^{3}$ in the closed-loop simulation, which is higher than the open-loop simulation, $2.31 \mathrm{~kg} / \mathrm{m}^{3}$. This higher value means that more substrate is consumed for biomass growth, rather than for producing ethanol in the new scenario. This fact explains why some of other indicators, such as Resources Energy Efficient $\left(\eta_{E}\right)$ and Specific Resources Material Costs $\left(C_{S R M}\right)$, do not show improvement even though the substrate conversion rate increased by $5.1 \%$.
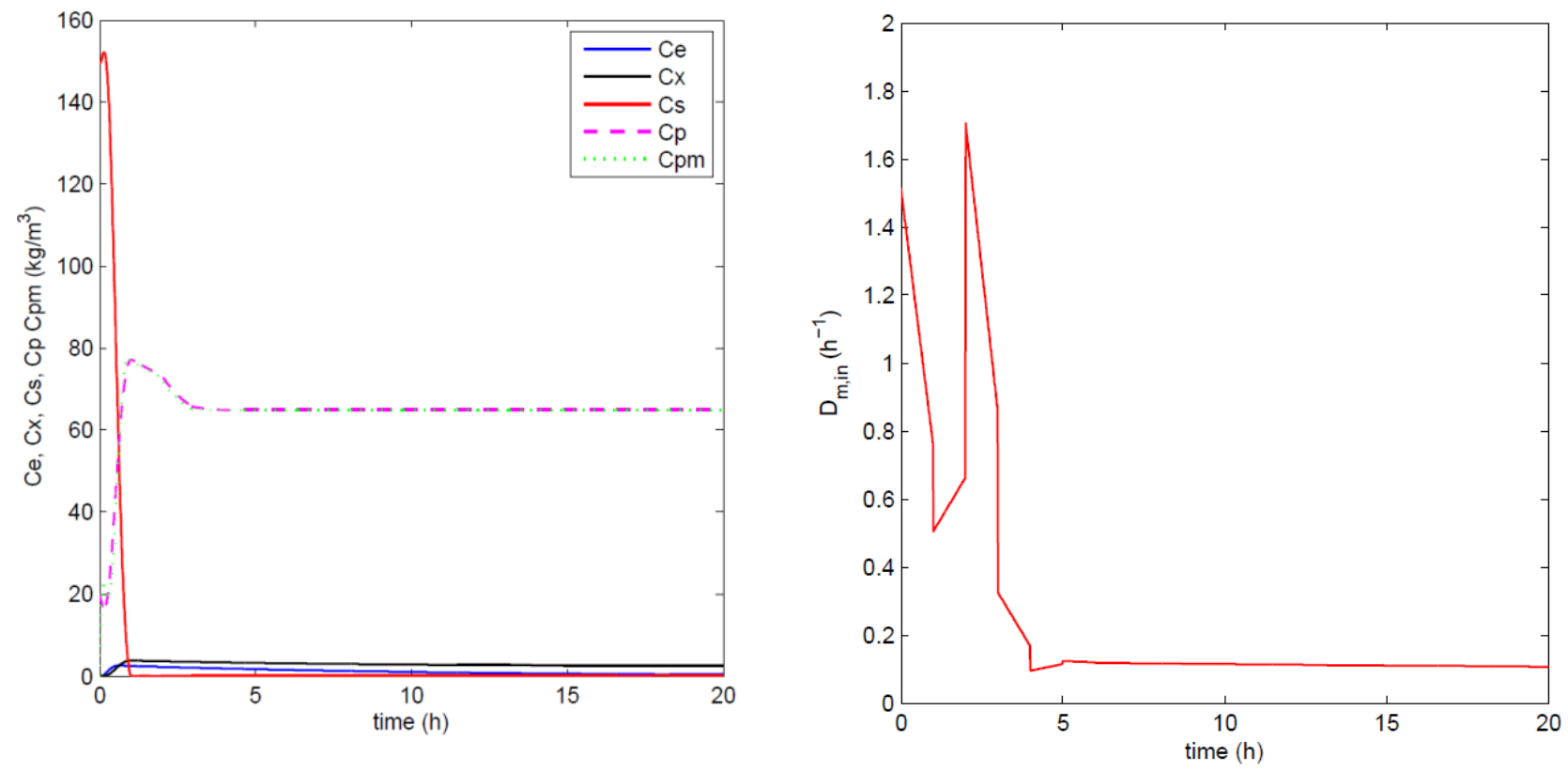

Figure 5.5 Closed-loop simulation (Case 1): concentration (key component, biomass, substrate, product in fermentor and membrane sides) and input profiles 

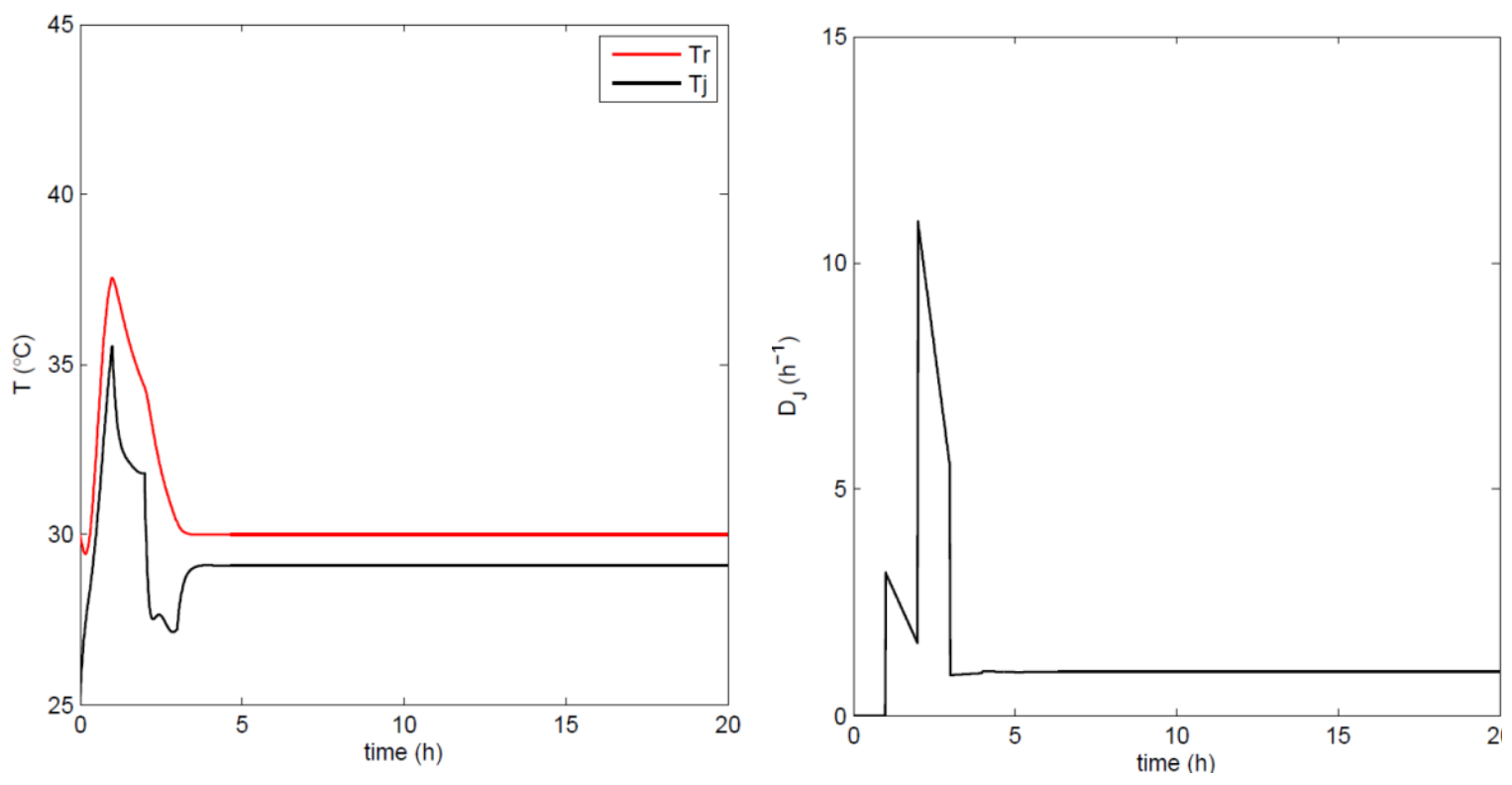

Figure 5.6 Closed-loop simulation (Case 1): temperature (fermentor and jacket) and input profiles

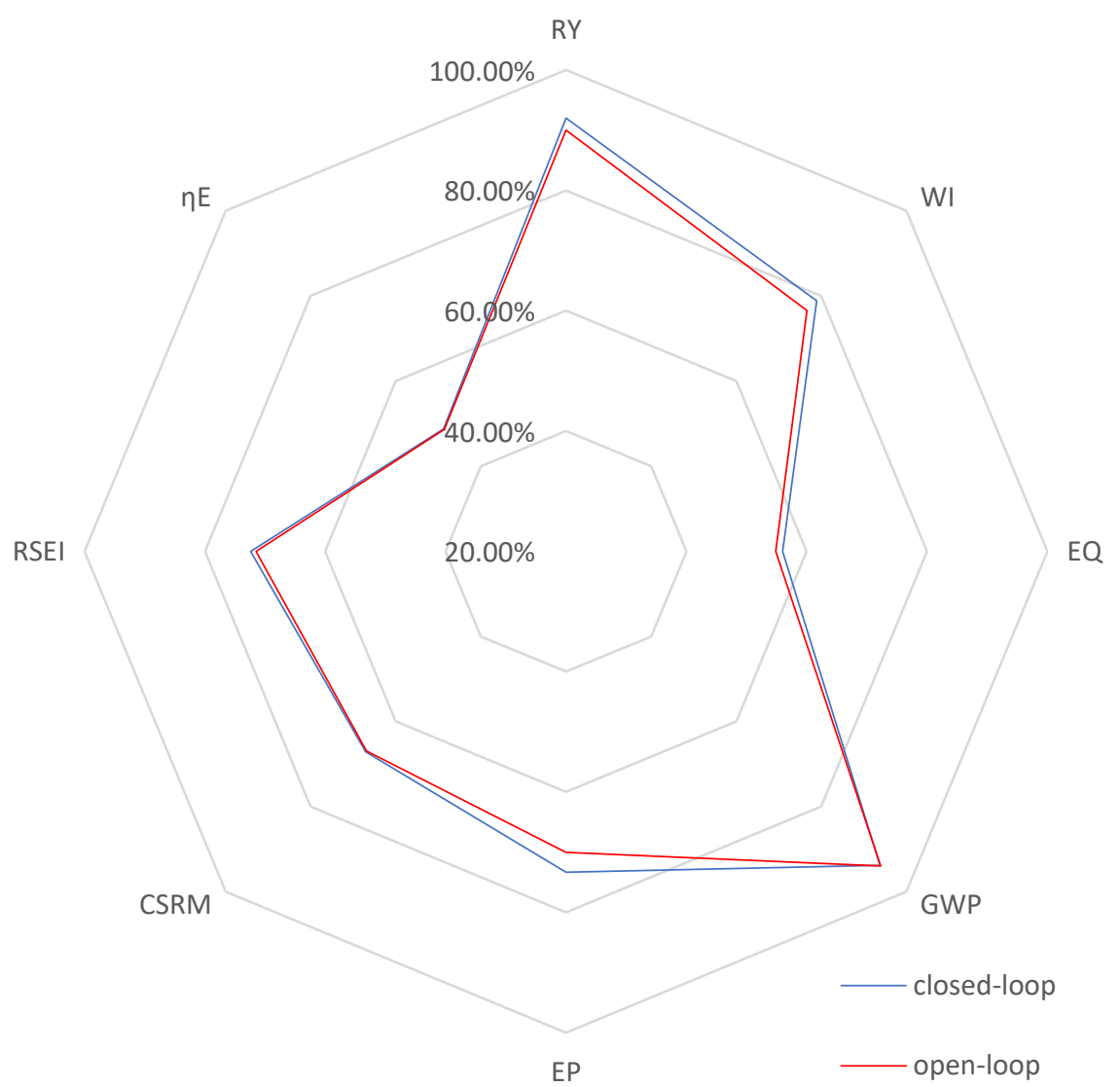

Figure 5.7 Radar plot with GREENSCOPE indicators for the closed-loop and open-loop simulations (Case 1)

Case 2: As discussed above, ethanol concentration and temperature have great effect on the living biomass and thus controlling the reaction environment at optimal 
conditions can enable higher fermentation process efficiency. Based on the fact that a lower product concentration may reduce the effect of product inhibition, a lower value of $C_{P}=45 \mathrm{~kg} / \mathrm{m}^{3}$ is defined as the setpoint for the closed-loop scenario and keep the setpoint of $T_{r}$ at $30{ }^{\circ} \mathrm{C}$ in Case 2. Figures 5.8 and 5.9 show concentration and temperature profiles as well as the input profiles for the closed-loop simulation. Comparing to the results in Figure 5.5, Figure 5.8 shows that the system reaches the steady state in this case in a shorter time, and with a lower substrate concentration of $0.03 \mathrm{~kg} / \mathrm{m}^{3}$. In addition, the steady state $D_{m, \text { in }}$ increases to $0.61 \mathrm{~h}^{-1}$, which means more ethanol is removed by the membrane to keep a lower ethanol concentration in the reactor. All GREENSCOPE indicators except Water Intensity $(W /)$ in Figure 5.10, such as Reaction Yield (RY), Environmental Quotient $(E Q)$, Environmental Potential $(E P)$, Specific Raw Material Costs $\left(C_{S R M}\right)$, Specific Energy Intensity (RSEI), and Resources Energy Efficiency $\left(\eta_{E}\right)$, demonstrate the higher degree of sustainability for the closed-loop scenario. This improvement of sustainability performance can be attributed to the elimination of oscillations and removal of the inhibition effect by the product after the implementation of the biomimetic control strategy. 

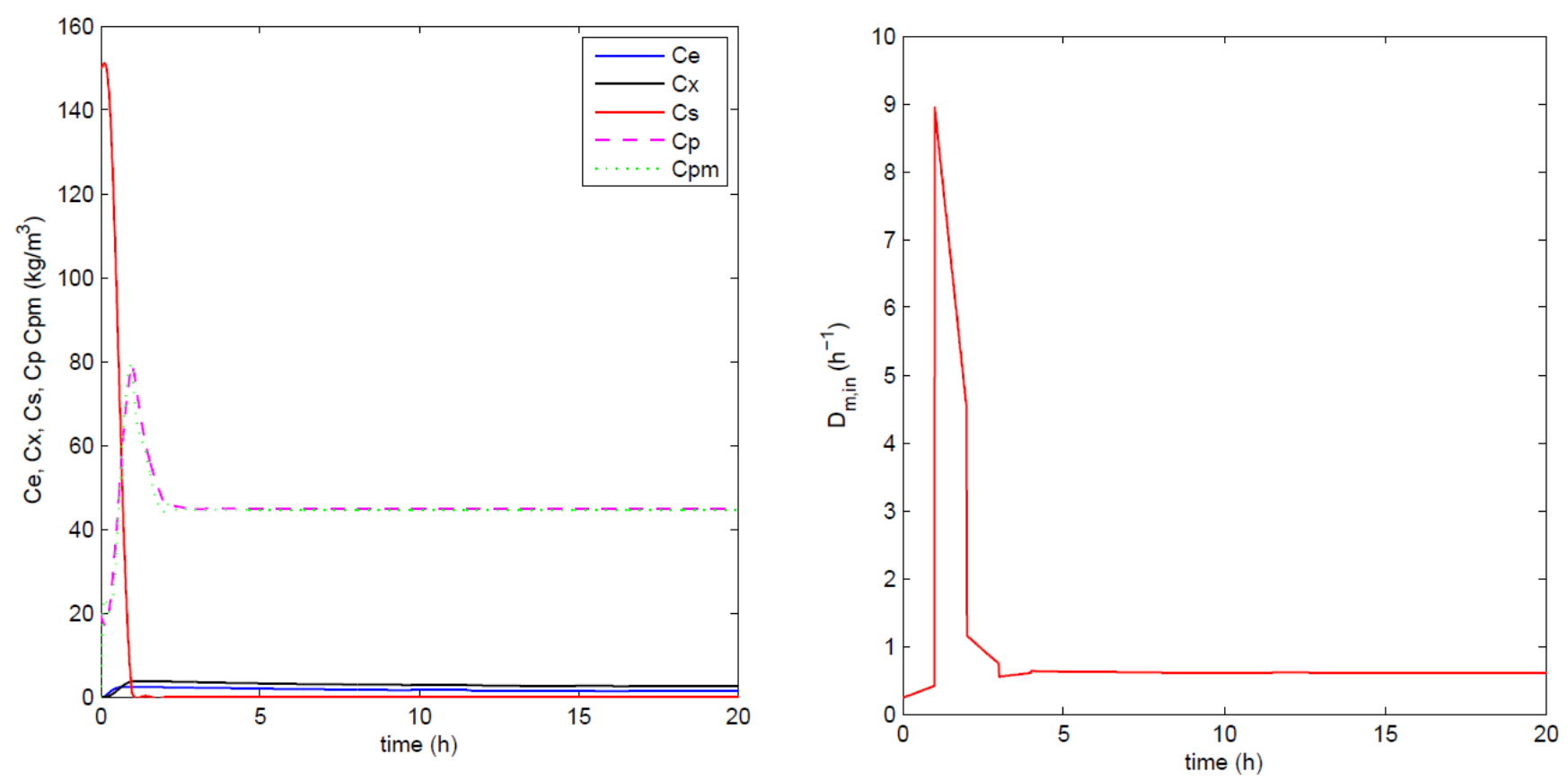

Figure 5.8 Closed-loop simulation (Case 2): concentration (key component, biomass, substrate, product in fermentor and membrane sides) and input profiles
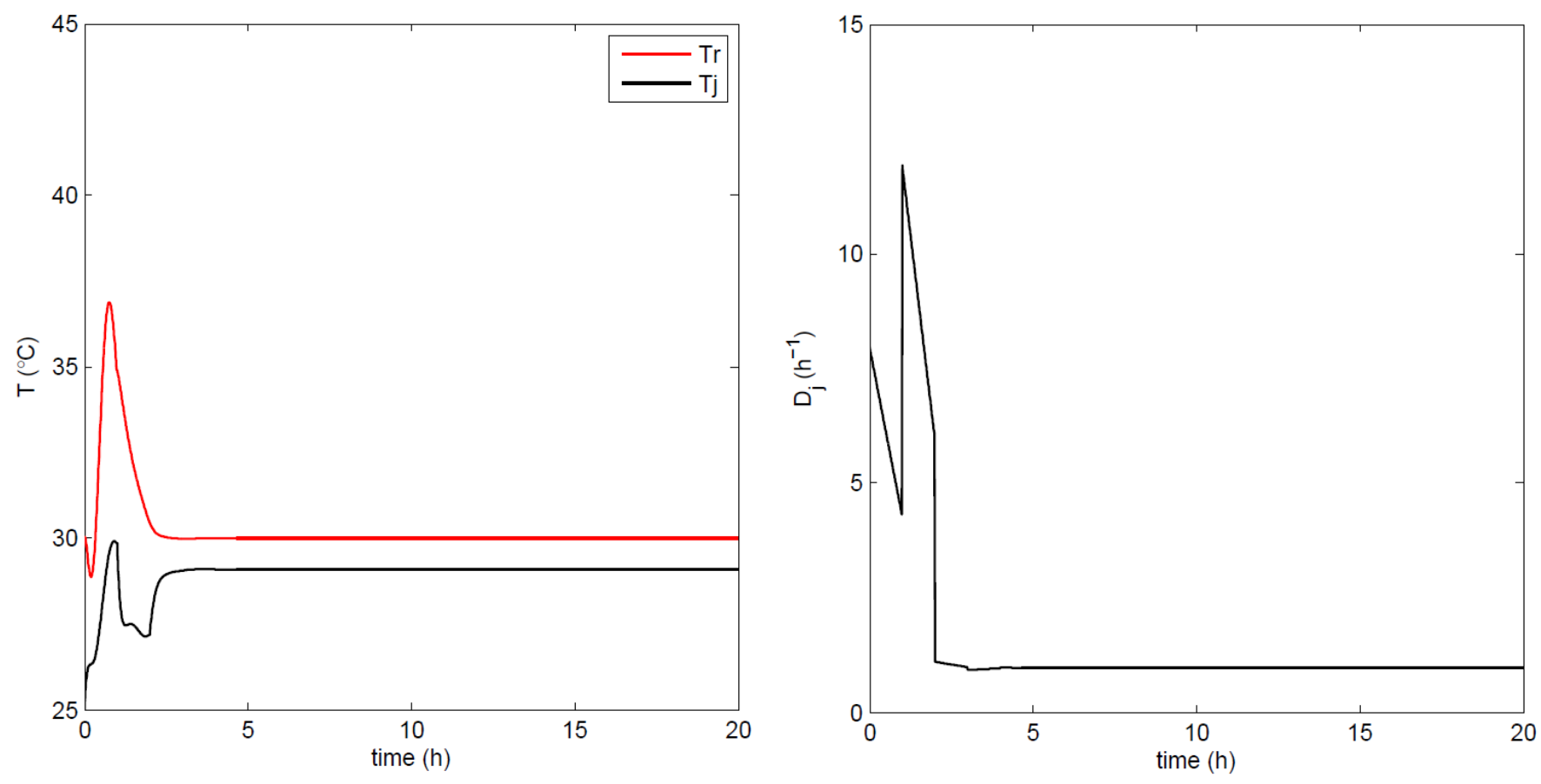

Figure 5.9 Closed-loop simulation (Case 2): temperature (fermentor and jacket) and input profiles 


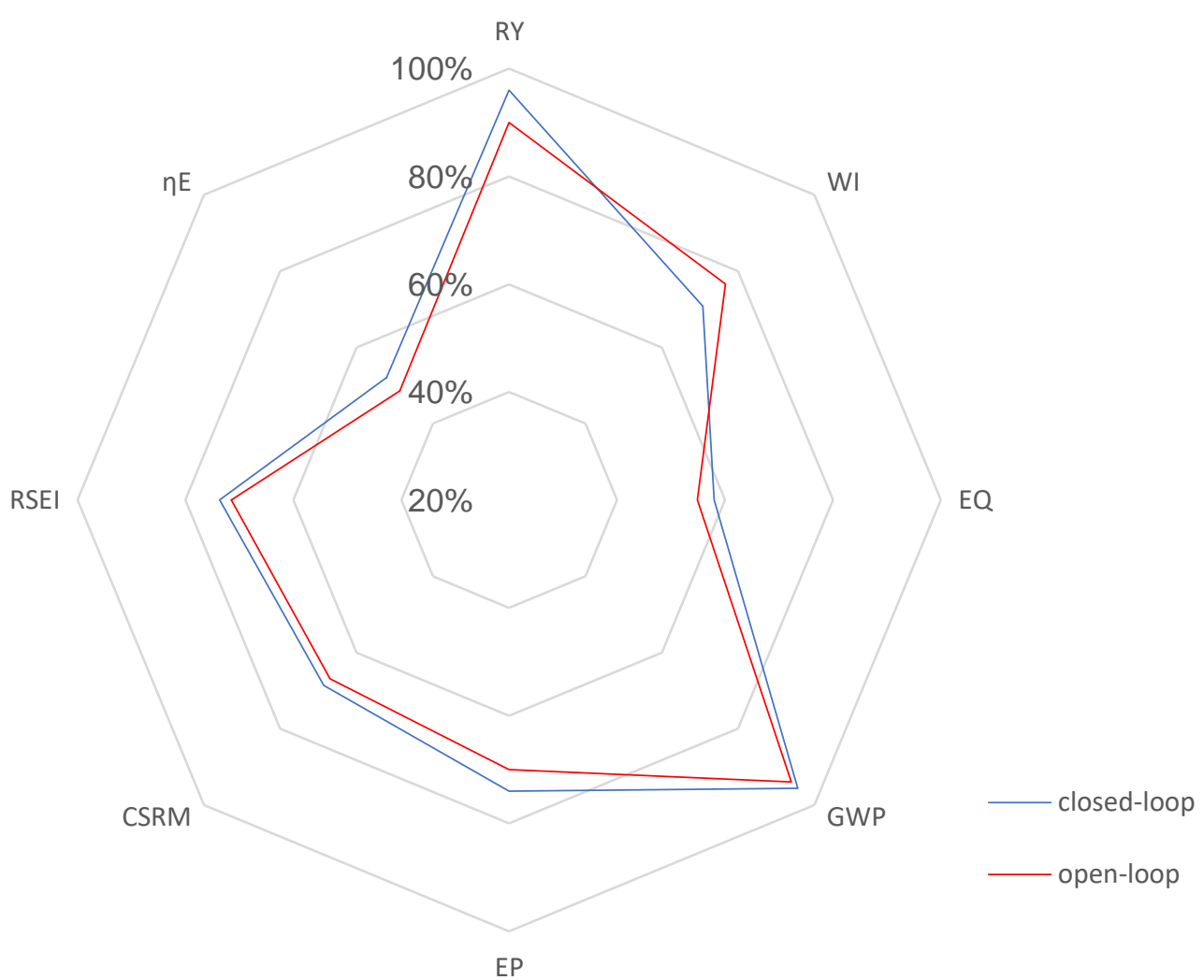

Figure 5.10 Radar plot with GREENSCOPE indicators for the closed-loop and open-loop simulations (Case 2)

Case 3: It is documented that fermentation processes are characterized by the conflict between yield of the desired product and productivity of the reactor, which are both important performance indicators from a stakeholders' commercial point of view. Operating points that correspond to a good trade-off between yield and productivity may be achieved, if the fermentation process is optimized by manipulating $D_{i n}$. In previous work ${ }^{110}$, it was showed that a high $D_{\text {in }}$ generates high productivity but with a low yield due to the end-product inhibition. One advantage of using $D_{m, i n}$ as manipulated variable, however, is to reduce the coupling between yield and productivity. Based on this information, for this case study, a closed-loop simulation with $D_{\text {in }}$ of $0.2 \mathrm{~h}^{-1}$ is studied, where the setpoints are kept at the same values as in Case 2. Figures 5.11 and 5.12 present the concentrations of key 
component, biomass, substrate, product and temperature as well as the inputs profiles for the closed-loop simulation in this case. When compared to the results of Case 2, which are depicted in Figures 5.8 and 5.9, the closed-loop scenario in this case shows that the manipulation of $D_{m, i n}$ effectively enables the system to achieve high conversion rate even at high $D_{i n}$. The residual substrate concentration in the fermentor is now $0.075 \mathrm{~kg} / \mathrm{m}^{3}$, which is slightly higher than that in Case $2(0.03$ $\mathrm{kg} / \mathrm{m}^{3}$ ). The GREENSCOPE indicators in Figure 5.13 demonstrate that the Specific Energy Intensity indicator ( $\left.R_{S E I}\right)$ becomes more sustainable and environment and economic indicators for Case 2 and Case 3 overlap with each other. Moreover, efficiency indicators for Case 3 are slightly less sustainable than that of Case 2 due to the relatively lower substrate conversion rate.
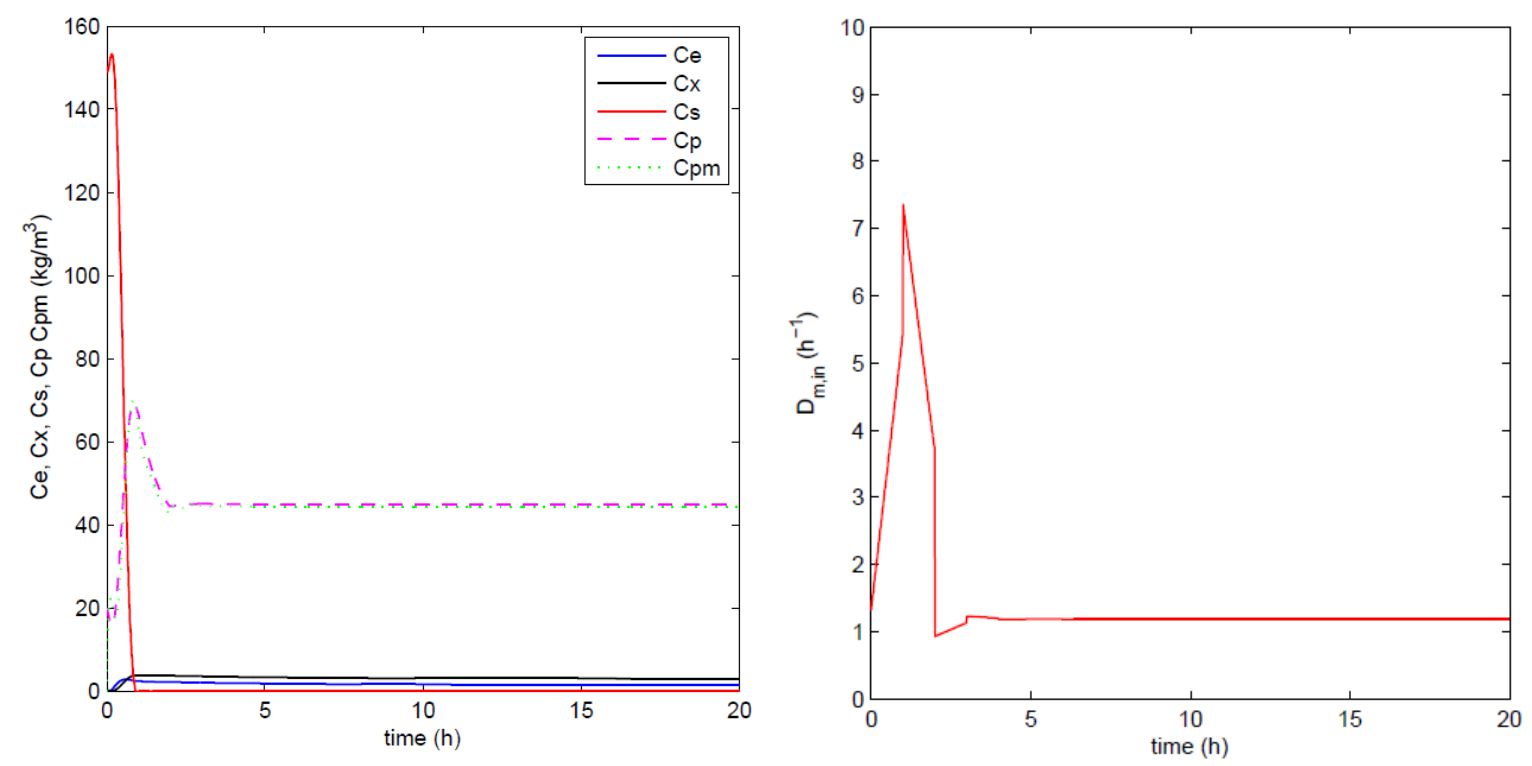

Figure 5.11 Closed-loop simulation (Case 3): concentration (key component, biomass, substrate, product in fermentor and membrane sides) and input profiles 

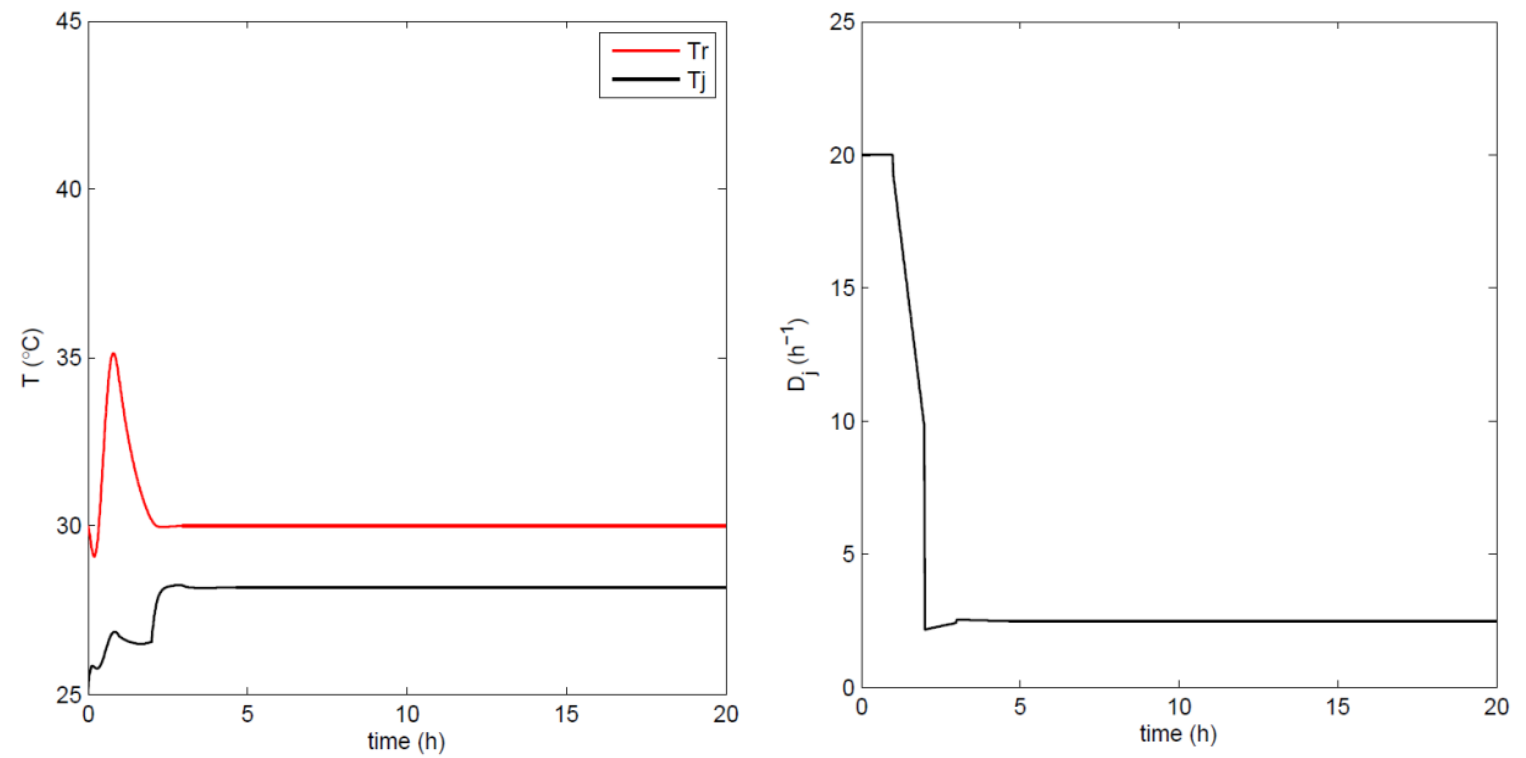

Figure 5.12 Closed-loop simulation (Case 3): temperature (fermentor and jacket) and input profiles

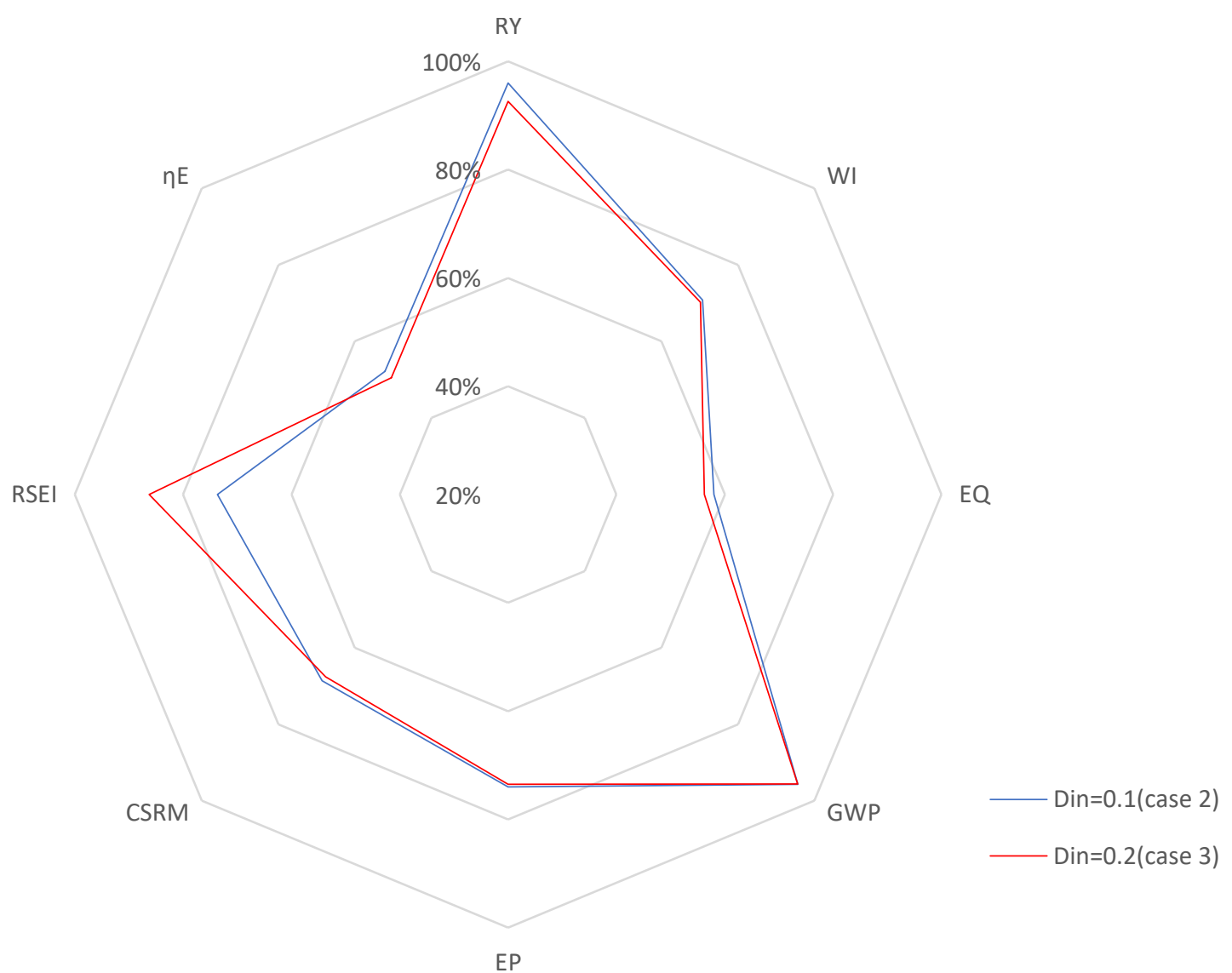

Figure 5.13 Radar plot with GREENSCOPE indicators for closed-loop simulations with different $D_{\text {in }}$ (Case 3)

Case 4: From the performance of the cases above, it is shown that a relatively lower setpoint for $C_{P}$ will bring benefits to the process in terms of sustainability due 
to the reduction of the end-product inhibition. In addition, it is important to note that lower setpoints for $C_{P}$ should be reachable based on the open-loop dynamic analysis presented above. In this case, to locate the optimal value for $C_{P}$ in terms of sustainability, the setpoint of $C_{P}$ is set at $35 \mathrm{~kg} / \mathrm{m}^{3}$ in the closed-loop simulation with $D_{i n}$ of $0.2 \mathrm{~h}^{-1}$ and then the process performance is compared with that of Case 3. Figures 5.14 and 5.15 show the concentrations of key component, biomass, substrate, product and temperature as well as the input profiles for this closed-loop simulation. The radar plot in Figure 5.16 shows that most selected GREENSCOPE indicators do not change except Water Intensity $(W)$ that reduces its score. This can be explained by the fact that there is little room for improvement in terms of sustainability when compared to Case 3 , which has a fermentation process with a high level of efficiency. Therefore, the system has reached its limitation in terms of the optimal $C_{P}$ setpoint without compromising in process sustainability.
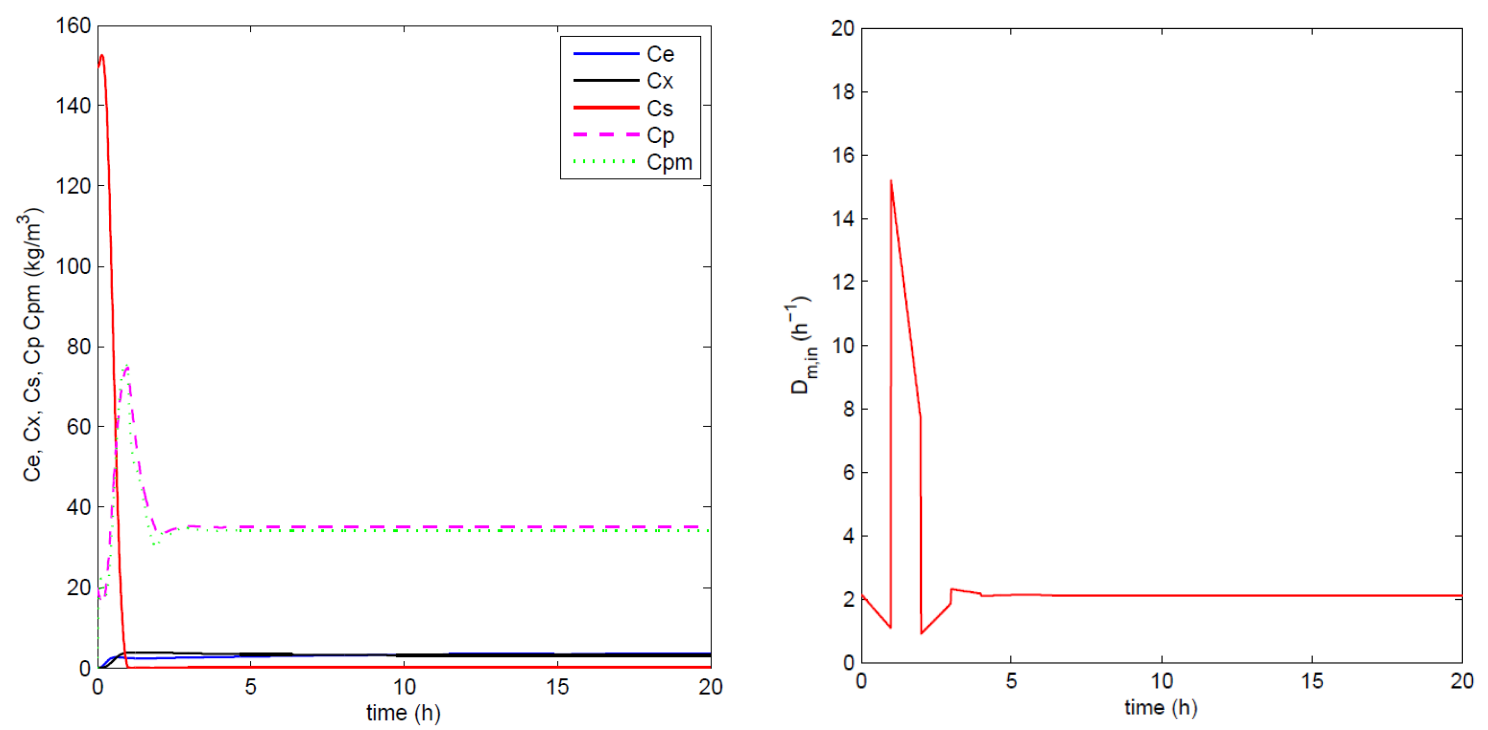

Figure 5.14 Closed-loop simulation (Case 4): concentration (key component, biomass, substrate, product in fermentor and membrane sides) and input profiles 

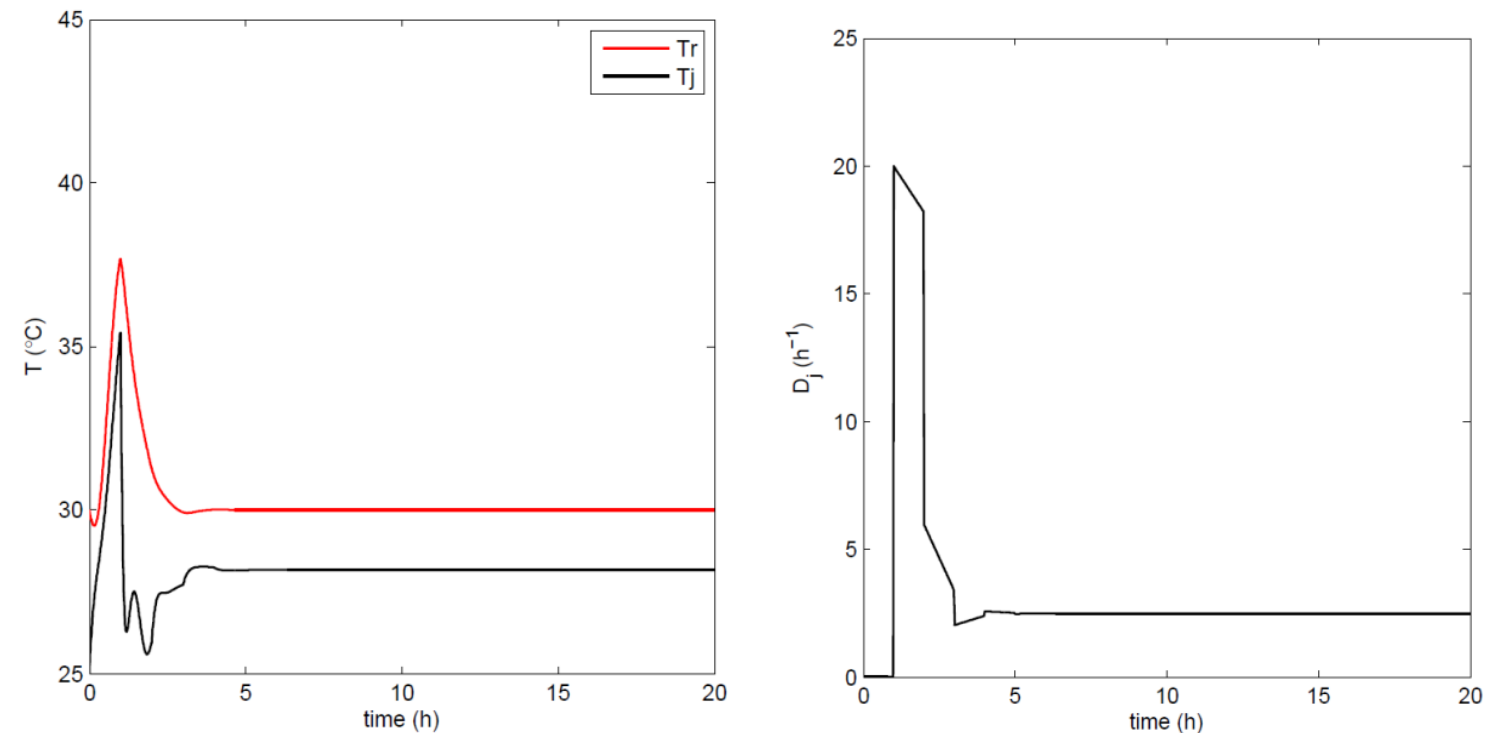

Figure 5.15 Closed-loop simulation (Case 4): temperature (fermentor and jacket) and input profiles

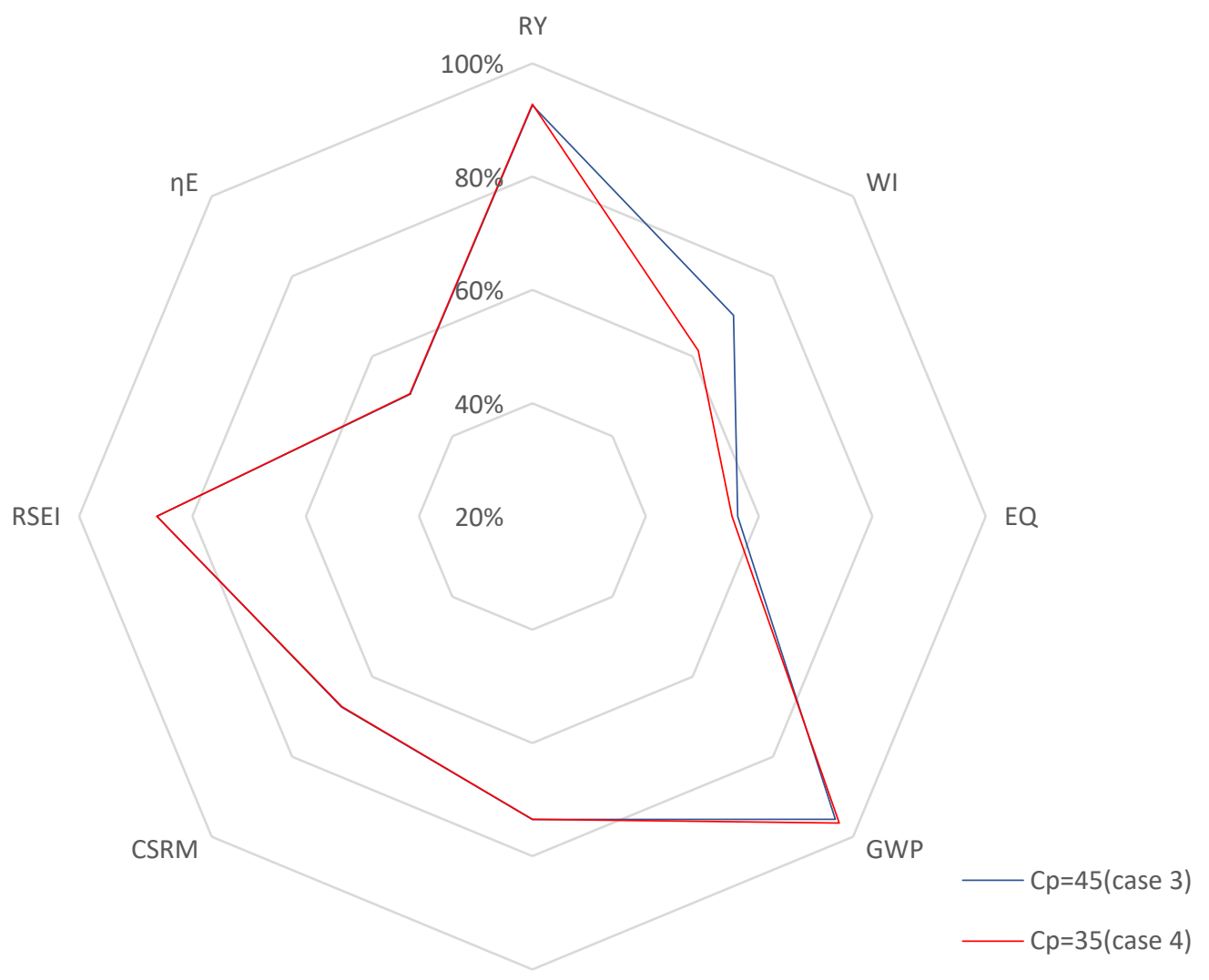

EP

Figure 5.16 Radar plot with GREENSCOPE indicators for the closed-loop and open-loop simulations (Case 4) 


\subsection{Conclusions}

The study in this chapter successfully demonstrated a novel approach for process systems to achieve sustainable operations through the application of an advanced control strategy combined with sustainability assessment tools. The effectiveness of the developed framework was highlighted via a case study of a bioethanol production process. In this case study, closed-loop scenarios were performed with fixed product concentration and optimal temperature setpoints. The steady states of the process were assessed through selected indicators of the GREENSCOPE sustainability assessment tool in 4 categories (efficiency, environmental, economics and energy). The obtained indicator results from GREENSCOPE were used to guide the selection of the fermentation process case with the most sustainable performance. Thus, the proposed framework, if applied to chemical processes, can provide systematic guidelines for decision-makers to determine the process optimal operating points based on the obtained indicator results, which show whether the implementation of the advanced biomimetic controller can improve the system's sustainable performance. 


\section{Chapter 6 A Novel Control Strategy for Sustainability of Chemical Processes}

\subsection{Introduction}

As a step forward to contribute in the field of process control for sustainability, in this chapter, the previously developed framework in Chapter 5 that integrated an advanced process control strategy with sustainability assessment tools is enhanced. In the previous chapter, process control was employed to take the system to the optimal process operation in terms of sustainable performance. Then, an offline sustainability assessment was used to comprehensively evaluate the reached steady-state alternatives. An improved steady-state sustainability performance was obtained after the controller implementation without considering the process performance during transient. In the proposed framework of this chapter, the dynamic sustainability assessment during transient is incorporated using a novel visualization method with dynamic radar plots. With the better understanding of the process dynamic behavior in economic, environmental and social aspects, sustainability constraints can be defined and directly embedded into the control strategy so that the control action can be calculated considering the sustainability performance. The effectiveness of the proposed framework is demonstrated via the case study of a fermentation process for bioethanol production. The outline of the rest of this paper is as follows: Subsection 6.2 presents the background on the fermentation process model and the sustainability assessment tools. In Subsection 6.3, the proposed sustainability-oriented framework and the advanced controller for sustainability are described. Subsection 6.4 introduces the visualization method for dynamic sustainability performance with an example. In Subsection 6.5 , the proposed framework is applied to the fermentation process to demonstrate the controller's effectiveness. 


\subsection{Background}

\subsubsection{Fermentation Process}

In this chapter, the continuous fermentation process with Zymomonas mobilis for ethanol production from glucose solution is revisited. The schematic of the ethanol fermenter studied is shown in Figure 6.1. This process dynamics have been studied in the previous chapter, including the challenging characteristics of steadystate multiplicity and oscillatory behavior. A set of seven ordinary differential equations (ODEs) for mass and energy balances and two algebraic equations for inlet dilution rate $\left(D_{\text {in }}\right)$ and membrane dilution rate $\left(D_{m, i n}\right)$ were described in Chapter 5 for this process. Also, Table 5.1 provided the parameter values of the model and the initial operating conditions used in this Zymomonas mobilis fermentation process. The same process will be studied in this chapter.

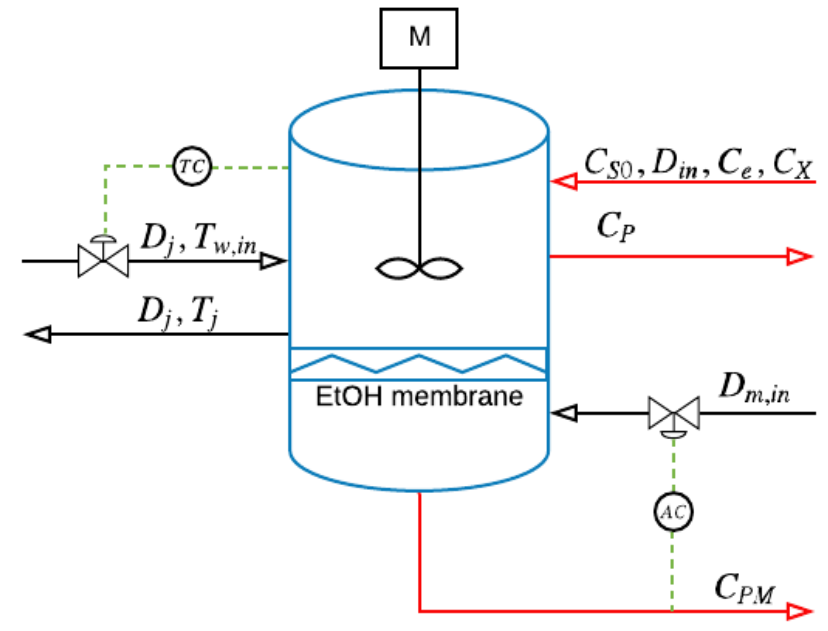

Figure 6.1 Schematic diagram of the fermentation reactor

\subsubsection{Sustainability Assessment Tool}

Many sustainability tools have been developed for process performance assessment and management. However, most of the available sustainability tools are not comprehensive enough for evaluating the operating performance of chemical processes. A suitable tool should be able to meet the following requirements: 1) 
quantify the process impact on social, environmental and economic pillars of sustainability; 2) describe the assessment results in a transparent and standard way; 3) extend traditional sustainability analysis to assess process dynamic performance. GREENSCOPE, as a sustainability evaluation and design tool, can provide a holistic sustainability performance analysis for chemical processes that meets these requirements and helps the process designers and decision-makers with comparing multiple processes or locating areas for analyzing the optimal trade-offs in terms of sustainability. As mentioned above, GREENSCOPE provides dimensionless indicator scores for sustainability performance. The normalized indicators offer some advantages for applying GREENSCOPE to different scenarios. Moreover, the dimensionless indicators can be lumped or aggregated for process optimization or control studies based on a user-selected weighting method. Finally, the dimensionless indicator scores enable visualization of the multi-dimension sustainability performance using radar plots. A novel visualization technique for analyzing process sustainability performance during transient is described in Section 6.4 .

\subsection{Process Control for Sustainable Process Operations}

\subsubsection{Integrated Control Strategy for Sustainability}

The proposed control framework in this chapter is built as an integrated approach that includes nonlinear process control and online sustainability assessment, as shown in Figure 6.2. The role of the online sustainability assessment part is to monitor the impact of the control action in terms of sustainability and provide information to the controller on the thresholds for selected sustainability indicators. Sustainability concerns/policies can then be successfully translated to process control actions to improve the process sustainable performance. 


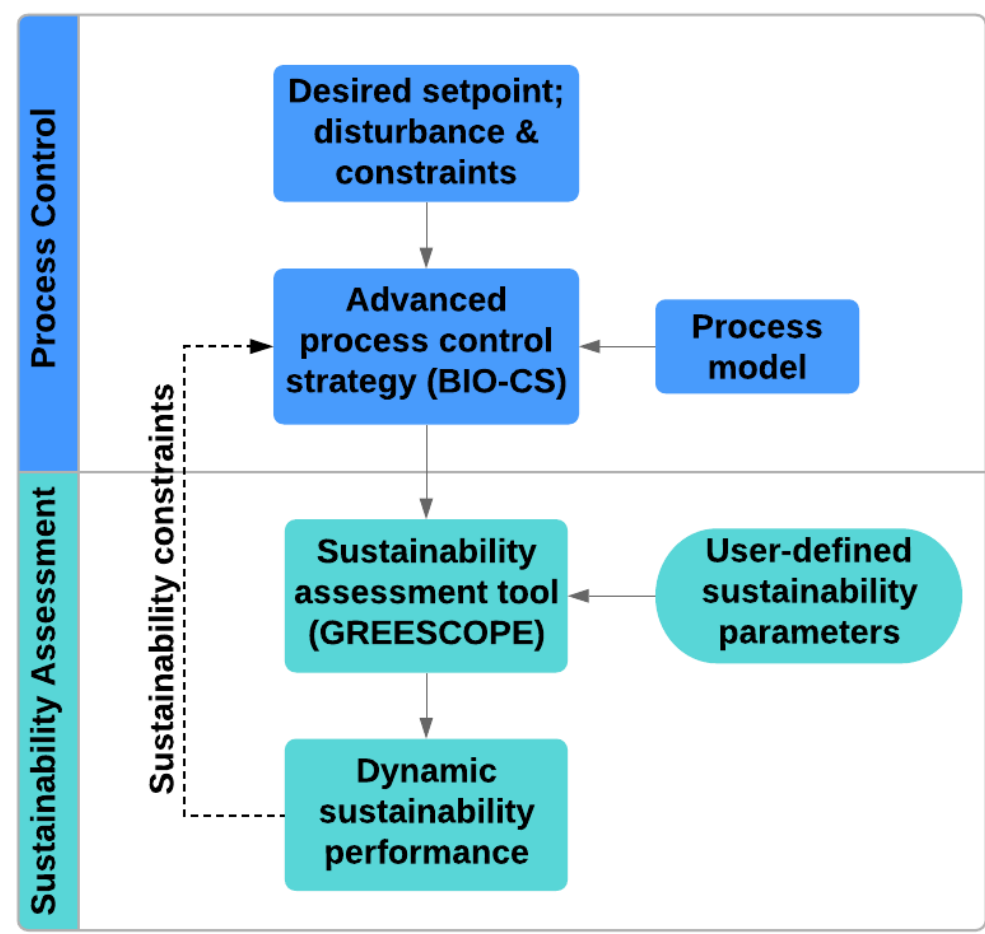

Figure 6.2 Proposed framework for novel sustainable process control

\subsubsection{BIO-CS controller}

An in-house control toolbox for BIO-CS ${ }^{99}$ developed in MATLAB (available upon request) is implemented to address the control task. As described above, BIO-CS is an optimal control approach that combines the ants' rule of pursuit idea with multiagent concepts. The resulting agent-based control framework allows each follower agent to update its path toward the set point based on the leader agent's feasible trajectory. As the number of agents progresses, the trajectories converge to an optimal solution. The developed algorithm employs gradient-based optimal control solvers (e.g., dynopt optimization toolbox ${ }^{111}$ ) in the toolbox for solving the constrained/unconstrained nonlinear optimization problems. The effectiveness of the developed control algorithm has been illustrated via applications associated with fermentation processes ${ }^{112}$, a hybrid energy system ${ }^{113}$, and a coal-fired power plant ${ }^{114}$. In this chapter, the capability of integrating sustainability into BIO-CS is explored. The sustainability-oriented BIO-CS is formulated as follows: 


$$
\begin{aligned}
& \min _{u^{*}(t)} J=\int_{\tau_{i}}^{\tau_{s}}\left(\left\|y(\tau)-y_{s p}\right\|_{w 1}^{2}+\left\|u(\tau)-u^{-}(\tau)\right\|_{w 2}^{2}\right) d \tau \\
& \text { s.t. } \dot{x}(t)=f(u(t), x(t), \mathrm{y}(\mathrm{t}), \mathrm{p}, \mathrm{t}) \\
& \qquad S I_{i} \geq S I_{t h} \\
& x(t) \in\left[x(t)^{l b}, x(t)^{u b}\right] \\
& u(t) \in\left[u(t)^{l b}, u(t)^{u b}\right]
\end{aligned}
$$

in which $u(t), x(t)$, and $y(t)$ are the input, state and output variables, respectively, and $\tau$ stands for time. The optimal input trajectory of the control problem is $u^{*}(t)$, which is calculated over the sampling time $t \in\left[\tau_{i}, \tau_{s}\right)$. This calculation is subject to the process model, $f(\cdot)$, sustainability constraints specified by a sustainability index, $S I_{i}$, and boundary constraints on $u(t)$ and $x(t)$. Please refer to publication ${ }^{115}$ for the detailed algorithm of BIO-CS.

\subsection{Visualization of Dynamic Sustainability Performance}

\subsubsection{Visualization Approach}

Most of the work in the sustainability area only focuses on steady-state operations, thus ignoring dynamic behavior even though chemical processes exhibit complex dynamics. Understanding the dynamic behavior of sustainable systems and controlling the process to meet the sustainability goals is a critical task in the sustainability field. However, research in this direction is scarce. This fact can be attributed to the complex and integrated nature of the resulting problems when sustainability is incorporated into chemical process operation at different time and space scales. For example, sustainability requires the expansion of the traditional energy, economic and product quality-focus to multiple objectives (e.g., 
environmental, economic and social objectives). Despite of these challenges, it is expected that sustainability will be a major driver for process systems engineering (PSE) to advance the capability of future chemical processes to deal with multiple control targets while balancing conflicting objectives. Before moving to the implementation of the proposed framework, the proposed approach to monitor the process sustainability performance during transient is introduced so that the characteristics of dynamic sustainability performance of the process can be analyzed.

Here process dynamics are referred to the essential relationships among different process variables (e.g., temperature, pressure, concentrations) while dynamic sustainability performance focuses on the understanding of the dynamic nature of the system from the sustainability perspective (e.g., in terms of sustainability indicators). For example, the fermentation process can be operated with fermenter dilution rate $\left(D_{i n}\right)$, membrane dilution rate $\left(D_{m, i n}\right)$, and cooling water flow rate $\left(D_{j}\right)$ fixed at $0.5 \mathrm{~h}^{-1}, 0.1 \mathrm{~h}^{-1}$, and $0.1 \mathrm{~h}^{-1}$, respectively. The dynamic sustainability performance of the process can be represented by selected GREENSCOPE indicators, such as Reaction Yield (RY), Water Intensity (WI), Environmental Quotient (EQ), Global Warming Potential (GWP), Specific Raw Material Cost (CsRm) and Specific Energy Intensity (RsEl) (refer to Table A4 in Appendix A for indicator definitions and details). The obtained GREENSCOPE indicator scores translate the process data into sustainability information for process monitoring and analysis in real-time operation. In this chapter, a time-explicit radar plotting technique is developed for displaying the multivariate sustainability information as depicted in Figure 6.3. In this approach, as shown in Figure 6.3(a), each radar plot (or polygon) represents the selected six sustainability indicators with specific score values. According to the definition of a sustainability indicator score, 
the center represents $0 \%$ sustainable while the outside edge $100 \%$ sustainable. Thus, the wider polygon means the better performance in terms of sustainability. Hence, visualization of sustainability performance along the time dimension can be accomplished by stacking multiple polygons on top of one another on the time axis, as shown in Figure 6.3(b). The developed plotting method provides an efficient and intuitive way of presenting high-dimensional time-explicit sustainability performance. However, with the indicator numbers and time horizon increasing, it is hard to identify whether or not the operation is moving towards a more sustainable area especially when some indicators selected are conflicting. To better balance the tradeoff between conflicting indicators as well as help with the decision-making step, a lumped sustainability index $(S I)$ is defined for combining indicators with user-defined weighting factors. An average sustainability index $(\overline{S I})$ can then be derived from the calculated $S I$ values for analyzing or measuring the performance during any specific time interval. The definitions of these indices are shown below in equations (6.6-6.7) .

$$
\begin{gathered}
\text { Sustainability Index }(S I(t))=\frac{\sum w_{i} \cdot P S_{i}(t)}{\sum w_{i} \cdot P S_{\text {max }, i}} \\
\text { Average Sustainability Index }(\overline{S I})=\frac{\int_{t_{0}}^{t_{f}} S I(t)}{\left(t_{f}-t_{0}\right)}
\end{gathered}
$$

where $w_{i}, P S_{\max , i}, t_{0}$ and $t_{f}$ are the weighting factors and maximum percent score $(P S)$ for the specific indicator $i$ as well as the initial and final time interval. Note that different weights can be assigned to selected indicators depending on the user preferences or the application. A larger number means higher impact of the indicator on the overall sustainability performance. In this chapter, equal weights for the selected six sustainability indicators has been used throughout this study. 


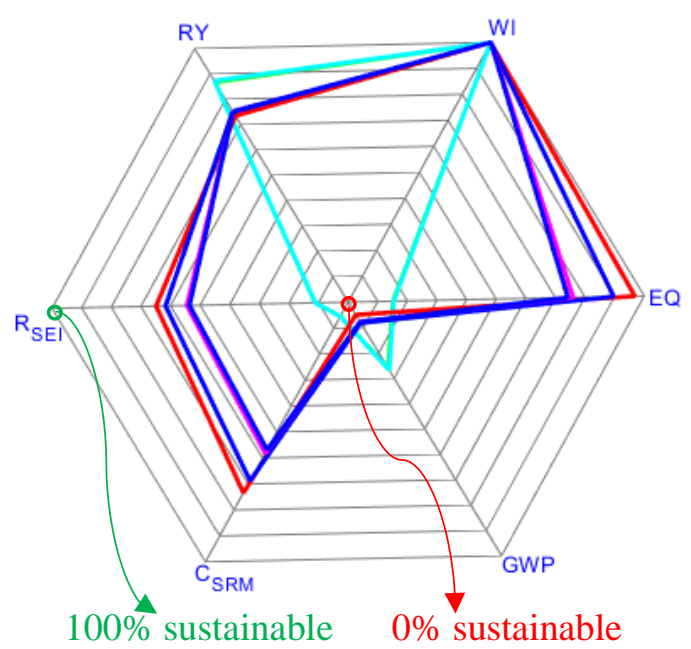

(a)

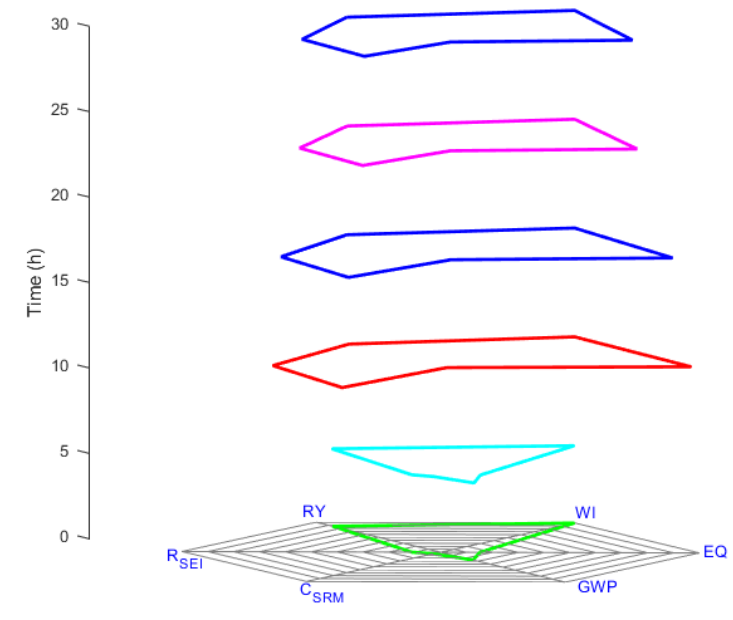

(b)

Figure 6.3 Visualization method for monitoring high-dimensional sustainability performance: (a) 2D radar plot; (b) 3D radar plot

\subsubsection{Open-loop Simulation Example}

The process dynamics have direct relationship with the dynamic sustainability performance of the process. Here open-loop simulation results of the fermentation process are used to illustrate the effectiveness of the proposed dynamic sustainability visualization approach. Figure 6.4 shows the concentration profiles of the key component $\left(C_{e}\right)$, biomass $\left(C_{X}\right)$, substrate $\left(C_{S}\right)$, product in the fermenter $\left(C_{P}\right)$ and membrane sides $\left(C_{P M}\right)$ as well as fermenter temperature profile $\left(T_{r}\right)$ with the predefined operating conditions. As reported in Chapter 5, the open-loop fermentation process exhibits oscillatory dynamic behavior. From the sustainability perspective, the six indicators mentioned above have been selected for evaluating the fermentation process in terms of efficiency, environmental, energy and economic aspects and for identifying how the overall performance of the process can be improved in terms of sustainability. As shown in Figure 6.5, most indicators (except WI) follow the trends in the process oscillations shown in Figure 6.4. This can be 
explained by the fact that the dilution rates of $D_{i n}, D_{m, i n}$, and $D_{j}$ that are associated with WI are kept constant for the open-loop simulation and the other indicators, such as RY, EQ, GWP, Csrm, and Rsel, are strongly related to the process dynamics. Fermentation involves two types of reactions: one is microbial growth reaction and the other is the metabolite reaction for ethanol production. From the process dynamics in Figure 6.4(a), it is clearly shown four distinguished process phases, including $0-1 \mathrm{~h}, 1-5 \mathrm{~h}, 5-18 \mathrm{~h}$ and $18-30 \mathrm{~h}$. For the time zone of $0-1 \mathrm{~h}$, the substrate is mostly consumed for biomass and key component formation and the yield for ethanol is relatively low. Hence, process performance in terms of sustainability for this region is shown as red in Figure 6.5, which means less sustainable. This color scheme is defined according to the $S I$ value for every time step. It is interesting to note that the most sustainable part of the simulation occurs during the transient stage of $1-5 \mathrm{~h}$, which corresponds to the highest average reaction yield. During 5-18 h, strong oscillations start due to ethanol inhibition and the SI values start to decrease, which is reflected by a gradually changing green color along the time axis in Figure 6.5(a). After $18 \mathrm{~h}$, the system is prone to steady state with light green sustainability status, as shown in Figure 6.5. Through a deeper analysis of the dynamic sustainability performance, note that EQ, CSRM, RSEI and overall sustainability performance improve with the higher RY, while GWP drops with RY increasing. Such monitoring approach thus can help the design and implementation of the controller for keeping the system within a designed sustainable operating range. 


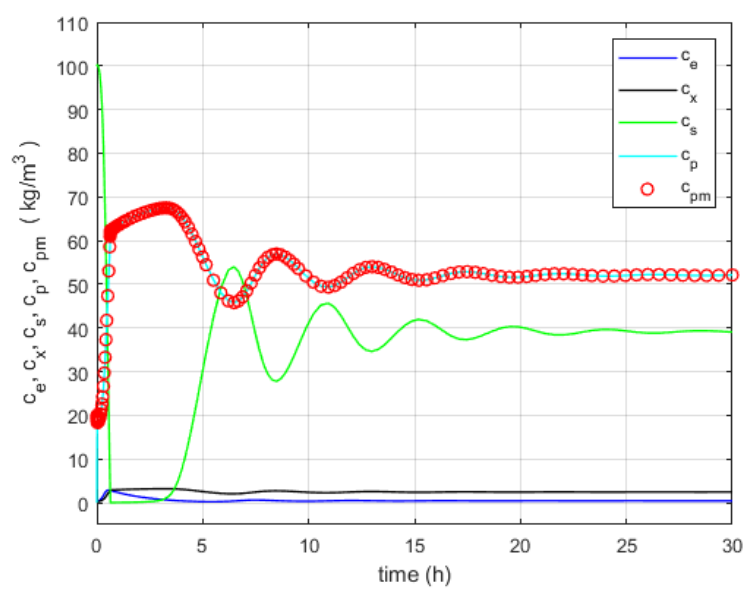

(a)

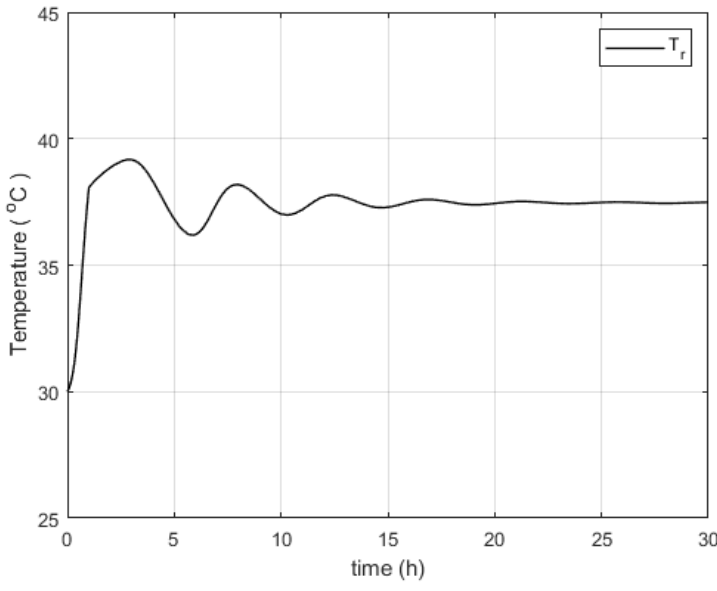

(b)

Figure 6.4 Process open-loop simulation dynamics: (a) concentration profiles of different components and (b) reactor temperature profile

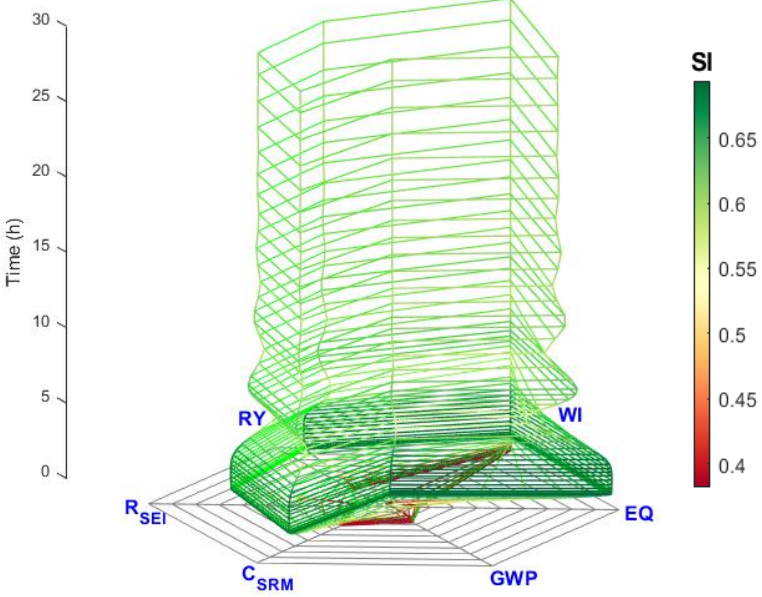

(a)

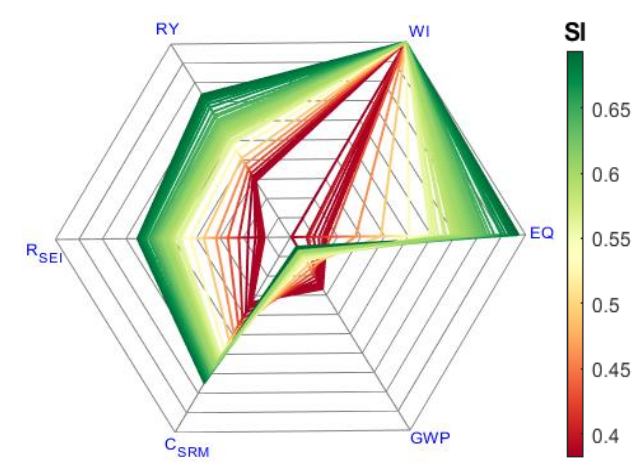

(b)

Figure 6.5 Dynamic sustainability performance of open-loop simulation (red represents less sustainable while green more sustainable according to calculated SI values): (a) 3D sustainability indicator dynamic radar plot; (b) 2D projection of sustainability indicator radar plot

\subsection{Results and Discussion}

Two case studies are presented here to evaluate the effectiveness of the novel sustainable process control framework. The first case with a fixed $D_{\text {in }}$ value of 0.1 $\mathrm{h}^{-1}$ is chosen to illustrate the application of the sustainability-oriented control strategy to improve the process sustainability performance. Specifically, the dynamic sustainability performance visualization approach is used to analyze how places with lower sustainability performance can be improved by adding sustainability 
constraints to the controller. The second case study shows the framework performance for a more challenging case with a higher $D_{\text {in }}$ of $0.5 \mathrm{~h}^{-1}$, which corresponds to a higher volumetric productivity in the fermenter. For all simulations, the parameter values in Table 5.1 are kept constant.

\subsubsection{Case 1}

The effectiveness of the sustainability-oriented control strategy is first demonstrated using the fermentation process for a setpoint tracking study. In this case study, the optimal setpoints for $C_{P M}$ and $T_{r}$ are set at $48 \mathrm{~kg} / \mathrm{m}^{3}$ and $30{ }^{\circ} \mathrm{C}$, respectively, based on our previous studies. The objective function of the controller is to minimize the difference between the values of the controlled variables, $C_{P M}$ and $T_{r}$, with respect to their setpoints by optimizing the input variable $\left(D_{m, i n}\right.$ and $\left.D_{j}\right)$ trajectories, as shown in Equation 6.1. Figure 6.6 depicts the closed-loop simulation results obtained for the output and input profiles. Note in this figure that, with the implementation of the proposed BIO-CS, the oscillations observed in the open-loop simulations are eliminated completely and the system reached the desired setpoints in $\sim 3.5 \mathrm{~h}$. Chapter 5 has shown that the steady state obtained here using the controller is more sustainable than the open-loop result. The proposed control strategy in this chapter takes a step forward towards analyzing the sustainability performance along the path from the initial starting point (e.g., during start-up) to the desired steady-state so that sustainability constraints can be defined and added to the controller design. As shown in Figure 6.7(a), three distinguished regions in terms of sustainability performance characteristics can be observed at $0-0.8 \mathrm{~h}, 0.8-2 \mathrm{~h}$, and 2-10 h. The time zone of $0-0.8 \mathrm{~h}$ (reddish zone with $\overline{S I}$ of $\sim 0.78$ ) is the start-up, which involves the conversion of substrate to ethanol as well as biomass cell reaction. The relatively low SI for this phase can be explained by the low efficiency 
of the fermentation process at the beginning and biomass and key component are not growing enough for completely converting substrate into product. During $0.8-2 \mathrm{~h}$, the overall sustainability performance first improves for a short time and then decreases. This can be attributed to the fact that the reaction yield or efficiency reached the highest level at $1 \mathrm{~h}$ and then the water usage starts to increase from 1 to $2 \mathrm{~h}$ as shown in Figure 6.6. Note that the WI indicator performance is directly associated with the profiles of the manipulated variables while EQ, GWP, CsRM, and RSEl are more prone to changes with RY. After $2 \mathrm{~h}$, the main variables of the system reach the steady state and thus the sustainability performance kept the same with $\overline{S I}$ of $\sim 0.84$. By further analyzing the sustainability performance, it is found that 0.8 $2 \mathrm{~h}$ has relatively low $\overline{S I}$ at 0.77 , which can be attributed to the lowest sustainability indicator of WI (lowest value of 58\%). In order to make sure the WI score is above a certain threshold during transient, a nonlinear sustainability constraint related to the WI score is added to the BIO-CS controller as follows:

$$
\frac{D_{\text {in }} \cdot V_{f}+D_{m, \text { in }} \cdot V_{m}+D_{j} \cdot V_{J}}{\left(\mathrm{WI}_{\text {upper }}-\mathrm{WI}_{\text {lower }}\right) \times \dot{m}_{\text {product }}}>0.7
$$

in which the sum of terms in the numerator corresponds to the total water usage in the system, $\mathrm{WI}_{\text {upper }}, \mathrm{WI}_{\text {lower }}$, and $\dot{m}_{\text {product }}$ represent the upper and lower boundaries for $\mathrm{WI}$ as well as production rate, respectively. The BIO-CS solver implemented can handle such nonlinear constraints effectively. Figures 6.8 and 6.9 show the input and output profiles of the fermentation process and the dynamic sustainability performance, respectively, after the implementation of a WI constraint $(\mathrm{WI}>70 \%)$. It is shown in Figure 6.9 that the BIO-CS controller with the sustainability constraint can successfully drive the system to the setpoints within a more sustainable range for water use while meeting the constraint. During $0.8-2 \mathrm{~h}$, the 
sustainability performance with $\overline{S I}$ of 0.84 increases by $9.65 \%$, when compared to the scenario without the constraint $(\overline{S I}$ of 0.77$)$. To clearly show the comparison in terms of the sustainability performance for the cases with/without the added sustainability constraint, Figure 6.10 shows all the sustainability indicators at three representative time points: $1.8 \mathrm{~h}, 2.1 \mathrm{~h}$, and $10 \mathrm{~h}$. Note that the constrained scenario changes the other sustainability indicators slightly during transient time (during 0-3 h) but the final steady states are the same due to the same setpoints used for both scenarios. By comparing the inputs profiles in Figures 6.6 and 6.8 , it is found that BIO-CS optimizes the input profiles of $D_{m, i n}$ and $D_{j}$ to avoid increasing these two variables simultaneously, thus optimizing the WI score. It is worth mentioning that the sustainability constrained problem slightly decreases the controller performance though in terms of smoothness of the input profiles and time to reach steady state. 

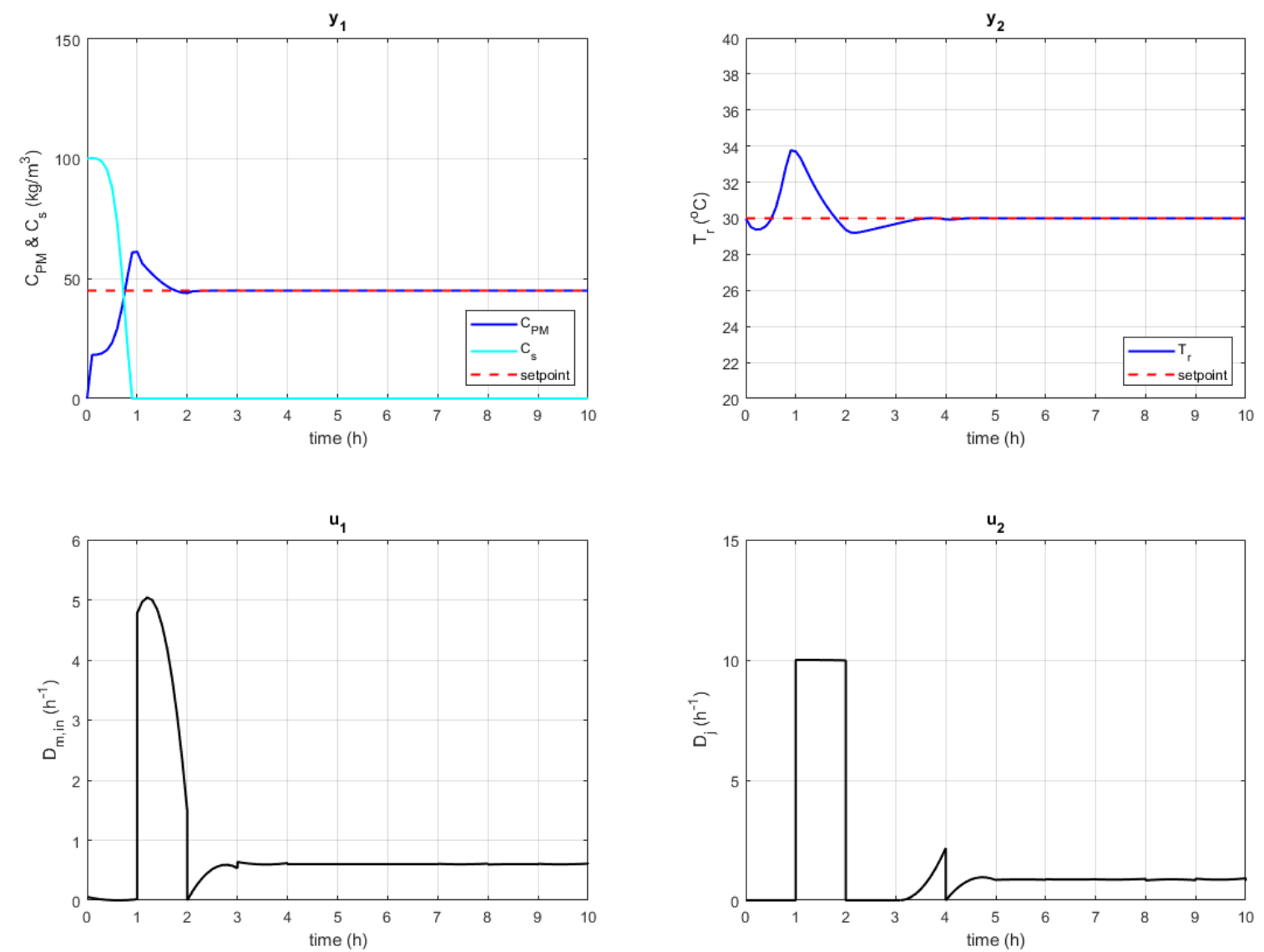

Figure 6.6 Case 1 - closed-loop simulation without sustainability constraint: output ( $y_{1}$ and $\left.y_{2}\right)$ and input ( $u_{1}$ and u2) profiles

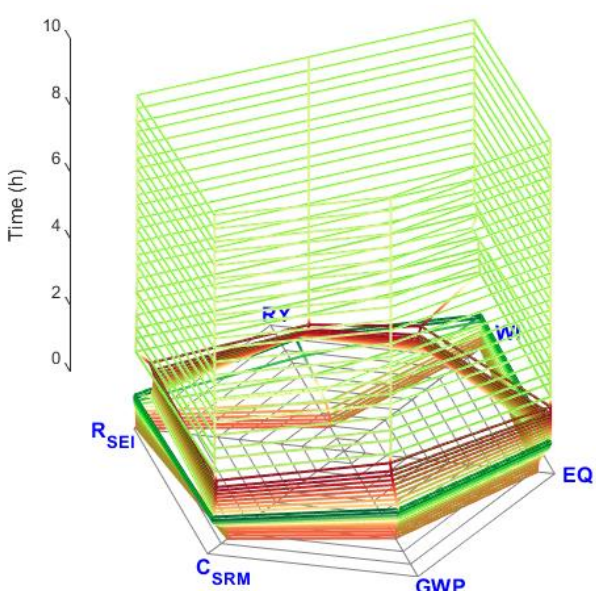

(a)

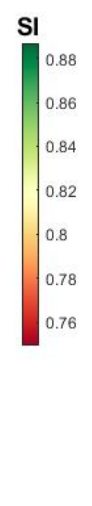

(b)

Figure 6.7 Case 1 - dynamic sustainability performance without sustainability constraint: (a) 3D sustainability indicator dynamic radar plot; (b) 2D projection of sustainability indicator radar plot 

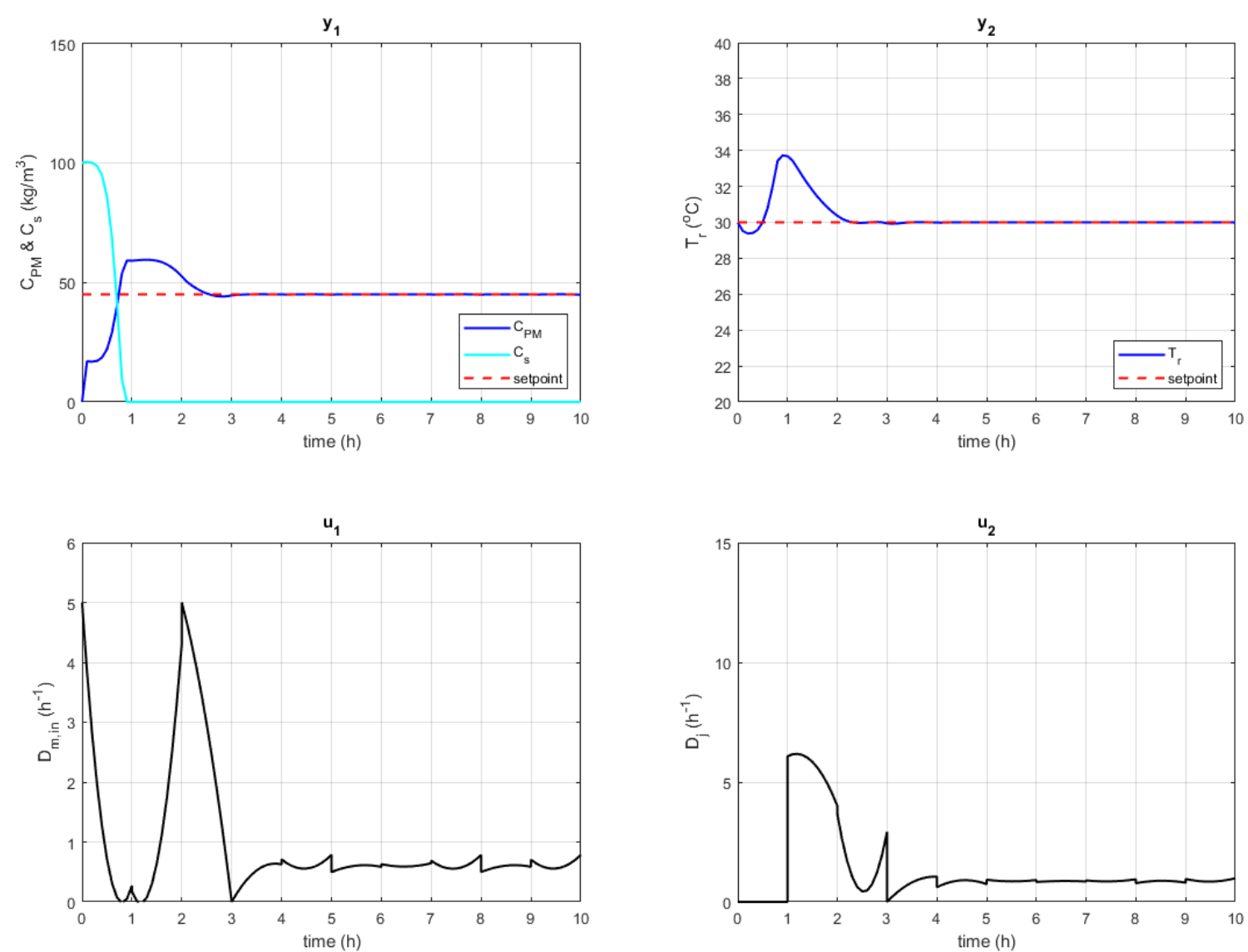

Figure 6.8 Case 1 - closed-loop simulation with sustainability constraint: output ( $y_{1}$ and $\left.y_{2}\right)$ and input ( $u_{1}$ and $\left.u_{2}\right)$ profiles

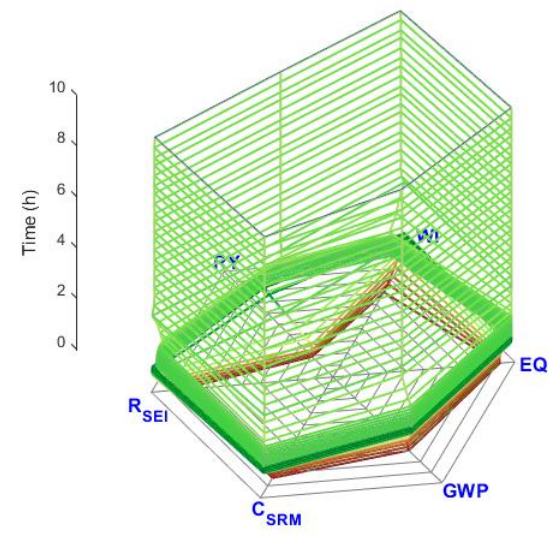

(a)

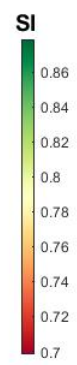

(b)

Figure 6.9 Case 1 - dynamic sustainability performance with sustainability constraint: (a) 3D sustainability indicator dynamic radar plot; (b) 2D projection of sustainability indicator radar plot 

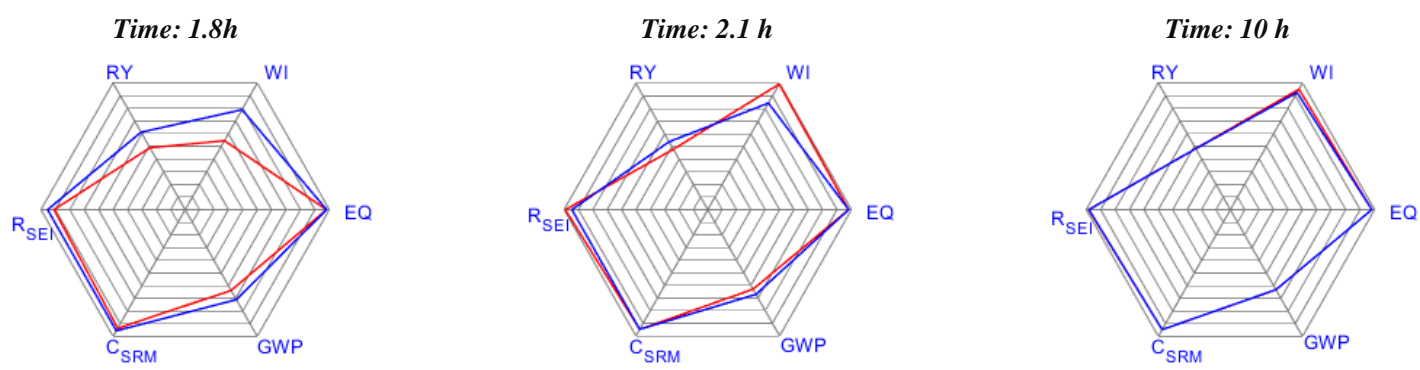

Figure 6.10 Case 1 - comparison between control without WI constraint (red line) and control with WI constraint (blue line) at three representative sample points

\subsubsection{Case 2}

To further investigate the capability of the proposed sustainability-oriented process control framework, a more challenging case with $D_{\text {in }}$ of $0.5 \mathrm{~h}^{-1}$, which represents a higher ethanol production rate with the same fermenter size is addressed in Case 2. Operation with higher $D_{\text {in }}$ can increase the fermenter productivity which is an important performance indicator from the economic point of view. In this case, the setpoints, the manipulated variable boundaries and the objective function of the controller are kept the same as in Case 1. Figure 6.11 depicts the closed-loop simulation results for the output and input profiles. In this figure, it is shown that the implemented BIO-CS can also successfully eliminate the oscillations and drive this more challenging case to the desired setpoints. Note that the manipulated variables reach their upper boundaries in the first 2 hours which cause higher water consumption, thus worsen the overall sustainability performance. Figure 6.12 shows the dynamic sustainability performance results for Case 2 without the sustainability constraint. Compared with Case 1, the overall sustainability performance of Case 2 for the same obtained steady state is lower than that of Case 1 due to the lower efficiency and more water usage for the high $D_{\text {in }}$ operating condition. However, the dynamic sustainability performance shares similar characteristics with Case 1 for the different zones: 1) 0-1 h with low sustainability 
performance; 2) $1-2.5 \mathrm{~h}$ for transient time before steady state; 3$) 2.5$ - $10 \mathrm{~h}$ for steady state. From the control results with the sustainability constraint on WI in Case 1, it is anticipated that the sustainability performance before steady state can be improved by adding a sustainability constraint on WI. Moreover, it is known from Figure 6.12 that the $\mathrm{WI}$ score for the obtained steady state is of $55.47 \%$ and thus a reasonable threshold of $55 \%$ is selected for the WI score constraint.

Figures 6.13 and 6.14 show the input and output profiles for the closed-loop simulation as well as the dynamic sustainability performance, respectively, for the scenario with the WI constraint. It is shown in Figure 6.13 that the BIO-CS controller with the sustainability constraint can successfully drive the system to the setpoints within a more sustainable range, while meeting the constraint (WI score $>55 \%$ ). It is worth mentioning that the controller could not push the system to the setpoints if the WI score constraint was increased to $60 \%$. This is because the controller fails to achieve the setpoints with such high WI threshold (higher than WI score of the obtained steady state). During transient time of $0-2.5$ hours, the process sustainability performance in terms of $\overline{S I}$ is 0.66 , which increased by $16.86 \%$, when compared to the unconstrained problem with $\overline{S I}$ of 0.56 during the same transient. To clearly show the comparison in terms of sustainability indicators for the two cases with/without the sustainability constraint, Figure 6.15 shows all the sustainability indicators at three representative time points: $0.36 \mathrm{~h}$ (the time of lowest WI score for the unconstrained scenario), $2.1 \mathrm{~h}$ (the time of highest $\mathrm{WI}$ score for the constrained scenario), and $10 \mathrm{~h}$ (the time that reached steady state). It is worth mentioning in Figure 6.15 that during transient the other sustainability indicators except WI improve while the sustainability performance of the final steady states are exactly the same for the two scenarios. By comparing the input profiles in Figures 6.11 and 6.13, it is 
found that the BIO-CS input profiles for the constrained problem have slightly higher oscillations, which might have been caused by the challenging sustainability constraint as the system is operating close to the boundary of the steady-state WI score.
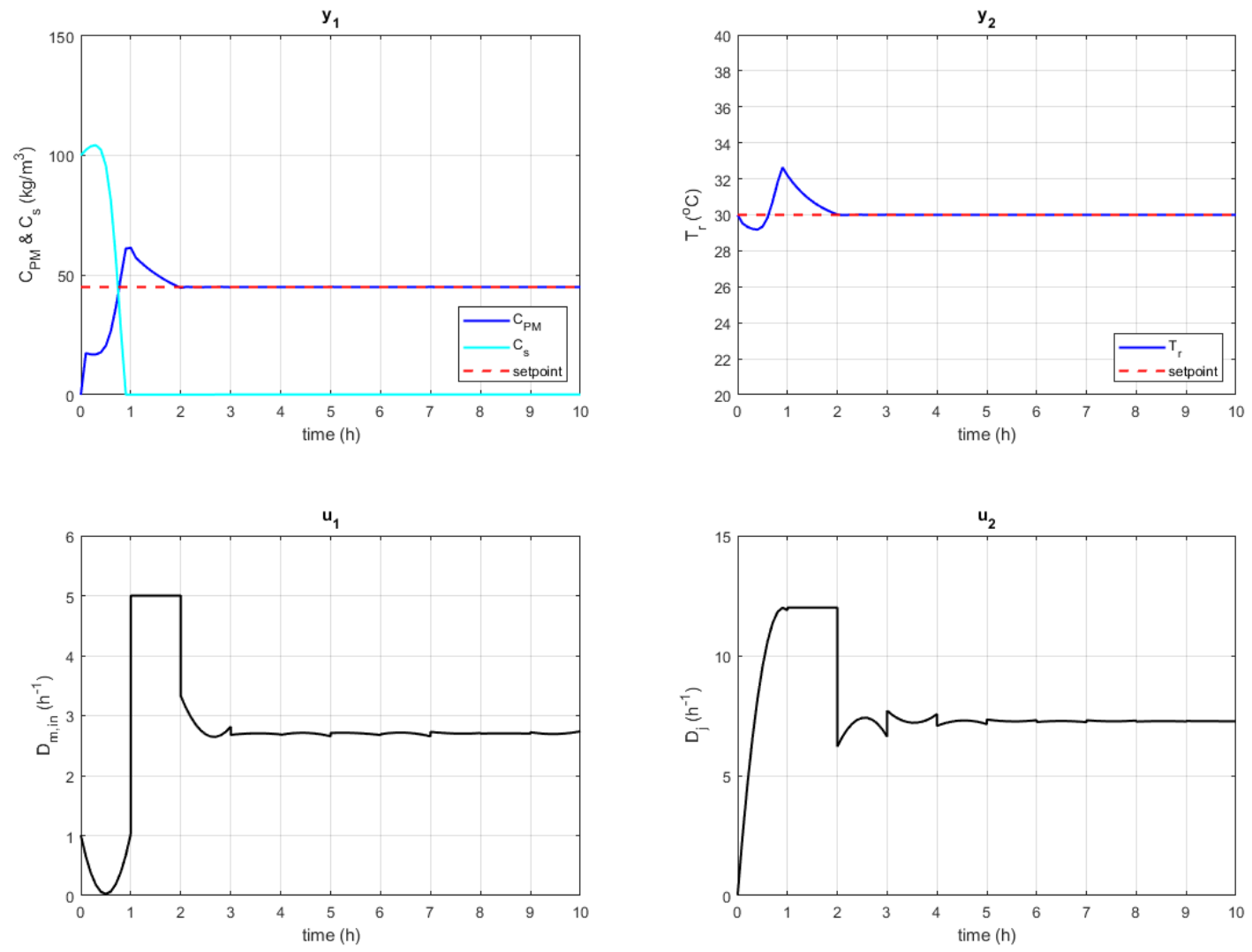

Figure 6.11 Case 2 - closed-loop simulation without sustainability constraint: output ( $y_{1}$ and $\left.y_{2}\right)$ and input ( $u_{1}$ and $u_{2}$ ) profiles

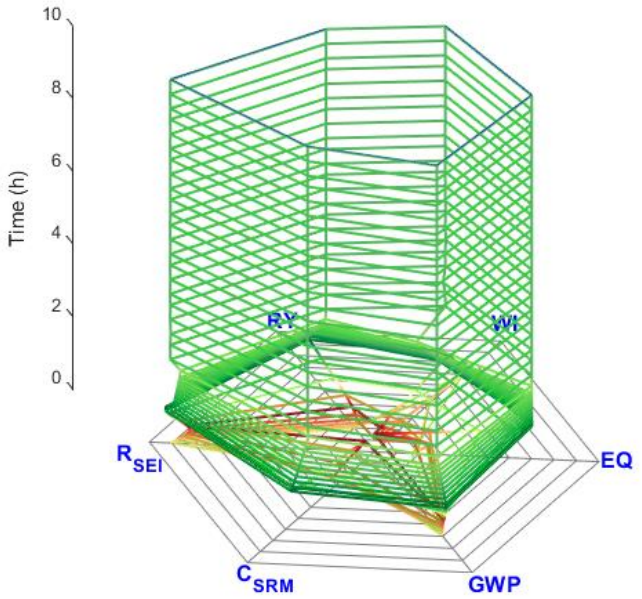

(a)
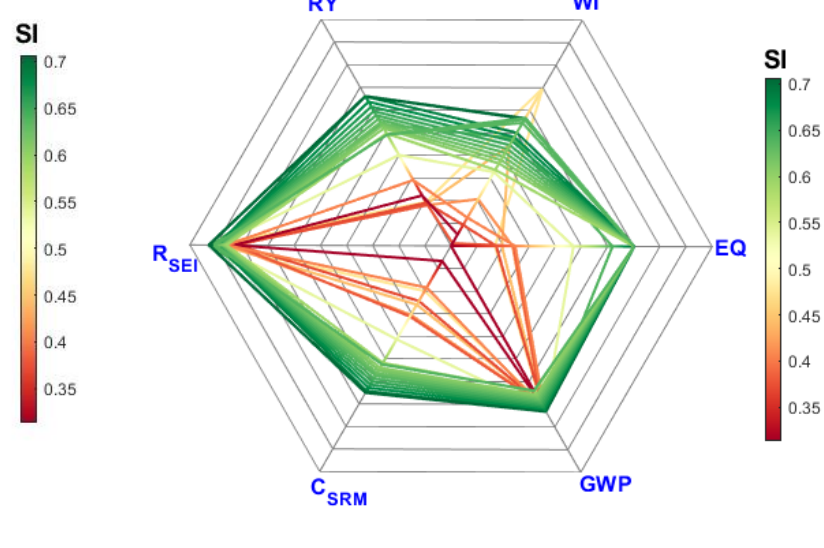

(b)

Figure 6.12 Case 2 - dynamic sustainability performance without sustainability constraint: (a) 3D sustainability indicator dynamic radar plot; (b) 2D projection of sustainability indicator radar plot 

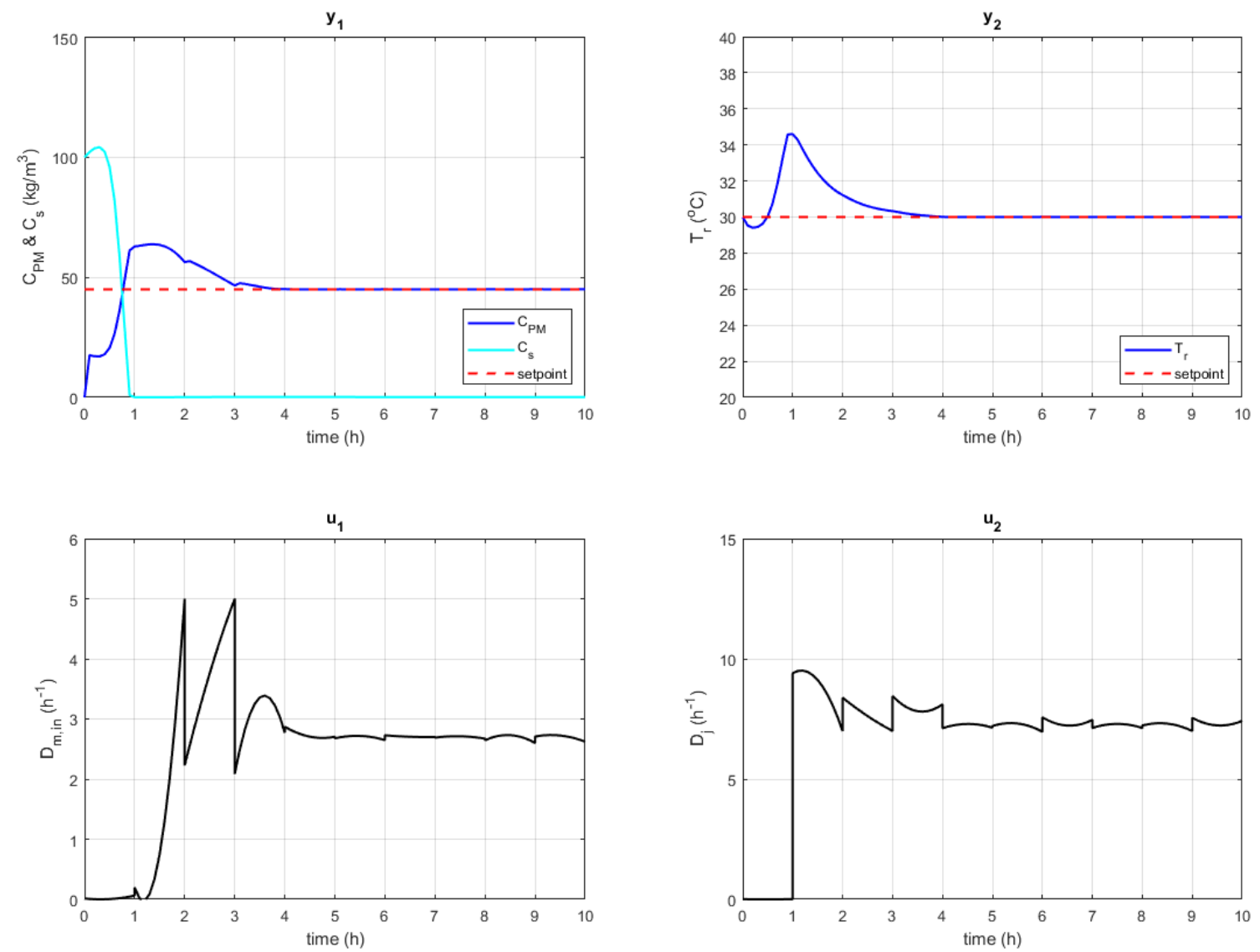

Figure 6.13 Case 2 - Closed-loop simulation with sustainability constraint: output ( $y_{1}$ and $\left.y_{2}\right)$ and input $\left(u_{1}\right.$ and $\left.u_{2}\right)$ profiles

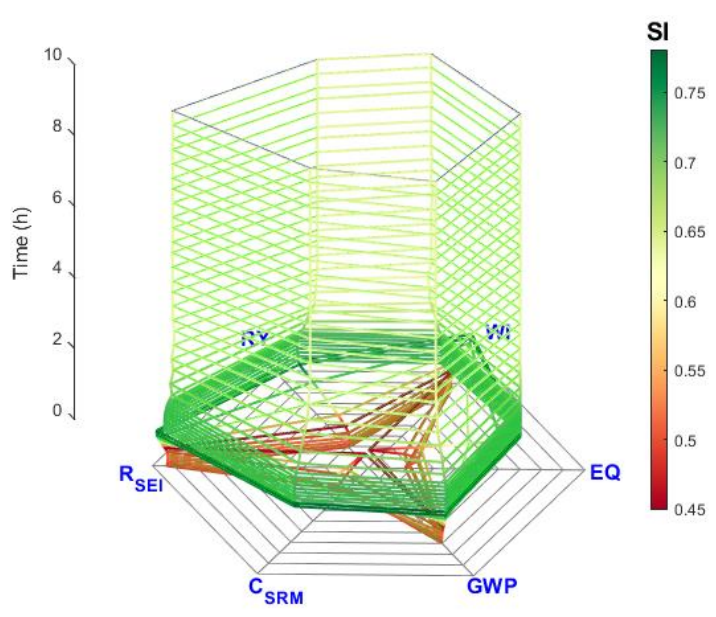

(a)

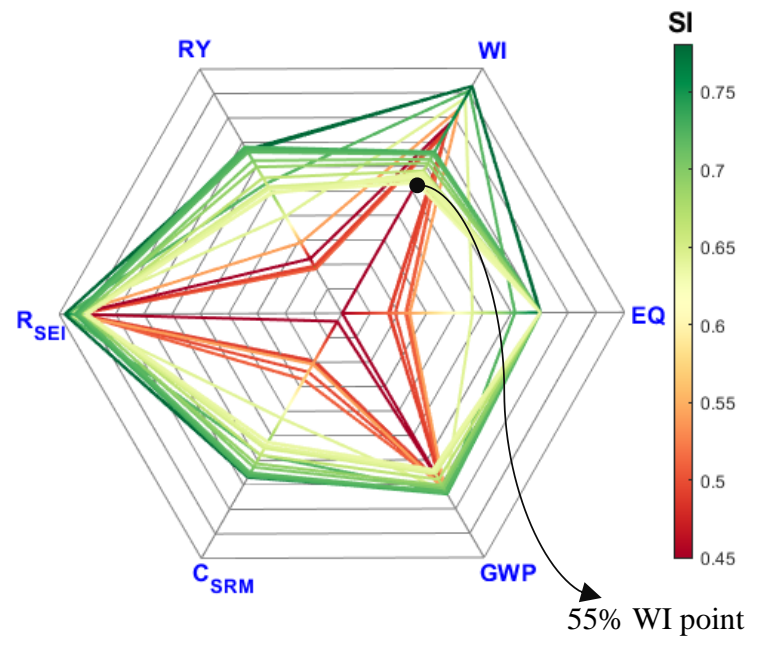

(b)

Figure 6.14 Case 2 - Dynamic sustainability performance with sustainability constraint: (a)3D sustainability indicator dynamic radar plot; (b) 2D projection of sustainability indicator radar plot 
Time: $0.36 \mathrm{~h}$

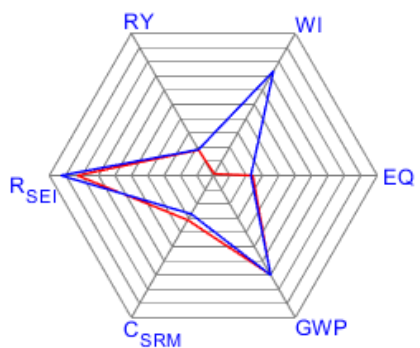

Time: $1 \mathrm{~h}$

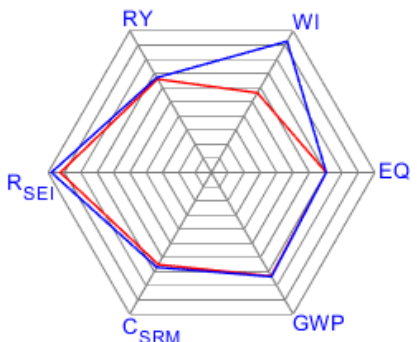

Time: $10 \mathrm{~h}$

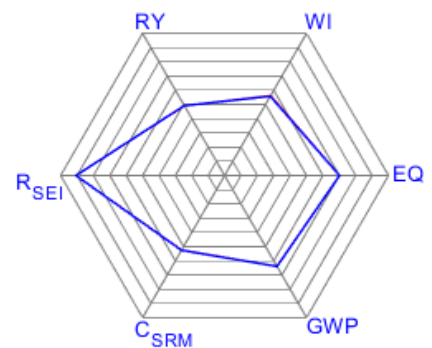

Figure 6.15 Case 2 - Comparison between control without WI constraint (red line) and control with WI constraint (blue line) at three representative sample points

\subsection{Conclusions}

This chapter introduced and demonstrated the proposed novel sustainabilityoriented control strategy to improve process sustainability during transient. Two case studies of a fermentation process with different dilution rates $\left(D_{\text {in }}\right)$ were used to illustrate the application of the proposed dynamic sustainability performance visualization approach as well as the benefits of integrating a sustainability constraint into the BIO-CS control strategy. Specifically, integrating process control with dynamic sustainability helps with the understanding of the dynamic characteristics of the system in terms of sustainability. Based on the analysis of the dynamic sustainability performance, regions with lower sustainability percentage can be detected, and a reasonable constraint can be imposed on selected sustainability indicators so that the control actions can be optimized for improving sustainability performance. Such framework successfully improved the sustainability performance of the two addressed cases by $9.65 \%$ and $16.86 \%$, respectively. 


\section{Chapter 7 Multi-objective Optimization and Sustainable Process Control:}

\section{Application to Gasification System}

\subsection{Introduction}

In this chapter, the previously developed sustainable process control framework is integrated with a multi-objective optimization method. Specifically, the multiobjective optimization problem is formulated based on economic and environmental objectives. The resulting multi-objective problem can be solved using optimization algorithm (e.g., Genetic Algorithm) to generate a Pareto-optimal set. In Pareto optimal analysis, a compromise among the objectives must be considered. Based on a ranking scheme algorithm for decision making, an optimal solution is selected from the Pareto set and then sent to the controller to define the desired set points. The role of the controller implementation is to drive the process system to the chosen optimal sustainable operating point along predefined sustainability constraints. For the controller design, linear MPC is explored in this chapter with the addition of a sustainability constraint. The state-space model for control purposes is derived from the step responses of a developed dynamic biomass/coal co-gasification model in Aspen Hysys. Control structure selection is determined based on sensitivity analyses and mapping of input and output variables. Here the input variables represent potential manipulated variables for the controller, which are varied in a certain range according to the typical operation, while the output variables correspond to potential controlled variables. In summary, the implemented controller is expected to automatically take the process to the optimal steady state determined by the multiobjective optimization algorithm according to the decision maker.

The effectiveness of the proposed framework is demonstrated via the case study of a biomass/coal co-gasification process. The outline of the rest of this chapter 
is as follows: in Subsection 7.2, the proposed framework is presented, including the multi-objective optimization, decision maker algorithm as well as the model predictive control approach. In Section 7.3, the proposed framework is applied to the case study to demonstrate its effectiveness.

\subsection{Approach}

\subsubsection{Framework}

As shown in Figure 7.1, the proposed sustainable control strategy contains three main steps: process and sustainability assessment model construction, multiobjective optimization formulation, and implementation of the control strategy. For the model, a rigorous model is developed in Aspen Hysys and then a state-space model is derived for process control purposes. The developed sustainability assessment tools in Chapters 4 and 5 are used to represent the sustainability model. Based on the Aspen Hysys model, a non-dominated sorting genetic algorithm-III (NSGA-III) is used to solve the multi-objective optimization problem to obtain the Pareto frontier, as detailed below. Then MPC is implemented to take the system to the selected setpoints determined by the weighted decision maker method while meeting the sustainability constraints.

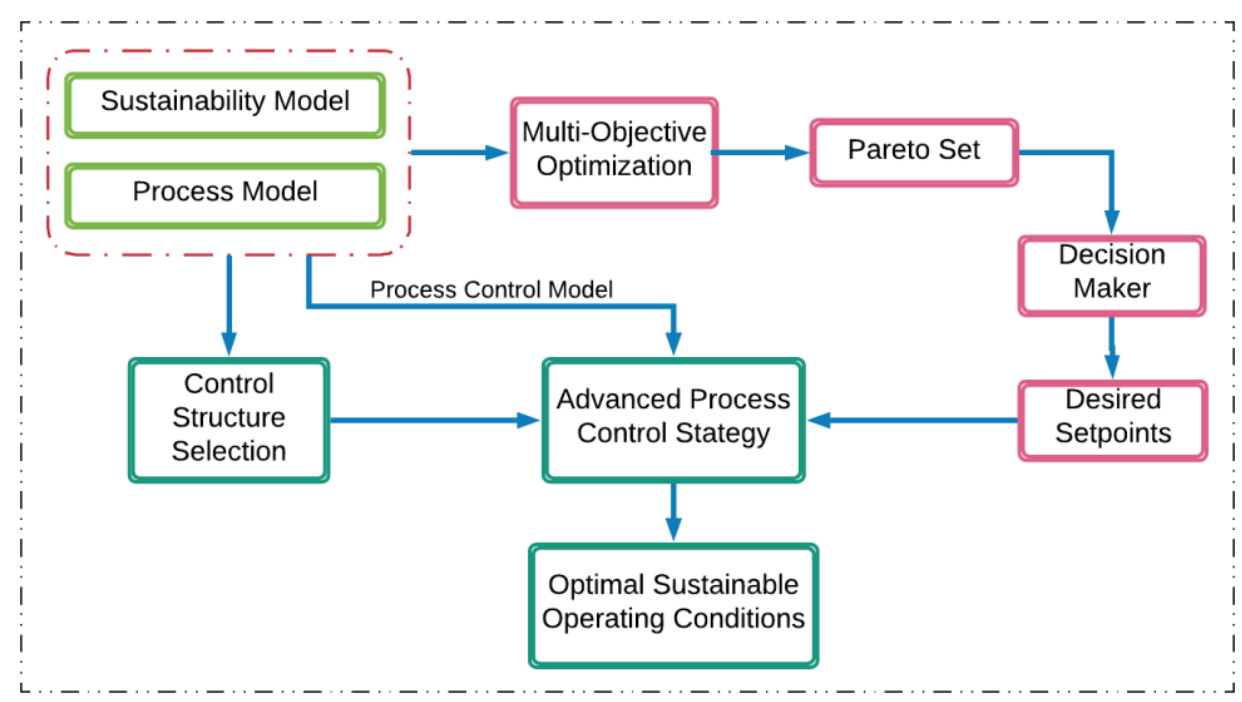

Figure 7.1 Schematic of the sustainable control strategy based on multi-objective optimization 


\subsubsection{Multi-objective Optimization}

Genetic Algorithms (GA), unlike the classical methods of combining all objectives into one fitness function, can handle multiple objectives simultaneously. The concept of GA is inspired by the mechanism of natural selection, using chromosomes, crossover and mutation as searching and exploring operators. Specifically, GA generates/updates the current solutions (chromosomes) using crossover and mutation. Typically, the crossover operator stochastically updates the next generations based on the current solutions by combining two parents' solutions while mutation alters the current solutions to explore the new searching space. To efficiently search for Pareto-optimal solutions for multi-objective optimization problem, GA algorithm has been integrated with other selection algorithms. For example, NSGA-II16,117 is based on the non-dominated ranking and elitepreservation concepts for passing the diversified solution from one generation to the next. Specifically, the non-dominated solution is a solution that is not possible to be outperformed in all criteria simultaneously, relative to a set of supplied solutions. A set of non-dominated solutions is not necessarily Pareto optimal. To improve the performance of NSGA-II, NSGA-III employs more steps to add more Pareto optimal solution candidates besides general framework and parameters (e.g., population size, crossover probability, etc.) of NSGA-II. As shown in Figure 7.2, NSGA-III starts with generation $\mathrm{N}$ random solutions and then crossover and mutation operators are applied to parent population to generate offspring populations, as NSGA-II does. To avoid inter-direction competition, parent and offspring populations are combined. The whole combined population goes through the non-dominated sorting. Starting at the first Pareto frontier, solutions pass to the next parent generation. Typically, the algorithm will reach a frontier that has more individuals than the remaining slots in 
the next parent population. In such case, the Pareto frontier points will be normalized using extreme values of the current population. After normalization, all the frontier points are associated with reference direction. Finally, to fill the next parent generation, a niching strategy is applied to select solutions attached to underrepresented/un-represented reference directions. Overall, NSGA-III combines nondominated sorting and niching techniques to locate the well-distributed Pareto frontier solutions in the close vicinity of each supplied reference direction.

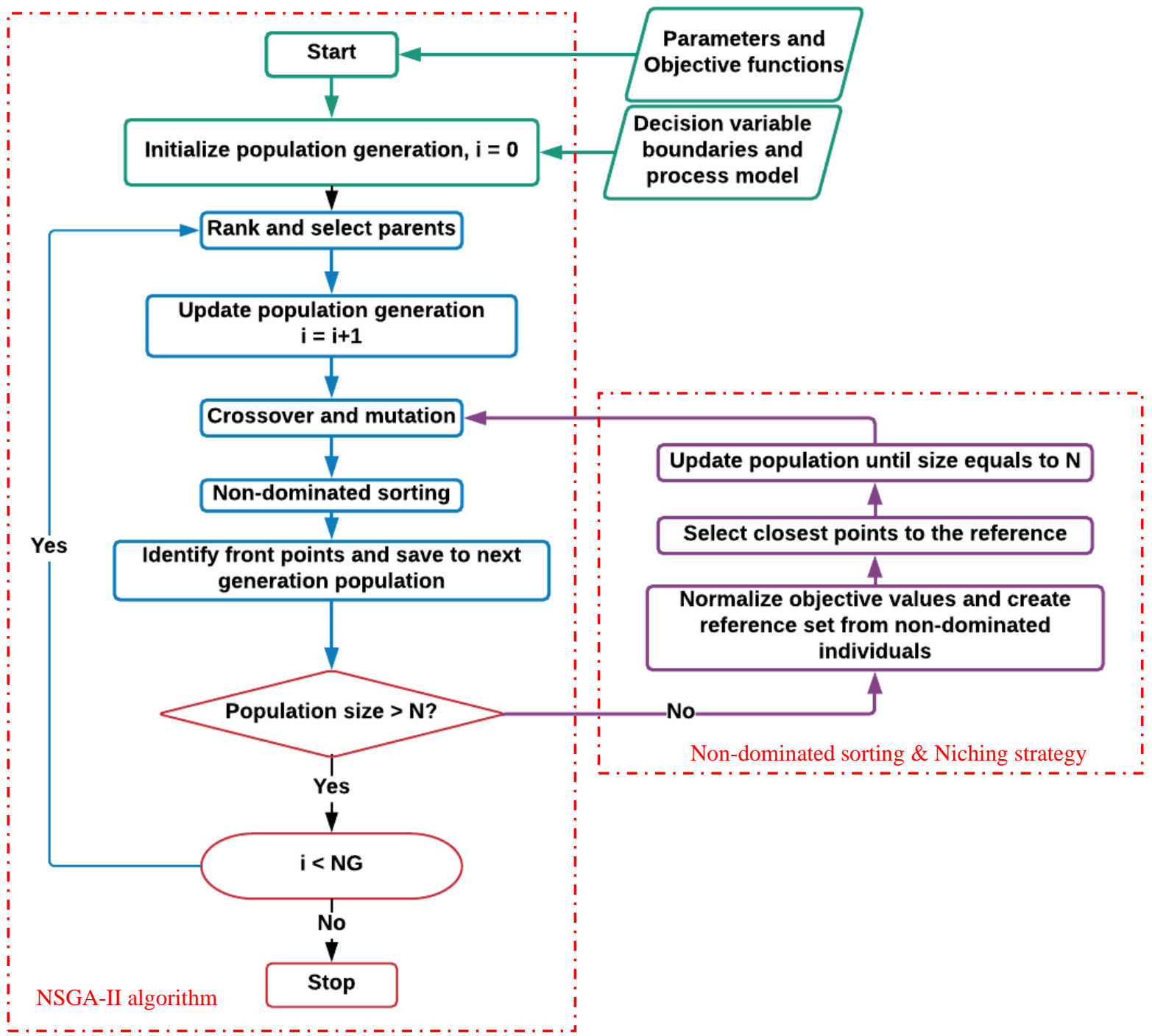

Figure 7.2 NSGA-III algorithm flowsheet 


\subsubsection{Decision Making Algorithm}

To automatically select the operating point from the available Pareto frontier solutions, a subjective weighting method is used as the multi-criteria decision-making method. As shown in Figure 7.3, this method involves normalizing the objective values by the minimum value, assigning preference weights for each objective function, multiplying the assigned weights by the normalized value and summing up the resulting scores to obtain the total weighted value for each solution on the Pareto frontier. Based on the obtained weighted scores, the minimum one is automatically selected as the optimal operating point if the problem is a minimization problem.

1. Normalized objective

$$
\text { matrix }
$$$$
F_{i j}=\frac{\operatorname{Minf}_{i j}}{f_{i j}}
$$

2. Weighted normalized objective matrix

$v_{i j}=F_{i j} \times w_{j}$

3. Selected optimal solution

$$
A_{i}=\min \left(\sum_{j=1}^{n} v_{i j}\right)
$$

4. Desired setpoint for controller

Figure 7.3 Weighting method for the decision maker

\subsubsection{Model Predictive Control (MPC)}

As mentioned previously, the chosen Pareto solution is used to define the set points for the controller. For this chapter, the MPC with a sustainability indicator index can be defined by the following optimization problem:

$$
\min _{u^{*}(t)} J=\int_{\tau_{i}}^{\tau_{s}}\left(\left\|y(\tau)-y_{s p}\right\|_{w 1}^{2}+\left\|u(\tau)-u^{-}(\tau)\right\|_{w 2}^{2}\right) d \tau
$$




$$
\begin{aligned}
& \text { s.t. } \dot{x}(t)=A x(t)+B u(t) \\
& y(t)=C x(t)+D u(t) \\
& S I_{i} \geq S I_{t h} \\
& x(t) \in\left[x(t)^{l b}, x(t)^{u b}\right] \\
& u(t) \in\left[u(t)^{l b}, u(t)^{u b}\right]
\end{aligned}
$$

in which $u(t), x(t)$, and $y(t)$ are the input, state and output variables, respectively, and $\tau$ stands for time. The optimal input trajectory of the control problem is $u^{*}(t)$, which is calculated over the sampling time $t \in\left[\tau_{i}, \tau_{s}\right)$. The control model corresponds to a state-space model derived from input-output data of a high-fidelity Aspen Hysys model. This control action calculation is subject to the state-space process model, sustainability constraints specified by a sustainability index, $S I_{i}$, and boundary constraints on $u(t)$ and $x(t)$.

\subsection{Results \& Discussions}

\subsubsection{Gasification Process in Aspen Hysys}

Gasification technologies can convert different forms of hydrocarbons into synthesis gas (syngas) in the presence of water and oxygen. The syngas composition and yield depend on the operating conditions of the gasification process as well as the hydrocarbon source. In this work, the entrained flow gasifier is modeled based on the General Electric (GE) gasification technology, including partial oxidizer (POX), radiant synthesis gas cooler (RSC) and water quench sections. As shown in Figure 7.4, the POX part is modeled as three CSTRs with the reaction kinetics as defined in Table 7.1. RSC is modeled as a heat exchanger while the water quench part is considered as a mixer. To overcome the limitation of the current Aspen Hysys 
simulation tools in handling solid hydrocarbon materials, a pseudo component, $\mathrm{C}_{18} \mathrm{H}_{20}$, is used as pseudo coal in the simulation. Also, the biomass is thermally decomposed to release volatile matter (VM), leaving behind a high carbon residue generically known as char during pyrolysis. This process is extremely complex due to the large number of chemical and physical transformations that rapidly and simultaneously occur. The required heat for biomass pyrolysis is provided by the exothermic reactions of partial combustion. Pyrolysis can be simplified as the following equations $7.6-7.10$ :

$$
\begin{aligned}
\text { Biomass }=\alpha_{1} \mathrm{CH}_{4}+\alpha_{2} \mathrm{H}_{2} & +\alpha_{3} \mathrm{CO}+\alpha_{4} \mathrm{CO}_{2}+\alpha_{5} \mathrm{H}_{2} \mathrm{O}+\alpha_{6} \operatorname{char}\left(C_{18} \mathrm{H}_{20}\right) \\
+\alpha_{7} \mathrm{H}_{2} \mathrm{~S}+\alpha_{8} \mathrm{~N}_{2}+\alpha_{9} \text { ash } & \\
\omega_{\mathrm{H}_{2}}= & 0.157-0.868 \omega_{V}+1.388 \omega_{V}^{2} \\
\omega_{C H_{4}} & =0.201-0.469 \omega_{V}+0.241 \omega_{V}^{2} \\
\omega_{C O} & =0.428-2.653 \omega_{V}+4.845 \omega_{V}{ }^{2} \\
\omega_{\mathrm{H}_{2} O} & =0.409-2.389 \omega_{V}+4.554 \omega_{V}^{2} \\
\omega_{C O_{2}} & =0.135-0.9 \omega_{V}+1.906 \omega_{V}^{2}
\end{aligned}
$$

where $\alpha_{i}$ is the number of moles of the species after devolatilization ${ }^{118} ; \omega_{V}$ is the mass fraction of the volatile matter in the biomass on a dry ash free basis, and $\omega_{i}\left(\mathrm{i}=\mathrm{CO}, \mathrm{CO}_{2}, \mathrm{H}_{2} \mathrm{O}, \mathrm{CH}_{4}, \mathrm{H}_{2}\right)$ is the mass fraction of species involved in the biomass pyrolysis. The char yield is calculated by the total mass balance, in which the $\mathrm{H}_{2}$ and $\mathrm{H}_{2} \mathrm{~S}$ yields are calculated by element balances. 
Table 7.1 Reaction kinetics for the gasification process considered

\begin{tabular}{|c|c|l|}
\hline Reaction & Reaction rate expressions (kmol $\left.\mathbf{m}^{-3} \cdot \mathbf{s}^{-1}\right)$ & Ref \\
\hline $\mathrm{CO}+0.5 \mathrm{O}_{2} \rightarrow \mathrm{CO}_{2}$ & $r_{1}=1.0 \times 10^{17.6} \exp (-20130 / \mathrm{T})[\mathrm{CO}]\left[\mathrm{H}_{2} \mathrm{O}\right]^{0.5}\left[\mathrm{O}_{2}\right]^{0.5}$ & 119 \\
\hline $\mathrm{CH}_{4}+2 \mathrm{O}_{2} \rightarrow \mathrm{CO}_{2}+2 \mathrm{H}_{2} \mathrm{O}$ & $r_{2}=5.44 \times 10^{12} \exp (-24358 / T)\left[\mathrm{CH}_{4}\right]^{0.3}\left[\mathrm{O}_{2}\right]^{1.3}$ & 119 \\
\hline $\mathrm{H}_{2}+0.5 \mathrm{O}_{2} \rightarrow \mathrm{H}_{2} \mathrm{O}$ & $r_{3}=2.85 \times 10^{16} \exp (-20130 / T)\left[\mathrm{H}_{2}\right]^{0.25}\left[\mathrm{O}_{2}\right]^{1.5}$ & 119 \\
\hline $\mathrm{C}_{18} \mathrm{H}_{20}+9 \mathrm{O}_{2} \rightarrow 18 \mathrm{CO}+10 \mathrm{H}_{2}$ & $\mathrm{r}_{4}=1.0 \times 10^{6}$ & 85 \\
\hline $\mathrm{CO}+\mathrm{H}_{2} \mathrm{O} \leftrightarrow \mathrm{CO}_{2}+\mathrm{H}_{2}$ & $\mathrm{r}_{5 f}=1.612 \times 10^{-6} \exp (-47400 / T) P_{C O} P_{\mathrm{H}_{2} O}$ & 120 \\
& $\mathrm{r}_{5 r}=1.224 \times 10^{-3} \exp (-85460 / T) P_{\mathrm{CO}_{2}} P_{\mathrm{H}_{2}}$ & \\
\hline $\mathrm{CO}+3 \mathrm{H}_{2} \leftrightarrow \mathrm{CH}_{4}+\mathrm{H}_{2} \mathrm{O}$ & $\mathrm{r}_{6 f}=312 \exp (-30000 / T) C_{C O}\left(C_{\mathrm{H}_{2}}\right)^{3}$ & 120 \\
& $\mathrm{r}_{6 r}=6.09 \times 10^{14} \exp (-257000 / T) C_{\mathrm{CH}_{4}} C_{\mathrm{H}_{2} \mathrm{O}}$ & \\
\hline
\end{tabular}

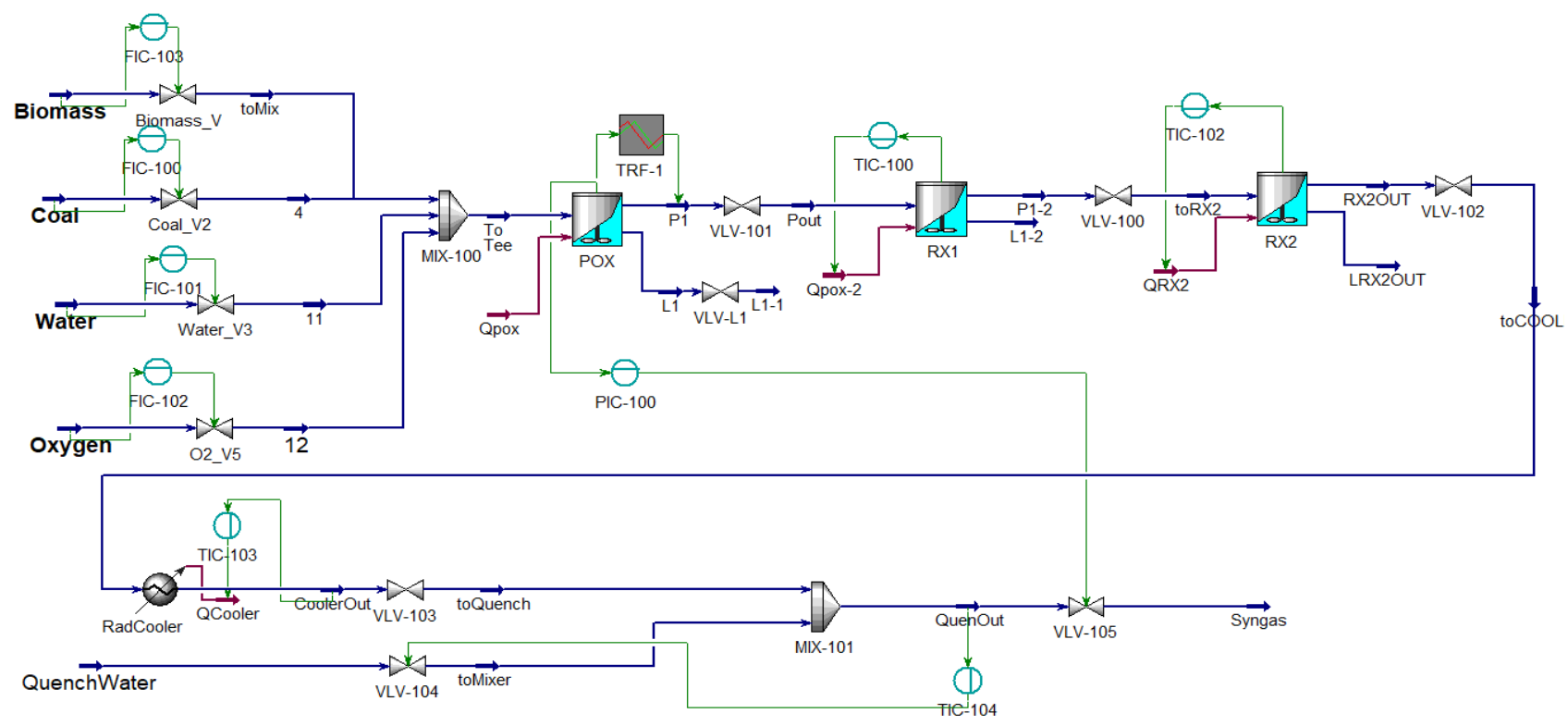

Figure 7.4 Aspen Hysys model of the gasification process addressed

Figure 7.5 shows the communication interface built to connect different software platforms. As shown in this figure, both the steady-state simulation and dynamic simulations are developed in Aspen Hysys while the multi-objective optimization (MOO) and control algorithm are coded in MATLAB. MOO is based on the steadystate model in Aspen Hysys and the connection between MATLAB and Aspen Hysys is accomplished via the component object model (COM) server. The Aspen Hysys dynamic simulation is connected with MATLAB by Aspen OTS and OPC server (OLE (Object Linking and Embedding) for Process Control). 


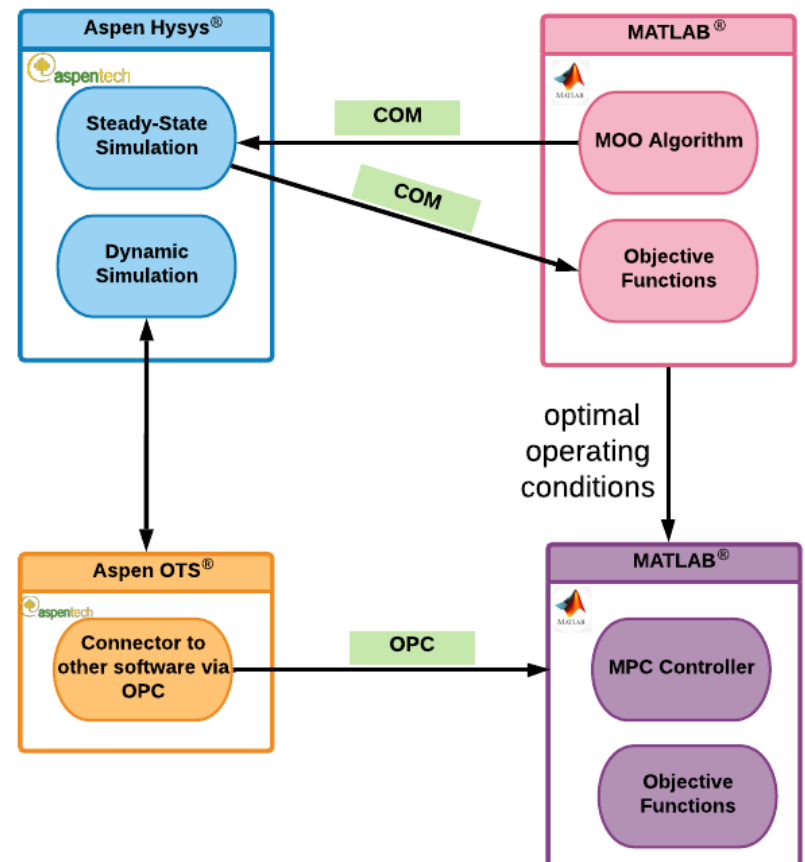

MoO: Multi-Objective Optimization

COM: Component Object Model

OPC: OLE (Object Linking and

Embedding) for Process Control

Figure 7.5 Communication interface between different software platforms

\subsubsection{MOO Results}

NSGA-III is an efficient and powerful algorithm for finding trade-offs between conflicting optimization objectives. The objective of the implemented NSGA-III is to find the optimal feeding ratio for biomass/coal to simultaneously minimize the environmental impact and operating cost objectives, which are defined in equations 7.12 and 7.13 , respectively.

$$
\begin{aligned}
& f_{1}=w_{1} \cdot S I_{G W P}+w_{2} \cdot S I_{m_{s, \text { spec }}}+w_{3} \cdot S I_{V_{L, \text { spec }}} \\
& f_{2}=\frac{\text { Operating Cost }}{\text { Syngas Production Rate }}
\end{aligned}
$$

s.t. Aspen Hysys Steady - State Model

$$
\begin{aligned}
& x(t) \in\left[x(t)^{l b}, x(t)^{u b}\right] \\
& u(t) \in\left[u(t)^{l b}, u(t)^{u b}\right]
\end{aligned}
$$


in which, $f_{1}$ and $f_{2}$ are the two objective functions. In $f_{1}, S I_{G W P}$, $S I_{m_{s, \text { spec }}}$ and $S I_{V_{L, \text { spec }}}$ are the sustainability indices associated with Global warming potential $(G W P)$, Specific solid waste mass $\left(m_{s, \text { spec }}\right)$, and Specific liquid waste volume $\left(V_{L, \text { spec }}\right)$, respectively.

By solving the resulting MOO problem with population size of 120 and generation number of 150, the Pareto frontier result is shown in Figure 7.6. Such Pareto trend shows that better economic performance requires higher waste/emissions (see for example the reference coal case). This can be attributed to the fact that biomass has lower environmental waste index and higher operating cost than coal due to the high cost of pre-treating and lower syngas yield comparing to coal gasification. Additional analysis is performed based on biomass content in the feeding stream. The results in Figure 7.6 show that by adding $<6.65 w t \%$ biomass in the gasification feeding, the environmental waste index can decrease dramatically (up to 11.5\%) while operating cost does not increase that much. A linear relationship is displayed for the environmental waste and operating cost indices from the biomass content in the feeding between $6.65 \sim 23.76 \%$. Also, it is shown that high biomass content (>23.76\%) makes the operating cost increase greater than $30 \%$, consistent to the literature on the study of biomass/coal co-gasification ${ }^{121,122}$.

For this case study, the weighting factors for environmental and operating cost functions are selected as 0.7 and 0.3 , respectively. A point can then be chosen by the decision maker using the method described above, as shown in Figure 7.7. For the control implementation, a setpoint tracking study is performed considering this point as reference to the controller. 


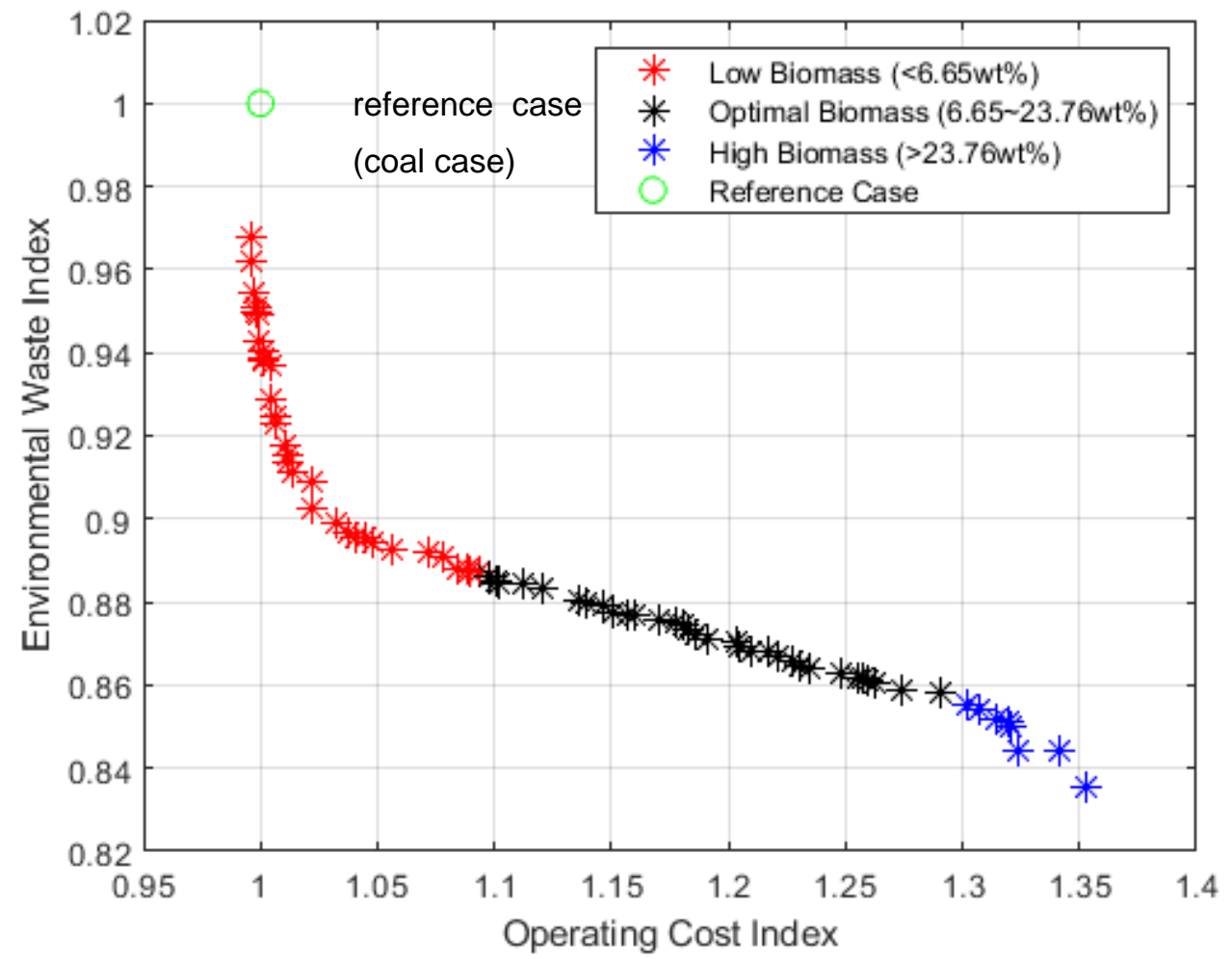

Figure 7.6 Pareto frontier for biomass/coal co-gasification process

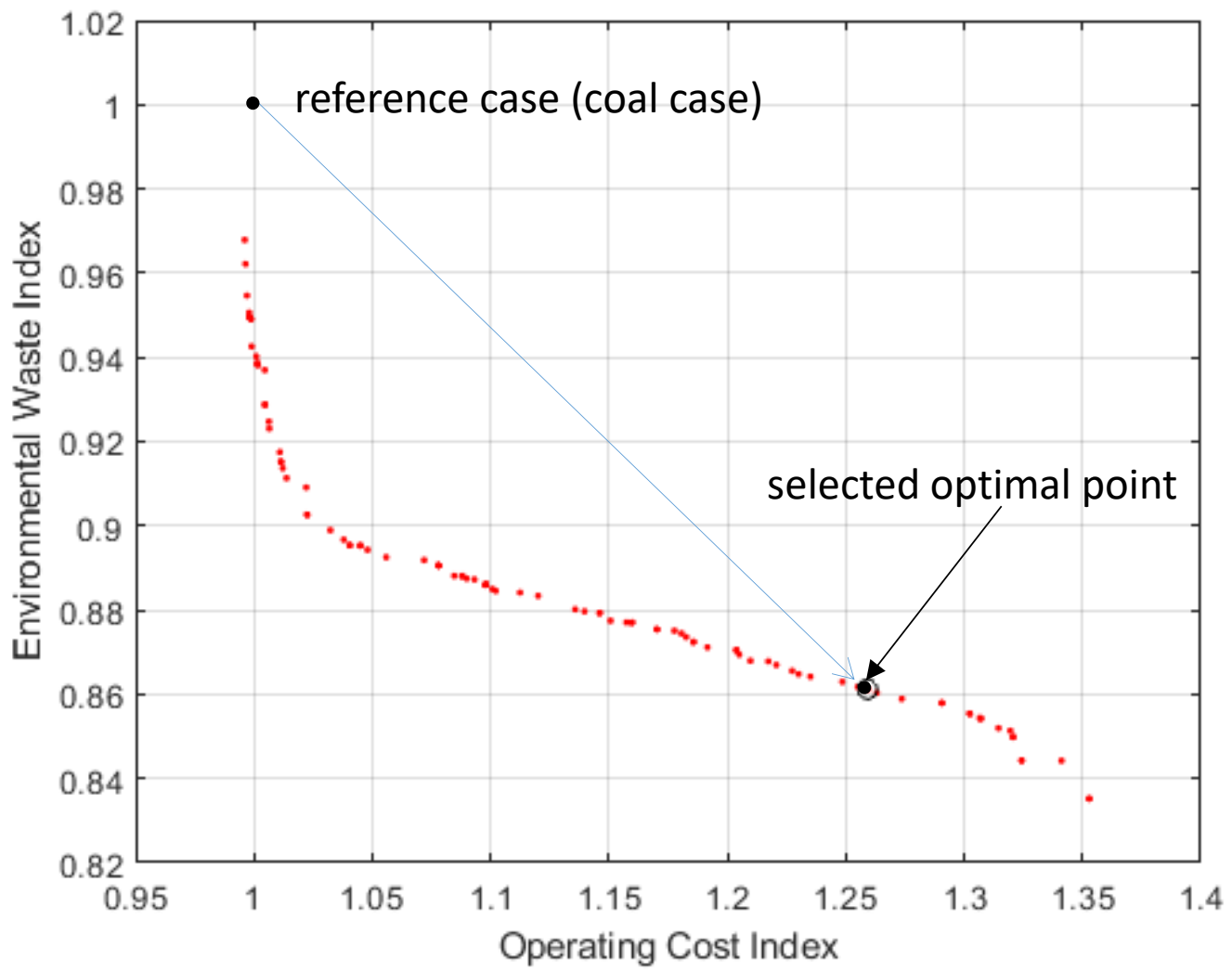

Figure 7.7 Selected operating condition for the MPC controller 


\subsubsection{MPC Implementation Results}

One case study is presented here to evaluate the effectiveness of the sustainable process control framework based on the multi-objective optimization. Based on previous analysis of this gasification process, a 3 by 3 control strategy is selected for the MPC by manipulating coal, oxygen and water flowrates to achieve the setpoints for syngas production rate, gasifier temperature and $\mathrm{H}_{2} / \mathrm{CO}$ ratio. The setpoints for the controlled variables are obtained from the decision making algorithm. Figure 7.8 shows the controller input and output trajectories. Note that the controller can take the system successfully to the setpoints. Moreover, the dynamic sustainability performance in Figure 7.8 shows that the control actions can also meet a pre-defined sustainability constraint in this case for GWP>0.6.
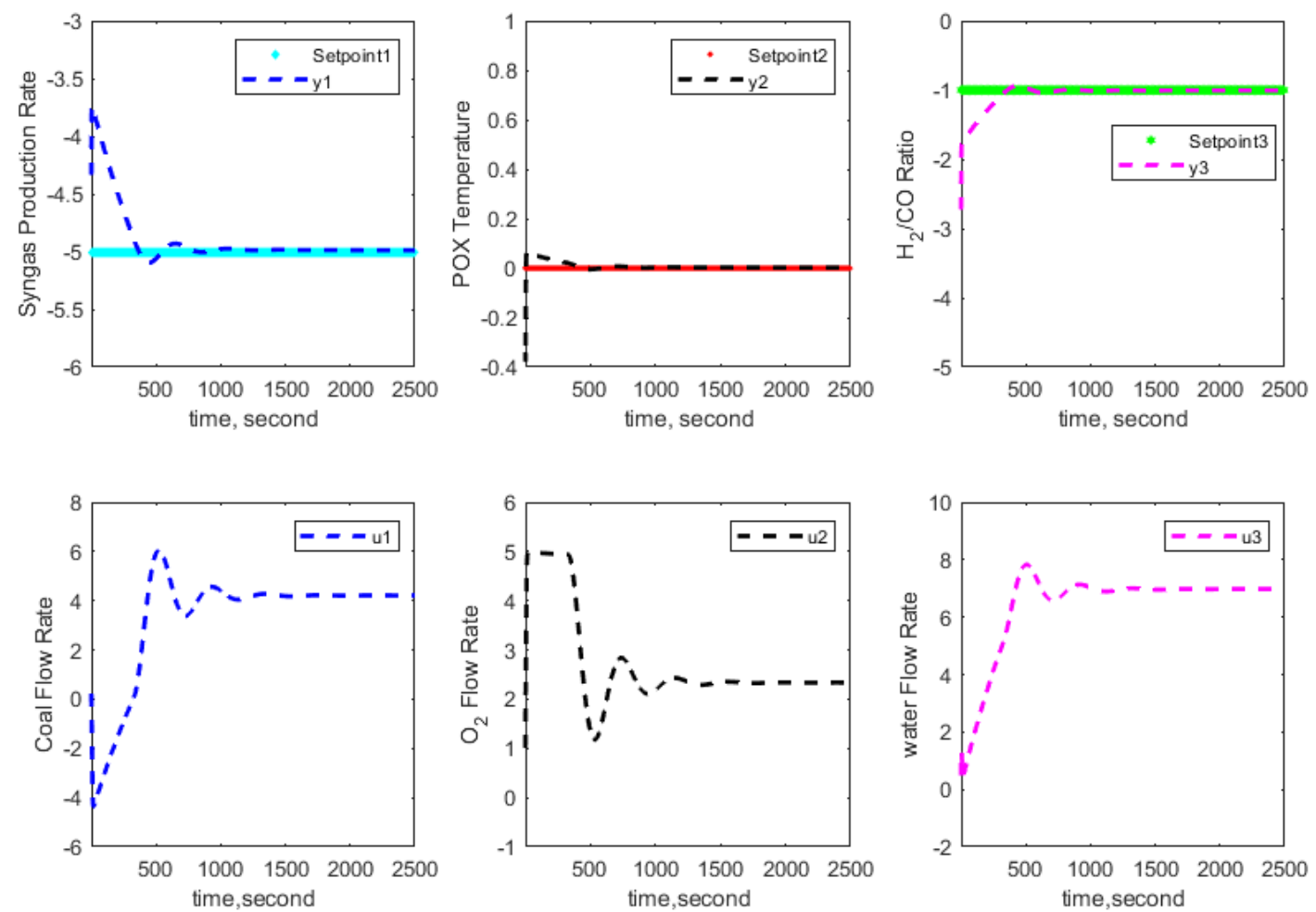

Figure 7.8 MPC results: input and output profiles 

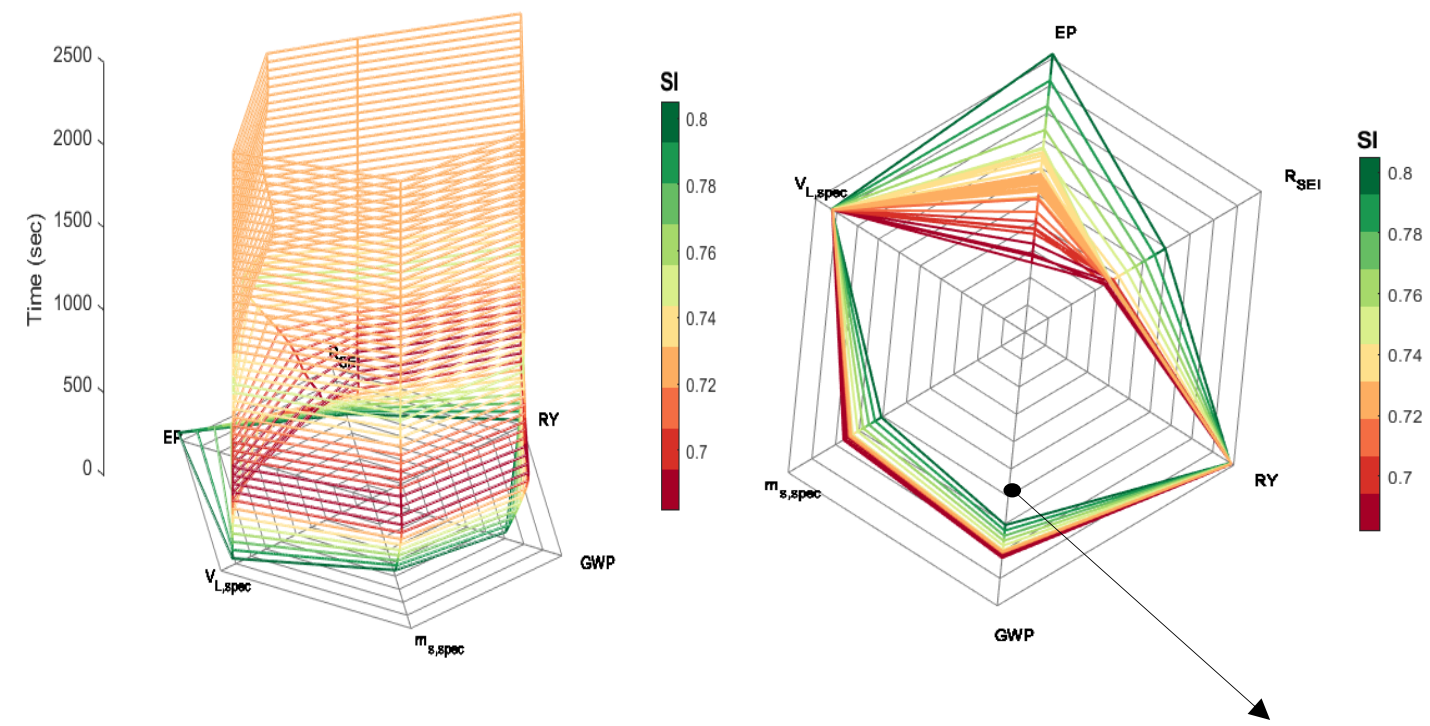

Figure 7.9 Sustainability performance of closed-loop simulation for gasification process

GWP Constraint (>0.6)

\subsection{Conclusions}

This chapter combined the previously introduced sustainability-oriented control strategy with a multi-objective optimization algorithm. Specifically, the multi-objective optimization solution considered the conflicting objective functions to define the setpoints for the sustainable process controller. Such integrated framework is developed to take the system to sustainable operating conditions along a predefined sustainable zone. The effectiveness of the proposed framework is demonstrated via a large-scale biomass/coal co-gasification process. 


\section{Chapter 8 Conclusions and Recommendations}

In this dissertation, process systems engineering (PSE) methods were developed for evaluating and improving sustainability performance of chemical processes during steady-state and transient operations. In particular, an integrated tool was developed to provide a systematic and comprehensive way of quantifying the sustainability performance of chemical processes. This developed tool was applied to chemical manufacturing processes. In order to further examine and improve process sustainability performance during transient, a multi-variable sustainability visualization method, multi-objective optimization approaches and a sustainable process control strategy were proposed. These developed approaches can fill the knowledge gap regarding the lack of tools for assessing the dynamic sustainability performance of chemical processes.

Below, the major contributions made in this dissertation are summarized as well as some future directions that are worth research attention are provided.

\subsection{Major contributions}

In Chapter 2, a comprehensive literature review was given considering the current available tools and methods for sustainability of chemical manufacturing processes. Moreover, the limitations and gaps on current sustainability studies for chemical processes were pinpointed.

In Chapter 3, a sustainability assessment tool was developed, focusing on an integrated framework for automatically generate gate-to-gate LCI data based on process modeling, simulation, and design. To augment the current capability of commercial simulators, parameterized PCU tools were developed for providing data for rapid LCl estimation and sustainability assessment. This method showed to be more efficient and accurate than available $\mathrm{LCl}$ data base or top-down methods. 
Additionally, in Chapter 4, such integrated tool was further expanded to integrate process simulation, PCU, $\mathrm{LCl}$ and GREENSCOPE for sustainability indicator calculations and demonstrated with a large-scale biomass/coal-to-AA process. This framework provides a systematic and comprehensive way to evaluate the sustainability performance of chemical processes.

For the dynamic sustainability studies in Chapter 5 , the benefit of integrating sustainability assessment tool with process dynamics was presented using a motivating example. The obtained sustainability assessment results can provide systematic guidelines for decision-makers as well as show whether the implementation of an advanced controller can improve the system's sustainability performance. Then, in Chapter 6, a novel sustainability-oriented control strategy was proposed to improve process sustainability during transient. This sustainable process control framework with dynamic sustainability is capable of detecting regions of operation with lower sustainability performance. Using the dynamic sustainability result, a reasonable constraint can be imposed on the sustainability indicators so that control actions can be optimized for improving sustainability performance. Finally, in Chapter 7, the sustainable process control framework was combined with multi-objective optimization. This framework can provide the optimal setpoints in terms of sustainability for the controller considering sustainability aspects during transients.

\subsection{Recommendations}

Based on the findings presented in this dissertation, the following future directions are recommended:

- The integrated tool for $\mathrm{LCl}$ estimation and sustainability assessment is general and can be applicable to any process. Currently, only one case study was 
used to demonstrate this framework. It would be interesting if more chemical processes could be tackled. Also, it would be useful if a superstructure optimization algorithm could be equipped with the tool for selecting optimal PCUs for treating certain waste streams.

- Other multi-objective optimization and decision-making algorithms could be tested for the co-gasification processes, such as Particle swarm optimization (PSO) with a more advanced ranking algorithm. It would be interesting to see comparisons among different MOO algorithms.

- In the performed studies, one sustainability constraint was considered where the boundary was set through trial and error. In the future, an online performance analysis system for locating the most important sustainability indicator can be investigated to automatically give the sustainability indicator constraint. Also, it would be meaningful to study a dynamic operability method for guiding the definition of a constraint threshold for improving the controller robustness. 


\section{References}

(1) Cano-Ruiz, J. A.; McRae, G. J. Environmentally Conscious Chemical Process Design. Annu. Rev. Energy Environ. 1998, 23 (1), 499-536.

(2) Anastas, P. T.; Zimmerman, J. B. Through the 12 Principles GREEN Engineering. Env. Sci Technol 2003, 2 (37(5)), 94A-101A.

(3) UUNE Program. Report of the World Commission on Environment and Development: Our Common Future. http://www.un-documents.net/wced-ocf.htm (accessed Nov 17, 2019).

(4) Sikdar, S. K. Sustainable Development and Sustainability Metrics. AIChE J. 2003, 49 (8), $1928-1932$.

(5) Martins, A. A.; Mata, T. M.; Costa, C. A. V.; Sikdar, S. K. Framework for Sustainability Metrics. Ind. Eng. Chem. Res. 2007, 46 (10), 2962-2973.

(6) Bakshi, B. R.; Fiksel, J. The Quest for Sustainability: Challenges for Process Systems Engineering. AIChE J. 2003, 49 (6), 1350-1358.

(7) Allen, D. T.; Shonnard, D. R. Green Engineering: Environmentally Conscious Design of Chemical Processes; Pearson Education, 2001.

(8) Gao, J.; You, F. Endpoint-Oriented Life Cycle Optimization Models for Sustainable Design and Operations of Shale Gas Supply Chains with Modular Manufacturing. Comput. Aided Chem. Eng. 2018, $43,591-596$.

(9) Dubey, R.; Gunasekaran, A.; Papadopoulos, T.; Childe, S. J.; Shibin, K. T.; Wamba, S. F. Sustainable Supply Chain Management: Framework and Further Research Directions. J. Clean. Prod. 2017, 142, 11191130 .

(10) Lozano, F. J.; Lozano, R.; Freire, P.; Jiménez-Gonzalez, C.; Sakao, T.; Ortiz, M. G.; Trianni, A.; Carpenter, A.; Viveros, T. New Perspectives for Green and Sustainable Chemistry and Engineering: Approaches from Sustainable Resource and Energy Use, Management, and Transformation. J. Clean. Prod. 2018, 172, 227-232.

(11) Ghosh, T.; Liu, X.; Bakshi, B. R. Including Ecosystem Services in Sustainable Process Design across Multiple Spatial Scales. Comput. Aided Chem. Eng. 2018, 44, 1837-1842.

(12) Hellweg, S.; Milà Canals, L. Emerging Approaches, Challenges and Opportunities in Life Cycle Assessment. Science (80-. ). 2014, 344 (6188), 1109-1113.

(13) Guinée, J. B.; Heijungs, R.; Huppes, G.; Zamagni, A.; Masoni, P.; Buonamici, R.; Ekvall, T.; Rydberg, T. Life Cycle Assessment : Past, Present, and Future. Environ. Sci. Technol. 2011, 45 (1), 90-96.

(14) Handbook of Pollution Control and Waste Minimization; Ghassemi, A., Ed.; CRC Press, 2001.

(15) U.S. Environmental Protection Agency. TSCA Chemical Substance Inventory https://www.epa.gov/tscainventory/about-tsca-chemical-substance-inventory\%23whatistheinventory\#bonafide (accessed Jul 30, 2017).

(16) U.S. Environmental Protection Agency. TSCA Interim List of Active Substances https://www.epa.gov/tsca-inventory/interim-list-active-substances (accessed Aug 18, 2017).

(17) Cashman, S. A.; Meyer, D. E.; Edelen, A. N.; Ingwersen, W. W.; Abraham, J. P.; Barrett, W. M.; Gonzalez, M. A.; Randall, P. M.; Ruiz-Mercado, G.; Smith, R. L. Mining Available Data from the United States Environmental Protection Agency to Support Rapid Life Cycle Inventory Modeling of Chemical Manufacturing. Environ. Sci. Technol. 2016, 50 (17), 9013-9025.

(18) Smith, R. L.; Ruiz-Mercado, G.; Meyer, D. E.; Gonzalez, M. A.; Abraham, J. P.; Barrett, W. M.; Randall, P. M. Coupling Computer-Aided Process Simulation and Estimations of Emissions and Land Use for Rapid 
Life Cycle Inventory Modeling. ACS Sustain. Chem. Eng. 2017, 5 (5), 3786-3794.

(19) Subramanian, V.; Golden, J. S. Patching Life Cycle Inventory (LCI) Data Gaps through Expert Elicitation: Case Study of Laundry Detergents. J. Clean. Prod. 2016, 115, 354-361.

(20) Wernet, G.; Bauer, C.; Steubing, B.; Reinhard, J.; Moreno-Ruiz, E.; Weidema, B. The Ecoinvent Database Version 3 (Part I): Overview and Methodology. Int. J. Life Cycle Assess. 2016, 21 (9), 1218-1230.

(21) Geisler, G.; Hofstetter, T. B.; Hungerbühler, K. Production of Fine and Speciality Chemicals: Procedure for the Estimation of LCIs. Int. J. Life Cycle Assess. 2004, 9 (2), 101-113.

(22) Jiménez-González, C.; Kim, S.; Overcash, M. R. Methodology for Developing Gate-to-Gate Life Cycle Inventory Information. Int. J. Life Cycle Assess. 2000, 5 (3), 153-159.

(23) Bretz, R.; Frankhauser, P. Screening LCA for Large Numbers of Products. Int. J. Life Cycle Assess. 1996, 1 (3), 139-146.

(24) Hischier, R.; Hellweg, S.; Capello, C.; Primas, A. Establishing Life Cycle Inventories of Chemicals Based on Differing Data Availability (9 Pp). Int. J. Life Cycle Assess. 2005, 10 (1), 59-67.

(25) Yao, Y.; Masanet, E. Life-Cycle Modeling Framework for Generating Energy and Greenhouse Gas Emissions Inventory of Emerging Technologies in the Chemical Industry. J. Clean. Prod. 2018, 172, 768 777.

(26) Yang, Y.; Ingwersen, W. W.; Hawkins, T. R.; Srocka, M.; Meyer, D. E. USEEIO: A New and Transparent United States Environmentally-Extended Input-Output Model. J. Clean. Prod. 2017, 158, 308-318.

(27) Bojarski, A. D.; Guillén-Gosálbez, G.; Jiménez, L.; Espuña, A.; Puigjaner, L. Life Cycle Assessment Coupled with Process Simulation under Uncertainty for Reduced Environmental Impact: Application to Phosphoric Acid Production. Ind. Eng. Chem. Res. 2008, 47 (21), 8286-8300.

(28) Kiruchi, Y.; Mayumi, K.; Hirao, M. Integration of CAPE and LCA Tools in Environmentally-Conscious Process Design: A Case Study on Biomass-Derived Resin. In 20th European Symposium on Computer Aided Process Engineering - ESCAPE20; S. Pierucci, G. Buzzi Ferraris, Eds.; Elsevier B.V., 2010; Vol. 28C, pp 1051-1056.

(29) Petrescu, L.; Fermeglia, M.; Cormos, C.-C. Life Cycle Analysis Applied to Acrylic Acid Production Process with Different Fuels for Steam Generation. J. Clean. Prod. 2016, 133, 294-303.

(30) Sugiyama, H.; Fischer, U.; Hungerbühler, K.; Hirao, M. Decision Framework for Chemical Process Design Including Different Stages of Environmental, Health, and Safety Assessment. AIChE J. 2008, 54 (4), 1037-1053.

(31) Villalba, G.; Ayres, L.; Ayres, R. U. A Proposal for Emission Calculations for Chemical Processes, Part I. Resour. Conserv. Recycl. 2006, 48 (3), 280-299.

(32) Ling-Chin, J.; Heidrich, O.; Roskilly, A. P. Life Cycle Assessment (LCA) - From Analysing Methodology Development to Introducing an LCA Framework for Marine Photovoltaic (PV) Systems. Renew. Sustain. Energy Rev. 2016, 59, 352-378.

(33) Heijungs, R.; Suh, S. Reformulation of Matrix-Based LCI: From Product Balance to Process Balance. J. Clean. Prod. 2006, 14 (1), 47-51.

(34) Chemstations. ChemCAD 7.0 http://chemstations.com/.

(35) AspenTech. Aspen Hysys 8.4 http://www.aspentech.com/products/aspen-hysys/.

(36) Charpentier, J.-C. What Kind of Modern “Green" Chemical Engineering Is Required for the Design of the "Factory of Future"? Procedia Eng. 2016, 138, 445-458.

(37) Bakshi, B. R. Toward Sustainable Chemical Engineering: The Role of Process Systems Engineering. Annu. Rev. Chem. Biomol. Eng. 2019, 10, 265-288. 
(38) Ruiz-Mercado, G. J.; Carvalho, A.; Cabezas, H. Using Green Chemistry and Engineering Principles to Design, Assess, and Retrofit Chemical Processes for Sustainability. ACS Sustain. Chem. Eng. 2016, 4 (11), 6208-6221.

(39) Young, D. M.; Cabezas, H. Designing Sustainable Processes with Simulation: The Waste Reduction (WAR) Algorithm. Comput. Chem. Eng. 1999, 23 (10), 1477-1491.

(40) Xu, D.; Li, W.; Shen, W.; Dong, L. Decision-Making for Sustainability Enhancement of Chemical Systems under Uncertainties: Combining the Vector-Based Multiattribute Decision-Making Method with Weighted Multiobjective Optimization Technique.

(41) Warning, N.; Copyright, C. Sustainable and Innovative Solutions through an Integrated Systematic Framework.

(42) Sikdar, S. K. Sustainable Development and Sustainability Metrics. AIChE J. 2003, 49 (8), 1928-1932.

(43) Cobb, C.; Schuster, D.; Beloff, B.; Tanzil, D. The AIChE Sustainability Index the Factors in Detail. Chem. Eng. Prog 2009, 111, 59-63.

(44) Inst. Chem. Eng. The Sustainability Metrics: Sustainable Development Progress Metrics Recommended for Use in Process Industries; Inst. Chem. Eng., Ed.; Warwickshire, UK: Inst. Chem. Eng., 2014.

(45) Ruiz-Mercado, G. J.; Gonzalez, M. A.; Smith, R. L. Sustainability Indicators for Chemical Processes: III. Biodiesel Case Study. Ind. Eng. Chem. Res. 2013, 52 (20), 6747-6760.

(46) Ruiz-Mercado, G. J.; Gonzalez, M. A.; Smith, R. L. Expanding GREENSCOPE beyond the Gate: A Green Chemistry and Life Cycle Perspective. Clean Technol. Environ. Policy 2014, 16 (4), 703-717.

(47) Ruiz-Mercado, G. J.; Smith, R. L.; Gonzalez, M. A. Sustainability Indicators for Chemical Processes: I. Taxonomy. Ind. Eng. Chem. Res. 2012, 51 (5), 2309-2328.

(48) Ruiz-Mercado, G. J.; Smith, R. L.; Gonzalez, M. A. Sustainability Indicators for Chemical Processes: II. Data Needs. Ind. Eng. Chem. Res 2012, 51, 2329-2353.

(49) Freeman, H.; Harten, T.; Springer, J.; Randall, P.; Curran, M. A.; Stone, K. Industrial Pollution Prevention: A Critical Review. J. Air Waste Manage. Assoc. 1992, 42 (5), 618-656.

(50) Eberle, A.; Bhatt, A.; Zhang, Y.; Heath, G. Potential Air Pollutant Emissions and Permitting Classifications for Two Biorefinery Process Designs in the United States. Environ. Sci. Technol. 2017, 51 (11), 5879-5888.

(51) Bhatt, A.; Zhang, Y.; Davis, R.; Eberle, A.; Heath, G. Economic Implications of Incorporating Emission Controls to Mitigate Air Pollutants Emitted from a Modeled Hydrocarbon-Fuel Biorefinery in the United States. Biofuels, Bioprod. Biorefining 2016, 10 (5), 603-622.

(52) Li, S.; Feliachi, Y.; Agbleze, S.; Ruiz-Mercado, G. J.; Smith, R. L.; Meyer, D. E.; Gonzalez, M. A.; Lima, F. V. A Process Systems Framework for Rapid Generation of Life Cycle Inventories for Pollution Control and Sustainability Evaluation. Clean Technol. Environ. Policy 2018, 20 (7).

(53) Bakshi, B. R. Methods and Tools for Sustainable Process Design. Curr. Opin. Chem. Eng. 2014, 6, 69-74.

(54) El-Halwagi, M. M. Pollution Prevention through Process Integration: Systematic Design Tools; Elsevier, 1997.

(55) Stankiewicz, A. I.; Moulijn, J. A. Process Intensification: Transforming Chemical Engineering. Chem. Eng. Prog. 2000, 96 (1), 22-34.

(56) Li, C.; Zhang, X.; Zhang, S.; Suzuki, K. Environmentally Conscious Design of Chemical Processes and Products: Multi-Optimization Method. Chem. Eng. Res. Des. 2009, 87 (2), 233-243.

(57) Banos, R.; Manzano-Agugliaro, F.; Montoya, F. G.; Gil, C.; Alcayde, A.; Gómez, J. Optimization Methods Applied to Renewable and Sustainable Energy: A Review. Renew. Sustain. energy Rev. 2011, 15 (4), 17531766. 
(58) Wang, B.; Gebreslassie, B. H.; You, F. Sustainable Design and Synthesis of Hydrocarbon Biorefinery via Gasification Pathway: Integrated Life Cycle Assessment and Technoeconomic Analysis with Multiobjective Superstructure Optimization. Comput. Chem. Eng. 2013, 52, 55-76.

(59) Gong, J.; You, F. Global Optimization for Sustainable Design and Synthesis of Algae Processing Network for CO2 Mitigation and Biofuel Production Using Life Cycle Optimization. AIChE J. 2014, 60 (9), $3195-$ 3210.

(60) Rossi, F.; Manenti, F.; Mujtaba, I. M.; Bozzano, G. A Novel Real-Time Methodology for the Simultaneous Dynamic Optimization and Optimal Control of Batch Processes. In Computer Aided Chemical Engineering; Elsevier, 2014; Vol. 33, pp 745-750.

(61) Stefanis, S. K.; Pistikopoulos, E. N. Methodology for Environmental Risk Assessment of Industrial Nonroutine Releases. Ind. Eng. Chem. Res. 1997, 36 (9), 3694-3707.

(62) Chen, H.; Shonnard, D. R. Systematic Framework for Environmentally Conscious Chemical Process Design: Early and Detailed Design Stages. Ind. Eng. Chem. Res. 2004, 43 (2), 535-552.

(63) Othman, M. R.; Repke, J.-U.; Wozny, G.; Huang, Y. A Modular Approach to Sustainability Assessment and Decision Support in Chemical Process Design. Ind. Eng. Chem. Res. 2010, 49 (17), 7870-7881.

(64) Aslam, T.; Amos, H. C. N. Multi-Objective Optimization for Supply Chain Management: A Literature Review and New Development. In 2010 8th International Conference on Supply Chain Management and Information; IEEE, 2010; pp 1-8.

(65) Alanqar, A.; Ellis, M.; Christofides, P. D. Economic Model Predictive Control of Nonlinear Process Systems Using Empirical Models. AIChE J. 2015, 61 (3), 816-830.

(66) Mesbah A. Stochastic Model Predictive Control: An Overview and Perspectives for Future Research. IEEE Control Syst. 2016, 36 (6), 30-44.

(67) Zhang, Z.; Wu, Z.; Rincon, D.; Garcia, C.; Christofides, P. D. Operational Safety of Chemical Processes via Safeness-Index Based MPC: Two Large-Scale Case Studies. Comput. Chem. Eng. 2019, 204-215.

(68) Daoutidis, P.; Zachar, M.; Jogwar, S. S. Sustainability and Process Control: A Survey and Perspective. J. Process Control 2016, 44, 184-206.

(69) Rossi, F.; Manenti, F.; Pirola, C.; Mujtaba, I. A Robust Sustainable Optimization \& Control Strategy (RSOCS) for (Fed-)Batch Processes towards the Low-Cost Reduction of Utilities Consumption. J. Clean. Prod. 2016, 111, 181-192.

(70) Zhu, Q.; Lujia, F.; Mayyas, A.; Omar, M. A.; Al-Hammadi, Y.; Al Saleh, S. Production Energy Optimization Using Low Dynamic Programming: A Decision Support Tool for Sustainable Manufacturing. J. Clean. Prod. 2015, 105, 178-183.

(71) Cheung, H.; Tanke, R. S.; Torrence, P. G. Acetic Acid. In Ullmann's Encyclopedia of Industrial Chemistry; Hawkins, S., Russey, W., Eds.; 2001; pp 209-237.

(72) Sunley, G. J.; Watson, D. J. High Productivity Methanol Carbonylation Catalysis Using Iridium. The Cativa Process for the Manufacture of Acetic Acid. Catal. Today 2000, 58 (4), 293-307.

(73) Zhu, Y.; Jones, S. B. Techno-Economic Analysis for the Thermochemical Conversion of Lignocellulosic Biomass to Ethanol via Acetic Acid Synthesis (DOE Report); 2009.

(74) Sundaram, S.; Kolb, G.; Hessel, V.; Wang, Q. Energy-Efficient Routes for the Production of Gasoline from Biogas and Pyrolysis Oil-Process Design and Life-Cycle Assessment. Ind. Eng. Chem. Res. 2017, 56 (12), 3373-3387.

(75) Peters, M. S.; Timmerhaus, K. D.; West, R. E. Plant Design and Economics for Chemical Engineers; Peters, M. S., Timmerhaus, K. D., West, R. E., Eds.; McGraw-Hill: New York, 2003. 
(76) U.S Environmental Protection Agency. EPA Air Pollution Control Cost Manual https://www3.epa.gov/ttncatc1/dir1/c_allchs.pdf (accessed Jul 30, 2017).

(77) U.S. Environmental Protection Agency. Wet Scrubbers for Acid Gas Control https://www3.epa.gov/ttn/ecas/docs/cs5-2ch1.pdf (accessed Jun 30, 2017).

(78) Theodore, L. Air Pollution Control Equipment Calculations; John Wiley \& Sons, Inc.: Hoboken, New Jersey, 2008.

(79) U.S. Government Publishing Office. Title 40: Protection of Environment, Chapter I (subchapter I, part 266, subpart H): Hazardous Waste Burned in Boilers and Industrial Furnaces https://www.ecfr.gov/cgibin/textidx?SID=27dc7fde95016674672f62fcb318cf19\&mc=true\&node=pt40.27.266\&rgn=div5\#sp40.29.266.h. (accessed Aug 19, 2017).

(80) U.S. Environmental Protection Agency. EPA Enforcement Targets Flaring Efficiency Violations. https://www.epa.gov/sites/production/files/documents/flaringviolations.pdf (accessed Jul 30, 2017).

(81) Diana K. Stone; Lynch, S. K.; Pandullo, R. F.; Evans, L. B.; William M. Vatavuk. Flares. Part I: Flaring Technologies for Controlling VOC-Containing Waste Streams. J. Air Waste Manage. Assoc. 1992, 42 (3), 333-340.

(82) Worley, M.; Yale, J. Biomass Gasification Technology Assessment: Consolidated Report http://www.nrel.gov/docs/fy13osti/57085.pdf (accessed Jul 28, 2017).

(83) Robinson, P. J. Dynamic Modeling and Plantwide Control of a Hybrid Power and Chemical Plant: An Integrated Gasification Combined Cycle Coupled with a Methanol Plant.; 2011.

(84) Fout, T.; Zoelle, A.; Keairns, D.; Turner, M.; Woods, M.; Kuehn, N.; Shah, V.; Chou, V.; Pinkerton, L. Cost and Performance Baseline for Fossil Energy Plants Volume 1b: Bituminous Coal (IGCC) to Electricity. 2015, 1b, 265.

(85) Robinson, P. J.; Luyben, W. L. Simple Dynamic Gasifier Model That Runs in Aspen Dynamics. 2008, 7784-7792.

(86) U.S. Environmental Protection Agency. Wet Scrubbers for Acid Gas Control https://www3.epa.gov/ttn/ecas/docs/cs5-2ch1.pdf. Accessed 20 June 2017 (accessed Jan 10, 2018).

(87) NGC+ Interchangeability Work Group. White Paper on Natural Gas Interchangeability and NonCombustion End Use. https://www.ferc.gov/eventcalendar/Files/20050316082958-interchangeability.pdf (accessed Aug 22, 2017).

(88) National Renewable Energy Laboratory. U.S. Life Cycle Inventory Database https://www.lcacommons.gov/nrel/search (accessed Aug 22, 2017).

(89) Li, S.; Mirlekar, G.; Ruiz-Mercado, G.; Lima, F. Development of Chemical Process Design and Control for Sustainability. Processes 2016, 4 (3), 23.

(90) Lima, F. V.; Li, S.; Mirlekar, G. V.; Sridhar, L. N.; Ruiz-Mercado, G. Modeling and Advanced Control for Sustainable Process Systems. In Sustainability in the design, synthesis and analysis of chemical engineering processes; Elsevier, 2016; pp 115-138.

(91) EPA. Air Pollution Control Technology Fact Sheet: Fabric Filter Pulse-Jet Cleaned Type. Environ. Prot. agency 2002, 1-6.

(92) EPA. Air Pollution Control Technology. 1-7.

(93) James H Turner; John D Mckenna; William M. Vatavuk. Baghouses and Filters (Particulate Matter Controls); 1998.

(94) US EPA Office of Water. Work Breakdown Structure-Based Cost Models for Drinking Water Treatment 
Technologies. 2014, No. May.

(95) Smith, R. L.; Tan, E. C. D.; Ruiz-Mercado, G. J. Applying Environmental Release Inventories and Indicators to the Evaluation of Chemical Manufacturing Processes in Early Stage Development. ACS Sustain. Chem. Eng. 2019, acssuschemeng.9b01961.

(96) Ruiz-Mercado, G. J.; Smith, R. L.; Gonzalez, M. A. GREENSCOPE.Xlsm TOOL; 2013.

(97) Anastas, P. T.; Tundo, P. Green Chemistry: Challenging Perspectives; Oxford University Press Oxford:, 2000.

(98) Bruckstein, A. M. Why the Ant Trails Look so Straight and Nice. Math. Intell. 1993, 15 (2), $59-62$.

(99) Mirlekar, G.; Li, S.; Lima, F. V. Design and Implementation of a Biologically Inspired Optimal Control Strategy for Chemical Process Control. Ind. Eng. Chem. Res. 2017, 56 (22), 6468-6479.

(100) Daugulis, A. J.; McLellan, P. J.; Li, J. Experimental Investigation and Modeling of Oscillatory Behavior in the Continuous Culture of Zymomonas Mobilis. Biotechnol. Bioeng. 1997, 56 (1), 99-105.

(101) Ghommidh, C.; Vaija, J.; Bolarinwa, S.; Navarro, J. M. Oscillatory Behaviour OfZymomonas in Continuous Cultures: A Simple Stochastic Model. Biotechnol. Lett. 1989, 11 (9), 659-664.

(102) Humphrey, A. E. Fermentation Process Modeling: An Overview. Ann. N. Y. Acad. Sci. 1979, 326 (1), 1733.

(103) Jarzębski, A. B. Modelling of Oscillatory Behaviour in Continuous Ethanol Fermentation. Biotechnol. Lett. 1992, 14 (2), 137-142.

(104) Jöbses, I. M. L.; Egberts, G. T. C.; Luyben, K.; Roels, J. A. Fermentation Kinetics of Zymomonas Mobilis at High Ethanol Concentrations: Oscillations in Continuous Cultures. Biotechnol. Bioeng. 1986, 28 (6), 868877.

(105) Jöbses, I. M. L.; Roels, J. A. The Inhibition of the Maximum Specific Growth and Fermentation Rate of Zymomonas Mobilis by Ethanol. Biotechnol. Bioeng. 1986, 28 (4), 554-563.

(106) Pirt, S. J. The Maintenance Energy of Bacteria in Growing Cultures. Proc. R. Soc. London. Ser. B. Biol. Sci. 1965, 163 (991), 224-231.

(107) Huang, S.-Y.; Chen, J.-C. Analysis of the Kinetics of Ethanol Fermentation with Zymomonas Mobilis Considering Temperature Effect. Enzyme Microb. Technol. 1988, 10 (7), 431-439.

(108) Mahecha-Botero, A.; Garhyan, P.; Elnashaie, S. Non-Linear Characteristics of a Membrane Fermentor for Ethanol Production and Their Implications. Nonlinear Anal. Real World Appl. 2006, 7 (3), 432-457.

(109) Wang, H.; Zhang, N.; Qiu, T.; Zhao, J.; He, X.; Chen, B. Analysis of Hopf Points for a Zymomonas Mobilis Continuous Fermentation Process Producing Ethanol. Ind. Eng. Chem. Res. 2013, 52 (4), 1645-1655.

(110) Lima, F. V.; Li, S.; Mirlekar, G. V.; Sridhar, L. N.; Ruiz-Mercado, G. Modeling and Advanced Control for Sustainable Process Systems; 2016.

(111) Fikar, M. Dynopt Solver https://www.uiam.sk/ fikar/research/dynopt/dynopt.htm (accessed Sep 10, 2019).

(112) Mirlekar, G.; Gebreslassie, B. H.; Li, S.; Diwekar, U. M.; Lima, F. V. An Integrated Biomimetic Control Strategy with Multi-Agent Optimization for Nonlinear Chemical Processes. IFAC-PapersOnLine 2018, 51 (18), 55-60.

(113) Mirlekar, G.; Pezzini, P.; Bryden, M.; Tucker, D.; Lima, F. V. A Biologically-Inspired Optimal Control Strategy (BIO-CS) for Hybrid Energy Systems. In 2017 American Control Conference (ACC); IEEE, 2017; pp 4821-4826.

(114) Mirlekar, G.; Al-Sinbol, G.; Perhinschi, M.; Lima, F. V. A Biologically-Inspired Approach for Adaptive Control of Advanced Energy Systems. Comput. Chem. Eng. 2018, 117, 378-390.

(115) Mirlekar, G.; Gebreslassie, B., Diwekar, U. and Lima, F.V. Biomimetic model-based advanced control 
strategy integrated with multi-agent optimization for nonlinear chemical processes. Chemical Engineering Research and Design, 2018, 140, 229-240.

(116) Tavana, M.; Li, Z.; Mobin, M.; Komaki, M.; Teymourian, E. Multi-Objective Control Chart Design Optimization Using NSGA-III and MOPSO Enhanced with DEA and TOPSIS. Expert Syst. Appl. 2016, 50, 17-39.

(117) Otte, D.; Lorenz, H. M.; Repke, J. U. A Toolbox Using the Stochastic Optimization Algorithm MIPT and ChemCAD for the Systematic Process Retrofit of Complex Chemical Processes. Comput. Chem. Eng. 2016, 84, 371-381.

(118) Loison, R.; Chauvin, R. Rapid Pyrolysis of Coal. Chim. Ind. 1964, 91, 269-275.

(119) Kong, X.; Zhong, W.; Du, W.; Qian, F. Three Stage Equilibrium Model for Coal Gasification in Entrained Flow Gasifiers Based on Aspen Plus. Chinese J. Chem. Eng. 2013, 21 (1), 79-84.

(120) Robinson, P. J. Dynamic Modeling and Plantwide Control of a Hybrid Power and Chemical Plant: An Integrated Gasification Combined Cycle Coupled with a Methanol Plant. 2011, 259.

(121) Chmielniak, T.; Sciazko, M. Co-Gasification of Biomass and Coal for Methanol Synthesis. Appl. Energy 2003, 74 (3-4), 393-403.

(122) Wu, Z.; Ouyang, D. Technical-Economical Analysis on Co-Gasification of Coal and Biomass Based on the IGCC System with a Two-Staged Gasifier. Energy Procedia 2017, 142, 774-779. 


\section{Appendix A}

Table A1. PCU_Flare Unit

\begin{tabular}{|c|c|c|c|c|c|c|c|c|c|c|}
\hline \multicolumn{3}{|c|}{ Flare Input } & \multicolumn{8}{|c|}{ Flare Dutput } \\
\hline Temperature & $\mathrm{C}$ & 30 & & \multirow{9}{*}{\multicolumn{2}{|c|}{ Gas Phase }} & \multirow{9}{*}{\multicolumn{3}{|c|}{ Utility }} & \multirow{9}{*}{ Land } & \multirow{9}{*}{ Material } \\
\hline Pressure & $\mathrm{kPa}$ & 150 & & & & & & & & \\
\hline Flare type & -.......... & Steam-assisted & & & & & & & & \\
\hline Desired CE & $\%$ & 98 & & & & & & & & \\
\hline Local Wind Velocity & mits & 5 & & & & & & & & \\
\hline Mach Number & (........... & 0.2 & & & & & & & & \\
\hline Max Allowable Radiation & $\mathrm{k} W / \mathrm{m}^{2}$ & 1.58 & & & & & & & & \\
\hline Radiation Fraction & -........... & 0.3 & & & & & & & & \\
\hline Horizaontal Distance & $m$ & 50 & & & & & & & & \\
\hline & Normal & Emergency & Emission Species & kgthr & wt\% & $\mathrm{NG}, \mathrm{kg}$ & Purge Gas & Steam,kg & $m^{2}$ & $\mathrm{~kg}$ \\
\hline Flowrate, kgls & 3.32 & 3.82 & & & & \multirow{17}{*}{524} & \multirow{17}{*}{45.675} & \multirow{17}{*}{0} & \multirow{17}{*}{471} & \multirow{17}{*}{84313.8} \\
\hline Components, wt\% & & & $\mathrm{CO} 2$ & 5007.49 & 37.55 & & & & & \\
\hline $\mathrm{CO} 2$ & 29.800 & 26.0269 & $\mathrm{NO}$ & 0.72 & 0.01 & & & & & \\
\hline $\mathrm{SO} 2$ & 0.000 & 0 & $\mathrm{CO}$ & 32.10 & 0.24 & & & & & \\
\hline NO & 0.006 & 0.005526611 & $\mathrm{~N} 2$ & 8295.55 & 62.20 & & & & & \\
\hline $\mathrm{CH} 4$ & 0.001 & 0.0532 & $\mathrm{CH} 4$ & 0.00 & 0.00 & & & & & \\
\hline $\mathrm{CO}$ & 0.220 & 11.9146 & $\mathrm{PM}$ & 0.06 & 0.00045 & & & & & \\
\hline $\mathrm{N} 2$ & 68.954 & 59.887 & & & & & & & & \\
\hline 02 & 1.019 & 0.885 & & & & & & & & \\
\hline $\mathrm{H} 2 \mathrm{O}$ & 0.000 & 0.0000 & & & & & & & & \\
\hline $\mathrm{PM}$ & 0.001 & 0.000436311 & & & & & & & & \\
\hline Methanol & & 0.0083 & & & & & & & & \\
\hline $\mathrm{AA}$ & & 0.1572 & & & & & & & & \\
\hline Methyl Acatate & & 0.5711 & & & & & & & & \\
\hline $\mathrm{HI}$ & & 0.4911 & & & & & & & & \\
\hline Methyl lodide & & 0.0000 & & & & & & & & \\
\hline Propionic Acid & & 0.0000 & & & & & & & & \\
\hline
\end{tabular}


Table A2. PCU_Boiler Unit

\begin{tabular}{|c|c|c|c|c|c|c|c|}
\hline \multicolumn{2}{|c|}{ Boiler Input } & \multicolumn{6}{|c|}{ Boiler Dutput } \\
\hline Total Flowrate, kqds & 0.474512038 & & & & \multirow{7}{*}{ Utility } & \multirow{7}{*}{ Material } & \multirow{7}{*}{ Land } \\
\hline Temperature, $\mathrm{C}$ & 30 & & & & & & \\
\hline Pressure, kPa & 100 & & & & & & \\
\hline Burner Tupe & Uncontrolled & & & & & & \\
\hline Heat Input, MW' & 5 & & & & & & \\
\hline Waste Heat, MW' & 5.07 & & & & & & \\
\hline MP Steam, kg & 10457.16405 & & & & & & \\
\hline Components & wt\% & Emission Species & kgthr & $w 1 \%$ & $\mathrm{k} W^{\prime}$ & $\mathrm{kg}$ & $m^{2}$ \\
\hline $\mathrm{CO}$ & 93.82 & $\mathrm{CO} 2$ & 3559.07 & 29.19 & \multirow{15}{*}{2.98} & \multirow{15}{*}{2870.17} & \multirow{15}{*}{227.48} \\
\hline $\mathrm{CO} 2$ & 1.17 & $\mathrm{SO2}$ & 0 & 0.00 & & & \\
\hline $\mathrm{CH} 4$ & 0.42 & NO & 0.76 & 0.01 & & & \\
\hline $\mathrm{H} 2 \mathrm{O}$ & 0.00 & & & 0.00 & & & \\
\hline Methanol & 0.00 & & & 0.00 & & & \\
\hline$A A$ & 0.00 & & & 0.00 & & & \\
\hline Methyl Acatate & 4.59 & $\mathrm{CH} 4$ & 0.08 & 0.00 & & & \\
\hline $\mathrm{HI}$ & 0.00 & & & 0.00 & & & \\
\hline Methyl lodide & 0.00 & & & 0.00 & & & \\
\hline Propionic Acid & 0.00 & & & 0.00 & & & \\
\hline Natural Gas & 336.66 & $\mathrm{CO}$ & 26.3 & 0.22 & & & \\
\hline 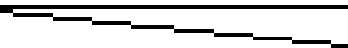 & -1 & $\mathrm{~N} 2$ & 8235.39 & 67.54 & & & \\
\hline -1- & -ー- & 02 & 121.7 & 1.00 & & & \\
\hline - - & $=-$ & $\mathrm{H} 2 \mathrm{O}$ & 250.24 & 2.05 & & & \\
\hline -1- & $=$ & $\mathrm{PM}$ & 0.06 & 0.00 & & & \\
\hline
\end{tabular}


Table A3. PCU_Scrubber Unit

\begin{tabular}{|c|c|c|c|c|c|c|c|c|c|c|}
\hline \multicolumn{3}{|c|}{ Scrubber Input } & \multicolumn{8}{|c|}{ Scrubber Qutput } \\
\hline Total Flowrate & $\mathrm{kgls}$ & 0.503882949 & & \multirow{4}{*}{\multicolumn{2}{|c|}{ Gas Phase }} & \multirow{4}{*}{ Utility } & \multirow{3}{*}{\multicolumn{2}{|c|}{ Material }} & \multirow{4}{*}{ Land } & \multirow{4}{*}{ Sovent } \\
\hline Temperature & $\mathrm{C}$ & 30 & & & & & & & & \\
\hline Pressure & $\mathrm{kPa}$ & 150 & & & & & & & & \\
\hline Packing Size & …...... & 1 & & & & & & & & \\
\hline Components & $w t \%$ & $\begin{array}{l}\text { Equilibrium Data } \\
\text { 'qd'tkq water] }\end{array}$ & Removal Efficiencl & kgthr & $w t \%$ & $\mathrm{~kW}$ & Shell[304], kg & raschig rings,kg & $\mathrm{m}^{2}$ & kgthr \\
\hline $\mathrm{CO}$ & 88.8743 & 0.78 & $0.59 \%$ & 1602.65 & 93.82 & \multirow{10}{*}{2.17} & \multirow{10}{*}{495.74} & \multirow{10}{*}{3499.97} & \multirow{10}{*}{13.16} & \multirow{10}{*}{90995} \\
\hline $\mathrm{CO} 2$ & 1.1056 & 1.588 & $0.60 \%$ & 19.94 & 1.17 & & & & & \\
\hline $\mathrm{CH} 4$ & 0.3988 & 0.0142 & $0.02 \%$ & 7.23 & 0.42 & & & & & \\
\hline $\mathrm{H} 2 \mathrm{O}$ & 0.3138 & 10000 & $100 \%$ & 0.00 & 0.00 & & & & & \\
\hline Methanol & 0.0627 & 1000 & $100 \%$ & 0.00 & 0.00 & & & & & \\
\hline$A A$ & 1.1919 & 1000 & $100 \%$ & 0.00 & 0.00 & & & & & \\
\hline Methyl Acatate & 4.3295 & 0.5 & $0.14 \%$ & 78.43 & 4.59 & & & & & \\
\hline HI & 3.7230 & 100 & $100 \%$ & 0.00 & 0.00 & & & & & \\
\hline & & & & 0.00 & 0.00 & & & & & \\
\hline Propionic Acid & 0.0003 & 500 & $100 \%$ & 0.00 & 0.00 & & & & & \\
\hline
\end{tabular}


Table A4. Definitions and reference values for selected GREENSCOPE indicators

\begin{tabular}{|c|c|c|c|c|c|}
\hline \multirow{2}{*}{ Category } & \multirow{2}{*}{ Indicator } & \multirow{2}{*}{ Formula } & \multirow{2}{*}{ Unit } & \multicolumn{2}{|c|}{ Sustainability Value } \\
\hline & & & & $\begin{array}{l}\text { Best Case } \\
(100 \%)\end{array}$ & $\begin{array}{l}\text { Worst Case } \\
\qquad(0 \%)\end{array}$ \\
\hline \multirow{2}{*}{ Efficiency } & $\begin{array}{l}\text { Reaction Yield } \\
(R Y)\end{array}$ & $R Y=\frac{\text { Mass of product }}{\text { Theoretical mass of product }}$ & $\mathrm{kg} / \mathrm{kg}$ & 1.0 & 0 \\
\hline & $\begin{array}{l}\text { Water Intensity } \\
(W I)\end{array}$ & $W I=\frac{\text { Volume of fresh water consumed }}{\text { Sales revenue or value added }}$ & $\mathrm{m}^{3} / \$$ & 0 & 0.1 \\
\hline \multirow[b]{2}{*}{ Environmental } & $\begin{array}{l}\text { Environmental Quotient } \\
(E Q)\end{array}$ & $\begin{aligned} E Q=\frac{\text { Total mass of waste }}{\text { Mass of product }} \\
\quad \\
\times \text { Unfriendliness quotient }\end{aligned}$ & $\mathrm{m}^{3} / \mathrm{kg}$ & 0 & 2.5 \\
\hline & $\begin{array}{l}\text { Global Warming Potential } \\
(G W P)\end{array}$ & $G W P=\frac{\text { Total mass of } \mathrm{CO}_{2} \text { equivalents }}{\text { Mass of product }}$ & $\mathrm{kg} / \mathrm{kg}$ & 0 & $\begin{array}{c}\text { Any waste } \\
\text { released has a } \\
\text { potency factor } \\
\text { at least equal to } \\
1\end{array}$ \\
\hline Economic & $\begin{array}{l}\text { Specific Raw Material Cost } \\
\left(C_{S R M}\right)\end{array}$ & $S R W C=\frac{\text { Raw material costs }}{\text { Mass of product }}$ & $\$ / \mathrm{kg}$ & 0 & 0.5 \\
\hline Energy & $\begin{array}{l}\text { Specific Energy Intensity } \\
\left(\mathrm{R}_{\mathrm{SEI}}\right)\end{array}$ & $R_{S E I}=\frac{\text { Net energy used as primary fuel equivalent }}{\text { Mass of product }}$ & $\mathrm{kJ} / \mathrm{kg}$ & 0 & 100 \\
\hline
\end{tabular}

